\title{
Entrepreneurial traits and innovation
}

Citation for published version (APA):

Olivari Narea, J. (2016). Entrepreneurial traits and innovation: evidence from Chile . [Doctoral Thesis, Maastricht University]. Datawyse / Universitaire Pers Maastricht. https://doi.org/10.26481/dis.20160419jo

Document status and date:

Published: 01/01/2016

DOI:

10.26481/dis.20160419jo

Document Version:

Publisher's PDF, also known as Version of record

\section{Please check the document version of this publication:}

- A submitted manuscript is the version of the article upon submission and before peer-review. There can be important differences between the submitted version and the official published version of record.

People interested in the research are advised to contact the author for the final version of the publication, or visit the DOI to the publisher's website.

- The final author version and the galley proof are versions of the publication after peer review.

- The final published version features the final layout of the paper including the volume, issue and page numbers.

Link to publication

\footnotetext{
General rights rights.

- You may freely distribute the URL identifying the publication in the public portal. please follow below link for the End User Agreement:

www.umlib.nl/taverne-license

Take down policy

If you believe that this document breaches copyright please contact us at:

repository@maastrichtuniversity.nl

providing details and we will investigate your claim.
}

Copyright and moral rights for the publications made accessible in the public portal are retained by the authors and/or other copyright owners and it is a condition of accessing publications that users recognise and abide by the legal requirements associated with these

- Users may download and print one copy of any publication from the public portal for the purpose of private study or research.

- You may not further distribute the material or use it for any profit-making activity or commercial gain

If the publication is distributed under the terms of Article $25 \mathrm{fa}$ of the Dutch Copyright Act, indicated by the "Taverne" license above, 


\section{ENTREPRENEURIAL \\ TRAITS AND INNOVATION \\ EVIDENCE FROM CHILE}

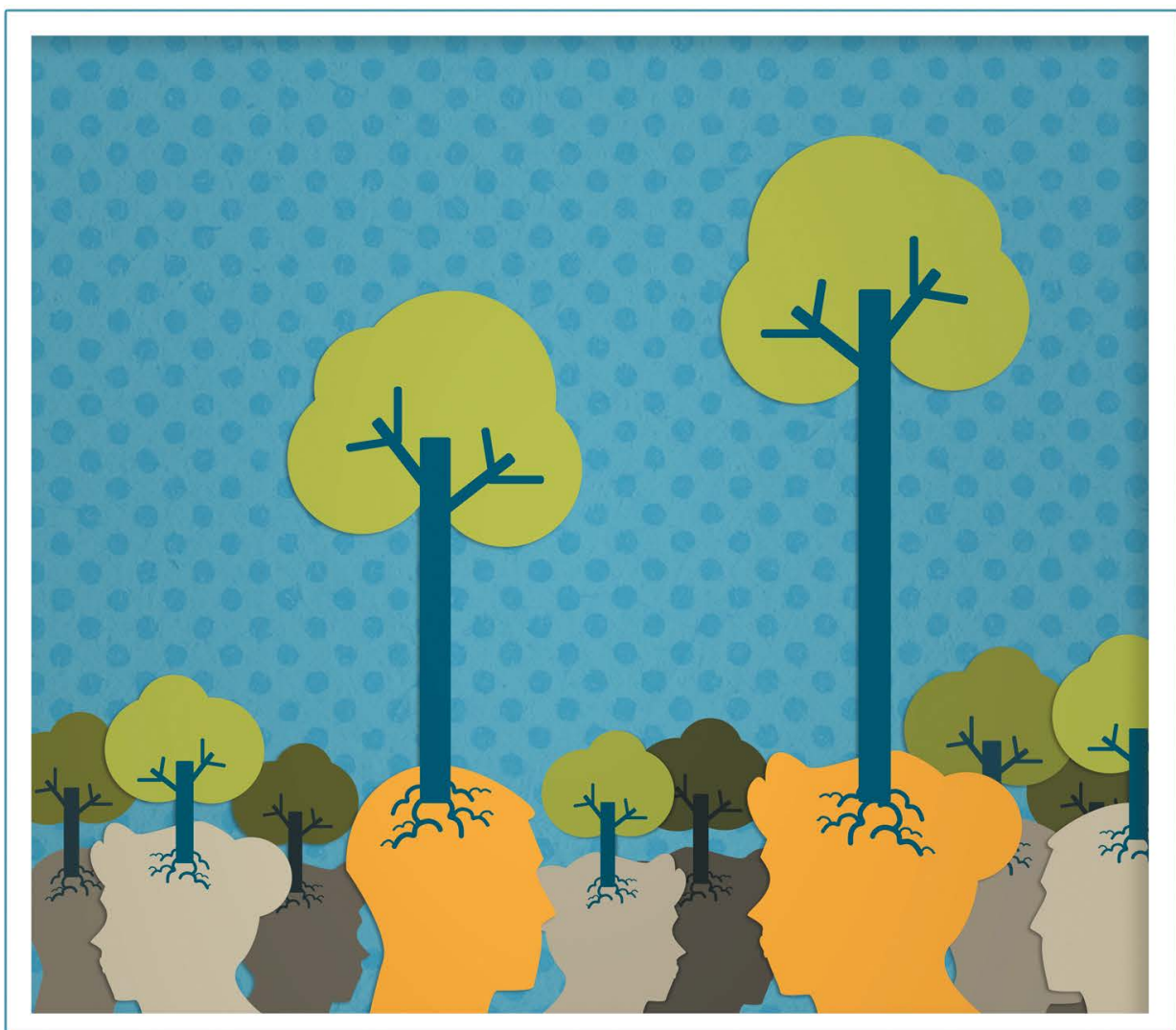

JOCELYN OLIVARI NAREA 
(C) Copyright Jocelyn Olivari Narea, Maastricht 2016 Cover Design: Miguel Lage

Printing: Datawyse | Universitaire Pers Maastricht ISBN 9789461595454

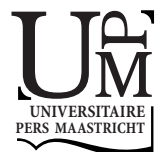




\title{
Entrepreneurial Traits and Innovation
}

\author{
Evidence from Chile
}

\section{DISSERTATION}

to obtain the degree of Doctor at Maastricht University, on the authority of the Rector Magnificus, Prof. Dr. L.L.G. Soete in accordance with the decision of the Board of Deans,

to be defended in public

on Tuesday 19 April 2016, at 16.00 hours

by

Jocelyn Olivari Narea 


\section{Supervisor:}

Prof. Dr. Pierre Mohnen

\section{Co-supervisor:}

Dr. Micheline Goedhuys

\section{Assessment Committee:}

Prof. Dr. John Hagedoorn (Chair)

Prof. Dr. Werner Bönte, Schumpeter School of Business and Economics, Bergische Universitat Wuppertal

Dr. Michiko Iizuka

Prof. Dr. Marco Vivarelli, Universitá Cattolica del Sacro Cuore, Facolta di Economia

Financial support for this dissertation has been provided by the Becas Chile Program from CONICYT, Government of Chile. 
To my Mother

for her unconditional love and support 



\section{Acknowledgements}

In a very evolutionary fashion, I am certain that all the moments I experienced, and the diverse people I interacted with throughout these years, shaped the person that I am today. And there is absolutely no way back. I treasure all the moments that were part of this fulfilling trip that I bravely decided to take in 2009. And I am grateful to the people that accompanied me on this journey.

I deeply thank my supervisor, Pierre Mohnen, for his trust and constant guidance through the moments of confusion. His warm smile always made me feel understood and that, after all, I was not alone in my ideas. Thank you Pierre for reminding me that I could do it, and that the finish line was closer than I thought.

I am also grateful to Micheline Goedhuys, my co-supervisor. Thank you for helping me reach the end and for your valuable comments.

I would also like to thank the reading committee members John Hagedoorn, Werner Bönte, Michiko IIzuka and Marco Vivarelli. Thank you for your suggestions to improve my research.

This dissertation was written in Maastricht and Washington DC, although the journey started much earlier, back in Chile. I would like to acknowledge my Alma Mater, University of Chile, who taught me that economists have the duty to contribute to solving the many social and economic challenges that countries face, and will continue to face. While working as a researcher in the Department of Economics at the University of Chile, I decided to pursue my $\mathrm{PhD}$ to learn more about the economics of innovation. I am grateful to José Miguel Benavente, Jorge Katz and Nicolás Eyzaguirre who supported me when making this decision. I also thank the Chilean Government for providing me with the scholarship that financed my $\mathrm{PhD}$.

I also want to express my special gratitude to two friends back in Chile that were very influential in the development of this dissertation. Jean Jacques Duhart helped me to discover the fascinating world of innovative entrepreneurship when we worked together on a consultancy for the OECD. It was Jean Jacques who encouraged me to study innovative entrepreneurs more closely. And it was Gonzalo Miranda who helped me do it. I am extremely grateful for the opportunity you gave me to conduct my fieldwork in Chile, not only for financing it but for all 
those interesting discussions we had. Thank you Gonzalo for your time, your trust and your friendship. I would also like to thank all the entrepreneurs I interviewed when conducting my fieldwork in Chile: your stories kept me motivated!

The journey of my PhD started in Maastricht, and my UNU-MERIT classmates François, Ale, Daniel, Giorgio, Tatevik, Samyukta and Sayan made the first years much easier. Thank you for the interesting discussions and comradership. It was a pleasure sharing the $\mathrm{PhD}$ with you guys! I also made awesome friends from other cohorts: Simonito, thank you for your 24/7 open italian kitchen; I really miss having coffee with you. Jennifer, office mate, thanks for the latin complicity. Andi, thank you for helping me not forgetting the Chilean slang! And Marco, thank you for our tango sessions! In the institute I also met wonderful people that made life in the institute super rich: thank you Michiko, Daniel V., Nora, Shuan, Jojo, Paula, Andrea, Francesca, Iman, Carlos, Julieta, Agustín, Lorena, Biljana, Rodolfo and Alison. Outside the institute I also met awesome friends that made life in Maastricht so much fun: Meriç, Giorgos, Kaan, Milla and Froso. I was also very lucky to meet María Paz and Gonzalo.

When I left Santiago and arrived to Maastricht everything felt so different and confusing. But Eveline was ready to make this transition as smooth as possible, trying to make all the newcomers feel home away from home. Thank you very much for all your help and support Eveline! I am also very grateful to Ad, who always helped me to find the book I was looking for. I would also like to thank all the other UNU-MERIT staff members: Herman, Mourik, Mitie, Marc, Eric, Howard and Wilma.

I would also like to thank to all the UNU-MERIT professors that inspired me during the discovery process that comes together with a PhD: Bart, Adrian, Robin, Eddie, Shiama, Theophile, Mulu, Gerry, Luc and Anthony. I am also grateful to all those who commented my work in the conferences and workshops I attended, especially to Reinhilde Veugelers.

I also made beautiful friends in Maastricht that I know will be always part of my life, wherever I go. Lilia, thank you for welcoming me so warmly in Maastricht. Many years have passed since then and am so happy that despite the distance, we have always managed to find the time to see each other: in Santiago, Buenos Aires, Rio de Janeiro, Montevideo and Washington DC! Julia, my beautiful salsa dancer, if there was an award to the happiest person in the world, you would definitely win it. Thank you for being there for me, always with a beautiful smile and positive energy. Lila, bonita, thank your for your friendship and love. Our beautiful collection of memories in Maastricht will always have a special place 
in my heart; they are so many! And we keep counting now that we have the luxury to be in the same city again! Chach, your Chilean accent and easy laugh conquered my heart. Thank you for being always ready to devise a plan with me to tackle any obstacle found on the way. Thank you also for the endless hours on Skype and for your healing love.

This dissertation was finished in Washington DC, while working in the IDB. I am grateful to my colleagues of the CTI Division who accompanied me towards the finish line, especially to José Miguel Benavente who gave me the space I needed to bring this dissertation to an end. Thank you for all those Fridays. I am also grateful to Liora, Gabi and Lorena, who also became my friends: thank you girls for all your loving support and for not letting me forget that I could do it. Thank you also Gustavo, Carlo, Matteo and Juan Carlos, for supporting the Friday plan and for encouraging me to finish the thesis. Thank you also Elena, Blanca, Mariela, Carlos, Nico and the rest of the CTI crowd.

Other amazing friends have accompanied me along this journey, like Ana, who became my first friend in Washington DC. Also Cintia, my sister-friend, thank you for knowing me so well and for saying the right words whenever I needed them. And Lionel, yes, also thank you! I am also grateful to my good friends from Chile, Marcela and Osvaldo, who were always ready to give me energy to keep going, and to my school friends Sofía, Javiera, Fran, Pía and Mariluz. Also to Yll, for having been part of it.

Finally, I would like to thank my family, for understanding that my dreams were to be sought away from them. Thanks Cony for keep being a loving sister despite my absence. Thanks Dad for the words of comfort. And most importantly, I am deeply grateful to my mother for all her love and timely words of encouragement that kept me going throughout this long journey. 



\section{Summary}

The main goal of this thesis is to broaden the understanding of the intriguing and elusive figure of the innovating entrepreneur, one particular character among the continuum of individuals that compose the heterogeneous population of entrepreneurs. This is interesting because innovating entrepreneurs are the ones that have the potential to generate larger economic impacts through the ventures they create. However, they are a select few among the population. New insights that uncover who they are and what makes them different from the rest is relevant from a policy making point of view.

The research relies on both quantitative and qualitative methods to answer a set of research questions that explore the sources of entrepreneurial heterogeneity and how they relate to innovative ventures. The focus of the research is on Chile.

After an introduction, the second chapter analyzes the context, from a systemic and evolving perspective, in which innovative entrepreneurship occurs in Chile. A review of the evolution of the national innovation system in the last twenty five years and the analysis of two entrepreneurship indexes, allow assessing the current status of the entrepreneurial ecosystem in Chile. The results show that the system of entrepreneurship has evolved into a more mature stage in the last ten years, in which the majority of the enabling components are present. The government has played a key role in the changes observed. The positive development of the ecosystem has allowed Chile to lead the regional rankings, which has brought high hopes within the government to transform Chile in a regional hub for high growth entrepreneurship, or a Chilecon Valley, as was suggested by The Economist magazine. Nonetheless, there is plenty of room for improvement given the highly uneven performance of the different components that enable entrepreneurship to flourish. Public policies, which have mostly relied on financial instruments, should ensure that all components of the system are performing well.

Relying on quantitative methods, the third chapter analyzes the relationship between entrepreneurial motivations and individual background traits, while the fourth one goes a step further and analyzes the relationship between firm innovation and background traits of entrepreneurs. The fifth chapter aims at complementing the findings from the previous ones by applying qualitative research 
methods that allow capturing unobservable traits from entrepreneurs that are expected to influence the emergence of innovative ventures.

The thesis provides empirical evidence on the sources of entrepreneurial heterogeneity, suggesting that the variety of ventures we observe is partly explained by the heterogeneous traits of the entrepreneur. This implies that any attempt to understand the emergence of innovative startups should begin by understanding the person behind the business. The findings from the quantitative and qualitative chapters show that both observable and unobservable characteristics are important to understand the emergence of innovative ventures. In particular, the results show that the interplay between motivation and educational attainment of the entrepreneur explains the extent to which the business innovates. Particularly, intrinsically-motivated entrepreneurs that are highly educated are more prone to run innovative businesses.

This thesis also revealed that social capital determined the emergence of innovative startups by providing access to resources that the entrepreneur lacked. The results show that entrepreneurs with high quality social connections were mostly those that attended elite schools and top universities, which suggests that entrepreneurs that come from a higher socioeconomic status are in a better position to successfully launch and grow an innovative startup. This result has important policy implications given that access to quality education and social capital is unevenly distributed in the Chilean society. 


\section{Contents}

1 Introduction $\quad 1$

1.1 The heterogeneous nature of entrepreneurship and its role in economic development . . . . . . . . . . . . . . 1

1.2 Unveiling the intriguing and elusive figure of innovative entrepreneurs 4

1.3 Structure and content of the Book . . . . . . . . . . . . 5

2 Innovative entrepreneurship from a systemic perspective $\quad 11$

2.1 Introduction . . . . . . . . . . . . . . . . . 11

2.2 Conceptual framework . . . . . . . . . . . . . . . . . 12

2.3 Main historical trends of the Chilean NSI . . . . . . . . . . . 20

2.3.1 The first stage: $1990-2004$. . . . . . . . . . . . . 21

2.3.2 The second stage: 2005-to date . . . . . . . . . . 25

2.4 Measuring the performance of entrepreneurship systems . . . . . . 34

2.5 Concluding remarks . . . . . . . . . . . . . . . 43

3 The heterogeneous nature of entrepreneurial motivations $\quad 47$

3.1 Introduction . . . . . . . . . . . . . . . . . . . 47

3.2 Conceptual framework . . . . . . . . . . . . . . . . . . . . . 48

3.2.1 The heterogeneous nature of entrepreneurs . . . . . . . 48

3.2.2 Venture formation as a function of entrepreneurial traits . . 50

3.2.3 Entrepreneurial motivations . . . . . . . . . . . . 55

3.2.4 Research questions and hypothesis . . . . . . . . . . 58

3.3 Data . . . . . . . . . . . . . . . . . . . 59

3.3.1 The Micro-entrepreneurship Survey . . . . . . . . . . . 59

3.3.2 Variables ................... . . 61

3.3.2.1 Dependent variable . . . . . . . . . . . . . 61

3.3.2.2 Independent variables . . . . . . . . . . . 62

3.3 .3 Descriptive Statistics . . . . . . . . . . . . . 66

3.4 Methodology ..................... . . 70 
3.5 Results. . . . . . . . . . . . . . . . . . . . 72

3.5.1 Determinants of entrepreneurial motivations . . . . . . . 74

3.5.2 Predicted probability at representative values . . . . . . 79

3.5.2.1 Employers . . . . . . . . . . . . . . 79

3.5.2.2 Own account workers . . . . . . . . . . . . 83

3.6 Concluding remarks $\ldots \ldots \ldots \ldots$

4 Entrepreneurial traits and innovation $\quad 87$

4.1 Introduction . . . . . . . . . . . . . . . . . . . . 87

4.2 Conceptual framework . . . . . . . . . . . . . . 88

4.2.1 The Schumpeterian entrepreneur . . . . . . . . . . . 88

4.2.2 From entrepreneurial traits to firm innovation . . . . . . . 90

4.2 .3 Prior empirical evidence . . . . . . . . . . . . . . . . . . 91

4.2.4 Research questions and hypothesis . . . . . . . . . 94

4.3 Data . . . . . . . . . . . . . . . . . . . 94

4.3.1 The Longitudinal Enterprise Survey _. . . . . . . . . . . 94

4.3 .2 Variables . . . . . . . . . . . . . . . . . 96

4.3.2.1 The motivation equation . . . . . . . . . 96

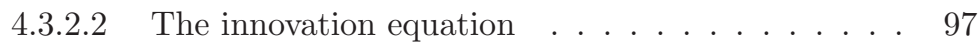

4.3.3 Descriptive Statistics . . . . . . . . . . . . . . . . . . . . 101

4.4 Methodology . . . . . . . . . . . . . . . . . . . . . 103

4.4 .1 The motivation equation . . . . . . . . . . . . . . . . 104

4.4 .2 The innovation equation . . . . . . . . . . . . . . . . 105

4.5 Results . . . . . . . . . . . . . . . . . . 106

4.6 Concluding remarks . . . . . . . . . . . . . . . . . . 109

5 Understanding the emergence of innovative entrepreneurship 113

5.1 Introduction . . . . . . . . . . . . . . . . . . . . . 113

5.2 Conceptual framework and research questions . . . . . . . . . 114

5.3 Methodology . . . . . . . . . . . . . . . . . 116

5.4 Data . . . . . . . . . . . . . . . . . . . 120

5.5 Analysis . . . . . . . . . . . . . . . . . . . . 123

5.5.1 The background of entrepreneurs . . . . . . . . . . . . 123

5.5.2 The personality of entrepreneurs _ . . . . . . . . . 126

5.5.3 Entrepreneurial motivations . . . . . . . . . . . . . . 132

5.5.4 The role of social capital . . . . . . . . . . . . . . 140

5.6 Concluding remarks . . . . . . . . . . . . . . . . 145 
$\begin{array}{lr}\text { A Apendix to Chapter 3 } & 161\end{array}$

A.1 Multinomial Logit Model (whole sample) . . . . . . . . . . . . . . 162

A.2 Multinomial Probit Model (whole sample) . . . . . . . . . . . . 163

A.3 Multinomial Logit Model: Estimated coefficients for employers . . 164

A.4 Multinomial Logit Model: Estimated coefficients for own account workers ...................... 165

B Appendix to Chapter $4 \quad 167$

B.1 The motivation equation: A comparison between the ELE and EME Surveys . . . . . . . . . . . . . . . . . 167

C Appendix to Chapter 5 171

C.1 List of interviewees . . . . . . . . . . . . . . . . . 171

$\begin{array}{lc}\text { Valorization } & 173\end{array}$

$\begin{array}{ll}\text { Biography } & 177\end{array}$ 



\section{List of Tables}

2.1 Organizations included in the NSI framework . . . . . . . . . 16

2.2 Institutions included in the NSI framework . . . . . . . . . . . 17

2.3 Activities included in the NSI framework . . . . . . . . . . . . 18

2.414 pillars measured in the Global Entrepreneurship Index . . . . . 36

2.510 pillars measured in the ICEd-Prodem Index . . . . . . . . . . . 41

3.1 Motivation factors that determine new venture creation . . . . . 56

3.2 Categories of entrepreneurial motivations . . . . . . . . . . . 62

3.3 Proportion of employers and own-account workers in the self-employed population . . . . . . . . . . . . . . 6 63

3.4 List of variables explaining entrepreneurial motivation . . . . . . 67

3.5 Descriptive statistics: Employers . . . . . . . . . . . . . . . . 69

3.6 Descriptive statistics: Own account workers . . . . . . . . . . . . 69

3.7 Wald tests for joint significance of independent of variables . . . . 73

3.8 Wald tests for combining alternatives . . . . . . . . . . . . . 73

3.9 Average marginal effects for employers (AME) . . . . . . . . 76

3.10 Marginal effects for own-account . . . . . . . . . . . . . . . 77

3.11 Business characteristics by employers' motivation . . . . . . . . . . 82

4.1 Motivation categories . . . . . . . . . . . . . . . 98

4.2 List of variables . . . . . . . . . . . . . . . . . . . 100

4.3 Descriptive statistics . . . . . . . . . . . . . . . . 103

4.4 Error correlation between the motivation and innovation equation 106

4.5 Innovation Equation: Average Marginal Effects . . . . . . . . . . 107

5.1 List of companies under analysis . . . . . . . . . . . . . . . 122

5.2 Background characteristics of core founders . . . . . . . . . . . 125 



\section{List of Figures}

2.1 Global entrepreneurship index: 14 pillar comparison . . . . . . . . 39

2.2 Ecosystem of dynamic entrepreneurship: 10 pillar comparison . . . 43

3.1 A model on new venture initiation . . . . . . . . . . . . . . 52

3.2 Enhanced model on value creation performance . . . . . . . . . 54

3.3 Distribution of motivation and education categories by type of selfemployed ....................... 67

3.4 Employers: Predicted probabilities for different education and age levels .......................... 81

3.5 Own-account: Predicted probabilities for different education and age levels ........................ 84

4.1 Probability of innovating according to different entrepreneurial profiles ....................... . . 110 



\section{Chapter 1}

\section{Introduction}

\subsection{The heterogeneous nature of entrepreneurship and its role in economic development}

The interest on entrepreneurship has been increasing in the last decades ${ }^{1}$ and there seems to be a broad consensus among scholars and policymakers regarding the central role that entrepreneurial activity plays in economic growth (Audretsch and Thurik, 2001), for both developed and developing economies. However, entrepreneurship is a multifaceted concept that includes a population of very heterogeneous agents (Vivarelli, 2013) and not all of them have the same potential to contribute to economic development.

From a theoretical point of view, entrepreneurial activity has been considered a vehicle of innovation and change, and therefore it is expected to play a key role in economic development through a process of creative destruction (Schumpeter, 1934). Innovations can be brought to the economy by incumbent firms or by new startups emerging in the market place that challenge the status quo. This explains why entrepreneurial activity can be regarded as a vehicle to bring new innovations into the economy. Entrepreneurship can be also considered as a conduit that facilitates the spillover and commercialization of new knowledge as it is not automatically transformed into economic knowledge (Audretsch and Keil-

\footnotetext{
${ }^{1}$ During the last decades, scholars and policymakers shifted their attention from large companies to new small firms triggered by a context of social turmoil during the 60 s and the 70 s in which the Keynesian economic model was highly questioned in Western economies (Landström, 2005; Landström et al., 2012; Nightingale and Coad, 2013). In this context Birch (1981) argued that small young companies accounted for the majority of new jobs in the United States thus challenging the conventional wisdom about the sources of new job creation and suggesting a major shift in the industrial structure in favor of small companies. This spurred a renewed interest of scholars and policymakers in entrepreneurship and young small firms, framed by a change in political ideology towards pro-market policies.
} 
bach, 2007; Braunerhjelm et al., 2010). Entrepreneurial activity can then be seen as a mechanism through which knowledge is transformed into an economically relevant output and thus positively impacts growth rates ${ }^{2}$.

In his early work, Joseph Schumpeter, a common mentor for both innovation and entrepreneurship studies, viewed economic development emerging from a process of creative destruction through the introduction of new combinations of existing means of production (Schumpeter, 1934). The entrepreneurial function, triggered by a special type of businessman, the entrepreneur, consists in 'carrying out new combinations that appear discontinuously in time in groups or swarns'. ${ }^{3}$ These new combinations are embodied in new firms that emerge alongside the old ones, which are eventually eliminated through competition ${ }^{4}$. For Schumpeter the adjective new was crucial as it entailed employing resources in a different way, doing new things with them, things that differed in some respect or other from those that consumers had the habit of using ${ }^{5}$. In line with these ideas, Baumol (2010) asserts that the Schumpeterian entrepreneur is an innovator by definition and is only the innovating entrepreneur who can be associated firmly with revolutionary growth of the economy. This suggests that not all entrepreneurs are the same and only a subset of them have the potential to significantly impact economic growth. But, who is this innovating entrepreneur? What makes him $^{6}$ different from the rest?

The population of entrepreneurs is, in fact, highly heterogeneous and includes a wide variety of individuals co-existing within the same environment, some of which

\footnotetext{
${ }^{2}$ Braunerhjelm et al. (2010) provide empirical evidence supporting causality from entrepreneurial activities to economic growth.

${ }^{3}$ Entrepreneurs have also been associated with a special ability to discover and exploit profitable market opportunities overlooked by others (Kirzner, 1973, 1997), and to the ability to bear the uncertainty derived from exploiting opportunities. Following the Knightian school of thought, unlike risk, uncertain situations cannot be assigned probabilities of occurrence, as they are the outcome of a unique event and there is no prior knowledge that can inform probability estimation. The entrepreneur can be considered a special type of person that is able to deal with uncertainty and make decisions under this scenario (Landström, 2005).

${ }^{4}$ As opposed to Schumpeter, who saw the disequilibrium generated by the entrepreneurial function as the main driving force behind economic development, Kirzner's approach considered entrepreneurs as a mechanism to drive the economy towards equilibrium through arbitrage, which does not involve necessarily an innovative component. Furthermore, the fact that in reality most entry decisions turn out to be mistakes that are followed by rapid exit, suggests that entrepreneurship may multiply inefficiencies rather than mitigate them, moving the economy into further disequilibrium (Nightingale and Coad, 2013).

${ }^{5}$ In this regard, the Schumpeterian entrepreneur differs from the Kirznerian one since the latter one does not create anything new necessarily, whereas the former one does (Landström, 2005).

${ }^{6}$ Masculine personal pronoun is used for convenience to denote both female and male individuals or entrepreneurs.
} 
may be unproductive for the society. ${ }^{7} \mathrm{~A}$ fundamental implication of this fact is that their contribution to economic development is expected to differ (Quatraro and Vivarelli, 2014). That is, entrepreneurs pursuing ventures that have the potential to be innovative and achieve high growth rates, in terms of sales and job creation, are expected to generate a larger economic impact than those who remain small and local.

From an empirical point of view, these innovative pioneers are more the exception than the rule. Therefore, caution must be taken to avoid falling into the composition fallacy; that is, the tendency to assign the benefits of high impact entrepreneurship to the average firm (Nightingale and Coad, 2013). In fact, the typical startup is not innovative, creates few jobs, and generates little wealth (Shane, 2009). This empirical fact explains why public support towards generic entrepreneurship has been discouraged in the academic literature during the last years, arguing that policy makers have the flawed belief that creating more startup companies will transform depressed economic regions, generate innovation, and create jobs (Shane, 2009; Vivarelli, 2013; Nightingale and Coad, 2013). This implies that the efforts to encourage entrepreneurship should not focus just on creating new firms, but rather on promoting the emergence of new innovative firms that have high growth potential. The question is who are these intriguing and elusive pioneers that have the potential to impact economic development through the innovative businesses they pursue. A better understanding of who they are, why do they decide to engage in the launch of an innovative venture and what factors influence the founding process and innovative performance, can help enriching the discussion about innovating entrepreneurs without falling into cliché and anecdote (Bhidé, 2000). At the same time it can improve our understanding of the sources of entrepreneurial heterogeneity and identify better ways to promote their emergence and development.

\footnotetext{
${ }^{7}$ Baumol (1990) for instance argued that not all entrepreneurs are innovative and constructive. On the contrary, certain entrepreneurial practices, such as rent-seeking, can be regarded as unproductive for the society. According to the author, the emergence of these type of practices is a consequence of the pay-off structures within a specific society, which determines the allocation of these activities between productive and unproductive ones. And since goals of individuals and culture are difficult to modify, policymakers should focus on modifying the rules of the game (e.g., antitrust rules), such that the structure of rewards promotes productive entrepreneurship (Sautet, 2013).
} 


\subsection{Unveiling the intriguing and elusive figure of in- novative entrepreneurs}

This thesis focuses on the figure of innovating entrepreneurs, one particular character among the continuum of individuals that compose the highly heterogeneous population of entrepreneurs. The focus on the person stems from the fact that the entrepreneur is at the very center of the process of new venture creation (Herron and Robinson, 1993) and therefore constitutes a necessary condition for the phenomenon of entrepreneurship to occur. That is, if individuals do not act, entrepreneurship will not happen (Acs and Correa, 2014). But the decision by a given individual to act and launch a new innovative startup is influenced by a set of interdependent factors that, in interaction with a given environment, determine the emergence process of innovative ventures. Therefore, in order to have a complete picture of the emergence process of new innovative ventures we need to have a better understanding about the traits of the person behind the business. Life background characteristics, personality traits, motivations, skills and social capital of individuals are some of the factors that determine the type of startups that entrepreneurs decide to build within a given context. However, since many of these factors are unobservable, achieving a complete understanding of how innovative ventures emerge is difficult.

The goal of this thesis is to contribute to the literature on entrepreneurship by focusing on the traits of those intriguing and elusive individuals that are behind innovative ventures, particularly by providing new insights on a set of unobservable factors that influence the emergence process of innovative entrepreneurship. It also contributes to identify the sources of heterogeneity between entrepreneurs and the extent to which different entrepreneurial traits relate to venture emergence and innovative performance. A better understanding of these aspects is necessary not only to depart from thinking about entrepreneurship as an homogeneous phenomenon, but also to realize that there is a set of unobservable individual traits that can explain an important share of the phenomenon we observe. New insights on these aspects can help policymakers to depart from a generic approach to entrepreneurship policy and to identify specific strategic areas that could be targeted to promote an increase in the number of innovating entrepreneurs, which are, at the end, the ones who have a higher likelihood of generating a larger impact in the economy.

This thesis focuses on Chile. Understanding the factors that influence the emergence of innovative entrepreneurship is relevant to the Chilean economy for 
at least three reasons. First, the highly concentrated business structure in Chile (Solimano, 2012) could be counterweighted by the emergence of a critical mass of innovating entrepreneurs able to capture niches that are not being captured by incumbent large firms (holdings), hence promoting a democratization of the business sector and social mobility ${ }^{8}$. This is especially relevant nowadays with the infinite opportunities that new technologies, like information and communication technology (ICT), are opening up. The pervasiveness of ICT and the widespread access to computers allow a wider range of individuals to start innovative businesses with relatively little initial capital. Second, new innovative firms brought into the market place by entrepreneurs have the potential (relative to larger firms) to cause technological turmoil by bringing disruptive ideas into the market (Acs and Audretsch, 1988). And third, the emergence of a critical mass of innovative entrepreneurs can constitute a source to promote structural change in the Chilean economy. The economy needs urgently to develop new areas of specialization, especially in knowledge-intensive sectors, in order to increase its productivity. New knowledge and technology-based startup companies have the potential to contribute to the process of economic transformation as new competitive advantages are developed.

\subsection{Structure and content of the Book}

The remainder of this thesis is structured in four Chapters and a final section with conclusions.

Chapter 2 aims at understanding the context, from a systemic and evolving perspective, in which innovative entrepreneurship occurs in Chile. It starts by describing the main elements of the Chilean National System of Innovation as a departing point to empirically analyze the institutional setting that entrepreneurs face when starting and growing their ventures. However, from a path-dependent point of view, the context that we see today is determined by a set of past events and by how the system has learned and adapted through time in relation to these events. Therefore a review of the evolution of the Chilean National System of Innovation in the last twenty five years is conducted, putting especial emphasis

\footnotetext{
${ }^{8}$ Recent research by Aghion et al. (2015) supports the original idea from Schumpeter regarding the relationship between the process creative destruction and social mobility, whereby competitive elimination of the old explains the process by which individuals and families rise and fall economically and socially. The authors analyze the relationship between innovation and top income inequality and find that innovativeness is positively and significantly correlated with social mobility, and that this correlation is driven mainly by entrant innovators and less so by incumbent innovators.
} 
on the institutional setting. It also reviews two indexes aimed at measuring the performance of the Chilean ecosystem of entrepreneurship, which can allow establishing some hypotheses on its current strengths and weaknesses. The analysis presented in this Chapter allows understanding the current status of the ecosystem of entrepreneurship, in terms of its maturity, and assessing whether the required conditions for innovative entrepreneurship to flourish are in place. It also allows to identify possible areas to be improved.

Chapter 3 analyzes the relationship between entrepreneurial motivations and individual background traits. Motivation can be considered as the closest stage during an individual's unobservable decision making process before a venture changes its status from an intention to an action. The underlying motivations that trigger entrepreneurial behavior and subsequent venture creation differ between entrepreneurs, which stems from the fact that the population under study is of a heterogeneous nature. Relatedly, the research question to be answered is What explains the heterogeneity in entrepreneurial motivations? The analysis is focused on a sample of self-employed individuals for which their main motivation to start a business is known. A novel aspect of this research is that it considers a wider range of entrepreneurial motivations than the standard 'opportunity' and 'necessity' ones typically used in the literature. The research approach is empirical and relies on quantitative methods to study the relationship between a set of observable individual traits, like education, gender and prior experience, and the probability to pick a given motivation category. The categorical nature of the dependent variable (eight categories of motivation) requires estimating a multinomial logit model to test the direction and magnitude of the relationship under study. The database used is the third wave of the Micro-Entrepreneurship Survey (EME), which collects information from a representative sample of Chilean self-employed individuals in 2013. The results show that background traits determine the type of entrepreneurial motivations that drive individuals to launch a business. The findings of this Chapter suggest that the unobservable decision making process before a venture changes its status from an intention to an action is also heterogeneous in the sense that new ventures emerge as a consequence of diverse motivations and different background traits. This implies that the variety of ventures we observe is partly explained by the heterogeneous traits of the entrepreneurs behind these businesses. One of the limitations of this study is related to the restricted number of background traits that could be analyzed, which stems from the difficulty of effectively capturing some of them in a survey, 
especially those that are unobservable. This limitation is addressed later in Chapter 5 by applying qualitative interviewing, a more suitable research method when dealing with unobservable variables.

Chapter 4 goes a step further and analyzes the relationship between firm innovation and background traits of entrepreneurs, in particular, educational attainment and entrepreneurial motivations. Entrepreneurial behavior is assumed to be influenced by the interaction of skills and motivations. And because entrepreneurial behavior is viewed as a causal determinant of firm performance, factors that affect behavior will also affect firm performance. Hence entrepreneurial motivations and skills are expected to exert influence over firms' performance, particularly over firm innovative performance. Given that results from the previous Chapter suggest that new ventures emerge as a consequence of diverse motivations and different background traits, the hypothesis is that different entrepreneurial background traits affect innovation performance differently. The research questions to be answered in this Chapter are Do entrepreneurial motivations and skills have a direct effect on firm innovation propensity? and if so, Is there a specific entrepreneurial profile that makes firms more innovative? The research approach is empirical and relies again on quantitative methods to study the relationship between entrepreneurial traits and firm innovation propensity, controlling for firm characteristics. Since innovation propensity is modeled as a function of entrepreneurial motivations and other explanatory variables, it is expected that unobservables in the error term are correlated with the variable capturing motivation categories and therefore estimated coefficients could be biased. To address this potential source of bias two equations are estimated simultaneously, a multinomial probit model for entrepreneurial motivations and a probit model for innovation propensity. The database used is the second wave of the Longitudinal Enterprise Survey (ELE) which collects information from a representative sample of Chilean formal firms in 2009. This wave in particular gathered information on both firm and owner characteristics, opening a window of opportunity to put the entrepreneur back in the analysis of the determinants of firm innovation, a dimension that is relatively less covered in the innovation survey-based literature due to data limitations. The results of this Chapter suggest that entrepreneurial traits are important to explain firm innovation propensity and therefore, any attempt to understand why innovative businesses emerge should take into consideration the person behind the decision making process, the entrepreneur. Furthermore, as expected, different entrepreneurial profiles are related to different innovation propensities, providing new evidence on the sources of firm heterogeneity. These 
results confirm the idea that not all entrepreneurs are the same and that innovating entrepreneurs have particular traits that are functional to the innovation performance of the businesses they run. The findings in this Chapter can increase our understanding on who are these intriguing and elusive individuals that are behind the innovative ventures that are supposed to have a larger impact on the economy. However, the restricted number of background traits that could be analyzed is still a limitation. Furthermore, some interesting relationships found posed new research questions that could not be answered relying on survey information. These limitations are addressed in the next Chapter.

Chapter 5 aims at complementing the findings from the previous Chapters by applying qualitative research methods that allow capturing relevant unobservable variables that are expected to influence the emergence of innovative ventures. It also aims at understanding the sources of some relationships found in the quantitative analysis. The research question to be answered in this Chapter is Why and how innovative startups emerge? It starts from the fact that the complex outcome we observe is partly a consequence of individual capabilities, personality traits, motivations, circumstances at birth and also the little twists and turns of fate at the individual level. All these unobservable factors combined are expected to explain the particular path followed by an individual towards entrepreneurship. And these factors, in interaction with the environment under which the entrepreneurial process occurs, determine the decisions that entrepreneurs make and the actions they take, which ultimately determine the evolution of the business they pursue. However, studying why and how innovative startups arise is extremely challenging because it requires dealing with a set of unobservable factors that are difficult to collect in standard surveys. This challenge is addressed in this Thesis by conducting qualitative interviewing, such that the richness of the latent process under analysis is better grasped. Following the responsive interviewing model (RIM) of Rubin and Rubin (2005), a set of in-depth interviews were applied to entrepreneurs and other relevant actors from an heterogeneous sample of Chilean ventures that fall under the category of innovative entrepreneurship. Even though a set of topics to be covered in the interviews was defined beforehand, the RIM interviewing methodology requires being open to new ideas not anticipated at the beginning, which is particularly relevant when dealing with a complex phenomenon like innovative entrepreneurship. The interviews allowed analyzing the role of unobservable traits of entrepreneurs, like personality, life background, motivations and social capital, in the emergence of innovative ventures in Chile. The findings of this Chapter bring new insights about the role of 
these unobservable factors on innovative entrepreneurship, some of which constitute a reflection of the particularities of the Chilean society. These findings can be very informative from a policy making point of view as it seems that the role of innovative entrepreneurship as a source of democratization of the business sector and social mobility could be jeopardized by socioeconomic inequality.

Finally, Chapter 6 presents a final discussion about the main findings of this Thesis and the most important lessons derived from the research. 



\section{Chapter 2}

\section{Innovative entrepreneurship from a systemic perspective}

\subsection{Introduction}

Innovative entrepreneurship, the main focus of this thesis, has the potential to create new jobs and advance innovations. The supply of entrepreneurs that are able to identify new technological opportunities and understand the possible technological and economic applications of new scientific breakthroughs is fundamental to fuel the process of technical change, as early claimed by Schumpeter (1934). New innovative firms brought to an economy by the elusive and intriguing character of the entrepreneur, can be considered to serve as a vehicle for innovation and change, and therefore as a conduit for knowledge spillovers (Audretsch and Keilbach, 2007; Braunerhjelm et al., 2010). Therefore, through high birth levels of new innovative firms, rates of technological change can be sustained, as suggested by Acs and Audretsch (1988).

Analyzing the institutional and economic conditions that enable entrepreneurship and the successful entry of new innovative firms in the market, becomes therefore an important area of research. The main approach to study enabling conditions for innovation and entrepreneurship in economic systems has been the National System of Innovation (NSI) framework, putting special emphasis in the role of institutions (Acs and Correa, 2014). However, it has been argued that there is still limited understanding about the entrepreneurial agency of individuals in the NSI literature due to some incompatibilities between the two notions, like the person-centric view of entrepreneurship and the problem of analyzing it at the macro level (Radosevic, 2007). 
By combining the literature on national systems of innovation and entrepreneurship research, the analysis of the conditions that enable innovative entrepreneurship should take into consideration both institutional and individual variables, because "if individuals do not act, entrepreneurship will not happen, no matter how perfect the institutional is" (Acs and Correa, 2014, p. 5).

This Chapter, aims at understanding the context, from a systemic and evolving perspective, in which innovative entrepreneurship occurs in Chile. It starts by analyzing the main elements of the NSI approach as a base to empirically analyze the institutional setting in which innovative entrepreneurship is embedded. However, from a path-dependent point of view, the context that we see today is determined by past decisions and how the system had learned and adapted through time. Therefore, I have conducted a historical analysis of the evolution of the Chilean National System of Innovation, putting especial emphasis on the institutional setting. The last section before the concluding remarks reviews two indexes aimed at measuring the performance of the Chilean ecosystem of entrepreneurship, which include both institutional and individual variables. This will allow establishing some hypothesis on the strengths and weaknesses of the ecosystem of entrepreneurship.

The main objective of this Chapter is to have an overall idea of the context in which entrepreneurship occurs in Chile, mostly from an institutional point of view, leaving to the next three Chapters the challenge of zooming into the elusive character of the entrepreneur.

\subsection{Conceptual framework}

The emerging paradigm of complexity economics as a different framework for economic thought has been advocating to treat the economy as the complex system that it really is (Beinhocker, 2006; Farmer, 2012). Complexity economics ${ }^{1}$

\footnotetext{
${ }^{1}$ The basic assumptions in which complexity economics is built are: heterogeneous agents, related to the fact that agents exhibit different characteristics and are, most importantly, intrinsically different; importance of location, in the sense that the position of agents in a multidimensional space, and its density, influences their behavior and performance; local knowledge, related to the fact that agents only have access to localized information and knowledge; local context of interaction, meaning that agents are embedded in networks of relations -including transactions and feedbacks- where the broad array of interactions define their behavior; creativity, in the sense that although agents can follow some rules, they can also change them in response to feedbacks and in accordance with their own specific characteristics and features of local endowments -including the network of transactions and interactions into which they are embedded; and systemic interdependence, where the outcome of the behavior of each agent is strictly dependent on the web of interactions that take place within the system at each point in time (Antonelli, 2009, p. 635).
} 
has been argued to be a new way of seeing the economy, where non-equilibrium is the natural state of economies; where the whole is qualitatively different from the sum of its parts and therefore non-linear interactions between the elements of a system explain the emergent properties (economic and social phenomena) we observe; where actions and strategies of agents constantly evolve in response to the outcome they mutually create; where time becomes important; where structures constantly form and re-form (Farmer, 2012; Arthur, 2013).

The attractive ideas of complexity economics can also be applied to the economics of innovation as innovation can be seen as an emergent property of a complex evolving system (Antonelli, 2009, p. 629). Building on the complementary concepts of the main contributors to the economics of innovation ${ }^{2}$, and integrating them into the broader analytical platform provided by complexity economics, Antonelli (2009) views innovation as "a path-dependent, collective process that takes place in a localized context if, when and where a sufficient number of creative reactions are made in a coherent, complementary and consistent way. As such, innovation is one of the key emergent properties of an economic system viewed as a dynamic complex system" (Antonelli, 2009, p. 614).

If we agree that innovation does not take place in isolation but, on the contrary, is the result of the interactions among groups of actors under certain institutions and contexts within a given boundary (Lundvall, 1992; Edquist, 1997; Smith, 2000; Woolthuis et al., 2005; Edquist and Chaminade, 2006), the System of Innovation framework can become a useful approach to empirically analyze how the innovation process works and evolve in a given economy. Other than being consistent with the assumptions in which complexity economics is built, the advantage of applying this framework is related to the fact that scholars have made increasing efforts to define a conceptual framework that allows analyzing empirically the process of innovation by taking into consideration its main determinants. Following Edquist (1997, p. 2) 'if we want to describe, understand, explain — and perhaps influence - processes of innovation, we must take all important factors shaping and influencing innovations into account. The systems of innovation approach - in its various forms - is designed to do this'.

The literature on Systems of Innovation (SI) started flourishing in the beginning of the nineties with the contribution of the works of Freeman, Lundvall, Nelson and Edquist (Freeman, 1987; Lundvall, 1992; Nelson, 1993; Edquist, 1997) who, inspired by the premises of evolutionary processes, attempted to develop a

\footnotetext{
${ }^{2}$ See Antonelli (2009) for a literature review on the legacy of the classical economic theory (i.e. Adam Smith and Karl Marx) and the legacy of Joseph Schumpeter, Kenneth Arrow and Alfred Marshall.
} 
new approach that could capture the main features of the interactive innovation process. Since then, a lot of research in this field has been carried out by scholars ${ }^{3}$ and it has been widely adopted by policy makers as a framework to define policy actions. However, Lundvall (2007) claims that the wide diffusion of the NSI framework in policy circles is a mixed blessing as the concept has been, apparently, both used and abused, in the sense that often policy makers pay lip-service to the concept while neglecting it in their practice (Lundvall, 2007, p. 97).

Systems of innovation have been studied both from a theoretical (Lundvall, 1992; Edquist, 1997) and empirical (Freeman, 1987; Nelson, 1993; Edquist and Hommen, 2008) perspectives with the aim of understanding how SI work and evolve. In general, empirical work has mainly focused on mature SI in developed or fast growing countries, leaving less attended the case of developing economies. However, in the last years more attention has been given to understand how SI work in developing economies and to what extent the original set of ideas developed around the concept are valid in relation to less developed countries operating in a globalized context ${ }^{4}$.

The appropriate level of analysis ${ }^{5}$ will depend on the purpose of the research and the type of interactions that need to be analyzed (Carlsson et al., 2002). Since the focus of this Chapter is to describe the overall context in which innovative entrepreneurship occurs, within the national boundary of the Chilean economy, the national level of analysis is therefore used. And despite the fact that National Systems of Innovation (NSI) have been defined in different ways depending on the emphasis that different authors have given to different aspects of the framework ${ }^{6}$, they all coincide that both institutions and linkages are the building blocks of NSI.

Lundvall (1992) understood innovation as a process of interactive learning, in which interaction can be defined in two dimensions. First, interactions within a firm are crucial for successful innovations to occur given that they result from multi-directional feedbacks between the various forms of competence and skill on which a business relies: marketing, finance, and product-process development.

\footnotetext{
${ }^{3}$ As a reference, a search of the term "national system of innovation" on Google scholar in December 2015 generated around 2.7 million hits. While in 2004, according to Lundvall (2007), the number of hits were around 5 thousand.

${ }^{4}$ See for example Lundvall et al. (2009) and Niosi (2010).

${ }^{5}$ The unit of analysis can be technological, sectoral, regional, national or even transnational. See Edquist (1997) for a revision of the literature on technological, sectoral, regional and national systems of innovation.

${ }^{6}$ See Smith (2000) for an interesting comparison between the approach to systems of innovation at the national level by Freeman (1987), Lundvall (1992) and Nelson (1993).
} 
This implies, for example, that a new product not only must fulfill specific technical and performance attributes, but it should also include the information about user needs from the marketing department. The second dimension relates to interactions with other organizations of the system. Given that the knowledge of firms is bounded, they need to interact with other sources of information in order to complement their highly specific and path-dependent knowledge base (Smith, 2000).

Both the behavior and interaction of firms are unarguably shaped by the institutional set-up in which they are embedded, which clearly differs from country to country. Following the Northian perspective "institutions are the rules of the game in a society or, more formally, are the humanly devised constraints that shape human interaction. In consequence they structure incentives in human exchange, whether political, social or economic. Institutional change shapes the way societies evolve through time and hence is the key to understanding historical change" (North, 1990, p. 3). These rules of the game include both formal and informal institutions. Formal institutions are explicit rules of the game that are typically codified and are more visible than informal ones, which are tacit and must be observed indirectly through the behavior or people and organizations (Edquist and Johnson, 1997). Formal institutions, include for example anti-trust regulations, intellectual property rights (IPR) laws and the overall legal framework. Informal institutions are related to culture, social values and norms that define for example the tendency to trust and the willingness to share resources. They also shape the extent of collaborations between actors of the system. In relation to this, informal institutions can explain a big share of the nature of the innovation and entrepreneurship processes within a country, which can be especially relevant for developing economies where formal institutions are typically less developed.

The channels through which institutions shape actors' behavior and interactions are related to the function institutions have in the innovation context: to reduce uncertainty by providing information; to manage conflicts and cooperation; to provide incentives; and to channel resources to innovation activities (Edquist and Johnson, 1997). However, in some cases institutions can act as innovation brakes rather than accelerators precisely due to the stability they intend to provide. Rigidities will slow down processes of institutional change and transitional dynamics will be difficult to achieve (for example shifts towards new technological paradigms). It is true that there are limits to how fast institutions can change, 
nevertheless there should be a balance between rigidity and flexibility of institutions.

In relation to the elements to be included in the NSI analysis, Lundvall (1992) made a distinction between a narrow and a broad approach to NSI: 'The narrow definition would include organizations and institutions involved in searching and exploring — such as R\&D departments, technological institutes and universities. The broad definition (...) includes all parts and aspects of the economic structure and the institutional set-up affecting learning as well as searching and exploring - the production system, the marketing system and the system of finance present themselves as subsystems in which learning takes place' (Lundvall, 1992, p. 12). Despite the fact that broadness may be a double-edged sword, it makes sense to include "all important economic, social, political, organizational, institutional and other factors that influence the development, diffusion and use of innovations" (Edquist, 1997, p. 14). The crucial issue is then to identify all those important factors without getting lost in this holistic perspective.

In practical terms, the main components to be considered when analyzing NSI are organizations and institutions. Organizations can be defined as "formal structures that are consciously created and have an explicit purpose" (Edquist, 1997). In other words they are the players of the game. The most important organization at the center of the NSI is the firm, which interacts with other organizations like universities, technological institutes, angel and venture capital investors and government agencies, among other organizations, to develop and diffuse innovations. According to Woolthuis et al. (2005), the players of the game can be classified into categories according to the main role they play in the NSI. A list of organizations typically included in the NSI framework are listed below in Table 2.1.

Table 2.1: Organizations included in the NSI framework

\begin{tabular}{ll}
\hline Category of organization & Description \\
\hline & 1. Large firms \\
I. Companies & 2. MNCs \\
& 3. SMEs \\
& 4. Startups \\
& 5. Suppliers \\
\hline \multirow{2}{*}{ II. Knowledge organizations } & 1. Universities \\
& 2. Technological institutes \\
& 3. Public research organizations \\
\hline \multirow{2}{*}{ III. Demand related organizations } & 1. Consumers/users \\
& 2. Large buyers \\
\hline
\end{tabular}


Table 2.1 continued

\begin{tabular}{ll}
\hline \hline Category of organization & Description \\
\hline \multirow{3}{*}{ IV. Third parties } & 1. Banks/Angel and venture capital \\
& 2. Intermediaries \\
& 3. Sector organizations \\
\hline \multirow{3}{*}{ V. Public sector } & 1. Organizations involved in the definition, implemen- \\
& tation and coordination of innovation policies \\
& 2. Implementation agencies related to science, technol- \\
& ogy and innovation \\
& 3. Other public organizations \\
\hline
\end{tabular}

Source: Own elaboration based on Woolthuis et al. (2005)

Institutions, on the other hand, include "the set of common habits, norms, routines, established practices, rules or laws that regulate the relations and interactions between individuals, groups or organizations" (Edquist, 1997, p. 49). That is, they are the rules of the game. Some examples of both formal and informal institutions are presented below in Table 2.2 .

Table 2.2: Institutions included in the NSI framework

\begin{tabular}{ll}
\hline Institutions & Description \\
\hline 1. Technical standards \\
2. Labor law \\
3. Risk management laws \\
4. Health and safety regulations \\
5. General legal system relating contracts \\
6. Intellectual property right law \\
7. Anti-trust regulations \\
8. Tax Laws \\
9. Banking and financial sector regulations \\
10. Laws that define missions and objectives of public \\
organizations engaged in the definition and implemen- \\
tation of public organizations involved in the NSI \\
11. Laws that define conditions under which public re- \\
sources are transferred to different organizations within \\
the NSI \\
1. Social norms and values in general \\
2. Culture \\
3. Willingness to share resources with other actors \\
4. Entrepreneurial spirit \\
5. Tendencies to trust \\
6. Risk averseness \\
7. Tendency to consider failure as a learning process of \\
trial and error (second chance culture) \\
\hline
\end{tabular}

Source: Own elaboration based on Smith (2000) and Woolthuis et al. (2005)

Applying the NSI framework to understand how the innovation process works 
and evolves in a given economy requires a thorough analysis of the operation of the NSI in focus, which as Edquist and Chaminade (2006) argue, is easier said than done. The decision on which institutions and organizations to include when analyzing National Systems of Innovation from a broader perspective can become extremely challenging. Furthermore, as NSI evolves, organizations might change or vanish, or even new ones may emerge. This also holds for institutions.

A way to deal with this is to follow the activities-based framework applied in Edquist and Hommen (2008). Here the authors assume that the main function of the SI is to pursue innovation processes, that is, to develop and diffuse innovations. But the achievement of this goal is determined by specific activities within the system that altogether influence the development and diffusion of innovations. Ten activities, described below in Table 2.3, are considered by the authors as important determinants of the innovation outcome of a NSI (Edquist, 2005; Edquist and Chaminade, 2006; Edquist and Hommen, 2008). Probably some will be more important than others depending on how the innovation process is organized and how developed the NSI is (if its emerging or mature, following the taxonomy of Lundvall et al. (2009)). This means that as NSI evolves, different elements may become binding, making them critical at a specific point in time.

In each activity different players or organizations are involved. The same applies to institutions. Interactions between players in a specific institutional setup will determine the performance of each activity, which ultimately will affect the innovation intensity within the $\mathrm{NSI}^{7}$.

Table 2.3: Activities included in the NSI framework

\begin{tabular}{ll}
\hline Activity & Description \\
\hline \multirow{3}{*}{$\begin{array}{l}\text { I. Provision of knowledge inputs to } \\
\text { the innovation process }\end{array}$} & knowledge, primarily engineering, medicine and nat- \\
& ural science. \\
& $\begin{array}{l}\text { 2. Competence building through educating and } \\
\text { training the labor force for innovation and R\&D ac- } \\
\text { tivities. }\end{array}$ \\
\hline II. Demand-side activities & 3. Formation of new product markets. \\
& 4. Articulation of quality requirements emanating \\
& from the demand side with regard to new products. \\
\hline
\end{tabular}

Continued on next page...

\footnotetext{
${ }^{7}$ In each activity system failures might arise, which calls for policy action. The extent to which policy action has taken place and how effective it has been is useful to identify possible avenues for improvement.
} 
Table 2.3 continued

\begin{tabular}{|c|c|}
\hline Activity & Description \\
\hline III. Provision of constituents of NSI & $\begin{array}{l}\text { 5. Creating and changing organizations needed } \\
\text { for developing new fields of innovation. Exam- } \\
\text { ples include enhancing entrepreneurship to create } \\
\text { new firms and intrapreneurship to diversify exist- } \\
\text { ing firms; and creating new research organizations, } \\
\text { policy agencies, etc. } \\
\text { 6. Networking through markets and other mecha- } \\
\text { nisms, including interactive learning between differ- } \\
\text { ent organizations (potentially) involved in the in- } \\
\text { novation processes. This implies integrating new } \\
\text { knowledge elements developed in different spheres } \\
\text { of the SI and coming from outside with elements } \\
\text { already available in the innovating firms. } \\
\text { 7. Creating and changing institutions - e.g. patent } \\
\text { laws, tax laws, environment and safety regulations, } \\
\text { R\&D investment routines etc.- that influence in- } \\
\text { novating organizations and innovation processes by } \\
\text { providing incentives for and removing obstacles to } \\
\text { innovation. }\end{array}$ \\
\hline $\begin{array}{l}\text { IV. Support services for innovating } \\
\text { firms }\end{array}$ & $\begin{array}{l}\text { 8. Incubation activities such as providing access to } \\
\text { facilities and administrative support for innovating } \\
\text { efforts. } \\
9 \text {. Financing of innovation processes and other } \\
\text { activities that can facilitate commercialization of } \\
\text { knowledge and its adoption. } \\
\text { 10. Provision of consultancy services relevant for } \\
\text { innovation processes, e.g. technology transfer, com- } \\
\text { mercial information and legal advice. }\end{array}$ \\
\hline
\end{tabular}

Source: Own elaboration based on Edquist (2005), Edquist and Chaminade (2006) and Edquist and Hommen (2008).

As previously mentioned, the most important organization at the center of the NSI is the firm. However, both existing and new firms have the potential to contribute to the development and diffusion of innovations within an economy. As shown in Table 2.3, entrepreneurial activity can be considered a means through which new firms, or startups, emerge within national boundaries with the aim of developing new fields of innovation. That is, innovative entrepreneurship constitutes a key activity that partially determines the development and diffusion of innovations within the NSI. The process of innovative entrepreneurship is therefore shaped by the NSI's institutional setting in which it is embedded, and relies on other activities within the system to function, like incubating and financing activities.

The next three Chapters of this thesis will focus on the traits of the entrepreneur and how they relate to innovative entrepreneurship in Chile. But before analyzing this relationship, it is important to understand first the context in 
which innovative entrepreneurship occurs. And since innovative entrepreneurship is an activity embedded within the institutional setting of the national system of innovation, I start by analyzing how the institutional framework has evolved in the last 25 years. In this analysis I address the evolving aspect of the institutional setting by describing its trends from the year 1990s onwards, which allows capturing some interesting dynamics of how it has evolved, which ultimately explains the picture we see today. Since a detailed discussion goes beyond this Chapter, I focus on the aspects that are most relevant for the process of innovative entrepreneurship.

\subsection{Main historical trends of the Chilean NSI}

The evolution of the institutional setting of the Chilean National System of Innovation can be divided into two stages: before and after the year 2005. In the mid decade of the 2000s important improvements to the governance of the system were implemented, in particular the creation in 2005 of an Innovation Fund to finance innovation initiatives; the creation in 2005 the Innovation Council for Competitiveness $^{8}$ (CNIC) as an advisory body of the President of the Republic; and the creation in 2007 of the Inter-Ministerial Committee for Innovation (CMI) as a policy-making and coordinating body. These improvements responded to the general consensus regarding the fragmented, decentralized, poorly co-ordinated and inefficient system of innovation that Chile had until then (Benavente, 2005; Eyzaguirre et al., 2005).

These new organizations within the public dimension of the system implied a qualitative shift in the institutional framework. Public resources to finance innovation increased dramatically, and for the first time in Chile a long-run innovation strategy was going to be developed, which would give the guidelines to define an explicit innovation policy at the national level. Since then the national innovation system has been evolving towards a more mature stage where some prior weaknesses have been dealt with, but others have naturally emerged, which is expected from a system that learns and evolves. Within the NSI, the ecosystem of entrepreneurship has also experienced important transformations, as will be discussed throughout this subsection.

The remainder of this section reviews the main historical trends of the institutional setting of the Chilean System of Innovation. It starts at the beginning of the nineties, right after Chile reverted to democracy, dividing the evolution of

\footnotetext{
${ }^{8}$ Recently its name was changed to 'National Innovation Council for Development' (CNID).
} 
the system into two main stages: 1990-2004 and 2005-to date. It is important to clarify that an exhaustive and detailed analysis of the evolution of the institutional framework goes beyond this thesis. The main objective is to provide a general background such that the reader has an overall idea of the institutional context in which innovative entrepreneurship occurs in Chile, and how it evolved to the picture we see today.

\subsubsection{The first stage: $1990-2004$}

Innovation policies can be said to have started in Chile at the beginning of the 90 s with the creation of the first government program exclusively aimed at fostering innovation in the productive sector ${ }^{9}$. The Program of Science and Technology, PCT (1992-1995), was launched within the Ministry of Economics with the help of a loan ${ }^{10}$ from the Inter-American Development Bank (IDB) and its main objective was to encourage technological innovation in Chilean firms and to strengthen R\&D activities.

Together with the PCT two new contestable funding programs were launched: the FONTEC (1991-2004) within CORFO, the Economic Development Agency of the State, and FONDEF (1991-to date) within CONICYT, the National Commission for Scientific and Technological Research. The first one was created to co-finance innovation projects carried out by private firms, while FONDEF was created with the aim of strengthening and building R\&D capacities through the co-financing of research projects undertaken by firms in collaboration with universities. These two public funding programs came to complement the FONDECYT fund (1982 to date) within CONICYT, aimed at co-financing basic research in all disciplines.

The PCT program implemented science, technology and innovation (STI) policies through the two main public agencies of the then 'emerging' innovation system: CORFO and CONICYT. In total US\$155 million were allocated in related initiatives, which became the biggest public investment in this field until then. The allocation criteria of the subsidies was based on horizontal peer competition and followed the international best practices of the moment, in which the role of the State was considered to be neutral regarding the selection of projects. Thus, at the beginning of the nineties, the rather 'implicit' STI policy was characterized mainly by a horizontal approach.

\footnotetext{
${ }^{9}$ This section is based on the report MINECON (2005), elaborated by the Undersecretary of Economics, Government of Chile.

${ }^{10}$ The approved loan was US\$67 million and represented 36 percent of the total costs of the program (MINECON, 2005).
} 
The PCT contributed to increase efforts in the science and technology dimensions, through FONDECYT and FONDEF, as well as in the dimension of process and product innovations within the business sector through FONTEC. It also helped to include progressively within the public sector agenda the science, technology and innovation policy dimensions. The program came to an end in a context in which there were still weaknesses to be addressed: innovative activities had not reached yet the critical mass required to promote significant increases in national productivity; the collaboration between the business and research sectors was still weak; and there were clear disconnections between research and its applications in the productive sector.

These challenges motivated the next government to launch a new program within the Ministry of Economics, the Program of Technological Innovation ${ }^{11}$, PIT (1996-2000) with the aim of: strengthening R\&D and innovation activities within the business sector; achieving higher impact of research efforts through its focus on technical problems faced by the productive sector; and to improve the national technological infrastructure through the modernization of the network of Technological Institutes and Research Foundations ${ }^{12}$. As compared to PCT, the PIT Program gave more emphasis to innovation and less to basic research.

The STI policy of the PIT was also implemented through the contestable funds within the two main implementing agencies of the innovation system, CORFO and CONICYT. A fourth contestable funding program, targeted at the beginning to Technological Institutes, was created within CORFO: the Fund for Development and Innovation, FDI (1995-2004) ${ }^{13}$. The FDI was later on refocused on fostering innovation processes and technological change in the productive sectors of the Chilean economy. This was also the first fund that later on started supporting innovative entrepreneurship, through seed capital and incubation initiatives. Other two sectoral funding programs completed the picture: The Fund for Innovation in Agriculture, FIA, and the Research Centre on Metallurgy and Mining, CIMM.

\footnotetext{
${ }^{11}$ The Chilean Government assigned a budget of US\$355 million to the PIT Program (MINECON, 2005), which were allocated to firms, universities and technological institutes through the contestable funds within the two main implementing agencies, CORFO and CONICYT.

${ }^{12}$ Over the years the Ministry of Agriculture, the Ministry of Health and other sectoral ministries had established smaller technological institutes, foundations and/or self-standing research programs. The majority of them were created by special laws and focused on applied research, provision of technological services and knowledge diffusion to firms and producers. The quality and relevance of the research, and the achieved interaction with firms varied across institutes (World Bank, 2008).

${ }^{13}$ Before the creation of the FDI fund, Technological Institutes were financed through regular budget transfer. In order to increase their efficiency a new funding strategy, based on funding competition through the FDI Program was implemented.
} 
With this second government program, the PIT, a gradual shift in the policy approach took place. Some funding programs shifted from purely horizontal allocative criteria to a mixed one in which priority was given to some sectors that were considered relevant for development: ICT and Biotechnology. With this priority in mind, two new funding programs with sectoral flavor were launched: the Program for Research in Advanced Areas, FONDAP (1996-to date) within CONICYT, and the Milenio Scientific Initiative, ICM (1996-to date) within the Ministry of Planning ${ }^{14}$, which was aimed at supporting science and technology research through the creation and development of centers of excellence in social and natural sciences. The regional dimension was also given importance and a regional funding program was launched within CONICYT, the Regional Program of Scientific and Technological Development (2000-to date), with the purpose of creating scientific and technological capacities in each region through the creation of research centers that brought together universities, private firms and the regional governments. All these new funding programs increased significantly the scope of the system, but at the same time the coordination of the system started to be difficult, as it will be discussed at the end of this subsection.

A third program was launched with a new government, the Program of Development and Technological Innovation, PDIT (2001-2006), also called ChileInnova, which was financed by the Chilean Government and the IDB ${ }^{15}$. Its mission was to contribute to increase the competitiveness of the country through the support of innovation and entrepreneurship in key areas of the national economy. The strategy of the PDIT was based on four core areas: biotechnology, ICT, clean production technologies and quality standards. In addition, prospective studies were carried out on a regular basis in different relevant sectors of the economy in order to improve long-run policy planning. Important efforts were also made within this new government program to improve coordination among the increasing number of components of the Innovation System and to support human capital formation. Within the PDIT program innovative entrepreneurship was explicitly supported for the first time, through the FDI public fund. It supported the incubation of new firms in the ICT sector and provided seed capital to support the creation of new innovation based firms.

\footnotetext{
${ }^{14}$ The ICM was transferred in 2011 to the Ministry of Economics and in August of 2015 the President of the Republic announced that it would be transferred to CONICYT, dependent of the Ministry of Education. The rationale behind the last transfer of this successful initiative is to unify the definition and management of a national policy of centers of excellence, which naturally falls within the scope of CONICYT, the main public agency supporting basic research.

${ }^{15}$ The budget of the PDIT was US $\$ 200$ million. The Chilean Government and the IDB contributed with US\$100 million each (MINECON, 2005).
} 
After almost a decade of a horizontal approach, innovation policymaking shifted clearly towards a more selective approach in which both horizontal funds coexisted with selective policies aimed at fostering specific sectors of the economy. A bunch of sectoral initiatives were implemented since then through the main implementing agencies CORFO, CONICYT and FIA. One of the most important initiatives was the Consortia Program. Other thematic initiatives aimed at fostering innovation projects in specific sectors were launched by CORFO through its instruments kit, particularly in mining, biotechnology, food industry, tourism, infrastructure and energy.

A better understanding of the systemic nature of the innovation process was gradually achieved after a decade of experience and further institutional initiatives were pushed forward to improve institutions for innovation. Important progress in the intellectual property and venture capital dimensions were achieved following international best practices and came timely to address the new requirements of a more mature Innovation System.

Summing up, between 1990 and 2005 the innovation policy in Chile was rather "implicit" in the sense that it was defined according to the different priorities of each government and the implementing public agencies, mainly CORFO and CONICYT. The main characteristic of this implicit policy was its instrumental approach, in which different funding programs were launched through all these fifteen years using an horizontal allocative criteria at the beginning and more selective after the 2000s. As the institutional setting evolved and the number of public funding programs significantly increased, some coordination problems started to become evident. After fifteen years of active actions from three different governments there was an important vacuum in the system. Chile did not have formal mechanisms to define and guide a comprehensive innovation strategy and evaluate its impact. The structure achieved until then was fairly decentralized, with priorities defined to a large extent by the main implementing agencies without enough coordination. Each of them responded to their own organizational main goals and not necessarily to national goals, because the NSI lacked a visible responsible for a national innovation policy. Furthermore, the increasing number of initiatives implemented in different components of the public implementing infrastructure ended up with a fragmentation of innovation initiatives, inadequate coherence and duplication of some innovation programs (Benavente, 2005). 


\subsubsection{The second stage: 2005-to date}

The shift from the first to the second stage is a good example of how the interplay between different actors within the system and specific institutional factors can reshape the structure of the system itself, which will ultimately influence back both actors and institutions. This is the essence of the evolving and systemic nature of a National System of Innovation.

Between 2005 and 2007 three new components were added to the NSI, which significantly changed the structure it will have from then onwards: the creation of the Innovation Fund for Competitiveness (FIC), the National Innovation Council for Competitiveness (CNIC) ${ }^{16}$ and the Inter-Ministerial Committee for Innovation (CMI). An interesting question is why and how these changes were made, or in other words, which factors explain the evolution the NSI had. Now I develop some of them.

The awareness among key actors within the "innovation social circle"17 about the low relative performance of Chile in the field of technological innovation started spreading little by little to other spheres of the society. There was a general consensus within this circle regarding the need to foster more $R \& D$ and technological innovation in Chile as a way to prevent the country from lagging behind in a context in which the new paradigm of knowledge-based economies was considered the natural way to keep countries competitive within the global economy. And even though the progress that previous governments had achieved in different dimensions of the innovation process was widely recognized, the consensus by 2004 was that there were still deep weaknesses to be addressed if Chile wanted to shift from the model of primary exports towards a knowledge-based economy (Benavente, 2005; Eyzaguirre et al., 2005).

In particular, Benavente (2005) claimed serious failures within the System of Innovation: low R\&D spending, low R\&D personnel, little private sector involvement in R\&D activities, low impact of innovations on productivity in manufacturing firms, apparent inefficiency in the operation of public funds and programs aimed at supporting $R \& D$ and other innovation related activities, among other deficiencies. In his view the core problem was not related to the extent to which

\footnotetext{
${ }^{16}$ See Footnote 8 above.

${ }^{17}$ I define the innovation social circle as all those actors that directly or indirectly belong to any level of the NSI. For example, it includes actors from the government (people from implementing agencies like CORFO, CONICYT and FIA, and people from the Ministry of Economics and Finance), from universities (for example researchers in related topics, like productivity, development and firm dynamics), from the science community (that use actively public resources aimed at fostering R\&D), from the business sector community (like sector associations, who represent the interests of firms) and other relevant actors that play a role in the NSI, like Fundación Chile.
} 
the public architecture was able or not to properly alleviate market failures, but to a systemic failure related with the lack of a national policy that could give clear guidelines regarding the direction that the system should follow. He furthermore suggested that a way to overcome this failure was to create a leading body responsible for the definition of clear directions, priorities and rules, and for monitoring the performance of the system as a whole.

The weaknesses highlighted by Benavente (2005) were in line with the stage of evolution the NSI had reached by then. In other words, as the system evolved and grew bigger during the 90 s and beginning of the 2000s the restrictions that before were not binding became binding by then, pushing for changes that could enable the system to adapt to the new scenario; changes that were clearly difficult to achieve. Furthermore, as Chile advanced towards the next stage of development the need for more complex productivity enhancing policies became evident. The complexity of both efficiency and innovation-enhancing policies had been a challenge for policymakers, as they had been less capable of generating good policy outcomes (Aninat et al., 2010). Nevertheless, the fact that Chile was facing these problems was because it had been successful to jump into the next stage of development in which education, innovation and other restrictions became binding to continue growing. Thus, in a scenario in which there was increasing awareness about the limitations of the current commodity-based export growth model, and about the need to add value to its productive structure through innovation, the eyes were obviously set on the structure of the NSI and how suitable it was to support a new knowledge-based economic development path.

Parallel to this, between the years 2000 and 2004, another public debate became stronger and stronger: taxing the mining sector. There was a widely shared view that several large MNCs mining firms were not paying income taxes, mainly because of the simultaneous application of write-off mechanisms and discounts on interests paid to headquarters due to loans used to finance initial investments. Both benefits were part of the DL 600 Law that ruled foreign direct investment in Chile, which was put in place during the dictatorship as a way to foster the inflow of investment capital. A second argument against the abuse of MNCs was that firms were not paying for the (Ricardian) rents that a scarce and non renewable resource generates. Some senators within the Congress had started this debate way back on the 90s. They publicly campaigned in favor of pressing large MNCs firms to pay their fair share. The initiative was at the beginning not supported by the incumbents of the sector and by the right wing coalition at the Senate, which represented the interests of the business class. The main arguments were 
that this implied changes in the rules of the game (which would give negative signals to foreign investors), it undermined the principle of tax neutrality and it could induce later a similar tax on other productive sectors. The government was initially reluctant to apply selective taxing as well, mainly because of the signals it could generate to foreign investors (Boeninger, 2007; Aninat et al., 2010).

Two main events made the debate eventually publicly visible. First, issues related to tax loopholes used by some mining firms provoked public outcry, especially the case of the Disputada Las Condes mine controversial transaction process $^{18}$. A second factor was related with the need to raise additional taxes to finance a major health program, the Plan Auge, as well as to finance an ambitious social program, known as Chile Solidario. As Boeninger (2007) claims, the fiscal situation was a major issue that helped building the required support for a mining royalty. One of the ways to finance these two programs was to raise the VAT from $18 \%$ to $19 \%$, a very unpopular measure, and to increase taxes on tobacco and diesel. The initiative of raising the VAT, although unpopular, was agreed to be supported by the coalition legislators (pro-government) only if the government agreed to establish a royalty on the mining sector. Boeninger (2007) explains that, compelled by the entire coalition, the Ministry of Finance eventually sent an ad valorem tax proposal to the Congress together with the creation of a Fund for Innovation (FIC) in mid-2004. The FIC was thought as a way to turn revenues from a non-renewable source into a long run source of growth: innovation. The revenues coming from the royalty were expected to feed the $\mathrm{FIC}^{19}$.

The royalty-related articles from the law were not approved by Congress due to the need to modify the foreign direct investment law, which was considered a bad signal to foreign investors. But the articles related to the FIC were approved and the initiative moved into the next legislative stage. A new version of the mining tax law was sent later to Congress in 2005 under the figure of a specific tax to mining exploitation rather than a tax on income so as not to modify the income tax laws. By 2005 the environment conditions had changed, as Boeninger (2007) explains. First, the royalty issue became more visible as public opinion overwhelmingly supported it. Second, both sides wanted to avoid the political costs of dealing with this issue in a year of Presidential elections. And third, the Government was

\footnotetext{
${ }^{18}$ The owner of the Disputada Las Condes mine, Exxon, sold it to Angloamerican, one of the world's largest mining company, at a very high price that failed to reflect the losses claimed in their tax declarations for more than 25 years. Moreover the transaction itself was done overseas without being subject to Chilean taxes (Aninat et al., 2010).

${ }^{19}$ Even though it is not allowed by the Constitution of Chile to earmark tax incomes to specific initiatives, the law project assured the FIC will at least receive the revenues the Government could yearly collect from the mining tax.
} 
interested in finding a way out to the problem without affecting foreign direct investment decisions. Eventually, all actors involved reached a consensus through bilateral negotiations and the specific mining tax was approved in a record of six months.

This is the context in which the FIC was created. The ultimate reason to introduce the tax was to make MNCs pay their fair share in a context of no way back: the issue was publicly visible by the citizenship. The fact that the revenues collected from this initiative were going to finance innovation was a mix of (good) foresight of the authorities and good luck, given all other needs the country had.

Both the mining royalty debate and the increasing awareness regarding the low performance of the Chilean economy in innovation, provoked the discussion to reach other spheres of society. One visible case was the reaction of the Finance Commission of the Senate of the Congress, who organized a special discussion about the situation of innovation in Chile. During these sessions, held between May and June 2004 several questions were posed by the senators, which were discussed together with some key actors of the innovation social circle ${ }^{20}$. The topics discussed covered indicators on R\&D and innovation, successful international experiences in other natural resource-based countries (Australia, Finland and New Zealand), main status of the implementing agencies within the NSI (CORFO and CONICYT), the role that applied sciences had in the productive sector and the governance of the NSI. The sessions came to an end with the consensus that Chile needed both to increase public spending on innovation and to create an advisory body in charge of defining a long-term innovation plan (see Benavente (2006)).

Around this time, in 2005, CORFO reorganized its instruments and merged the FONTEC and FDI programs to form InnovaChile, the main department within CORFO that supports innovation and entrepreneurship to date. With the creation of the division of entrepreneurship within InnovaChile, entrepreneurship started to be explicitly supported by the public sector.

The question about how the revenues from the mining tax collected in 2006 would be allocated triggered in 2005 an addition to the law that discussed the creation of the FIC. It included the creation of a National Innovation Council that, among other things, would oversee the proper allocation of these resources. Given that the law that formally created the FIC and the CNIC was still being

\footnotetext{
${ }^{20}$ I participated in these discussions back in 2004 as a research assistant of the main researcher (José Miguel Benavente) in charge of producing a technical report with recommendations on how to address the challenges faced by the system of innovation. The report, to which I collaborated, can be found in the References to this thesis under Benavente (2006).
} 
discussed in the Congress, the new President of the Republic that came to power in 2006 had to create both bodies by Presidential decree.

On the one hand, the FIC - managed by the Undersecretary of Economics had the mission to finance initiatives aimed at fostering the competitiveness of the country and its regions consistently with a long-run national innovation strategy. From 2006 to date the FIC has been operating within the Ministry of Economics and has received yearly an amount equivalent to the revenues coming from the specific tax to mining. On the other hand, the CNIC was created as an advisory body of the President of the Republic with the mission of designing, through public-private consensus building, a National Innovation Strategy that provided clear guidelines about the direction of public policies in innovation in the upcoming years. It also had the mission of making recommendations about how the FIC should be allocated. With these two initiatives, the FIC and the CNIC, two major weaknesses of the NSI were being tackled: the need to increase public investment on innovation, and the creation of a leader within the NSI that clearly defined where efforts should be directed, looking always towards the long term.

The first Council ended up its task in March 2006 with a document that gave guidelines ${ }^{21}$ on how to move forward on the definition of a National Innovation Strategy for Competitiveness. It also gave recommendations on how to allocate the FIC of 2006.

An important signal of continuity was given by the following government in 2006. The new President of the Republic created a new CNIC at the beginning of the mandate giving a signal that innovation was considered an important component of the development agenda of the government. The CNIC developed between 2007 and 2009 a two-volume document ${ }^{22}$, The National Strategy of Innovation for Competitiveness, with a review of the gaps that Chile should reduce in different indicators, the principles that should guide policy formulation within the system, and the areas in which policy action should focus, namely human capital, science and business innovation. One of the most important initiatives proposed by the CNIC to increase business innovation was the allocation of resources to promote the development of those sectors in which Chile had a competitive potential ${ }^{23}$.

\footnotetext{
${ }^{21}$ The Guidelines for a National Innovation Strategy can be accessed here (in Spanish): http://cnic.economia.cl/index.php/lineamientos-para-la-estrategia-nacional-de-innovacion.html

${ }^{22}$ The two-volume National Innovation Strategy for Competitiveness can be accessed here (in Spanish): http://cnic.economia.cl/index.php/estrategia-nacional-de-innovacion-volumen-i.html (volume I) and http://cnic.economia.cl/index.php/estrategia-nacional-de-innovacion-volumenii.html (volume II).

${ }^{23}$ The chosen sectors were identified by the Boston Consulting Group using two criteria: the potential of Chile to develop competitive advantages and the dynamics of world demand in different sectors. See the National Innovation Strategy for Competitiveness, volume II, for further
} 
This initiative was called the "clusters policy", which consolidated the transition of innovation policy towards a combination of selective and neutral approaches.

Promoting innovative entrepreneurship was another pillar of the strategy to increase business innovation (the other two were: adoption of knowledge in the productive process by existing firms; and technological diffusion). This provides evidence that in the second half of the 2000s innovative entrepreneurship started to be considered one of the main activities determining innovation within the NSI, and explicit support and policies were implemented with the aim of promoting its contribution to the main goal of the NSI, to develop and diffuse innovations that could enable economic development of the Chilean economy in the long run.

Later on, following the recommendations of the OECD and World Bank regarding the differentiation of the advisory and monitoring role from the design and implementation role, a new component within the NSI was created: the Inter-Ministerial Committee for Innovation $(\mathrm{CMI})^{24}$, which was presided by the Ministry of Economics. The CNIC's role was then to develop and review a longrun innovation strategy based on consensus, to monitor progress towards national goals of the innovation strategy and recommending priority investment or programs. The Committee was then in charge of the design and implementation (money decisions) of the innovation policy which requires an effective coordination across agencies and sectors. This initiative allowed for checks and balances within the higher level of the NSI. In fact, according to the World Bank the creation of these two high level components in the public infrastructure of the NSI, have been two critical steps in moving towards a more cohesive and better governed national innovation system (World Bank, 2008, p. vii).

After the two-volume National Innovation Strategy for Competitiveness was delivered, the CNIC focused on the implementation of the proposed strategy. At the end of its term of office, in 2010, the CNIC delivered the Innovation and Competitiveness Agenda 2010-202025, which contained a set of policies and actions aimed at increasing the potential for growth of the Chilean economy such that it could reach development by the year 2020. The Agenda was organized around five main pillars: strengthening business innovation; fostering the development of human capital at all levels; generating capabilities in mission oriented science

details on the long and short list of sectors with potential plus specific recommendations for improvement in each of them.

${ }^{24}$ This new figure was added in 2007 to the draft law project that in 2005 created both the FIC and the CNIC, which was still being discussed in the Congress.

${ }^{25}$ The Innovation and Competitiveness Agenda 2010-2020 can be accessed here (in Spanish): http://cnic.economia.cl/index.php/agenda-innovacion-y-competitividad-2010-2020.html 
base; strengthening universities' third mission; and consolidating the institutional setting within the NSI to promote innovation.

An external evaluation ${ }^{26}$ on the National Innovation Strategy for Competitiveness conducted by a panel of experts in 2010, concluded that although many initiatives were at an early stage, there was still some room for improvement. According to the experts, the key achievement of the CNIC had been to provide an arena to discuss the national development challenges and generate consensus for tackling them. In this sense, they agreed that the scope of the Strategy was appropriate, while the diagnosis of the issues and the policies proposed to address them was considered to be sound and largely correct. Regarding the governance of the NSI, the experts considered that there was a need to clearly establish the institutional status of the CNIC and its objectives, in the sense that it should have the autonomy to recommend a national strategy for innovation and the responsibility for effectively monitoring coordination across the elements that implemented the Strategy. This was related to the fact that the draft law that created the FIC, the CNIC and the CMI was still being discussed (or sleeping) in the Congress since 2005. On the other hand, the panel considered that the progress in implementing the Strategy proposed by the CNIC had been too slow, which was partly related to the little conduction and empowerment of the Inter-Ministerial Committee for Innovation. The weakness of the CMI provoked a lack of focus and coordination of the interventions. Furthermore, the experts deemed that there was an insufficient cohesion and coordination of the programs and instruments through which the innovation policy was implemented. This problem, present since the beginning of the 2000s, was clearly still there, meaning that the creation of both the CNIC and the CMI was not enough to alleviate the little coherence and coordination between public programs.

In 2010 the first right-wing President after the return to democracy at the end of the eighties came to power. With him a new vision emerged, a new President of the CNIC was appointed and some other substantial changes were made in the NSI. Without a doubt the change in the governing political coalition altered the continuity achieved and the knowledge accumulated for more than twenty years. A clear example was the abandonment of the cluster policy, going back to a less selective approach of the innovation policy. The arguments were related with pro-market reasons. During the right-wing government, between 2010-2014, the newly appointed CNIC focused on strengthening the innovation culture under

\footnotetext{
${ }^{26}$ The evaluation can be accessed here (in English): http://cnic.economia.cl/index.php/doc_ details/2-evaluation-report-of-national-innovation-strategy-for-competitiveness-chile.html
} 
the assessment that the most fundamental and urgent change within the NSI was cultural. The report "Surfing the Future" was delivered ${ }^{27}$ by the CNIC in 2013.

An interesting initiative implemented in 2010 by the right wing government was the program Start-Up Chile, a world-wide known program that made the Economist magazine publish an article in 2012 about "the lure of Chilecon Valley" as an analogy to the well known entrepreneurial hub in Silicon Valley. The lure was the offer to foreign young firms an amount of US\$40 thousand and a year's visa to come and work on their ideas in Chile. The main objective of the program was to strengthen the entrepreneurial culture in Chile through the attraction of foreign entrepreneurs. After some time, the program was opened to local entrepreneurs and is currently being extended to the regions of the country (initially it was based in the capital Santiago). Projects should involve innovative products or processes that have the potential to grow quickly and that can impact the world with new technologies. The main countries that have been attracted by Start-Up Chile are the United States, Argentina, India and Brazil.

Today, the main objective of Start-Up Chile is to capitalize on recent efforts and transform Chile as a regional hub for high growth entrepreneurship, attracting talent from the region and interacting with global startups. According to StartUp Chile reports, from the ten thousand applications received approximately, a total number of 1,054 startups were funded between 2010-2014, out of which 685 were alive by October 2015. From this living startups, 264 were raising capital, but only 108 remained in Chile, the rest left. These startups that left have raised 3 times more capital than their counterparts that remained in Chile. This is considered a flaw of the program as it has failed to retain entrepreneurs in Chile and to capture a higher proportion of the total value creation. As a reaction to this issue, the program launched SCALE, a follow-on fund that offers approximately US $\$ 100$ thousand to startups that have accomplished significant traction, are generating revenues and face the need of extra capital to increase growth in Chile and expand to the rest of Latin America ${ }^{28}$. This fund assigns the money through a co-financing grant in which Start-Up Chile will contribute with up to 70 percent, while recipients should match the other 30 percent. As in the original Start-Up Chile grant, no equity will be demanded from the program.

\footnotetext{
${ }^{27}$ The report "Surfing the Future" can be found here (in Spanish): http://cnic.economia.cl/index.php/orientaciones-estrategicas-para-la-innovacion.html

${ }^{28}$ Only companies that have first passed through the six-month Start-Up Chile program will be eligible to apply to this new fund.
} 
In 2014 the center-left coalition came into power again with a new President of the Republic ${ }^{29}$. The Ministry of Economics was in charge of defining an Agenda of Productivity, Innovation and Growth to be executed by the new government between $2014-2018^{30}$. The diagnosis is that the main source of the gap between Chile and advanced economies is its low level of productivity. Therefore, the Agenda aims at tackling the challenge of increasing the productivity of the Chilean economy through four strategic objectives: (1) promote productive diversification; (2) promote sectors with high growth potential; (3) increase firm productivity and competitiveness; and (4) generate a new export boost. Seven action lines will guide the accomplishment of these goals: (1) sectoral strategic investment and development plans; (2) infrastructure for the new development stage; (3) financing and support for SMEs; (4) promotion of entrepreneurship and innovation; (5) efficiency in regulation and in the supply of public services; (6) better markets; and (7) new institutional setup. Overall, this Agenda includes 47 measures, 10 law projects and 37 administrative initiatives that involve a total investment of around US\$1,500 million between 2014 and 2018.

With the Agenda of Productivity, Innovation and Growth 2014-2018 the selective approach to innovation policy was clearly resumed by the new authorities, which can also be inferred from the strategic areas that the CNIC will be focusing on in the period 2014-2017: achieve a broad agreement on the rationale and implementation of a selective action of the state in the fields of science, technology and innovation; make a leap forward in mission oriented research (science and research for development); broaden the scope of the innovation concept, from competitiveness to development; enlarge the mix of instruments available for science, technology and innovation; improve the quantity and quality of information to guide innovation policymaking; formalize the existence of the Council and its regional branches by law.

Following the guidelines of the Agenda 2014-2018, the Ministry of Economics launched in 2014 a National Innovation Plan 2014-2018 around four main pillars, which include: democratization of innovation; selectivity; strengthening R\&D and firm-university collaboration; and strengthening the institutional setting. Also, the Ministry of Economics and CORFO, the main public agency supporting entrepreneurship, launched in 2014 the Policy of Entrepreneurship 2014-2018. The

\footnotetext{
${ }^{29}$ The new President is Michel Bachelet, former President during the period 2006-2010.

${ }^{30}$ Further details on the Agenda of Productivity, Innovation and Growth can be found in http://www.agendaproductividad.cl/sobre-la-agenda/
} 
policy has three main goals: modernize the mix of instruments available for entrepreneurs; generate an ecosystem that supports innovation and entrepreneurship; and to democratize entrepreneurial opportunities. In general, it can be clearly observed that entrepreneurship is today one of the core activities that is being supported to foster innovation and productivity in the Chilean economy.

According to the Ministry of Economy, the public budget for innovation in 2015 was approximately US $\$ 244$ million, which grew by 13 percent with respect to the year 2014, while the FIC received approximately US\$172 million, 20 percent more than in 2014. This means an increase in the availability of resources of approximately 45 percent in 2015. The way these resources are allocated allows to infer what are some of the emphases of the innovation policy. For example, the budget for the CNIC was quintuplicated with respect to 2014 , reaching US $\$ 1.8$ million. This clearly aims at giving back the strength that the CNIC lost in the previous right-wing coalition government. Also, the budget to support dynamic entrepreneurship reached approximately US\$38.1 million, a 48 percent increase with respect to the year 2014. This increase in funds is consistent with the Policy of Entrepreneurship 2014-2018 mentioned earlier.

Overall, it is clear that in the last 25 years the Chilean system of innovation and entrepreneurship has evolved towards a more mature stage in which the majority of the components that should be there, are present. The recent report by Kantis et al. (2015) on the entrepreneurial framework conditions in Chile, allows to verify that the ecosystem is quite populated. The structure, or main building blocks are there. The public sector knows that fostering the creation of new innovative firms is key to foster innovation intensity in Chile and to diversify the economic structure. A substantial amount of resources has been allocated to this and a National Policy has been formulated. However, once the parts of the system are there, we need to make sure that they are linked in a proper way such that the system can produce its magic: generate that virtuous circle in which the whole is more than the sum of its parts. But how is Chile performing in this regard? The next section tries to answer this question by taking a look at two indexes aimed at capturing the performance of entrepreneurship ecosystems.

\subsection{Measuring the performance of entrepreneurship systems}

In this section I review two indexes that attempt to measure the overall performance of entrepreneurial framework conditions on a comparative basis, the 
Global Entrepreneurship Index and the recently published ICEd-Prodem Index. Both take into consideration the main components that build the system of innovation and entrepreneurship discussed in Section 2.2. The main objective is to identify, on a comparative basis, the areas in which the system is performing well and those in which there is room for improvement.

According to the Global Entrepreneurship and Development Institute, that publishes the Global Entrepreneurship Index (GEI), Chile ranks number 16 out of 132 countries in 2016, leading the ranking in South and Central America and the Caribbean. The countries leading the ranking overall are United States, Canada and Australia.

The report defines entrepreneurship as "the dynamic, institutionally embedded interaction between entrepreneurial attitudes, abilities, and aspirations by individuals, which drives the allocation of resources through the creation and operation of new ventures." (Acs et al., 2016, p. 19). The GEI aims at capturing the level of efficiency of the national startup ecosystem in which the entrepreneurship process takes place. For this, the index analyzes 34 individual and institutional variables organized in 14 pillars, which are summarized below in Table 2.4. These 14 pillars fall into three categories that take into account the different aspects of the entrepreneurial ecosystem: entrepreneurial attitudes (pillars 1 to 5), entrepreneurial abilities (pillars 6 to 9) and entrepreneurial aspirations (pillars 10 to 14$)^{31}$.

Entrepreneurial attitudes are associated with the "entrepreneurship-related behavior of the country's population, including opportunity perception, skills, risk aversion, networking potential and cultural support" (Acs and Correa, 2014, p. 6).

Entrepreneurial abilities are associated with the "potential of owners of nascent and startup businesses to produce high growth, which is assessed using measures of quality, activity in a technology-intensive sector, level of education, and the uniqueness of the offered product or service in relationship to those of competitors" (Acs and Correa, 2014, p. 6).

Entrepreneurial aspirations are associated with "distinctive, qualitative, marketexpanding, wealth-enhancing entrepreneurial activity, as reflected in the newness of the product and the technology a venture uses, internationalization, highgrowth ambitions, and the availability of risk capital" (Acs and Correa, 2014, p. 6).

\footnotetext{
${ }^{31}$ The methodology for calculating the scores of the GEI Index can be found in (Acs et al., 2016, Ch. 5)
} 
Table 2.4: 14 pillars measured in the Global Entrepreneurship Index

\begin{tabular}{ll}
\hline Pillar & Description \\
\hline Entrepreneurial attitudes &
\end{tabular}

Captures the potential of opportunity perception (through the

(1) Opportunity perception

(2) Startup skills

(3) Risk acceptance

(4) Networking

(5) Cultural support size of a country's domestic market and level of urbanization). It also captures opportunity recognition, measured as the percentage of the population that is able to identify good opportunities to start a business.

Captures skill perception through the percentage of the population that believe to have the skills required to start a business. It also measures tacit skills (acquired through trial and error in relatively simple business activities) and formal skills (acquired through formal education and training).

Fear of failure can be an important obstacle to startups since it can delay nascent entrepreneurship. This pillar captures the proportion of the population that does not believe that fear of failure would prevent them from starting a new venture. It also measures business risk, in terms of the availability and reliability of corporate financial information, legal protection of creditors, and institutional support of inter-company transactions.

Networking is important for venture creation and performance since entrepreneurs with better networks are more successful, can identify more viable opportunities, and can access more and better resources. This pillar measures the percentage of the population who personally know an entrepreneur who started a business within two years. It also includes the entrepreneur's ability to use the Internet for business purposes as it adds a new dimension of networking.

It measures how a country views entrepreneurs in terms of status and career choice, and how the level of corruption affects this view. Without cultural support, individuals may prefer to enter a traditional profession instead of becoming entrepreneurs. This pillar measures the proportion of the population age 18-64 that think entrepreneurship is a good career choice and enjoys high status. It also captures the level of corruption. 
Table 2.4 continued

\begin{tabular}{ll}
\hline \hline Pillar & Description \\
\hline & The motivation to start a business can be a signal of quality, in \\
the sense that opportunity-driven entrepreneurs are believed \\
to be better prepared, to have superior skills, and to earn \\
more than the so-called necessity entrepreneurs. This pillar \\
measures the percentage of the total entrepreneurial activity \\
(TEA) businesses that started to exploit an opportunity, to \\
increase income, or to fulfill personal aims, in contrast to those \\
started by people who had no other options for work. It also \\
captures business freedom, defined as the overall burden of \\
regulation and the government's regulatory efficiency in influ- \\
encing startups and operating businesses.
\end{tabular}

ICTs can provide good chances for businesses to survive and to achieve their growth potential. Also, the diffusion of new technology and the capacity to absorb it is key for innovative

(7) Technology absorp- firms with high growth potential. This pillar captures the tion businesses that are in technology sectors and also the country's capacity for firm-level technology absorption, as reported by the World Economic Forum.

Access to highly skilled and experienced workforce is a key input for highly innovative ventures. Also, entrepreneurs behind ventures with high growth potential are more prone to

(8) Human capital be highly educated. Highly skilled human capital can be enhanced through institutional variables like staff training, captured as the country's level of investment in business training and employee development.

Captured through a combination between the business's product or market uniqueness and the market power of existing businesses. This pillar is measured by the percentage of busi-

(9) Competition nesses (TEA) that have a few competitors offering the same product or service; and by the extent to which there is market dominance that hinders market entry (Market Dominance from the World Economic Forum).

Entrepreneurial aspirations

Measures the country's potential to generate new products and to adopt or imitate existing ones. To quantify the poten-

(10) Product innovation tial for new product innovation, a technology and innovation transfer variable is captured by measuring the extent to which the business environment allows the application of innovations for developing new products.

The application and creation of new technologies is also important for ventures with high growth potential. This pillar measures the usage of new technologies through the percentage of businesses whose principal underlying technology is less than five years old. However, since some businesses also create their own technologies, it is relevant to measure R\&D efforts as a a percentage of GDP. 
Table 2.4 continued

\begin{tabular}{ll}
\hline \hline Pillar & Description \\
& It combines the percentage of high growth businesses that in- \\
& tend to employ at least ten people and plan to grow more \\
& than 50 percent in five years (Gazelles) with business strat- \\
& egy sophistication. Business strategy captures the ability of \\
& companies to pursue distinctive strategies, which involves dif- \\
& ferentiated positioning and innovative means of production \\
& and service delivery. \\
& Internationalization can be a major determinant of growth, \\
& which can be captured through exports. The country's open- \\
& ness to international entrepreneurs can be estimated by its de- \\
& gree of globalization. This pillar therefore captures the degree \\
& of internationalized entrepreneurs, measured by the exporting \\
& potential of businesses, controlling for the extent to which the \\
& country is globalized. \\
& The availability of risk finance, particularly equity rather than \\
& debt, is a precondition for fulfilling entrepreneurial aspirations \\
that are beyond an entrepreneur's personal financial resources. & Two types of finance are captured: informal investment (per- \\
& centage of informal investors in the population age $18-64$ mul- \\
& tiplied by the average size of their investment in new busi- \\
& nesses) and the institutional depth of capital market (mea- \\
& sured by the size and liquidity of the stock market, level of \\
& IPO, M\&A, and debt and credit market activity). \\
(14) Risk capital &
\end{tabular}

Source: Summarized from Acs et al. (2016, p. 19-20)

The score of Chile in each of the 14 pillars of the GEI 2016 are depicted below in Figure 2.1. Its performance is compared to the overall performance of the region (South and Central America and the Caribbean) and to the top three countries leading the ranking, United States, Australia and Canada. A quick look at the graph shows Chile depicting a star-shaped pattern that contrasts with the rounder profile of the top three countries, implying that the high score of Chile hides an uneven performance among the pillars that compose the index. For example, good performance in startup skills coexists with low technology absorption and process innovation.

The star-pattern suggests the existence of bottlenecks that hold back entrepreneurial performance as a whole due to the interdependence trait that characterizes systems. That is, the outcome of the system depends on the web of interactions that take place within the system, where the behavior of each component is influenced by the behavior of the rest, and vice versa. Another implication of interdependence is that modifying one component can affect the behavior of 
the whole system, meaning that by focusing on alleviating the bottlenecks entrepreneurial performance should increase. This is why it is important to keep doing research on the elements that should be present in the ecosystem of entrepreneurship and understand the types of linkages between them, such that it can help policymakers getting feedback for policy action. If key elements are missing from the analysis, no matter how we improve a subset of them, the overall performance will not significantly improve as it is subject to the performance of the weakest link.

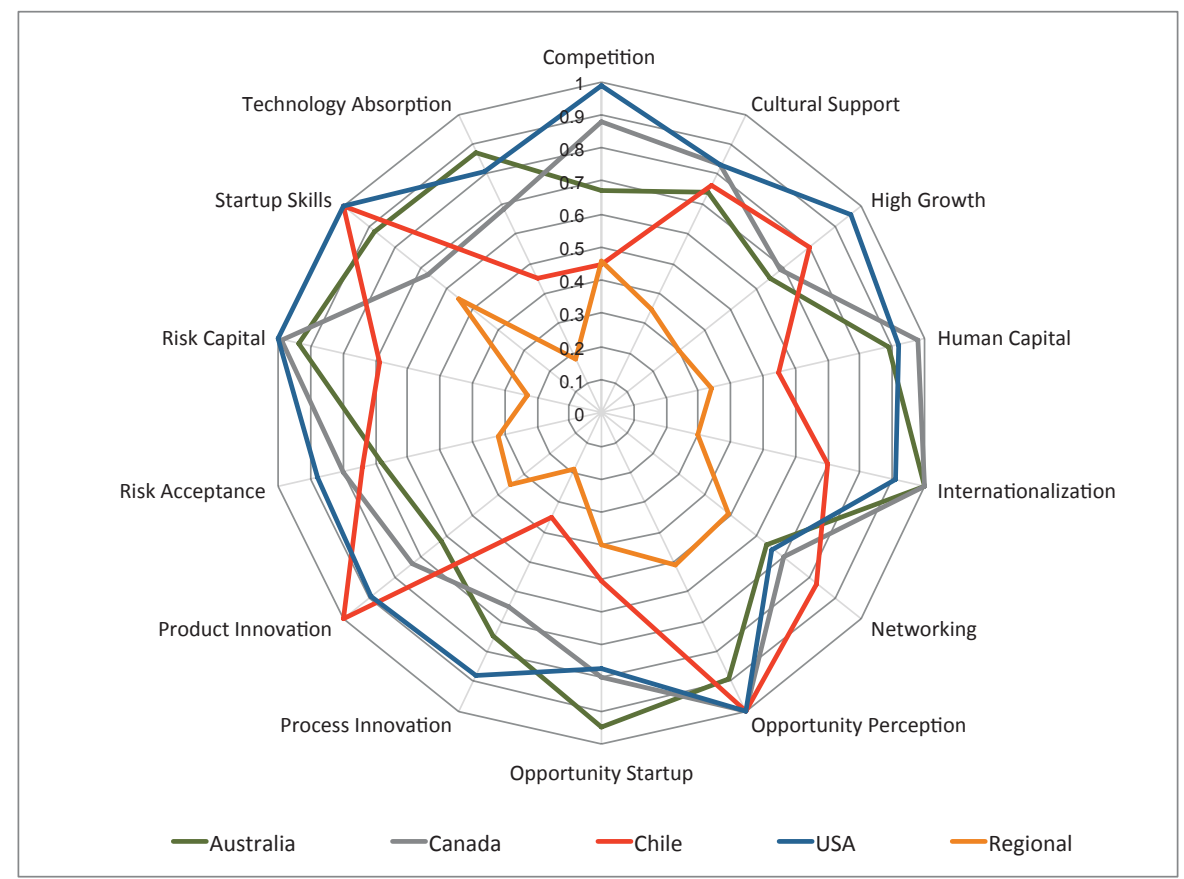

Source: Own elaboration based on GEI 2016 (Acs et al., 2016)

Figure 2.1: Global entrepreneurship index: 14 pillar comparison

The pillars in which Chile performs well are those in which its performance is close the the one of the top three countries, which include (in order): product innovation, startup skills, networking, high growth, cultural support and risk acceptance. Interestingly, five out of the seven pillars fall in the category of entrepreneurial attitudes. This implies that the Chilean population believes that there is room to create new products and think that they have the skills required 
to start a business, in a context that welcomes and supports entrepreneurship. Furthermore, they do not seem to be discouraged by the fear of failure and seem to have good networking. The combination of the good performance in these pillars captures the fact that Chile has been able to develop a culture in which there is room for entrepreneurship to occur, in the sense that is not an esoteric phenomenon anymore left to reckless individuals.

The good performance in entrepreneurial attitudes may be the result of the efforts of the government, through CORFO, and other organizations of the ecosystem, like Endeavor, Fundación Chile, the media, the association of entrepreneurs in Chile (SECHI) and incubating offices, among other relevant actors of the ecosystem, to increase awareness of entrepreneurship. This good performance in entrepreneurship-related behavior is somehow a good news in the sense that it includes some important informal institutions like attitudes towards failure and the perception regarding the status of entrepreneur as a career choice. As discussed earlier in Section 2.2, informal institutions are related to culture, social values and norms that shape the behaviors of individuals in a society. These tacit rules of the game are in general very rooted in a society's idiosyncrasy and are generally very difficult to modify, especially by authorities.

However, when looking at the pillars in which Chile underperforms one may become a little worried as they may constitute important bottlenecks in the entrepreneurial ecosystem. These pillars are: process innovation, competition, technology absorption, opportunity startup, human capital, risk capital and internationalization. Four out of seven fall in the category of entrepreneurial abilities and the other three fall in the category of entrepreneurial aspirations. This implies that there may be "structural" bottlenecks that need to be addressed urgently, otherwise the system will never work at its full potential. Particularly worrying are the pillars of technology absorption, process innovation and human capital, which are necessary conditions for knowledge and technology-based startups to emerge and successfully diversify the economic structure of the economy.

The ICEd-Prodem, on the other hand, captures the enabling systemic conditions for dynamic entrepreneurship, which is built ${ }^{32}$ using different variables and information sources ${ }^{33}$. Chile ranks number 29 out of 56 countries in 2015 (out of which 15 are from Latin America), leading the ranking in the region (Latin America). The countries leading the ranking are Singapore, United States, and Finland.

\footnotetext{
${ }^{32}$ The methodology for calculating the index can be found in Kantis et al. (2015a, p. 154-160)

${ }^{33}$ See Kantis et al. (2015b, p. 145-146) for the list of variables and sources of information used to build the index.
} 
This index focuses exclusively in dynamic entrepreneurship, defined as those ventures that have the capacity to create quality employment and help diversify the productive structure of the region. Following Kantis et al. (2015b, p. 24-25) "dynamic companies are usually founded by teams that have enthusiasm, aspirations and competencies that allow them to grow and leverage helpful contact networks to pursue value propositions based on differentiation, innovation and/or business opportunities targeting the capitalization of dynamic and scalable economic trends".

The concept of dynamic entrepreneurship resembles the concept of gazelle firms defined by the OECD as enterprises with average annualized growth in employees (or in turnover) greater than 20 percent a year, over a three-year period, and with ten or more employees at the beginning of the observation period and that were born five years or less before the end of the three-year observation period. However, Kantis et al. (2015b, p. 25) argues that the concept of dynamic company fits better the Latin American context and better captures the complexity of the enterprise growth phenomenon than other rather rigid definitions based on the establishment of minimum levels of sales or employment over the first year, or specific growth rates.

The ICEd-Prodem index is based on a set of variables organized in 10 pillars, which are summarized below in Table 2.5.

Table 2.5: 10 pillars measured in the ICEd-Prodem Index

\begin{tabular}{ll}
\hline Pillar & Description \\
\hline (1) Social conditions & $\begin{array}{l}\text { Inversed Gini coefficient; National per-capita income; Youth } \\
\text { unemployment }\end{array}$ \\
$\begin{array}{ll}\text { (2) Entrepreneurial human } \\
\text { capital }\end{array}$ & $\begin{array}{l}\text { Improvement-driven opportunity entrepreneurial activ- } \\
\text { ity/TEA; Growth expectation early-stage entrepreneurial } \\
\text { activity/TEA; Risk aversion coefficient }\end{array}$ \\
& $\begin{array}{l}\text { Entrepreneur's social status; Entrepreneurship in the media; } \\
\text { (3) Culture }\end{array}$ \\
& $\begin{array}{l}\text { Secondal hierarchy } \\
\text { ment; Public spending per student/GDP per capita; En- } \\
\text { trepreneurship education at initial levels, Entrepreneurship } \\
\text { education at tertiary levels }\end{array}$ \\
& $\begin{array}{l}\text { GDP at PPP (in logs); Demand quality; GDP growth; Pur- } \\
\text { chasing power parity }\end{array}$ \\
&
\end{tabular}


... Table 2.5 continued

\begin{tabular}{ll}
\hline \hline Pillar & Description of variables \\
\hline (6) STI Platform & $\begin{array}{l}\text { Companies' spending in R\&D (\% GDP); Productive units' } \\
\text { spending in R\&D (\% GDP) S\&T institution quality; Re- } \\
\text { searchers/AEP }{ }^{34} ; \mathrm{S} \& \mathrm{~T} \text { production; University-company re- } \\
\text { lations }\end{array}$ \\
& $\begin{array}{l}\text { Business sophistication index; Work productivity (GDP per } \\
\text { person employed); High-tech exports; Industry technologi- } \\
\text { (7) Business structure }\end{array}$ \\
& $\begin{array}{l}\text { Interpersonal trust; Individualism; Social support network } \\
\text { (8) Social capital }\end{array}$ \\
& $\begin{array}{l}\text { Opening companies; Closing companies; Foreign trade; } \\
\text { Contractual security Tax burden, General entrepreneurial } \\
\text { (9) Policies and regulations }\end{array}$ \\
& $\begin{array}{l}\text { support policies; Specific programs for dynamic en- } \\
\text { trepreneurship support }\end{array}$ \\
& $\begin{array}{l}\text { Accessibility to VC; Accessibility to bank loans; En- } \\
\text { trepreneurship funding }\end{array}$
\end{tabular}

Source: Summarized from Kantis et al. (2015b, p. 145-146)

The score of Chile and its comparison with the regional and international benchmark $^{35}$ is presented in Figure 2.2. Again, a highly uneven performance can be observed, which contrasts with the more homogeneous performance of the countries included in the international benchmark.

One of the strongest pillars is 'policies and regulations' which possibly captures the significant progress in the institutional setting achieved in the last decade, as was discussed earlier in Section 2.3. The recent initiatives specifically aimed at fostering entrepreneurship and the substantial increase in public financing to support entrepreneurship capture the transition of entrepreneurship policies towards a more mature phase. 'Demand conditions' also appears relatively strong, which is consistent with the good performance in the 'opportunity perception' pillar from the GEI.

The weakest pillars are: entrepreneurial human capital, culture, STI platform, social capital and financing. In general, results are consistent with the GEI, especially regarding human capital and financing. However, the result on culture seems to differ between both indexes, as it appeared as a very strong pillar in

\footnotetext{
${ }^{34} \mathrm{AEP}$ is the acronym for Active Economic Population.

${ }^{35}$ The international and regional benchmark refer to the average value of the top 3 countries for each dimension in the overall ranking and in Latin America, respectively.
} 
the GEI but not in the ICEd-Prodem Index. This may be explained y the fact that the indexes differ in the type of variables included. For example, the GEI includes the perception on the level of corruption, which is generally low in Chile so it may explain a better performance in the culture indicator. The social capital pillar also differs between both indexes. Again, this may be explained by methodological differences. However, the type of variables included in the ICEd-Prodem Index seem to be more accurate than the ones included in the GEI. The weakest dimension in Chile is the STI platform, which is expected from the general diagnosis of low R\&D efforts both at the national and the business sector levels.

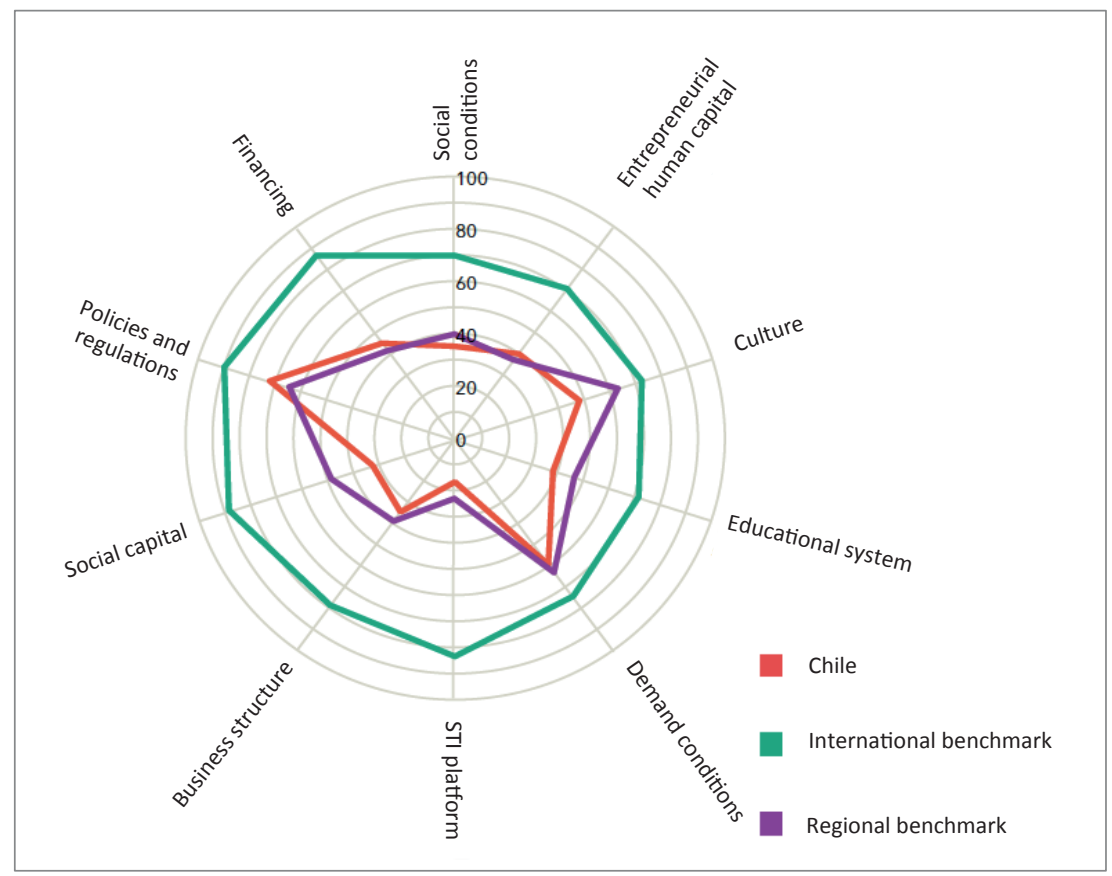

Source: Based on ICSEd-Prodem 2015 (Kantis et al., 2015b)

Figure 2.2: Ecosystem of dynamic entrepreneurship: 10 pillar comparison

\subsection{Concluding remarks}

As discussed in the Introduction, the population of entrepreneurs is highly heterogeneous and includes a wide variety of individuals co-existing within the 
same environment. However, only those that have the potential to be innovative and achieve high growth rates, in terms of sales and job creation, are expected to generate a larger economic impact than those who remain small and local. This is why public support towards generic entrepreneurship has been increasingly discouraged in the academic literature during the last years suggesting that the focus should be on promoting the emergence of innovative startups instead.

Based on the evidence presented in this Chapter, it seems that public support to entrepreneurship in Chile has been mostly focused on generic entrepreneurship, probably as a result of the horizontal approach to policymaking that has prevailed in the NSI. However, it is clear that in the last ten years the system has evolved towards a more mature stage in which the majority of the enabling components of an ecosystem of entrepreneurship are there. The public sector is currently fostering the creation of new innovative firms as a driver to foster innovation, productivity and economic diversification. This can be verified by the substantial amount of resources that have been recently allocated to support entrepreneurship and its ecosystem, which are now part of the first National Entrepreneurship Policy. Through different initiatives, authorities want to transform Chile in a regional hub for high growth entrepreneurship, attracting talent from the region. And apparently it is on its way, as Chile ranks first in the region in two indexes that measure the performance of entrepreneurial framework conditions.

Nonetheless, some concerns should be taken into consideration. The first one relates to the highly uneven performance in the different conditions that enable entrepreneurship, suggesting the existence of bottlenecks that may be holding back a better performance of the system. That is, given the inter-dependence between the components, where the behavior of each component is influenced by the behavior of the rest and vice versa, the system as a whole will be subject to the performance of the weakest component. Nevertheless, this also means that focusing on identifying and overcoming those bottlenecks can improve the performance of the whole system. According to the two indexes reviewed some improvements need to be made within the ecosystem, like increasing the availability of risk capital. However, promoting higher availability of smart money will not yield the overall expected benefits if internal technical capabilities of startups and entrepreneurs are not improved. In fact, technology absorption and human capital appear also as relatively weak areas in the ecosystem, both of which are key to promote the availability of a critical mass of innovative startups eligible to receive smart funding. 
The second concern relates to the fact that being an entrepreneur in Chile has lately become a highly regarded activity and there is increasing interest among the population to succeed as one. More and more stories of successful entrepreneurs appear in the media and a wide range of programs aimed at supporting startups have been emerging in the last years. And despite the fact that this should be considered a positive trend in terms of demonstration externalities (Acs and Virgill, 2009), there should be precaution in giving wrong signs to the population regarding the 'easiness' of the entrepreneurial process, especially of innovative entrepreneurship, which is highly complex and uncertain. In fact, failure is more the rule than the exception in innovating startups. Still, such failures can constitute an important source of information for entrepreneurs to learn and to become increasingly professionalized.

A third concern is that public support has mainly taken the form of financial support through subsidies and matching grants of different sorts. However, this should go together with larger efforts to promote training and information regarding how the entrepreneurial process works. That is, helping entrepreneurs to become more professionalized. This is especially relevant at the regional level, where the ecosystem is relatively less developed given the high concentration of entrepreneurial activity in the capital Santiago. For example, potential innovating entrepreneurs should be aware that banks are not aimed at financing innovative ideas because they administer risk, not uncertainty. Furthermore, entrepreneurs tend to fall in love with their ideas and may fail in visualizing a clear business plan, which is an important signaling strategy when looking for smart investors. The idea might be technically perfect, but the entrepreneur needs to be able to visualize its business years from now and convince an investor to spend time and money on them. This implies that the government should be aware that the proliferation of a wide range of (mostly financial) instruments aimed at supporting entrepreneurship can end up in frustration and waste of resources if the system does not promote simultaneously the development of entrepreneurial human capital.

A final concern relates to the continuity of entrepreneurship policies in the upcoming governments as the draft law that formally creates the FIC, CNIC and CMI is still in discussion in the Congress since 2005. This raises a red flag warning regarding the problems of dynamic inconsistency that the NSI is being exposed to. Dynamic inconsistency is one of the most detrimental state failures that a society can face and it relates to the unwillingness or difficulty to undertake an action whose benefits will be observed after an authority's term of office. Consequently, 
the need of policy-related organizations within the NSI that are not exposed to government cycles is a way to address problems of dynamic inconsistency of this sort. In this sense, even though the CNIC was created as an advisory body that should not be exposed to government cycles, the truth is that it has been subject to these cycles with the recent swing of political coalitions governing the country.

Furthermore, since the benefits of the initiatives that are currently being implemented by the government to enhance the performance of the entrepreneurship ecosystem will take time to be observed, it is very important to let them yield their fruits at their own pace. And although fine-tuning policy actions is necessary as the system learns, radical swerves should be definitely avoided. Relatedly, permanent monitoring, adequate evaluation and informed adaptation becomes crucial.

Finally, we must not forget that entrepreneurship is driven by individuals, and no matter how perfect and sound the institutional setting is, if individuals do not act, entrepreneurship does not occur. The next Chapters of this thesis attempt to take a close look at the elusive and intriguing character that the entrepreneur is, and analyze the way in which his entrepreneurial traits can determine the emergence of innovative entrepreneurship in Chile. 


\section{Chapter 3}

\section{The heterogeneous nature of entrepreneurial motivations}

\subsection{Introduction}

In this Chapter I analyze the relationship between entrepreneurial motivations and individual background traits. In psychology, motivation refers to the initiation, direction, intensity and persistence of behavior. Therefore, motivation can be considered as the closest stage during a person's unobservable decision making process before a venture changes its status from an intention to an action. The underlying motivations that trigger entrepreneurial behavior and subsequent venture creation differ between entrepreneurs, which stems from the fact that the population under study is of an heterogeneous nature. Relatedly, the research question I aim to answer in this Chapter is What explains the heterogeneity in entrepreneurial motivations?

Following prior literature I consider eight categories of motivations to start a venture: role models, unemployment, dismissal, wealth, market opportunity, independence, self-realization and other factors. Using a multinomial logit model I estimate how a set of individual background traits, like gender, age, prior experience and education, affect the probability that self-employed individuals choose a given category as their main motivation to start their business.

I use the third wave of the Micro-Entrepreneurship Survey (EME) which collects information from a representative sample of the Chilean self-employed population in 2013, composed of employers and own account workers. The main difference between them is that the former ones create jobs while the latter ones do not. I study both subgroups separately putting a special emphasis in the employer category given its higher potential to impact the economy; at least in terms 
of employment generation.

My results show that the self employed population under study not only has different background characteristics (in terms of educational attainment, prior professional experience and prior business ownership experience) but also that the effect these traits have on motivation differ between the categories under study. For example, for employers I find that the effect that education has on the probability of being a market opportunity-driven entrepreneur differs from the effect it has on being an independence-driven entrepreneur. For the former one I find a negative and significant relationship, while for the latter one I find a positive and significant one: jumping from the mandatory level of secondary education to achieving an bachelor degree decreases the probability of being opportunitymotivated by 12 percentage points, while it increases the probability of being independence-motivated in 12 percentage points.

The study in this chapter contributes to prior literature on entrepreneurial traits in at least three ways. First, it focuses on that unobservable stage of the entrepreneurial process that transforms a latent intention into real action, a link that is typically missing from the study of the entrepreneurial process. In particular, it provides evidence on how some background characteristics of individuals relate to the heterogeneity of entrepreneurial motivations. Second, it goes a step further by analyzing a broader set of motivations than the standard opportunity and necessity ones, which are typically used in the literature that follows the approach of the Global Entrepreneurship Monitor. And third, it provides evidence about the sources of entrepreneurial heterogeneity, which is necessary to depart from thinking about entrepreneurship as a homogeneous phenomenon.

\subsection{Conceptual framework}

\subsubsection{The heterogeneous nature of entrepreneurs}

Entrepreneurship research has pursued for a long time the goal to identify the set of personality traits and characteristics that differentiate entrepreneurs from non-entrepreneurs. The main research question behind the literature on entrepreneurial traits, especially prominent during the 70s and 80s (Landström et al., 2012), was 'Why are some individuals entrepreneurial, while others are not?'. The main assumption behind this question was that entrepreneurs caused entrepreneurship, or $E=f(e)$, where entrepreneurship $(E)$ was assumed to be a function of the entrepreneur (e) (Gartner, 1989). This implied that entrepreneurs 
were assumed to have certain personality traits and characteristics that made them different from non-entrepreneurs. ${ }^{1}$

Despite the numerous studies conducted during the $70 \mathrm{~s}$ and the $80 \mathrm{~s}$ that were aimed at identifying differences in traits between entrepreneurs and nonentrepreneurs, such strand of research was considered to have failed on reaching a consensus on a generic definition of the entrepreneur (Brockhaus and Horwitz, 1986; Gartner, 1988). This lack of consensus stemmed from the fact that there is no such typical entrepreneurial profile, since the diversity among entrepreneurs can be even larger than the differences between entrepreneurs and non-entrepreneurs (Gartner, 1985). Gartner (1988) also criticized the excessive focus on who is the entrepreneur, and argued that to understand new venture creation the focus should rather be on what the entrepreneur does, suggesting a more behavioral approach. However, others still saw value in the trait approach arguing that the whole is extremely complex and any attempt to understand it needs first to tackle the understanding of its parts (Carland et al., 1988). And despite the dead end that the 'trait approach' seemed to have reached in the $80 \mathrm{~s}$, interest on the role of personality in entrepreneurship has recently seen a reemergence after a break of almost 20 years (Zhao et al., 2010, p. 382), with some new research on the relationship between personality traits and entrepreneurial intentions and performance. $^{2}$

The broad concept of entrepreneurship includes a population of highly heterogeneous individuals, which means that entrepreneurs should be regarded as a heterogeneous group where $E_{(n)}=f\left(e_{(n)}\right)$. That is, the variation within the phenomenon of entrepreneurship $\left(E_{(n)}\right)$ is explained by the variation in the type of entrepreneurs $\left(e_{(n)}\right)$ (Gartner, 1985). Notwithstanding, the variation in the phenomenon of entrepreneurship is not only a consequence of the heterogeneity among entrepreneurs, but is also shaped by environmental factors (Aldrich, 2011, Ch.1), like the institutional setting in which entrepreneurs are embedded, as previously discussed in Chapter 2.

\footnotetext{
${ }^{1}$ The most frequent personality traits entrepreneurs have been identified with are need for achievement, internal locus of control and self efficacy. For example achievement-motivated individuals are moved by the need for success and typically set challenging, but achievable, goals which can be influenced with their effort and ability. While individuals with internal locus of control are those who believe that what happens to them depends on them, not on fate or the environment making them more independent and suitable for jobs that require initiative and independence of action. On the other hand, self-efficacy is related to people's belief and confidence about their own capabilities to perform various tasks under uncertain situations, such that difficult tasks are seen as challenges to be mastered rather than threats to be avoided.

${ }^{2}$ See the relatively recent meta-analysis conducted by Rauch and Frese (2007) and Zhao et al. (2010) on personality traits and entrepreneurship.
} 
This Chapter builds on previous evidence on entrepreneurial heterogeneity and understands the phenomenon of entrepreneurship, i.e. new venture formation, as one that emerges from a complex systemic process as a consequence of the interaction, in an interdependent fashion, of a wide set of factors. Different profiles of entrepreneurs, in interaction with the environments in which they are embedded, are expected to develop a variety of ventures. Thus, different types of entrepreneurs are expected to contribute differently to economic development through the variety of ventures they pursue (Baumol, 1990; Shane, 2009; Szirmai et al., 2011; Vivarelli, 2013; Coad and Nightingale, 2013).

\subsubsection{Venture formation as a function of entrepreneurial traits}

From a theoretical point of view the decision making process of an individual to engage in the creation of a new venture starts first with the occupational choice of becoming self-employed. In the economics literature this has been typically addressed by a variety of labor market models based on the maximization of the present value of career earnings (Acs, 2008). However, when making this choice the individual not only considers the expected pecuniary benefits under each category of occupation (for example between paid- and self-employment) but also non pecuniary benefits. In line with this, Hamilton (2000) argues that non pecuniary benefits of self-employment are substantial and explain the fact that most entrepreneurs enter and persist in business despite the fact that they have both lower initial earnings and lower earnings growth than in paid employment. In the same direction, $\mathrm{Xu}$ and Ruef (2004) argue that many of the motivations that individuals have for founding a business venture are non pecuniary in nature since this is the only way to reconcile financial risk aversion of entrepreneurs with the high risk of financial loss among startups ${ }^{3}$. Yet, these non pecuniary benefits are expected to differ between self-employed individuals, which are related to the underlying motivations that pulled or pushed them into entrepreneurship ${ }^{4}$. For example, some individuals may value the condition of independence and freedom

\footnotetext{
${ }^{3}$ Using data for nascent entrepreneurs in the US, Xu and Ruef (2004) find that entrepreneurs may be even more risk-averse than non-entrepreneurs, which goes against the assumption that entrepreneurs are more risk-tolerant than the general population. To reconcile this finding with the high rate of financial loss among new ventures, the authors suggest that the motivations that individuals have for founding a new business are non-pecuniary in nature and are related to the need for autonomy and identity fulfillment.

${ }^{4}$ Push factors are related to the 'Drive Theory' of motivation, which suggests that there is an internal stimulus driving the person to do something and thus seeks a way to reduce the resulting tension. For example, hunger. While Pull factors are related to the 'Incentive Theory' of motivation, where an end point in the form of some kind of goal pulls the person towards it, such as achievement motivation (Carsrud and Brännback, 2011).
} 
that self-employment brings. While others may value more the fulfillment that brings accomplishing something that took effort and planning and in which the fruit of such effort is directly perceived by them.

Alternatively, Katz (1992) proposes an interesting model of employment choice based on a psychosocial cognitive approach. The author aims at explaining how individuals faced to a pull or push situation end up deciding on paid-employment or self-employment status. An appealing feature of this model is the application of cognitive heuristics ${ }^{5}$, like availability and representativeness (Tversky and Kahneman, 1974), to explain the cognitive process an individual goes through when analyzing the alternatives available to react to a pull or push event. For example, based on availability heuristics ${ }^{6}$, individuals that come from a family with self-employed parents (role models) are more likely to retrieve the possibility of self-employment than individuals who come from a background of waged parents. Thus, based on this cognitive heuristics Katz (1992) explains why individuals who have role models for example are more prone to engage in self-employment when faced to a precipitating event.

But the decision of an individual about being self-employed ${ }^{7}$ is a necessary but not sufficient condition to initiate a new venture. In the launch of a new venture there are many interdependent factors that intervene and thus there is much more than the intention derived from the application of availability heuristics or an exercise of maximizing the present value of career earnings.

A more comprehensive framework to model venture initiation was proposed by Martin (1984) who understands the process of entrepreneurial venture initiation as a result of the interaction of different factors, as shown in Figure 3.1. He argues that certain individuals have a predisposition or readiness to initiate a new venture, which is determined by their psychological makeup (i.e. high need for achievement, internal locus of control, among other personality traits), their social background and the exposure to demonstration effects (i.e. role models, relationship with mentors or incubators, etc.). The readiness to act, in interaction with a

\footnotetext{
${ }^{5}$ See Kahneman (2011) for an interesting and amusing discussion about cognitive heuristics individuals use on a daily basis.

${ }^{6}$ When faced to a decision under uncertainty individuals tend to rely on availability heuristics to assess the frequency or plausibility of an event or development. That is, the instances or scenarios individuals have been formerly exposed to will have a higher saliency to them which will influence their perception about the plausibility of such events (Tversky and Kahneman, 1974).

${ }^{7}$ This does not imply that an individual can only be in either a paid-employee or selfemployment status. An individual can start a venture as a secondary activity keeping her job as an employee, which is a common practice. Still, the status changes from a full time employee to a mixed-status one.
} 


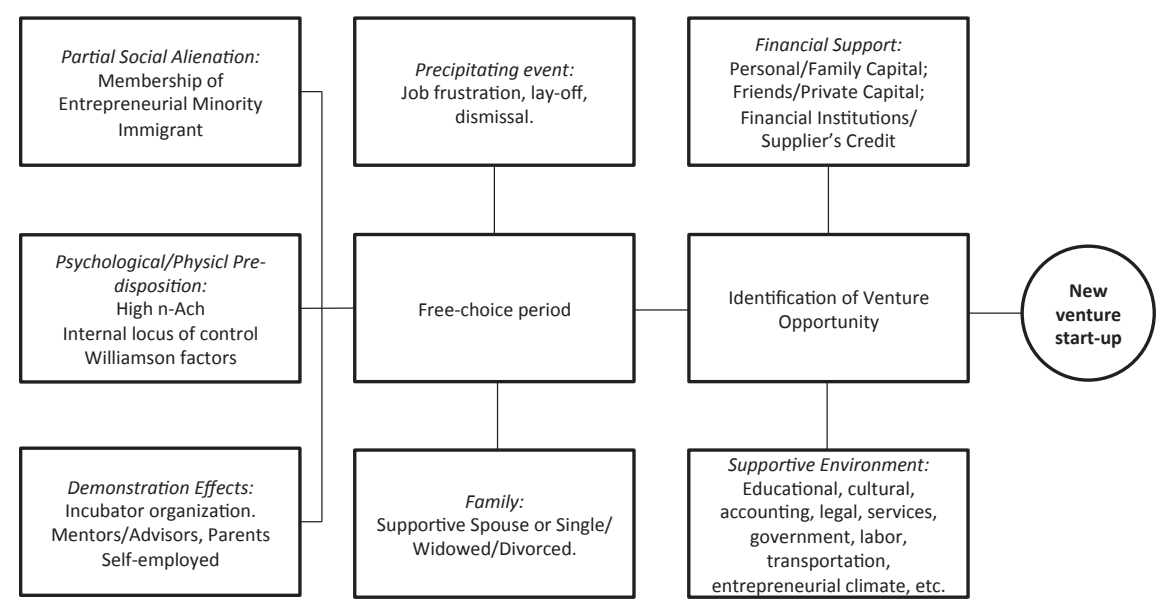

Source: Martin (1984), Chapter 14, p.269

Figure 3.1: A model on new venture initiation

precipitating event (a pull or push motivation) occurring during a period of 'free choice $^{8}$ will predispose the individual to launch his or her own company. However, this predisposition is expected to be reinforced by a supportive environment, both at the personal/family level and at the external level. ${ }^{9}$

Going a step further, Herron and Robinson (1993) developed a structural model of the relationship between entrepreneurial traits and value creation performance arguing that the entrepreneur is at the very center of it. They claim that 'Venture capitalists, angel investors, and experienced, successful entrepreneurs, when asked to identify the most important determinant of new venture performance, will undoubtedly answer: the entrepreneur.' (pp.281). 'Standing on the shoulders' of prior scholars and following a behavioral approach, the authors developed an enhanced model of value creation performance assuming a causal link between entrepreneurial traits and venture performance. The authors considered

\footnotetext{
${ }^{8}$ Martin (1984) story-tells the life cycle of an individual that ends up being an entrepreneur. He argues that an individual typically enters the labor force in the early or middle twenties and gains progressive experience and responsibility until he is around 40. During this period the individual probably has a family and has acquired increasing financial commitments like a mortgage. It is before this period of non career concerns (40s) and after some experience has been accumulated (after 25) that the individual faces a free-choice period in which he has the readiness to act.

${ }^{9}$ See Chapter 2 for a review on the main enabling components of an entrepreneurial ecosystem.
} 
the combination of individual traits as a determinant of entrepreneurial behavior. At the same time, the interaction between entrepreneurial behavior and the environment end up causing venture performance.

An interesting feature of the model in Herron and Robinson (1993) is that personality traits are related to venture performance, but not necessarily in a direct fashion. This idea was taken from Hollenbeck and Whitener (1988) who argued that low validity and utility of personality measures to explain job performance is due to the fact that there is an indirect causality between them. Hollenbeck and Whitener (1988) claim that when determining job performance, personality traits are mediated by motivation, and motivation is moderated by ability. This partly explains the long debated relationship between personality traits and entrepreneurial condition discussed earlier in section 3.2.1. In fact, some scholars have argued that there has been a missing link in this debated relationship: entrepreneurial motivations (Carsrud and Brännback, 2011).

In Figure 3.2 a sketch of the model of Herron and Robinson (1993) is presented. In this Chapter I focus on the part of the model that discusses the determinants of entrepreneurial motivation applying a quantitative approach. In Chapter 4 I analyze, also from a quantitative approach, the relationship between entrepreneurial motivations and venture performance, particularly in terms of innovation propensity. While in Chapter $5 \mathrm{I}$ analyze the relationship between personality traits, skills, motivation and entrepreneurial behavior from a qualitative perspective.

According to the model in Herron and Robinson (1993), personality traits are mediated by motivations in the determination of entrepreneurial behavior. Both personality traits and motivations are non observable constructs, but while personality is considered to be relatively static, motivations are allowed to evolve depending on the additional information the entrepreneur is constantly receiving, like performance of the venture itself or the expectations of it. In this model motivations are also assumed to be moderated by the 'skills' of the individual, which are the result of the interaction between 'aptitudes' and 'training'. Aptitudes can be considered as abilities that arise without training, and the interaction between abilities and training result in 'skills', which are 'the ready abilities that entrepreneurs bring to a situation in any point in time. They are the result of both the natural aptitudes such as differential intelligence, and of the training and practice which the entrepreneur has had in previously exercising these skills' (Herron and Robinson, 1993, p.290). Other traits such as educational experience, entrepreneurial experience, demographics and social learning, among other traits, 
would enter the model through the auspices of training, aptitudes and personality traits (Herron and Robinson, 1993, p.291).

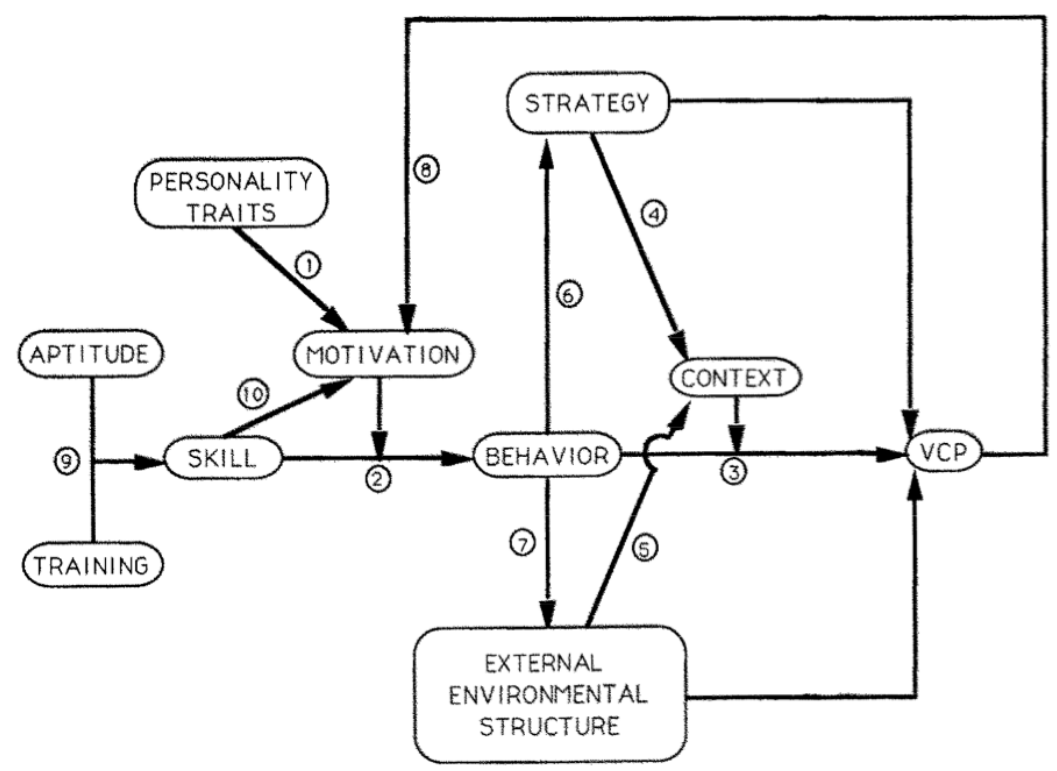

Source: Herron and Robinson (1993), p.290

Figure 3.2: Enhanced model on value creation performance

Even though the object of the study of Martin (1984) and Herron and Robinson (1993) differs (the former one focuses on the state of entrepreneurship while the latter one on the performance of it) they have two things in common. First, the emphasis that both put in entrepreneurial traits, not only on unobservable ones like personality traits and aptitudes, but also other more observable or measurable ones, like training. However, Herron and Robinson (1993) consider individuals' traits as a determinant of entrepreneurial behavior, considering behavior as the most significant factor that affects the management and allocation of resources for which entrepreneurs are responsible for when pursuing a new venture. And second, both models start from the premise that entrepreneurial motivations, skills and behavior are no guarantee of "producing" an entrepreneur. The interaction 
with the context, environment and other external enablers also matter in both the entrepreneurial state and performance.

\subsubsection{Entrepreneurial motivations}

A question that arises from the discussion above is What motivate entrepreneurs to initiate a new venture? From 3.2.2 we know that there are a set of both observable and unobservable individual traits that determine entrepreneurial motivation and subsequent behavior, which in interaction with certain environmental factors determine venture initiation and performance. And from 3.2.1 we know that entrepreneurs are of an heterogeneous nature, which determines the variety of ventures we observe, $E_{(n)}=f\left(e_{(n)}\right.$. This implies that we can expect that the underlying motivations that trigger entrepreneurial engagement and subsequent venture creation differ between entrepreneurs, stemming from the fact that the population under study is of an heterogeneous nature. Individuals differ in their willingness and abilities to pursue an entrepreneurial career simply because they are different from each other, and this variation in people's willingness and ability to act has important effects on the entrepreneurial process (Shane et al., 2003). So, what explains then the heterogeneity in entrepreneurial motivations?

In psychology, motivation refers to the initiation, direction, intensity and persistence of behavior. And in the particular setting of entrepreneurship, motivations may be considered as the spark that transforms a latent intention into real action and therefore, the missing link between intentions and actions (Carsrud and Brännback, 2011, p.12). Since having the "intention" to be involved in entrepreneurial activity do not automatically induce entrepreneurial behaviors (de Jong, 2013), it is interesting to focus on the closest stage during the individual's unobservable decision making process before a venture changes its status from an intention to an action. Thus, since new businesses are not created by accident it is interesting to understand what triggers the decision of individuals to assign time, effort and resources to accomplish what they intend to accomplish through the venture they pursue (Carter et al., 2003). Furthermore, policy goals usually do not correspond with the motives of individuals to engage in entrepreneurial activities. That is, it is quite unlikely that an entrepreneur starts a business in order to achieve innovation, job creation or economic growth at the national level (Hessels et al., 2008). Still, as discussed in section 3.2.2, entrepreneurial motivations influence the goals, management and performance of new ventures, such that at the aggregate level, macroeconomic outcomes may also be influenced. So, understanding the sources and outcomes of entrepreneurial 
motivations, should be of interest of policymakers aiming at fostering economic growth through new venture creation.

There is a broad set of entrepreneurial motivations that have been studied in the literature (Scheinberg and MacMillan, 1988; Birley and Westhead, 1994; Carter et al., 2003; Shane et al., 2003). Scheinberg and MacMillan (1988) for example were one of the first scholars to empirically study the reasons that explained business creation and how they differed across countries. Based on the answers to a similar questionnaire applied to entrepreneurs in 11 countries (mainly OECD ones), the authors conducted a factor analysis of 38 reasons and were able to identify six categories that motivated individuals to start their own business (see Table 3.1 below). A similar exercise was later done by Birley and Westhead (1994) for Great Britain based on 23 reasons explaining business creation. The principal components analysis threw seven components, two of which were not included in the study of Scheinberg and MacMillan (1988): tax reduction and indirect benefits, and following role models. While in a subsequent study, Carter et al. (2003) re-examined the reasons nascent entrepreneurs gave for engaging in a new business, comparing them to the reasons given by non-entrepreneurs when asked about their career decisions. An interesting feature of their approach is the use of prospective motivations instead of retrospective ones, which are considered to be a more accurate proxy of the initial motivation an individual had when making an occupational choice ${ }^{10}$.

Table 3.1 below presents a summary of categories of motivations based on these studies including the main related reasons associated to each of them.

Table 3.1: Motivation factors that determine new venture creation

\begin{tabular}{|c|c|c|}
\hline Study & Motivation factor & Main related reasons \\
\hline $\begin{array}{l}\text { SM- } \\
\text { BW- } \\
\text { CGSG }\end{array}$ & $\begin{array}{l}\text { Need for Approval, } \\
\text { Recognition }\end{array}$ & $\begin{array}{l}\text { Be respected by friends; Achieve something and get } \\
\text { recognition; Achieve position in society; Increase } \\
\text { status of family; Have more influence in community. }\end{array}$ \\
\hline $\begin{array}{l}\text { SM- } \\
\text { BW- } \\
\text { CGSG }\end{array}$ & $\begin{array}{l}\text { Perceived Instrumen- } \\
\text { tality of Wealth, Fi- } \\
\text { nancial Success }\end{array}$ & $\begin{array}{l}\text { Desire to have high earnings; Needed more money } \\
\text { to survive; Give self and family security; Access } \\
\text { to indirect benefits; Build business children can in- } \\
\text { herit. }\end{array}$ \\
\hline
\end{tabular}

Continued on next page...

\footnotetext{
${ }^{10}$ Relatedly, Brockhaus (1980) argue that individuals' opinion may suffer from cognitive dissonance, defined as the tendency to change the perception of something ex-post. For example, an entrepreneur may have expressed some level of job dissatisfaction immediately prior to quitting a job. However, after leaving it, the entrepreneur may have re-considered the previous job as highly unsatisfactory in order to resolve an internal conflict resulting from the decision to quit (re-affirmation).
} 
Table 3.1 continued

\begin{tabular}{|c|c|c|}
\hline Study & Motivation factor & Main related reasons \\
\hline SM-BW & $\begin{array}{l}\text { Degree of Communi- } \\
\text { tarism }\end{array}$ & $\begin{array}{l}\text { Welfare of ethnic group; Welfare of community I } \\
\text { live in; Welfare of relative. }\end{array}$ \\
\hline SM- & Need for Personal & Develop idea for product/business; To keep learn- \\
\hline $\begin{array}{l}\text { BW- } \\
\text { CGSG }\end{array}$ & $\begin{array}{l}\text { Development, Innova- } \\
\text { tion }\end{array}$ & $\begin{array}{l}\text { ing; To be innovative and in forefront of new tech- } \\
\text { nologies; Direct contribution to success of company. }\end{array}$ \\
\hline $\begin{array}{l}\text { SM- } \\
\text { BW- } \\
\text { CGSG }\end{array}$ & $\begin{array}{l}\text { Need for Indepen- } \\
\text { dence }\end{array}$ & $\begin{array}{l}\text { Control of my own time; Have greater flexibility for } \\
\text { private life; Freedom to adopt my own approach to } \\
\text { work. }\end{array}$ \\
\hline SM-BW & Need for Escape & $\begin{array}{l}\text { Frustrated in previous job; Not to work for an un- } \\
\text { reasonable boss. }\end{array}$ \\
\hline BW & $\begin{array}{l}\text { Tax Reduction and } \\
\text { Indirect Benefits }\end{array}$ & $\begin{array}{l}\text { To have access to indirect benefits such as tax ex- } \\
\text { emptions; As a vehicle to reduce the burden of taxes } \\
\text { I face. }\end{array}$ \\
\hline $\begin{array}{l}\text { BW- } \\
\text { CGSG }\end{array}$ & $\begin{array}{l}\text { Follow Role models, } \\
\text { Roles }\end{array}$ & $\begin{array}{l}\text { To follow the example of the person that I admire; } \\
\text { To continue a family tradition; To be respected by } \\
\text { my friends. }\end{array}$ \\
\hline CGSG & Self-Realization & $\begin{array}{l}\text { To challenge myself; To fulfill a personal vision; } \\
\text { Grow and learn as a person; To lead and motivate } \\
\text { others; Power to influence an organization. }\end{array}$ \\
\hline
\end{tabular}

Source: Own elaboration based on Scheinberg and MacMillan (1988) (SM), Birley and Westhead (1994) (BW) and Carter et al. (2003) (CGSG).

More recently, empirical research on entrepreneurial motivations produced the popular pull and push theories of entrepreneurial motivations, akin to the opportunity- and necessity-driven approach of Reynolds et al. (2002). Following Gilad and Levine (1986), the push theory argues that individuals are pushed into entrepreneurship by negative situations such as dissatisfaction with the current job (Brockhaus, 1980), being fired and career setbacks. These negative events are considered to activate latent entrepreneurial talent pushing individuals into entrepreneurial activities. On the other hand, the pull theory argues that the existence of attractive and potentially profitable business opportunities will attract or pull, and not necessarily push, alert individuals into entrepreneurial activities ${ }^{11}$. But although the environmental factors that influence pull and push situations clearly differ, both theories should not compete (Gilad and Levine, 1986), but complement each other in the understanding of the heterogeneous nature of entrepreneurial motivations.

\footnotetext{
${ }^{11}$ This is in line with Kirzner's theory of entrepreneurship, in which the entrepreneur is regarded as a unique type of individual in terms of its capacity to discover and exploit profitable market opportunities overlooked by others (?).
} 


\subsubsection{Research questions and hypothesis}

Starting from the fact that the population of self-employed workers is of an heterogeneous nature and that entrepreneurial motivations are the spark that transforms a latent intention into real action, the research question this chapter aims to answer is What explains the heterogeneity in entrepreneurial motivations? This question is interesting for at least three reasons.

First, because it is unlikely that entrepreneurial motivations correspond with the goals of innovation, job creation and economic growth that policymakers expect to accomplish when fostering entrepreneurship. So, understanding the different reasons that trigger the decision of individuals to assign time, effort and resources to transform a latent intention into a real action of entrepreneurship can be informative for policymakers. Not only as a source of information when designing policy incentives, but also when targeting desired subpopulations.

Second, because understanding the roots of entrepreneurial motivations can shed some light on the sources of entrepreneurial heterogeneity. From an empirical point of view successful entrepreneurial cases are more an exception than a rule so there is a strong trend in the entrepreneurial literature to criticize the tendency to talk about entrepreneurship as an homogeneous concept. Thus, caution must be taken to avoid falling into the composition fallacy, i.e. the tendency to assign benefits of entrepreneurship to the average firm (Nightingale and Coad, 2013). In fact, the typical start-up is not innovative, creates few jobs, and generates little wealth (Shane, 2009).

Third, because the empirical literature has mainly focused on the relationship between entrepreneurial traits and occupational choice (Carter et al., 2003; Schjoedt and Shaver, 2007; Cea et al., 2009), new venture creation (Evans and Leighton, 1989; Blanchflower and Oswald, 1998), levels of entrepreneurial engagement (Grilo and Thurik, 2008; Verheul et al., 2010), and venture performance (Cooper et al., 1994; Arrighetti and Vivarelli, 1999), leaving less attended an important link between them: motivation. The empirical literature focusing on the relationship between entrepreneurial traits and motivation is scarce and mostly relies on the GEM dataset (Wagner, 2005; Bergmann and Sternberg, 2007), which is somewhat limited since it mainly focuses on necessity- and opportunity-driven entrepreneurship. However, there are more motivations to start a business than wealth creation, independence and necessity (Hessels et al., 2007).

The study in this chapter aims at contributing to fill the gap in the literature on heterogeneities in entrepreneurial motivations by answering the research question What explains the heterogeneity in entrepreneurial motivations?. Since the 
focus has been typically in distinguishing opportunity- versus necessity- driven motivations, this paper goes a step further and analyzes how entrepreneurial traits relate to a wider set of motivation categories. The hypothesis is that different individual backgrounds, in terms of age, experience, education and gender, will have different effects on the motivation categories under study.

\subsection{Data}

\subsubsection{The Micro-entrepreneurship Survey}

The results of the third wave of the Micro-Entrepreneurship Survey (EME 3) were used in this paper, which collected information for the trimester MayJune-July of 2013. The targeted population were self-employed individuals of the labour force, that is, workers whose employment status ${ }^{12}$ was either employer ${ }^{13}$ or own-account ${ }^{14}$. The unit of information were employers and own-account workers of 15 years old or more that resided in occupied private dwellings. The sampling frame to build the EME 3 relied on the results of the New National Employment Survey (NENE) for the March-April-May trimester of 2013 (MAM-2013).

The EME 3 used a stratified multistage cluster sampling design, a common approach to reduce the costs and time of data collection and to increase the precision of estimation for subgroups of the population that are of particular interest (Cameron and Trivedi, 2005a). Ideally a truly random sample of the population under study is preferable, but this is extremely difficult, impractical and costly.

The first stage shared the sample design of the NENE and involved two substages. The first sub-stage selected residential blocks and sections from urban and rural areas respectively (primary sampling units or PSU) with a probability

\footnotetext{
${ }^{12}$ Employment status is classified following the International Classification of Status in Employment (ICSE) adopted the International Labour Organization in 1993 during the XV International Conference of Labour Statisticians. According to the ICSE-93 the occupied population can be classified in: employees, employers, own-account workers, member of producers' cooperatives, contributing family workers and workers not classifiable by status.

${ }^{13}$ Employer workers are defined by the ILO in the ICSE-93 as "those workers who, working on their own account or with one or a few partners, hold the type of job defined as a 'self-employment job', and, in this capacity, on a continuous basis (including the reference period) have engaged one or more persons to work for them in their businesses as 'employee(s)'". (ILO, 1993)

${ }^{14}$ Own-account workers are defined by the ILO in the ICSE-93 as "those workers who, working on their own account or with one or more partners, hold the type of job defined as 'selfemployment job', and have not engaged on a continuous basis any employees to work for them during the reference period. It should be noted that during the reference period the members of this group may have engaged employees, provided that this is on a non-continuous basis". (ILO, 1993)
} 
proportional to its size in terms of the number of dwellings in each block or section. The sample excluded units in areas of difficult access (which represented approximately $0.3 \%$ of total dwellings) and those with 7 or less dwellings (the coverage still reached almost $99 \%$ of dwellings within the country). The second sub-stage selected private dwellings (secondary sampling units or SSU) from the PSU through systematic sampling, with each dwelling in a block or section having the same probability of selection.

The second stage involved the selection of self-employed workers. The sample of dwellings selected in the first stage that did not have self-employed workers were discarded, while the remaining subset was removed from those cases where individuals did not fall effectively under the definition of either 'employer' or 'own-account worker'. After this "cleaning" procedure, a sample of dwellings was selected through systematic sampling considering equal probability of selection. Self-employed workers in each dwelling were sorted and then one individual per economic activity was randomly selected.

The sample size was estimated considering corrections for the complex design of the survey (two-staged, clustered and stratified), for the finite population under study (self-employed workers) and for the rate of non-response ${ }^{15}$. The resulting sample size was estimated in 6,880 dwellings, considering a confidence interval of $95 \%$, an absolute error of $1.48 \%$ and a $15 \%$ rate of non-response. Within these 6,880 dwellings, a total number of 7,632 self-employed workers were aimed at being interviewed.

Since the sample frame comes from the results of the NENE for the trimester MAM-2013, the interviews of the EME 3 survey were carried out between May, June and July of 2013 (MJJ-2013) to prevent individuals from changing their employment status. A total number of 6,765 individuals, out of the 7,632 initially targeted, were successfully interviewed, meaning a non-response rate of $11.4 \%$. Out of these 6,765 self-employed workers, representative at the national level, $82.5 \%$ was still performing the same activity (6,376 individuals). The rest had either changed activity within their self-employed status or directly changed their status. These 6,376 individuals represented a total number of 1,855,389 selfemployed workers of 15 years old or more that lived in a private dwelling during the trimester of MJJ-2013 (around 4\% of the Chilean occupied population during MJJ-2013 ${ }^{16}$ ). Complete information is available for a total number of 5,968 individuals, which determined the sample used in this study.

\footnotetext{
${ }^{15}$ See MINECON (2014) for more details on the estimation of the sample size.

${ }^{16}$ According to the MJJ-2013 report of the National Statistics Office (INE), there were 7,738.56 thousand individuals occupied in the labor force.
} 
As a consequence of the sampling methods described above, different selfemployed individuals have different probabilities of being sampled. The sample is then unrepresentative of the population under study. Sampling weights, which are intended to be inversely proportional to the probability of being sampled, are used to obtain unbiased estimators of population characteristics. Furthermore, survey data obtained from a stratified and clustered sample like the one in the EME 3 Survey leads to violations of the assumption of independent observations since observations within a cluster may be correlated due the presence of a common unobserved cluster-specific term (Cameron and Trivedi, 2005a). For example, one may expect that some blocks may be dominated by high-income individuals or by individuals that are relatively homogeneous in some dimensions of their preferences. The effect of a stratified and clustered sampling design underestimates standard errors leading to a greater likelihood of rejecting the null hypothesis (Lee and Forthofer, 2006). This means that ignoring the violation of the assumption of independent observations may result in inaccurate statistical inference, i.e. false positive hypotheses test results.

Consequently, the complex sample design of the EME 3 survey $^{17}$ was taken into consideration such that standard errors were adequately adjusted ${ }^{18}$. This was done using the Stata Survey [svy] family of commands, which provides estimates where the standard errors are adjusted for stratification, clustering and weights ${ }^{19}$. Following Long and Freese (2014a), the Stata Survey [svy] command need to be used to obtain correct standard errors whenever the sample design involves stratification. The use of standard regression commands using weights and variance corrections like vce(cluster) options are enough if sampling design involves weights or clustering, but not stratification.

\subsubsection{Variables}

\subsubsection{Dependent variable}

The dependent variable is of a categorical type and captures different reasons for motivated individuals to start a business activity. The EME 3 Survey asked interviewees to pick the main motivation out of ten possible reasons, which are shown in the first column of Table 3.2. Some of them have been largely discussed

\footnotetext{
${ }^{17}$ For a description of the sample design and suggestions on how to take it into consideration when carrying out estimations, see INE (2013).

${ }^{18}$ See Lee and Forthofer (2006) for a further discussion on the effects of complex survey sample design.

${ }^{19}$ Robust standard errors were estimated using the Taylor series linearization method.
} 
in the literature (see Table 3.1) and consequently were matched to the corresponding concept used in previous research (see second column in Table 3.2). Those reasons that were not matchable straightforwardly appear as Not clear. Given that more than one reason captured in the EME 3 can be related to one single motivation category, they have been collapsed into one. For example, 'having more (time) flexibility' and 'making my own decisions/being my own boss' were both considered to represent need for independence. A resulting set of eight motivation categories were built: Roles, Unemployment, Dismissal, Wealth, Market Opportunity, Independence, Self-realization and Other (see last column of Table $3.2)$.

Table 3.2: Categories of entrepreneurial motivations

\begin{tabular}{lcc}
\hline EME $\mathbf{3}$ Survey & Literature & $\begin{array}{c}\text { Categories under } \\
\text { study }\end{array}$ \\
\hline Family tradition or Inheritance & Roles & Roles \\
\hline Could not find a paid-job & Not clear & Unemployment \\
\hline $\begin{array}{l}\text { I was dismissed from a waged } \\
\text { job }\end{array}$ & Not clear & Dismissal \\
\hline To obtain a higher income & $\begin{array}{c}\text { Perceived Instrumentality of } \\
\text { Wealth } / \text { Financial success }\end{array}$ & Wealth \\
\hline Found a market opportunity & Not clear & Market opportunity \\
\hline $\begin{array}{l}\text { To have more flexibility (time, } \\
\text { etc.) }\end{array}$ & Need for Independence & Independence \\
\hline $\begin{array}{l}\text { I wanted to make my own deci- } \\
\text { sions/Be my own boss }\end{array}$ & Need for Independence & Independence \\
\hline $\begin{array}{l}\text { I wanted to organize a business } \\
\text { of my own }\end{array}$ & Self-realization & Self-realization \\
\hline Enjoyment & Self-realization & Self-realization \\
\hline \begin{tabular}{l} 
Other motivation \\
\hline
\end{tabular} & - & Other \\
\hline
\end{tabular}

\subsubsection{Independent variables}

Before describing the variables considered to explain motivational heterogeneity a distinction needs to be made, in terms of job creation, between the two subgroups that form the self-employed population under analysis. Following the International Labour Office (ILO) definition of employment status (ICSE-93), two categories of self-employed individuals were distinguished based on the available information about their businesses:

Employer: Individuals that work independently in a business or company of their own (possibly in ownership with other partners) on a permanent basis, 
and have engaged one or more employees to work for them (other than nonpaid family workers) in exchange for a remuneration that is handled to them according to legal procedures.

Own-account worker: Individuals that work independently who have not engaged any employees to work for them at all, or have engaged non-remunerated family relatives, or have engaged some employees but on a non permanentbasis.

Table 3.3 shows that the proportion of self-employed that fall under the category of employer is of about $15 \%$. Given that both groups are considered to represent different profiles within the self-employed population, the analysis is conducted separately. Hence, the research question can be rephrased into What explains the heterogeneity in entrepreneurial motivations for own-account workers and employers? Does the relationship between entrepreneurial traits and motivations differ between both types of self-employed individuals?

Table 3.3: Proportion of employers and own-account workers in the selfemployed population

\begin{tabular}{lc}
\hline Category & Proportion \\
\hline Employer & $14.6 \%$ \\
Own-account & $85.4 \%$ \\
\hline
\end{tabular}

The set of characteristics used as explanatory variables of the motivation to start a venture was defined based on the conceptual framework discussed in section 3.2.2, empirical literature and the available information in the dataset. Given that the dependent variable is based on retrospective information, I decided to rely on characteristics that were more likely to remain unchanged between the time the person started the business and the time he was interviewed, like location, gender, age, education and prior experience.

From a theoretical point of view, prior research has suggested that age depicts an inverted U-shaped relationship with entrepreneurial propensity. The propensity has been assumed to increase as the person gets older given that the potential period to accumulate wealth increases with age. This is due to the fact that a certain amount of wealth is assumed to be required to start a new venture (Evans and Leighton, 1989; Wagner, 2005). However, as time passes by, the impact of age on the propensity to start a new venture is expected to be negative as the related 
sunk costs become less attractive when the individual is on its 60s (Wagner, 2005). However, the empirical relationship between age and the type of entrepreneurial motivation is not clear. In fact, prior empirical evidence has reached mixed results in terms of the effect of age on opportunity- and necessity-driven entrepreneurship (Bergmann and Sternberg, 2007; Wagner, 2005).

Prior research conducted on the relationship between gender and entrepreneurial propensity tend to claim that women are less likely to become self-employed than men (Evans and Leighton, 1989; Grilo and Thurik, 2008). Empirical results have shown that women are less likely to become either an opportunity- or necessitydriven nascent entrepreneur (Bergmann and Sternberg, 2007). However, Verheul et al. (2010) found different profiles of entrepreneurs when comparing opportunity with necessity-driven entrepreneurs. In line with this, Carter et al. (2003) found that there are gender differences in the reasons that motivate individuals to pursue an entrepreneurial career: men tend to rate financial success and innovation higher than women. This is supported by Wasserman (2012), who found that the top four motivations for females to become a founder in their 20s were: autonomy, power \& influence, managing people and altruism; while the top four for men were power \& influence, autonomy, managing people and financial gain.

Education has been considered as a proxy of an individual's specific technical skills, problem-solving abilities, discipline and self-confidence, among other relevant non-observable traits (Cooper et al., 1994) that may be important for entrepreneurial activity. But it may also capture the "quality" of social network in which the individual is embedded, which may channel and facilitate or constrain and inhibit entrepreneurial activity depending on the position of the individual in its social network ${ }^{20}$ (Aldrich and Zimmer, 1986). It is quite intuitive to think that the more educated the individual, the more highly educated nodes can be found in his or her social network (strong ties). Furthermore, these highly educated nodes are likely to hold good job positions, which may increase the access of the entrepreneur, through both strong and weak ties, to actors that are key for the business success ${ }^{21}$ (Granovetter, 1973). However, even though education has been considered an important determinant of entrepreneurial propensity, there is a strand of the literature that argues that entrepreneurs must be jack-of-alltrades who need not excel in any one skill but be competent in many (Lazear,

\footnotetext{
${ }^{20}$ See a discussion about the relationship between education, social networks and firm behavior in Chapter 5.

${ }^{21}$ For example, during the start-up phase is is well known that entrepreneurs are faced to several challenges due to their liability of newness (Stinchcombe, 1965), one of them being able to get customers to buy their products and services. Social networks may be particularly useful for entrepreneurs to have access to key customers.
} 
2005). This implies that holding an educational level as high as a $\mathrm{PhD}$ may not necessarily increase entrepreneurial success. However, due to the increasing pervasiveness of new technologies and strong competition, education may become quite important for innovative and high impact businesses, in which the entrepreneur behind is more the result of nurture than nature (Brockhaus and Horwitz, 1986). But, which is the relationship between educational attainment and entrepreneurial motivations? Prior literature has found a positive relationship between highly qualified individuals and opportunity-driven motivations, but the relationship with necessity-driven motivations seems to be less clear (Bergmann and Sternberg, 2007; Block and Wagner, 2010).

Prior professional experience has been considered to influence the type of entrepreneurial motivation that trigger individuals to engage in a new business. Individuals go through a learning process in their former jobs which may shape the motivation to become self-employed. The competences acquired in a former job may include acquired technical capabilities, innovative learning, managerial learned competences (organization, accounting, finance) and entrepreneurial abilities (information, personal contacts and market knowledge) (Arrighetti and Vivarelli, 1999). It can provide the individual with valuable insider information in terms of which markets to enter or which technologies are more suitable to serve the market needs (Block and Wagner, 2010). This tacit knowledge acquired through professional experience ${ }^{22}$, and the valuable social networks accumulated through time, are expected to be more relevant for opportunity-driven entrepreneurs.

Prior business ownership experience, on the other hand, has been considered as a source of tacit knowledge and expertise required for better opportunity identification. Entrepreneurs that have developed prior business expertise are thought to be more likely to have the ability to put together seemingly unrelated information that cannot be properly grasped by novice entrepreneurs, and might be able to identify (and potentially implement successfully) more innovative opportunities. Thus, prior business ownership experience is expected to be related to opportunity-driven motivations. Notwithstanding, the literature has claimed that after an initial positive effect there may be a point in which experience becomes path-dependent and lock-in effects might take place. Ucbasaran et al. (2009) argued that path dependency on prior experience might introduce biases in the

\footnotetext{
${ }^{22}$ However, experience itself should be considered as a necessary but not sufficient condition for entrepreneurial activity to succeed. Vesper (1982) expressed the belief that the most likely entrepreneurs to fail would be those with experience but no education. The second most likely entrepreneurs to fail would be those with education but no experience. Conversely, those entrepreneurs who had both experience and education would be associated with the most profitable business enterprises (Brockhaus and Horwitz, 1986).
} 
entrepreneur's decision because of thinking that enough is known, inferring too much from limited information, becoming constrained by the familiar or becoming overconfident.

To the entrepreneurial characteristics above mentioned, I included an additional variable that captures whether the entrepreneur lives in the capital city Santiago or not. Given that Chile is a highly centralized country, resources are expected to be relatively more easily accessed in the capital city. Therefore, entrepreneurs residing in the capital are expected to be more prone to be more opportunity motivated given the fact that the resources required to exploit an opportunity (both financial and human) are expected to be relatively less binding in the capital city.

The characteristics that were considered to determine the type of entrepreneurial motivation are then the following (see also Table 3.4 below).

Capital city: Dummy variable that takes value 1 if the individual lives in the capital city.

Age: Age of the individual when the business or activity started.

Gender: Dummy variable that takes value 1 if the individual is male.

Education: Highest level of education attained by the individual captured by a categorical variable. Six education categories were considered: (1) Primary or less, (2) secondary, (3) technical (CFT), (4) professional institute (IP), (5) university (bachelor degree) and (6) graduate education. ${ }^{23}$

Prior professional experience: Dummy variable that takes value 1 if the individual was a paid-employee before being self-employed.

Prior business ownership experience: Number of businesses the individual previously owned or had been a partner of.

\subsubsection{Descriptive Statistics}

Descriptive statistics were calculated considering expansion factors such that they represent the overall self employed population. Statistics are reported separately for employers and own-account workers in Tables 3.5 and 3.6 respectively. Some specific patterns can be clearly distinguished. Regarding the distribution of

\footnotetext{
${ }^{23}$ Tertiary education includes technical, professional and university (bachelor degree) education in Chile.
} 
Table 3.4: List of variables explaining entrepreneurial motivation

\begin{tabular}{lll}
\hline Variable name & Definition & Type \\
\hline capital & 1 if from capital Santiago & Binary \\
age_started & Age of individual when started activity & Continuous \\
male & 1 if male & Binary \\
education & Educational attainment (6 categories) & Categorical \\
primary & 1 if primary or less education & \\
secondary & 1 if secondary education & \\
technical & 1 if technical education (CFT) & \\
prof_institute & 1 if professional education (IP) & \\
university & 1 if university education & Binary \\
graduate & 1 if graduate education & Continuous \\
professional_exp & 1 if prior professional experience \\
business_exp & Number of business previously owned & \\
\hline
\end{tabular}

motivational categories it can be observed that they differ substantially between both types of self-employed workers, which can be graphically seen in Figure 3.3. The proportion of employers motivated by a market opportunity and selfrealization together doubles the one of own-account workers. While own-account workers are relatively more prone to be motivated by the need for independence, unemployment and wealth than employers. The rest of the motivation categories (Roles and Dismissal) follow a quite similar pattern between both groups.
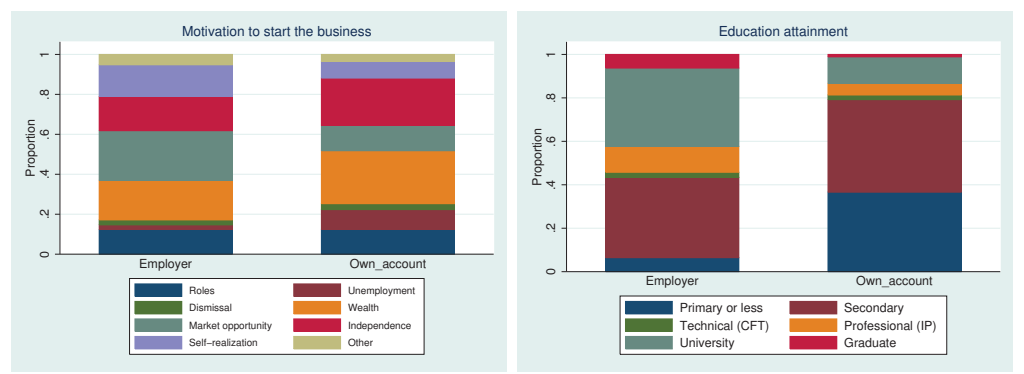

Figure 3.3: Distribution of motivation and education categories by type of selfemployed

Regarding some demographic traits, it can be observed that the venture was initiated when both employers and own-account workers were around 36 years old. This coincides with the upper bound of the 'free choice' period (between 26 and 36 years old) suggested by Martin (1984), where most entrepreneurs are expected 
to start a new venture (see footnote 8). In terms of gender, it can be observed that for every 3 male-employers there is only 1 female-employer. A relatively more equilibrated ratio is observed for own-account workers. In terms of educational attainment, a quite different pattern can be observed. Employers tend to be more educated than own-account workers. While $80 \%$ of the latter ones have secondary education or less, around $56 \%$ of the former ones have tertiary education or more. In terms of location, a higher prevalence of employers is settled in the capital city.

This characterization is consistent with Cea et al. (2009) who analyze the determinants of occupational choice in Chile: own-account, employer, paid-employee, unemployed and inactive. Based on a multinomial probit model, the authors find that own-account workers are mainly men with low education levels, low risk aversion, that have studied in public schools and that earn relatively lower wages than their employer or paid-employee counterparts. The authors claim that ownaccount workers tend to be individuals with lower productivity levels that are more prone to belong to a vulnerable socio-economic status, which suggests a higher prevalence of necessity-driven entrepreneurs within this category. This is consistent with the relatively higher proportion of unemployment-motivated own account workers. On the other hand, they find that the probability of being an employer in Chile is positively influenced by age, although at a decreasing rate. Being a man, being married, having more years of education and being risk tolerant also increases the propensity to perform as an employer. While having studied in a public school negatively influences the probability of being an employer ${ }^{24}$.

Still, a small proportion of "outsiders" with high education levels can be found in the subset of the own-account population as Table 3.6 and Figure 3.3 show. This proves that within each self-employed category individuals have different backgrounds and consequently motivational profiles are expected to differ.

Finally, prior professional experience does not differ between both types of self-employed and tends to be quite high; almost $80 \%$ of individuals have worked as an employee before being engaged in their ventures. But prior business ownership experience, measured as the number of businesses an individual has been

\footnotetext{
${ }^{24}$ One of the key traits of the Chilean education system is the distinction between schools in terms of their ownership status (public versus private) and their main source of funding (public subsidies versus family payments). These variables generate a system with three categories of co-existing schools (public, voucher-private and non-subsidized private) among which children end up being unevenly distributed according to their socioeconomic background (Núñez and Gutierrez, 2004; OECD, 2012; Valenzuela et al., 2013). This structure is the result of several market-oriented reforms implemented in the 1980s. Criticism against these reforms accumulated in recent years in a broad backlash against the education system. This led to a political discussion about the need to reform the education legislation in 2014.
} 
previously involved in (as an only owner or partner), seems to be slightly higher for employers.

Table 3.5: Descriptive statistics: Employers

\begin{tabular}{lccccc}
\hline \hline \multicolumn{1}{c}{ Variable } & Mean & Std. Dev. & Min. & Max. & N \\
\hline DEPENDENT VARIABLE: & & & & & \\
Motivation: Roles & 0.12 & 0.33 & 0 & 1 & 699 \\
Motivation: Unemployment & 0.02 & 0.15 & 0 & 1 & 699 \\
Motivation: Dismissal & 0.02 & 0.16 & 0 & 1 & 699 \\
Motivation: Wealth & 0.20 & 0.40 & 0 & 1 & 699 \\
Motivation: Market opportunity & 0.25 & 0.43 & 0 & 1 & 699 \\
Motivation: Independence & 0.17 & 0.38 & 0 & 1 & 699 \\
Motivation: Self-realization & 0.16 & 0.37 & 0 & 1 & 699 \\
Motivation: Other & 0.05 & 0.22 & 0 & 1 & 699 \\
\hline INDEPENDENT VARIABLES: & & & & & \\
1 if from capital Santiago & 0.50 & 0.50 & 0 & 1 & 699 \\
Age individual when started activity & 35.69 & 10.78 & 15 & 81 & 699 \\
1 if male & 0.77 & 0.42 & 0 & 1 & 699 \\
1 if primary or less education & 0.06 & 0.25 & 0 & 1 & 699 \\
1 if secondary education & 0.37 & 0.48 & 0 & 1 & 699 \\
1 if technical education & 0.02 & 0.15 & 0 & 1 & 699 \\
if professional education & 0.12 & 0.32 & 0 & 1 & 699 \\
1 if university education & 0.36 & 0.48 & 0 & 1 & 699 \\
1 if graduate education & 0.06 & 0.24 & 0 & 1 & 699 \\
1 if prior professional experience & 0.78 & 0.42 & 0 & 1 & 699 \\
Prior business ownership experience & 0.55 & 1.28 & 0 & 10 & 699 \\
\hline
\end{tabular}

Table 3.6: Descriptive statistics: Own account workers

\begin{tabular}{lccccc}
\hline \hline \multicolumn{1}{c}{ Variable } & Mean & Std. Dev. & Min. & Max. & N \\
\hline DEPENDENT VARIABLE: & 0.12 & 0.33 & 0 & 1 & 5269 \\
Motivation: Roles & 0.1 & 0.3 & 0 & 1 & 5269 \\
Motivation: Unemployment & 0.03 & 0.17 & 0 & 1 & 5269 \\
Motivation: Dismissal & 0.27 & 0.44 & 0 & 1 & 5269 \\
Motivation: Wealth & 0.13 & 0.33 & 0 & 1 & 5269 \\
Motivation: Market opportunity & 0.24 & 0.42 & 0 & 1 & 5269 \\
Motivation: Independence & 0.08 & 0.28 & 0 & 1 & 5269 \\
Motivation: Self-realization & 0.04 & 0.18 & 0 & 1 & 5269 \\
Motivation: Other & 0.37 & 0.48 & 0 & 1 & 5269 \\
INDEPENDENT VARIABLES: & 36.58 & 13.15 & 12 & 90 & 5269 \\
1 if from capital Santiago & 0.59 & 0.49 & 0 & 1 & 5269 \\
Age individual when started activity & 0.37 & 0.48 & 0 & 1 & 5269 \\
1 if male & 0.43 & 0.49 & 0 & 1 & 5269 \\
1 if primary or less education & \multicolumn{5}{c}{ Continued on next page... } \\
1 if secondary education & & &
\end{tabular}




\begin{tabular}{lccccc}
... table 3.6 continued & \multicolumn{1}{c}{ Mean } & Std. Dev. & Min. & Max. & N \\
\hline \multicolumn{1}{c}{ Variable } & 0.02 & 0.14 & 0 & 1 & 5269 \\
\hline 1 if technical education & 0.05 & 0.22 & 0 & 1 & 5269 \\
1 if professional education & 0.12 & 0.33 & 0 & 1 & 5269 \\
1 if university education & 0.01 & 0.11 & 0 & 1 & 5269 \\
1 if graduate education & 0.77 & 0.42 & 0 & 1 & 5269 \\
1 if prior professional experience & 0.42 & 1.04 & 0 & 23 & 5269 \\
Prior business ownership experience & & & & &
\end{tabular}

The above discussion shows that in fact the population of self-employed workers is quite heterogeneous. Not only in terms of the type of businesses they create (in terms of job creation) but also in terms of the background of the individual. Furthermore, the distribution of motivational categories differ between own-account workers and employers. Is there then a relationship between different backgrounds and entrepreneurial motivations? The next section discusses the methodology used to answer this question.

\subsection{Methodology}

As discussed in section 3.3.2.1, self-employed individuals were asked to choose one out of eight possible reasons as the main motivation to have started their businesses: (1) Roles, (2) Unemployment, (3) Dismissal, (4) Wealth, (5) Market Opportunity, (6) Independence, (7) Self-realization and (8) Other. A vector $\mathbf{x}$ of individual characteristics (discussed in section 3.3.2.2) is assumed to determine the motivation category chosen by individuals. Regressors are assumed to vary only between individuals and not between alternatives. Given the categorical nature of the dependent variable and the alternative-invariant vector of regressors, a Multinomial Logit Model is estimated.

Even though the Multinomial Probit (MNP) model is considered more appealing due to its flexibility regarding the condition of independence of irrelevant alternatives (IIA) (see Cameron and Trivedi (2005b)), it is more burdensome in terms of the estimation procedure. In discrete choice theory, the IIA condition implies that when an individual is asked to pick among a set of alternatives, the one that is picked does not depend on other alternatives that are present or absent from the set. If this does not hold, errors across the different choice probabilities would be correlated. The MNP model permits correlation across errors, although some restrictions need to be made on the variance-covariance matrix. However, the MNP poses the challenge that there is no closed-form expression for the choice 
probabilities (Cameron and Trivedi, 2005b), thus making it a less appealing approach to estimation. Still, a comparison between the marginal effects obtained for both MNL and MNP models using the whole sample was made to verify if they yield comparable results. This exercise is reported in Appendix A (A.1 and A.2) and it can be observed that the magnitude and significance of the average marginal effects do not differ substantially between both models. Therefore, MNL models can be applied without worrying about IIA $^{25}$.

The dependent variable $y$ captures the reason for motivated individuals to start a business activity, thus it can take any value $j$ where $j=1,2, \ldots, 8$. The probability that motivation $j$ is chosen by an individual $i$ is given by $p_{i j}=\operatorname{Pr}\left[y_{i}=\right.$ $\left.j \mid \mathbf{x}_{i}\right]$, where $j=1,2, \ldots, 8$. The functional form of this probability is given by:

$$
p_{i j}=\operatorname{Pr}\left[y_{i}=j \mid \mathbf{x}_{i}\right]=\frac{\exp \left(\mathbf{x}_{i}^{\prime} \beta_{j}\right)}{\sum_{l=1}^{8} \exp \left(\mathbf{x}_{i}^{\prime} \beta_{l}\right)}, \quad j=1,2, \ldots, 8
$$

Because $\sum_{l=1}^{8} p_{i j}=1$, a restriction is needed to ensure model identification, which means setting a vector of $\beta$ parameters for a given choice to 0 . Typically the first choice is used as a reference category so the estimated coefficients are interpreted in relation to this reference category. However, direct interpretation of estimated coefficients is tricky given the nonlinear form of the model. Consequently, given that the coefficients of the MNL model are not directly interpretable in terms of the effect that a change in a regressor has on the probability of choosing a specific motivation category, marginal effects will be reported instead. Consider for example the effect of changing a regressor by one unit on the $j^{\text {th }}$ probability; the expression for the marginal effect is given by:

$$
\frac{\partial p_{i j}}{\partial \mathbf{x}_{i}^{\prime}}=p_{i j}\left(\beta_{j}-\overline{\beta_{i}}\right)
$$

where $\overline{\beta_{i}}=\sum_{l} p_{i l} \beta_{l}$ is a probability weighted average of the $\beta_{l}$ vector. It follows from the expression in (3.2) that the sign of the response is not necessarily given by the sign of $\beta_{j}$, unless $\beta_{j}>\overline{\beta_{i}}$. Furthermore, the magnitude of the marginal

\footnotetext{
${ }^{25}$ For the reader wondering why a Hausman-McFadden or a Small-Hsiao test was not conducted to verify whether IIA has been violated or not, the reason is that recent literature suggests that both tests are not useful for assessing violations of the IIA property as they typically yield conflicting results (see a discussion in Long and Freese (2014b) about these tests in p.407-408). Long and Freese (2014b) mention that the best advise regarding IIA goes back to McFadden (1974) who wrote that the multinomial and conditional logit models should be used only in cases where the alternatives "can possibly be assumed to be distinct and weighted independently in the eyes of each decision maker". While Amemiya (1981) suggests these models work well when alternatives are dissimilar. So one is only left to the challenge of specifying a model in which the assumption that distinct alternatives are not substitutes seems to be reasonable.
} 
effect for a given change in a regressor will depend on the value of the rest of the regressors (through the expression of $p_{i j}$ in (3.1)) and on the effect the rest of the regressors have over the dependent variable (through $\overline{\beta_{i}}$ ). The marginal effect then depends on the value regressors are evaluated at. A common approach is to compute an average marginal effect (AME) between all individuals given by

$$
N^{-1} \sum_{i} \frac{\partial p_{i j}}{\partial \mathbf{x}_{i}^{\prime}}=N^{-1} p_{i j}\left(\beta_{j}-\overline{\beta_{i}}\right)
$$

This means that a marginal effect is computed for each individual based on its regressor values, and then they are averaged. Even though computing the average marginal effect (AME) is intuitively superior than the marginal effect at the mean (MEM) (Cameron and Trivedi, 2005b), still it is an average and it may obscure the differences in effects across cases (Williams, 2012). Therefore, marginal effect at representative values (MER) are also reported.

Estimation will be done using regressors in factor variable notation to account for any interdependencies between variables (Williams, 2012). This is fundamental when estimating marginal effects for nonlinear models. Also, as previously mentioned at the end of section 3.3.1, the complex design of the survey should be taken into consideration such that standard errors are properly corrected for clustering and stratification. This was done by using the Stata [svy] family of commands.

\subsection{Results}

Using a multinomial logit model, the relationship between the characteristics of the individual and the reported motivation to start the business was tested. Results are reported separately for employers and own account workers. Estimation coefficients are reported in Appendix A (see A.3 and A.4 respectively). When checking the estimation coefficients it can be observed that a regressor's significance varies between motivation categories, as expected. However, results of such testing may vary with the base comparison category (Cameron and Trivedi, 2010). Therefore, a Wald test for joint significance of regressors across all motivation categories was performed. The results are presented in Table 3.7 for both employers and own account workers, and indicate that most regressors are significant at the usual levels, except for primary and professional (IP) education levels.

In table 3.8 Wald tests for combining alternatives are shown for both models on employers and own-account workers. This test is useful to verify if some alternatives may be merged into one. The model for own-account workers shows 
that motivation categories cannot be combined. While the Wald tests for the model for employers indicate that some of them may be combined, for example 'Roles' and 'Independence', 'Roles' and 'Self-realization', 'Wealth' and 'Independence' and 'Independence' and 'Self-realization'. However, to keep comparison with the own-account workers model, where results of the Wald test indicate that alternatives may not be combined, the categories are analyzed separately.

Since estimation coefficients are not directly interpretable in terms of the effect that entrepreneurial traits have on the propensity that an individual chooses a given motivation category, the analysis is done using the average marginal effects (AME). Tables 3.9 and 3.10 report AME for both types of self-employed individuals.

Table 3.7: Wald tests for joint significance of independent of variables

\begin{tabular}{lcccc}
\hline \multirow{2}{*}{ Variable } & \multicolumn{2}{c}{ Employers } & \multicolumn{2}{c}{ Own-account } \\
capital & F-Statistic & $P>F$ & F-Statistic & $P>F$ \\
age_started $^{\text {age_started }}{ }^{2}$ & 1.951 & 0.063 & 6.954 & 0.000 \\
male $_{\text {primary }}$ & 2.920 & 0.066 & 5.497 & 0.000 \\
technical & 1.816 & 0.035 & 3.657 & 0.001 \\
prof_institute & 0.376 & 0.085 & 8.327 & 0.000 \\
university & 286.718 & 0.000 & 6.492 & 0.000 \\
graduate & 0.183 & 0.989 & 0.790 & 0.000 \\
professional_exp & 3.621 & 0.001 & 1.506 & 0.596 \\
businesses_exp & 177.939 & 0.000 & 4.147 & 0.000 \\
\multicolumn{1}{c}{$H_{0}:$ All coefficients associated with given variables are equal to 0}
\end{tabular}

Table 3.8: Wald tests for combining alternatives

\begin{tabular}{llllc}
\hline & \multicolumn{2}{c}{ Employers } & \multicolumn{2}{c}{ Own-account } \\
Motivation & F-Statistic & $P>F$ & F-Statistic & $P>F$ \\
\hline $1 \& 2$ & 45.803 & 0.000 & 13.851 & 0.000 \\
$1 \& 3$ & 103.313 & 0.000 & 7.362 & 0.000 \\
$1 \& 4$ & 5.072 & 0.000 & 27.069 & 0.000 \\
$1 \& 5$ & 2.074 & 0.023 & 7.028 & 0.000 \\
$1 \& 6$ & 1.447 & 0.153 & 18.012 & 0.000 \\
$1 \& 7$ & 1.279 & 0.238 & 13.559 & 0.000 \\
$1 \& 8$ & 55.707 & 0.000 & 7.152 & 0.000 \\
$2 \& 3$ & 44.643 & 0.000 & 3.996 & 0.000 \\
$2 \& 4$ & 101.739 & 0.000 & 6.151 & 0.000 \\
$2 \& 5$ & 47.605 & 0.000 & 5.245 & 0.000 \\
$2 \& 6$ & 67.272 & 0.000 & 10.030 & 0.000 \\
\hline
\end{tabular}




\begin{tabular}{|c|c|c|c|c|}
\hline \multirow[b]{2}{*}{ Motivation } & \multicolumn{2}{|c|}{ Employers } & \multicolumn{2}{|c|}{ Own-account } \\
\hline & F-Statistic & $P>F$ & F-Statistic & $P>F$ \\
\hline $2 \& 7$ & 57.569 & 0.000 & 5.593 & 0.000 \\
\hline $2 \& 8$ & 2.077 & 0.023 & 4.050 & 0.000 \\
\hline $3 \& 4$ & 121.737 & 0.000 & 4.736 & 0.000 \\
\hline $3 \& 5$ & 133.006 & 0.000 & 4.786 & 0.000 \\
\hline $3 \& 6$ & 143.875 & 0.000 & 5.971 & 0.000 \\
\hline $3 \& 7$ & 114.714 & 0.000 & 4.173 & 0.000 \\
\hline $3 \& 8$ & 84.776 & 0.000 & 5.913 & 0.000 \\
\hline $4 \& 5$ & 3.156 & 0.001 & 3.933 & 0.000 \\
\hline $4 \& 6$ & 1.134 & 0.336 & 7.723 & 0.000 \\
\hline $4 \& 7$ & 2.477 & 0.006 & 2.761 & 0.002 \\
\hline $4 \& 8$ & 105.800 & 0.000 & 2.703 & 0.003 \\
\hline $5 \& 6$ & 1.834 & 0.050 & 3.085 & 0.001 \\
\hline $5 \& 7$ & 1.830 & 0.050 & 2.144 & 0.018 \\
\hline $5 \& 8$ & 85.311 & 0.000 & 2.642 & 0.003 \\
\hline $6 \& 7$ & 1.549 & 0.116 & 4.209 & 0.000 \\
\hline $6 \& 8$ & 52.163 & 0.000 & 3.821 & 0.000 \\
\hline $7 \& 8$ & 63.640 & 0.000 & 2.594 & 0.004 \\
\hline \multicolumn{5}{|c|}{$\begin{array}{l}H_{0} \text { : All coefficients except intercepts associated with a given pair of } \\
\text { alternatives are } 0 \text { (i.e., alternatives can be collapsed). } \\
\text { Motivation categories: (1) Roles (2) Unemployment (3) Dismissal } \\
\text { (4) Wealth (5) Market opportunity (6) Independence (7) Self-realization } \\
\text { (8) Other. }\end{array}$} \\
\hline
\end{tabular}

\subsubsection{Determinants of entrepreneurial motivations}

The average marginal effects for employers and own account workers are presented in Tables 3.9 and 3.10 respectively. In general, the results show that entrepreneurial motivations to start a new venture tend to differ according to the background of the individual, for both employers and own account workers.

Results for employers presented in Table 3.9 show that individuals living in the capital city are, on average, more prone to have been motivated by a market opportunity than those living outside the capital. This relationship is statistically significant at the $5 \%$ level and the magnitude of the effect is of about 16 percentage points, showing that the capital city is more likely to host opportunity-driven employers. Employers in the capital are also less likely to be motivated by selfrealization (in 8 percentage points). Age or gender differences do not seem to be related to specific motivation categories in employers.

Education seems to explain important differences in entrepreneurial motivations. For example, as educational attainment goes up, employers tend to be, on average, more prone to be motivated by independence. This implies that jumping from secondary to university (or graduate) education increases the propensity to 
be an independence-motivated employer in 12 (or 21) percentage points. On the contrary, higher education levels statistically decrease the propensity of employers to be motivated by a market opportunity or by role models.

In terms of prior experience, professional experience is positively related to wealth-motivated employers (propensity to pick this motivation category increases in 9 percentage points when the individual has been an employee before) and negatively related to employers motivated by role models (propensity decreases in 15 percentage points). While prior business ownership experience, as expected, increases the propensity to be opportunity-motivated in about 4 percentage points with each additional business previously owned, but decreases the propensity to be motivated by wealth or dismissal.

The fact that prior business ownership has a positive relationship with being motivated by a market opportunity suggests that entrepreneurs are effectively learning from prior experiences and are able to accumulate tacit knowledge that allows them to identify needs and visualize opportunities that were probably not clear before. And although it is not clear whether prior businesses fall under the category of successful or unsuccessful, the truth is that being engaged in the process of entrepreneurship is a learning process that promotes the accumulation of tacit knowledge, which is very much needed in a highly uncertain activity like this one. This implies that prior business experience, failure included, should be seen as a source of experience and learning.

On the other hand, results for own account workers presented in Table 3.10 show that individuals with a higher educational attainment, as high as graduate level, are more prone to be independence-motivated and less prone to be motivated by a market opportunity or role models. The relationship with the independence category is statistically significant at the $1 \%$ level and the magnitude of the effect is, on average, of 24 percentage points increase (considering secondary education attainment as the base comparison category). This type of own account workers may be, for example, highly educated and experienced individuals that work freelance as expert consultants. Thus, the group of own-account workers includes a subpopulation of more vulnerable, less educated and necessity-driven individuals, and another one of highly educated individuals that work independently. 


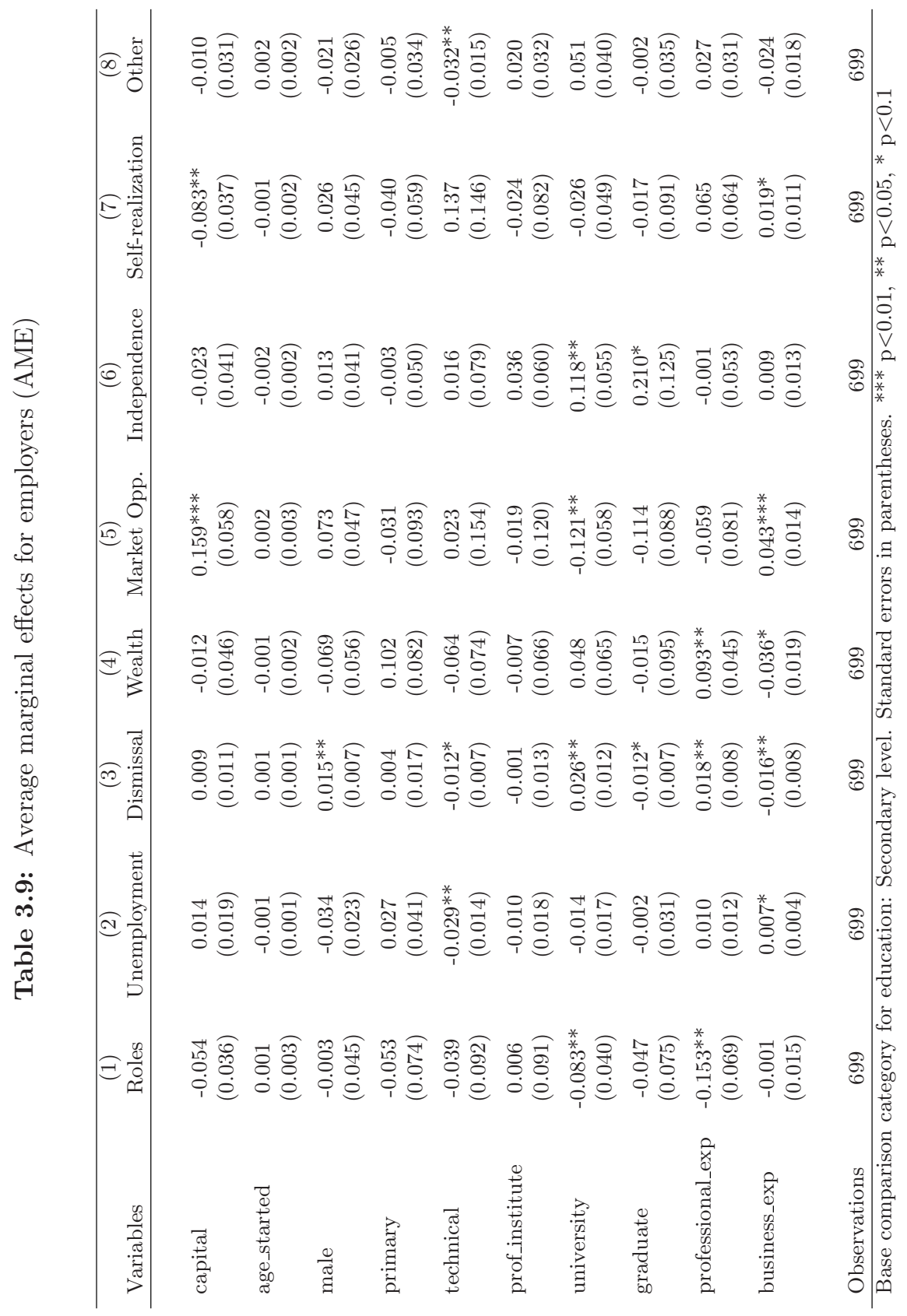




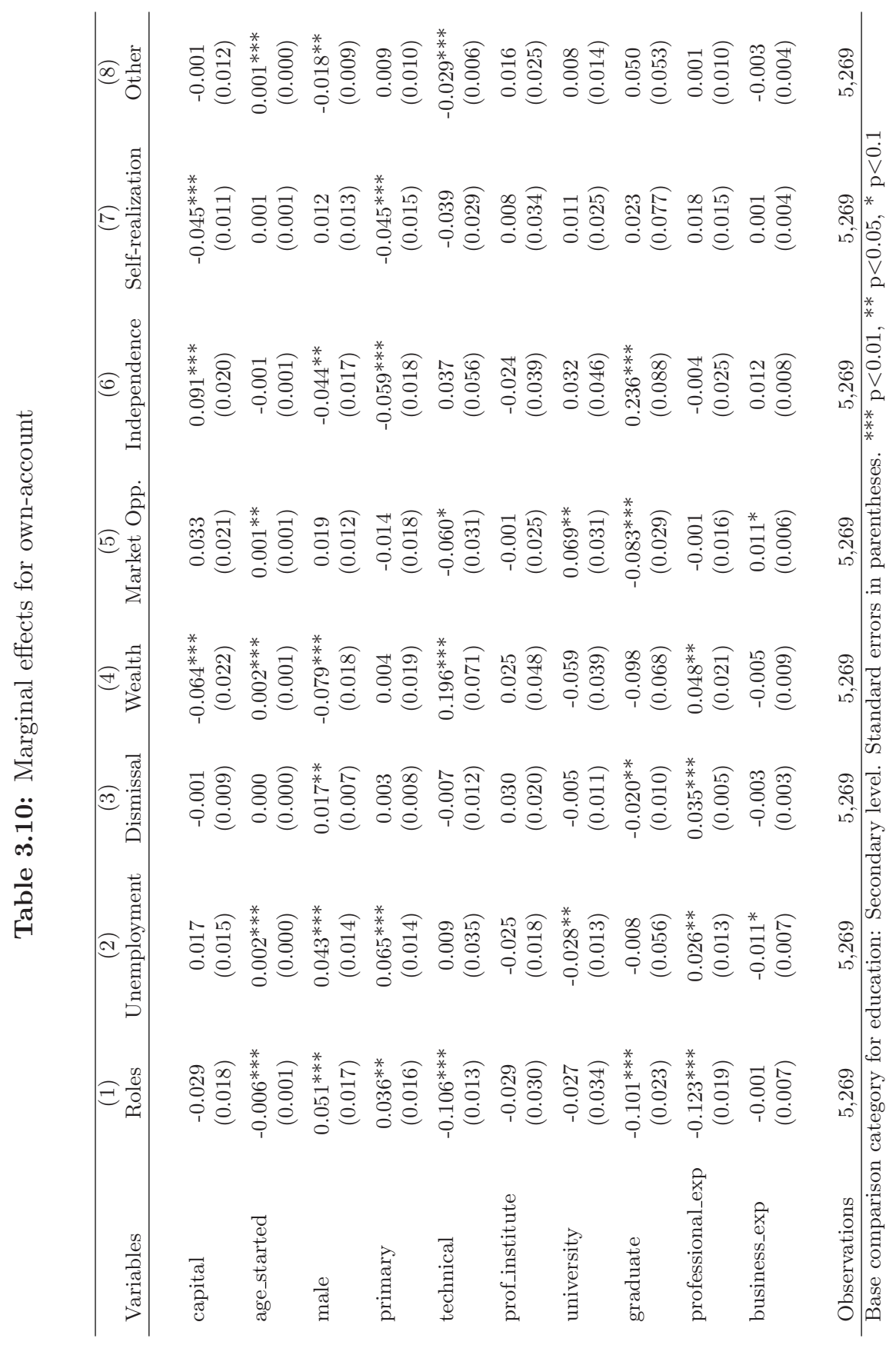


Another interesting result is the effect of jumping from secondary to technical education, which significantly increases the propensity of own-account workers to be wealth-motivated in approximately 20 percentage points. Moreover, those who are settled in the capital city are more prone to be motivated by independence, and less motivated by wealth or self-realization. Finally, some mild gender differences can be found; male own account workers are, on average, more prone to start a business motivated by family tradition, unemployment and dismissal, but less by wealth and independence, although the magnitudes of the effects are rather small.

These results based on means show that, as expected, different entrepreneurial motivations are related to different individual profiles, being the most important one the educational attainment of the individual. This holds for both employers and own account workers. However, means may obscure important differences in terms of the effect of given variables, especially when other characteristics vary. For example, it would be interesting to know whether the effect of jumping from secondary to university education on the propensity to be an independencemotivated employer differs according to the age of the individual. This can be verified through the calculation of marginal effects evaluated at representative values (MER), as discussed in the next subsection.

Before going ahead with the MER analysis it should be noted that a similar model was estimated using the results of the EME 2 survey with the aim of conducting robustness checks for the relationship found between motivation categories and individual characteristics. However, the sample of individuals under analysis substantially differed between waves in key variables, like educational attainment (EME 2 survey included a higher proportion of less educated individuals). Furthermore, the dataset did not include information about the survey design so clustering and stratification cannot be corrected for. Therefore, this exercise was not suitable to conduct the desired robustness checks. Notwithstanding, it was useful to test the direction of possible biases due to relevant omitted variables. For example, the literature typically emphasizes the importance of role models in the propensity to be engaged in entrepreneurial activity, so a positive relationship with the "Roles" motivation category is expected. EME 2 captured whether there were role models in the family of the interviewee so the effective presence of role models could be included in the analysis. The type of primary school the individual attended was also included as a proxy of socioeconomic background (see footnote 24). It could be verified that the coefficients did not change substantially when adding these extra variables, meaning that the specification of the model under analysis is quite robust. And even though estimation results based on EME 
3 and EME 2 survey data are not comparable one may expect that coefficients obtained in EME 3 are not necessarily biased due to the omission of these two background variables.

\subsubsection{Predicted probability at representative values}

This section discusses how the predicted probability for each motivation category varies according to specific values of the independent variables. For example, how the effect of different educational levels changes with the age of the individual. The results of this exercise are presented in a set of graphs in Figure 3.4 for employers and Figure 3.5 for own account workers. The predicted probability to choose each motivation category was calculated depending on the education level and age of the individual. The rest of the variables were evaluated in their observed value. ${ }^{26}$ The graphs do not distinguish between men and women since the patterns are quite similar (not reported here), so the graphs represent both genders. The same holds for location (living in the capital Santiago or not).

A quick look at the set of graphs, especially the ones for employers, show that: 1) The effect that different educational levels have on the probability of choosing each motivation category changes with the age of the individual; 2) The effects varies between motivation categories, which is specially clear for employers when comparing the "Dismissal" and "Independence" categories; and 3) Within the same motivation category, the effect of different education levels differ. Now we zoom into the patterns observed for employers and own-account workers separately.

\subsubsection{Employers}

A quite intuitive result is the one obtained for the "Dismissal" motivation category. It can be observed that the probability of having started the business due to dismissal is almost negligible for all educational levels until the late 40s but increases steadily for all levels, except for graduates, as individuals' age get closer to retirement age (around the late 50s and early 60s). An interesting trend is that the probability turns to be especially high for those with university education,

\footnotetext{
${ }^{26}$ In practical terms this is done by recovering the estimation coefficients associated with each variable and then calculating the expected probability for a given motivation using Equation (3.1) for every individual by evaluating education level and age at specific values. The rest of the independent variables were evaluated at the observed values, after which an average between individuals was taken. The procedure was repeated for all different educational and age levels in order to build the graphs. This exercise was done by using the Stata [margins] command.
} 
and by the end of the age 60 it exceeds by almost 10 percentage points the next educational level (primary).

An opposite pattern is observed for the "Independence" motivation category: starts high and ends low. The graph shows that if an individual is to start a business motivated by independence, this is more likely to occur at an earlier age, as early as the late 20 where the peak is observed. This holds for all educational levels but seems to be especially high for more educated individuals, i.e. those holding a bachelor or graduate degree. In fact, the probability of individuals with graduate education almost doubles the one of those with less than a bachelor degree. This pattern suggests that independence motivation is somehow linked to the personality or other background characteristics of individuals. In Chapter 5 is elaborate more on this applying a qualitative approach.

A similar pattern is observed for the "Wealth" motivation category, which also depicts a first-high-then-low pattern. The probability of being wealth-motivated increases at early ages reaching a peak at around the first half of the 30s, and then goes gradually down. Wealth seems to be a strong motivation for individuals with both university and primary educational attainment, although is slightly higher for the latter ones.

Regarding "Self-realization" it can be observed a rather unsloped pattern that remains around a probability of 20 percent for all educational and age levels except for technical education, which fluctuates around 35 percent. A slight decrease is observed for the former group of educational levels after age 55, which does not hold for those individuals with technical education, for which the probability seems to increase a little until the mid 70s.

In terms of opportunity-motivated individuals, a quite interesting pattern can be observed: more educated individuals are less prone to have started their businesses motivated by having found a market opportunity, especially those with university degrees. For all education levels the probability reaches its peak between the late 50s and early 60s, after which it goes down. Again, individuals with technical education lead the group and border the 40 percentage points level around the late $50 \mathrm{~s}$.

Finally, the graph for the "Role" motivation category shows that the probability remains between 10 and 20 percent for all categories of education until age 45 where it starts increasing a little. This is the age that most probably the individuals' parents have reached the age of retirement and they end up taking over the family company. It calls the attention that those with technical education 


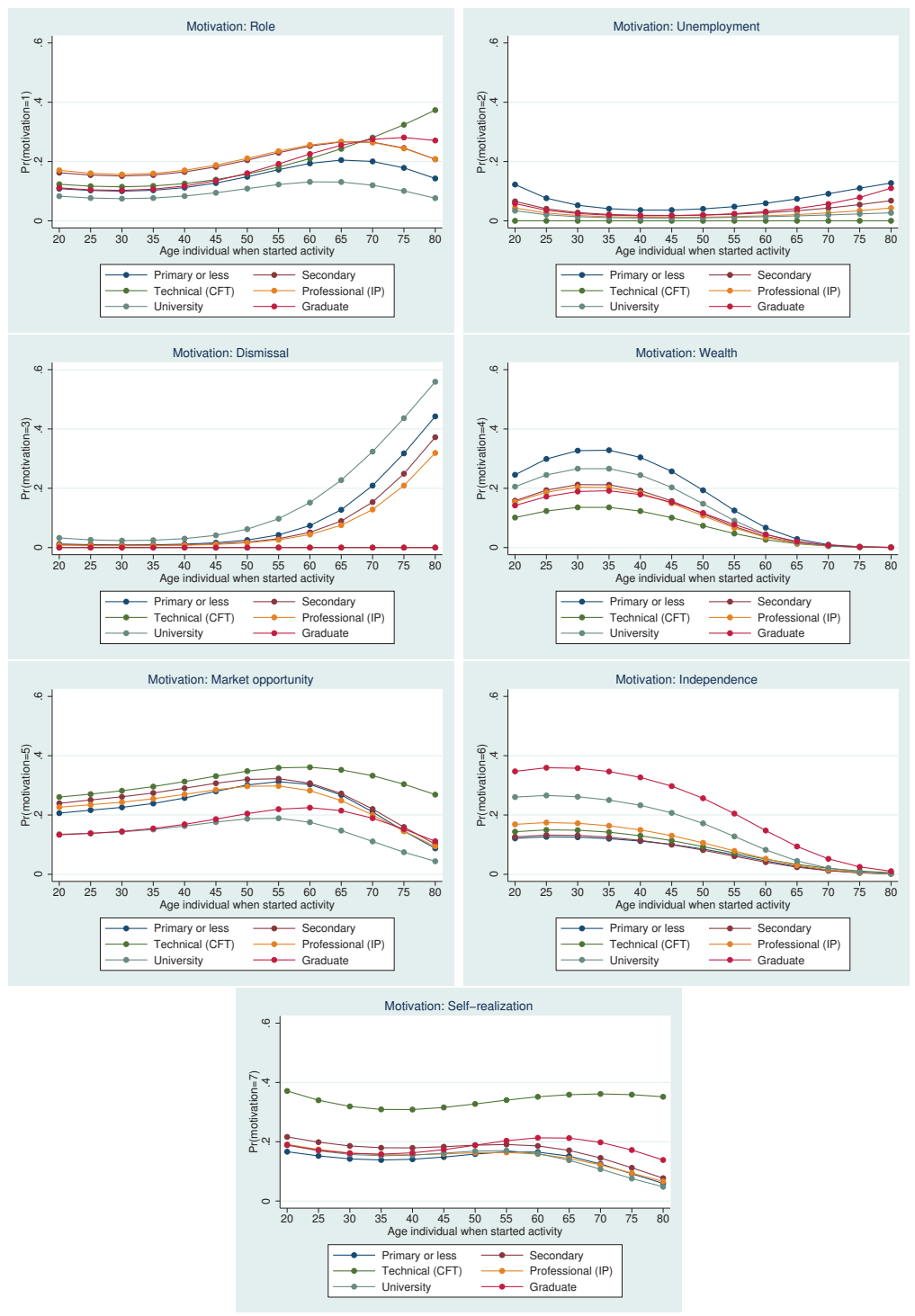

Figure 3.4: Employers: Predicted probabilities for different education and age levels 
increase steadily their propensity to be Roles-motivated, a pattern that differs from the rest of individuals with other educational levels.

Summing up, it can be observed that the effect that education level has on the propensity to pick each motivation category changes with the age. And the pattern differs between motivation categories. Employers of all education levels are more likely to be Independence and Wealth motivated when they are younger, which suggests that these motivations are linked to particular background characteristics. On the other hand, entrepreneurship motivated by dismissal is apparently related to an external factor, thus these individuals are considered as having been pushed-into entrepreneurship. Finally, education has different effects over different motivation categories. Highly educated individuals will be more likely to start a business for Independence and Wealth motivations. While less educated ones are more likely to start a business due to a market -opportunity. An interesting result is the pattern observed for individuals holding a technical education degree, which substantially differs from the rest of the educational levels. These individuals are more likely to have started due to market opportunity and self-realization, which resembles somehow the profile of both the Kirznerian and Schumpeterian entrepreneur.

But which are the characteristics of the businesses of these entrepreneurs? In order to have an idea of the type of businesses they own some descriptive statistics were calculated, which are shown in Table 3.11 .

Table 3.11: Business characteristics by employers' motivation

\begin{tabular}{|c|c|c|c|c|}
\hline \multirow[b]{2}{*}{ Variable } & \multicolumn{2}{|r|}{ Income* } & \multicolumn{2}{|c|}{ Formal employees } \\
\hline & Mean & Standard Dev. & Mean & Standard Dev. \\
\hline Roles & 5.83 & 2.15 & 2.90 & 1.83 \\
\hline Unemployment & 5.89 & 2.14 & 6.61 & 15.46 \\
\hline Dismissal & 6.27 & 2.27 & 8.44 & 12.16 \\
\hline Wealth & 6.93 & 2.32 & 26.17 & 103.55 \\
\hline Market Opportunity & 5.33 & 1.99 & 6.19 & 8.57 \\
\hline Independence & 6.32 & 2.83 & 9.22 & 7.87 \\
\hline Self-realization & 4.70 & 2.65 & 4.27 & 6.7 \\
\hline Other & 5.88 & 2.52 & 12.53 & 24.53 \\
\hline
\end{tabular}

Table 3.11 shows that businesses associated to owners motivated by Wealth, Independence and Dismissal are, on average, generating the highest monthly in- 
come. They also have hired, on average, a higher number of employees, especially those that are owned by Wealth motivated entrepreneurs.

\subsubsection{Own account workers}

Looking at the set of graphs in Figure 3.5 the effect of different education levels does not seem to change substantially with age, except for "Independence" and "Wealth".

For the "Independence" motivation category the patterns resemble the ones obtained for employers. Likewise, own account workers, especially those with graduate education, are more likely to start a business motivated by Independence at a younger age, reaching the peak of $50 \%$ between the 20 s and 30 s.

For the "Wealth" motivation category a different pattern from the one for employers is observed. A slightly positively sloped relationship with age is found for all educational levels, where the expected probability remains between the 20 and 40 percentage points, except for individuals with technical education. For this subgroup the propensity is higher, between $42 \%$ and $62 \%$, and the slope turns slightly steeper after age 45 .

In general, it can be observed that the effects of education for own-account workers differ from the patterns observed for employers. A lot more variation is observed for employers, which is a consequence of the lower education levels attained by own-account workers in general. The effects observed for the "Independence" category of motivation in particular seem to be capturing the behavior of those highly educated individuals that decide to work freelance (possibly as consultants), who fall into the same subpopulation of own-account workers together with more vulnerable, less educated and necessity-driven individuals. Education therefore matters more to explain the motivational behavior of employers than own-account workers.

\subsection{Concluding remarks}

In this Chapter I provided empirical evidence that contributes to answer the research question "What explains the heterogeneity in entrepreneurial motivations?". Using a multinomial logit model I found that background individual traits have different effects on different categories of motivation, suggesting that entrepreneurial motivations are related to different background profiles, especially for the subgroup of the self-employed population composed of employers. 


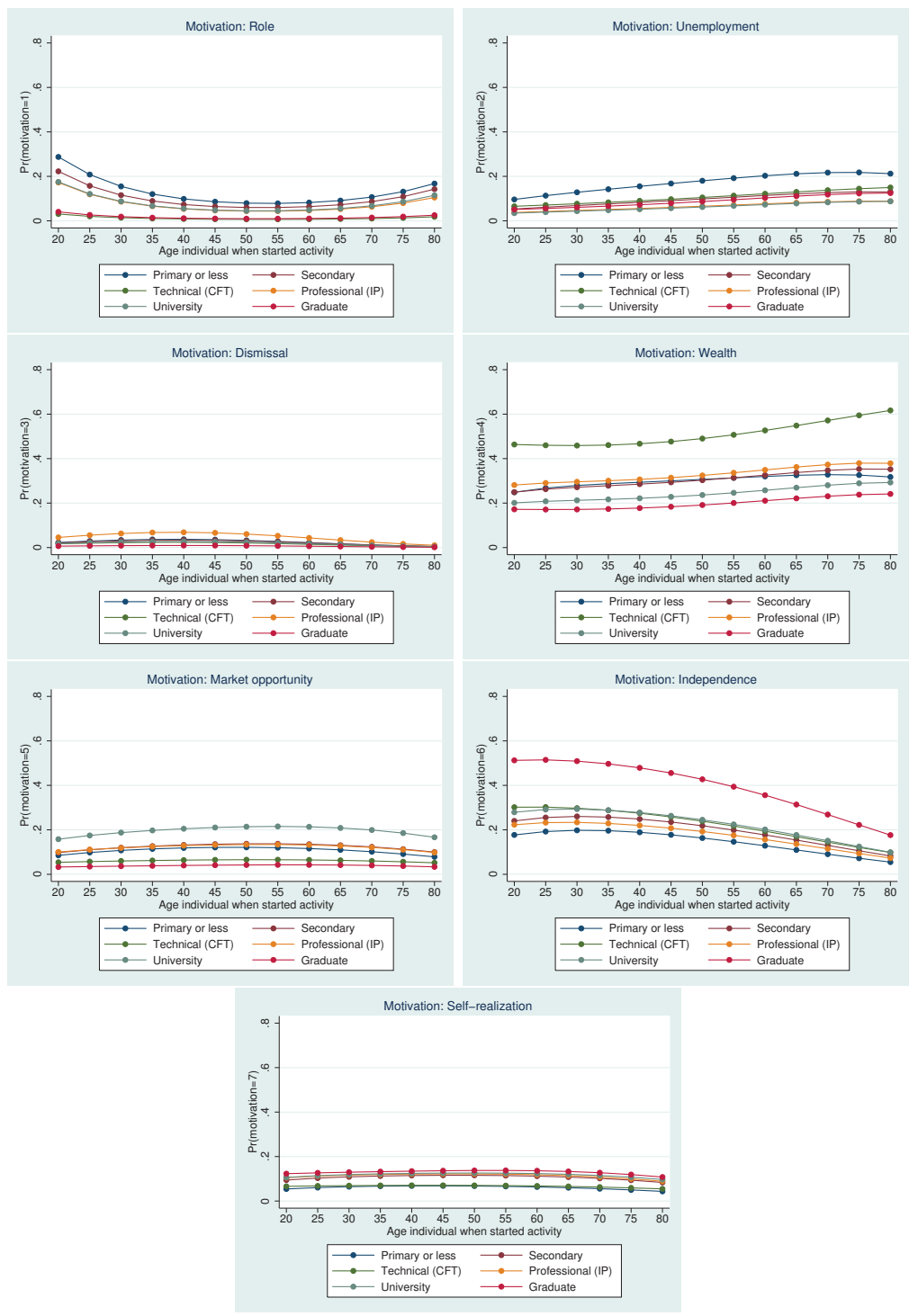

Figure 3.5: Own-account: Predicted probabilities for different education and age levels 
The results show that an increase in the educational attainment of an employer (from secondary to bachelor degree) increases the probability of being independence-motivated by, on average, 12 percentage points, but decreases the probability of being opportunity-motivated by 12 percentage points. Furthermore, the effect that the education level has on the propensity to pick each motivation category varies with age. For example, if an individual with a bachelor or graduate level of education is to start a business motivated by independence, this is more likely to occur at an earlier age, as early as the late 20 s.

Also, prior business ownership has a positive relationship with opportunitydriven individuals, suggesting that entrepreneurs are effectively learning and accumulating tacit knowledge from previous business experience. It can help entrepreneurs put together seemingly unrelated information and visualize opportunities that cannot be easily grasped by novice entrepreneurs. This implies that prior business experience, failure included, should be seen as a source of experience and learning, advocating for a failure-tolerant culture towards entrepreneurship.

The limitations of this paper relate to the use of retrospective information, the cross sectional nature of the dataset and possible biases due to the omission of relevant variables. The use of retrospective information, is a frequent drawback in the entrepreneurship literature as pinpointed by Carter et al. (2003). The authors question the validity of retrospective surveys applied to successful entrepreneurs when trying to capture the prospective reasons they had when they started the business, as they may be a biased and inaccurately mirror of what may have occurred in the past (see also Brockhaus (1980)). In fact, the set of motivations collected by the EME 3 rely on retrospective information. This means that an individual that has been running a business for some time already, i.e. for ten years, was asked in 2013 what was the main reason that motivated him or her to start the business ten years earlier. It is clear that the situation of the individual ten years after the decision to start a business was made, the set of events that he has gone through and even the performance of the business itself, may have influenced the answer reported in 2013, turning it into a rather subjective measure of what happened ten years ago. Even though this problem cannot be solved for already existing entrepreneurs, I used explanatory variables (individual traits) that were more likely to remain unchanged between the time the person started the business and the time the data was gathered.

Cross sectional data, on the other hand, prevented me from finding causal effects from background traits to entrepreneurial motivations, although the conceptual framework suggests that the direction goes from individual background 
traits to motivation. Furthermore, a cross sectional data set does not allow me to control for unobservable characteristics that affect entrepreneurial motivations like personality traits and abilities, which may be biasing my results due to the omission of these relevant variables. These two unobservable dimensions are addressed later in Chapter 5 following a qualitative approach.

Another source of variable omission bias comes from the fact that I was not able to control for the interaction between individual background traits and the environmental context. In fact, if the phenomenon of entrepreneurship is understood as one that emerges from a complex process resulting from the interaction of different factors, then one should take into consideration the interaction between certain types of entrepreneurs (in terms of their background traits) with certain types of environment. This is expected to produce a variety of ventures.

Further research should aim at building the next pieces of the entrepreneurial puzzle, that is, how different entrepreneurial motivations and other background traits from individuals affect venture creation and performance. This implies starting from the premise that venture creation and performance is influenced by the behavior of the entrepreneur in interaction with its environment, and that entrepreneurial behavior is affected by motivations and skills together. In the next two Chapters I deal with these questions. 


\section{Chapter 4}

\section{Entrepreneurial traits and innovation}

\subsection{Introduction}

In Chapter 3 I analyzed the relationship between individual background traits and entrepreneurial motivations. The current Chapter goes a step further and analyzes the relationship between entrepreneurial motivations and firm innovation.

Entrepreneurial behavior is assumed to be influenced by the interaction of skills and motivations. And because entrepreneurial behavior is viewed as a causal determinant of firm performance, given the context in which the firm is embedded, variables that affect behavior will indirectly affect the performance caused by that behavior. Hence entrepreneurial motivations and skills are expected to exert influence over firm performance; particularly over firm innovative performance. Therefore, the research questions I aim to answer in this Chapter are Do entrepreneurial motivations and skills have a direct effect on firm innovation propensity? and if so, Is there a specific entrepreneurial profile that makes firms more innovative?

There is a wide range of literature dealing with the factors that determine firm innovation. Organizational, environmental and entrepreneurial characteristics are among the categories of factors usually covered by the literature. This Chapter focuses on the third category, for which there is relatively less empirical evidence due to data limitations. In fact, studies that use innovation surveys based on the Oslo Manual framework fail to control for entrepreneurial traits as this dimension is not covered in the surveys. However, a relatively recent survey on Chilean firms collected valuable information on both firm and owner characteristics, opening a 
window of opportunity to put back the entrepreneur in the analysis and study the relationship between entrepreneurial traits and firm innovation.

To answer the research questions stated above I use the second wave of the Longitudinal Survey on Chilean Firms (ELE) which collects information for a representative sample of firms by economic activity and sector for year 2009. This database collects information about the characteristics of the firm owner and therefore it is possible to analyze the relationship between entrepreneurial traits and firm innovation, controlling for firm characteristics.

My results show that entrepreneurs that attain high levels of education and are "intrinsically" motivated manage firms that are more likely to introduce innovations (even after controlling for firm characteristics), although education seems to matter more than motivation. Hence, any attempt to understand what makes firms go innovative needs to take into consideration who is behind the decision making process: the entrepreneur.

\subsection{Conceptual framework}

As discussed in the Introduction to this thesis (Chapter 1), the population of entrepreneurs is highly heterogeneous in nature and therefore it includes a wide variety of entrepreneurs co-existing within the same environment. A fundamental implication of this fact is that different types of entrepreneurs are expected to contribute differently to economic development (Quatraro and Vivarelli, 2014). In particular, entrepreneurs pursuing ventures that have the potential to be innovative and achieve high growth rates, in terms of sales and job creation, are expected to generate a larger economic impact than those who remain small and local.

This Chapter focuses on innovative entrepreneurs, that elusive character among the continuum of individuals that compose the population of entrepreneurs. The question is who are these elusive pioneers that have the potential to impact economic development through the innovative businesses they pursue. Schumpeter described the profile of this special character back in the early years of the 20th century. Next I summarize how the author viewed this individual in charge of the process of creative destruction that would lead to economic development.

\subsubsection{The Schumpeterian entrepreneur}

In his early work Schumpeter viewed economic development emerging from a process of creative destruction triggered by 'the entrepreneur' through the intro- 
duction of new combinations of means of production (Schumpeter, 1934). The entrepreneurial function consists in 'carrying out new combinations', which appear 'discontinuously in time in groups or swarns'. These new combinations are embodied in new firms that emerge alongside the old ones, which are eventually eliminated through competition. The fact that these new businesses appear en masse, in the words of Schumpeter, provokes a substantial increase in the purchasing power of this group, explaining the process by which individuals and families rise and fall economically and socially.

The Schumpeterian entrepreneur is, according to the author, a special type of person in terms of his conduct. Doing something different and new, or carrying out innovations, involve high levels of uncertainty as the decisions to be taken do not rely on ordinary routines based on widespread knowledge and habits. Alternatively, the Schumpeterian entrepreneur goes against these ordinary routines and fixed habits of thinking, fighting the forces of habit that rise up against the one who wants to do something new. Facing this requires a special conduct, a specific psyche. First, the effort of will to work on a new combination believing in it as a real possibility, and not as a mere day-dream, requires a mental freedom that is by nature peculiar. Second, the reaction of the social environment against the one who wishes to do something new can be very strong, especially in initial stages. Successfully dealing with this opposition is a special kind of task that requires a special kind of conduct. Third, leadership is a trait that when mixed with the appearance of new possibilities, brings up the nature or conduct of the entrepreneur. In this sense, the entrepreneurial function is not to find or create new possibilities, but doing them. Is the capacity of executing the ideas what differentiates an entrepreneur from a creative person with thousands of ideas.

Schumpeter goes even further defining the underlying motives that explain the conduct of entrepreneurs, from a psychological point of view. First, the dream and will to found a private kingdom, which is specially strong for people who have no other chance of achieving social distinction. Second, the will to conquer, the impulse to fight, to prove themselves superior to others, to succeed for the sake of it and not for the economic reward, which is not an end itself but an index of success. And third, the joy of creating, of getting things done. The entrepreneur seeks out difficulties and changes, finding delight in the venture itself.

The entrepreneurial function carried out by this character involves the creation of new things, or things that significantly differ from those the consumer is fa- 
miliar to ${ }^{1}$. In this sense, innovation is a function carried out by the entrepreneur and therefore the entrepreneurial function, as defined by Schumpeter, is interlinked to innovation. However, in spite of the fact that innovative entrepreneurs play a central role in socio-economic development, they have not received enough attention in innovation studies (Baumol, 2010). And despite common roots in Schumpeterian ideas, entrepreneurship and innovation have evolved over time as two largely separate research fields (Landström et al., 2012).

This Chapter aims as putting the entrepreneur back into the analysis of firm innovation. Now I discuss how the entrepreneur is expected to exert influence over the innovative performance of his or her business.

\subsubsection{From entrepreneurial traits to firm innovation}

This Chapter follows the Enhanced Value Creation Performance (VCP) Model developed by Herron and Robinson (1993) that was discussed in Chapter 3. The previous Chapter analyzed the extent to which individual traits influenced the motivation to start a new venture. In this Chapter I focus on the extent to which entrepreneurial motivations, through its influence on entrepreneurial al behavior, affect firm innovative performance.

According to the model (see Figure 3.2 in Chapter 3), entrepreneurial behavior is explained by the interaction of individual skills and motivations ${ }^{2}$. And because behavior is viewed as a causal determinant of performance given the context in which the business is embedded, variables that affect behavior will also affect the performance caused by that behavior. Therefore, both entrepreneurial motivations and skills (approximated in this study by educational attainment) are expected to exert influence on firm performance.

This Chaper starts from the hypothesis that the motivation and skills of the entrepreneur have an influence over the organization, management and performance of the firm, which is expected to be particularly true for smaller enterprises where the owner of the firm is typically very close to day-to-day activities and directly influences the decision making process of the firm (Hausman, 2005). Decisions made by entrepreneurs shape the startup and its growth, an influence that starts even before the founding itself and that can extend through all stages of the

\footnotetext{
${ }^{1}$ See Schumpeter (1934) page 66 in Chapter 2 for a list of cases of innovations or new combinations.

${ }^{2}$ Personality traits also affect entrepreneurial behavior but in an indirect way as they are assumed to be mediated by motivation (Herron and Robinson, 1993).
} 
startup's development $^{3}$ (Wasserman, 2012). Thus, entrepreneurs' characteristics should be taken into account when analyzing factors that determine innovation at the firm level. However, since performance is contingent upon the situational context in which the business is embedded, I also consider some contextual factors that are typically considered in the literature to determine firm innovation.

From the discussion in the previous section we know that even though innovation and entrepreneurship are closely linked, the latter is not a sufficient condition for the former in the sense that not all entrepreneurs are innovative, or some of them are more innovative than others (Szirmai et al., 2011; Reynolds et al., 2002). Furthermore, according to the Schumpeterian approach to entrepreneurship discussed earlier, certain attributes of the entrepreneur make them more innovative, and consequently their firms end up being innovative. Also, from Chapter 3 we know that entrepreneurs are heterogeneous and therefore their motivations to pursue the creation of a new venture are different. The question is whether different entrepreneurial motivations ${ }^{4}$ and skills have different effects over firm innovation propensity.

\subsubsection{Prior empirical evidence}

The literature that has lately explored the relationship between firm innovation and the characteristics of the entrepreneur (see for example Hausman (2005); Marcati et al. (2008); de Mel et al. (2009); Pérez-Luño et al. (2010); Robson et al. (2011); Galasso and Simcoe (2011); Romero and Martínez-Román (2011); Gebreeyesus (2011)) has found that the latter do have an influence on innovation, even conditioning on firm size and other firm characteristics. This is especially true for small firms where the entrepreneur is typically closer to the decision making process and consequently his or her personality, motivations, skills and behavior are expected to have a higher influence on the organization, management and performance of the firm.

The relationship between innovation propensity and entrepreneurial personality and motivation has been tested empirically by de Mel et al. (2009), Pérez-Luño et al. (2010), Galasso and Simcoe (2011) and Romero and Martínez-Román (2011). Despite the fact that they test for different personality traits and motivations, they

\footnotetext{
${ }^{3}$ In his book Wasserman (2012) analyzes the different dilemmas that entrepreneurs behind technology- and science-based startups face and the critical decisions they have to make, from the decision to found or not in the first place, to the decision to exit the company. Each decision involves assessing different options and weighting trade-offs. And although there is no "right decision", any early decision will surely influence the development of the startup in the future, in a very path-dependent fashion.

${ }^{4}$ See Section 5.5.3 in Chapter 3 for a discussion on categories of entrepreneurial motivations.
} 
all find a significant influence on firm innovation. Romero and Martínez-Román (2011) for example explore how different motivations to start a business affect the probability of introducing innovations in Andalusian small firms. They distinguish between intrinsic, extrinsic and necessity driven entrepreneurs. Intrinsic motivation is considered to be more related to the need for success and professional development; extrinsic motivation is considered to be driven by economic reward and material achievement; and necessity motivation is associated with those people pushed to entrepreneurship by unemployment situations or dissatisfaction with their previous work. Their main findings show that both intrinsic and extrinsic motivated entrepreneurs have a higher probability of introducing innovations while necessity motivated entrepreneurs are less innovative. Furthermore, Pérez-Luño et al. (2010) explored the relationship between personality traits and innovation generation and adoption. Using a sample of innovative Spanish firms, they found that higher innovation is associated with an entrepreneur being more proactive and risk taking, although this holds for innovation generation rather than for innovation adoption. Finally, de Mel et al. (2009) show for a sample of micro, small and medium urban firms in Sri Lanka that impatient entrepreneurs are more likely to innovate, although no significant effect was found for risk seeking behavior.

In addition to personality traits, other characteristics of the entrepreneur have been found to have a significant influence over firm innovation. First, variations in experience may explain why entrepreneurs differ in their innovativeness (Ucbasaran et al., 2009; Robson et al., 2011). More experienced entrepreneurs, measured for example through prior business ownership experience or proportion of failed businesses over total number of businesses owned, may have developed the tacit knowledge and expertise required for better opportunity identification. As discussed in Section 3.3.2.2 of Chapter 3, entrepreneurs that have developed a business expertise will have the ability to put together seemingly unrelated information that cannot be properly grasped by novice entrepreneurs, and might be able to identify (and potentially implement successfully) more innovative opportunities. Despite this initial positive relationship, there might be a point in which experience becomes path-dependent and lock-in effects might take place. Ucbasaran et al. (2009) argues that path dependency on prior experience might introduce biases in the entrepreneur's decision because of thinking that enough is known, inferring too much from limited information, becoming constrained by the familiar, becoming overconfident and so on. So at some point the entrepreneur 
will face difficulties on finding new opportunities and eventually its innovativeness will be affected by this path-dependency on prior experience, and the firm will become less innovative as well. Their results using a sample of entrepreneurs for Great Britain show that in fact there is an inverted U-shape relationship between prior business ownership experience and opportunity identification. But the innovativeness of the last opportunity found does not decrease with experience, suggesting that experience is positively related to innovativeness, which is also supported by Robson et al. (2011) using a sample of firms from Ghana.

Furthermore, former employee condition can be also considered as an experience that may be useful to successfully run an innovative business as they are likely to develop tacit knowledge about the industry and accumulate some relevant social capital that may come up useful later on. Hellmann (2007) argues that employees of established companies turn out to be one of the most important sources of entrepreneurship. He develops a theoretical model in which employees-turnedentrepreneurs might be the result of two situations. One that he calls stubborn equilibrium, in which the firm refuses to turn any innovative idea of an employee into an intrapreneurship and the employee, which has poor prospects of its work in the company, finally decides to leave to implement his or her new idea through a new business. And the other one, that he calls entrepreneurial equilibrium, in which the firm encourages innovative ideas of its employees through start-ups (if the employee owns the intellectual property of the idea) or spin-offs (if the firm firm owns the IP). Even though it is not possible to differentiate between both situations with the data at hand, it is believed that prior condition of employee gives the entrepreneur a tacit knowledge about how a firm is organized and managed, about unfulfilled needs and unexploited opportunities within the sector and also access to the network of suppliers and customers. Supporting this view, Romero and Martínez-Román (2011) find that the prior condition of employee is a major determinant of innovation in small Andalusian firms, irrespective of the sector the experience was obtained.

The educational background of the entrepreneur is an important source of skills, knowledge, networks and problem-solving abilities, and it is considered a key aspect of entrepreneurial success. Furthermore, the literature finds that firms owned by more educated entrepreneurs have a higher likelihood of innovating (de Mel et al., 2009; Romero and Martínez-Román, 2011). But Lazear (2005) argues that entrepreneurs are jacks-of-all-trades who may not excel in one skill, but are competent in many. This implies that individuals with balanced skills are more likely to become successful entrepreneurs. In line with this, higher 
educational levels are expected to be more conducive to innovation, but only until some level. For example, it is not expected that having a doctorate degree is necessarily more conducive to entrepreneurship and innovative success, since a $\mathrm{PhD}$ is typically an expert in a very specific area and probably fails to develop the balanced skills that are required to manage a business.

\subsubsection{Research questions and hypothesis}

Based on the previous discussion the research questions explored in this Chapter are: Do entrepreneurial motivations and skills have a direct effect on firm innovation propensity? and if so, Is there a specific entrepreneurial profile that makes firms more innovative?. The hypothesis is that intrinsically motivated entrepreneurs (see definition in section 4.3.2.1), which resemble the Schumpeterian entrepreneur described in section 4.2.1, are more prone to pursue innovative businesses.

In the analysis I will also take into account firm characteristics. There is an extended literature, both theoretical and empirical, on determinants of firm innovation $^{5}$. A common finding in the literature is that size explains the propensity to innovate (not necessarily intensity). Size is assumed to capture access of firms to capabilities and resources required for innovation (financial, human, technical and so on), so I expect that larger firms will have a higher propensity to innovate than smaller firms. Sector dummies, which capture the context in which the business is embedded in is also expected to determine firm innovation. In particular it is expected to capture the differences in technological opportunities and market concentration. Age of the firm, R\&D efforts and exporting activities are also typically considered as factors determining firm innovation.

\subsection{Data}

\subsubsection{The Longitudinal Enterprise Survey}

This study uses the second wave of the Longitudinal Enterprise Survey, ELE 2011, which collects information for the year 2009. The targeted population are formal firms that perform a productive, commercial or service activity within

\footnotetext{
${ }^{5}$ For a review on econometric evidence using Innovation Surveys see Mairesse and Mohnen (2010).
} 
territorial boundaries and whose sales in 2009 were at least UF800 ${ }^{6}$. The status of formality is given by the enrollment of the firm in the administrative records of the Tax Office (SII) and therefore are subject to pay taxes. The sample to be surveyed was obtained from the National Statistics Office Directory of Firms, which is built based on the administrative records of the SII and other internal directories of the INE.

The survey was designed using a stratified probabilistic sampling procedure with no replacement. Two strata were considered: economic activity (12 sectors) and size category (5 sales categories). The primary sampling unit is firms; large firms within each stratum were compulsory included in the sample ${ }^{7}$, while the rest were chosen through random sampling (INE, 2011). A proportion of $37.8 \%$ of firms were also included in the first wave of the survey and therefore is possible to build a small panel.

The ELE 2011 sample totals 7,062 firms (representing 2,83\% of the national population of firms) and is representative by economic activity (ISIC Rev. 3 at one digit level) and $\operatorname{size}^{8}$ (measured through sales ${ }^{9}$ ).

Through 5 modules, the survey collects the following information: Module 1: Finances and accounting; Module 2: Commercialization; Module 3: General management; Module 4: Human resources; and Module 5: Information technologies. In particular, Module 3 gathers information about the characteristics of the firm's general manager and/or owner, like age, gender, last level of education attained, main motivation to start the business, sources of funding for launching the start-up, prior business ownership experience, former employee condition, attitude towards employee condition, attitude towards business failure, among other characteristics. Some of these questions were directed only to the owner or partner of the firm, so whenever the general manager did not coincide with the owner or partner they were left unanswered.

Relying on the information obtained from Module 3, this paper uses the subsample of firms in the ELE 2011 for which there is available information on the characteristics of the entrepreneur behind the business. The operational definition

\footnotetext{
${ }^{6}$ The UF (Unidad de Fomento) is an accounting unit that is adjusted periodically by the inflation rate. The average value of the UF in December of 2009 was $\$ 20,989.80$ Chilean pesos according to the Tax Office website, or $€ 29$. Meaning that the sample included firms whose sales were higher than $€ 23 \mathrm{k}$ approximately.

${ }^{7}$ Large firms were censed, meaning a total of 326 firms compulsory included in the sample.

${ }^{8}$ Unlike the first wave of ELE (2009), the second wave did not include Micro 1 firms in the universe of analysis as a new survey specific for this firm segment was implemented.

${ }^{9}$ In Chile firm size is measured through yearly sales. The different size categories and their sales levels measured in euros of 2009 are the following: Micro 1: < 23k ; Micro 2: $€ 23 \mathrm{k}-€ 69 \mathrm{k}$; Small 1: €69k-€158k ; Small 2: €158k-€792k ; Medium: €792k-€3,167k ; Large: >€3,167k.
} 
of entrepreneur in this paper include "owners or partners who perform as general managers in the firm" because they are expected to exert higher influence on the decision making process. In addition to being general managers, firm owners and partners considered in this paper include only those that work full time in the business (meaning that those with full or part time jobs as employees are left out of the analysis) and that were 17 years or older when they started their business.

It is important to remark that even though the ELE was built with $30 \%$ of the sample as a panel, the firms that appear in both waves are mainly large firms ${ }^{10}$, which are left out from this study given that the influence of the entrepreneur's traits over firm decisions is expected to decrease with size. That is, in large firms the decision making process is typically shared between more persons, like the board of directors, and therefore the direct influence of the owner of the firm may be diluted. Therefore, the small panel sample resulting from merging both waves of the ELE was not useful for the purposes of this paper since it mainly includes large firms.

Limitations of the cross sectional dataset used in this paper include the impossibility to control for both unobservable heterogeneities and observable ones, like the firm's innovative background, i.e. whether the firm introduced innovations before 2009 or not. The latter prevents distinguishing novice from habitual innovators. A further limitation of the database relates to the fact that the survey does not collect information on the number of innovations introduced or the share of innovations in sales, which would allow studying the effect of entrepreneurial motivations on innovation intensity.

The effective sample of firms managed by entrepreneurs that fall into the previous definition totals 3,366. However, complete information on both firm and entrepreneurial characteristics is only available for 1,714 firms. Estimation of the motivation equation (see section 4.4) uses the total sample of entrepreneurs for which there is available information on their background characteristics (the 3,366 observations). While the innovation equation relies in the subsample for which there is available information on firms characteristics (the 1,714 observations).

\subsubsection{Variables}

\subsubsection{The motivation equation}

Four motivation categories to start a business are considered in this study. These were built using the answers that owners and partners provided when they

\footnotetext{
${ }^{10}$ Large firms are compulsory included in the sample of both waves.
} 
were asked to pick and rank from a list of reasons the three main motivations to start their current business activity. I use the motivations that were ranked in the first position. The list includes the following seven reasons: (1) family tradition or inheritance; (2) could not find a waged job; (3) I was fired; (4) to complement family income; (5) I found an opportunity in the market; (6) I wanted to organize my own business; (7) other reason. A follow-up question was asked whenever entrepreneurs answered that the main reason was "I wanted to organize my own business" so they were asked for the main reason for wanting this. The list includes the following reasons: (1) have more time flexibility; (2) make my own decisions/be my own boss; (3) have economic success; (4) I like assuming new challenges; (5) social commitment; (6) obtain the results of my work; (7) other reasons.

Using these two questions four motivations were built: (1) Roles, (2) Necessity, (3) Extrinsic and (4) Intrinsic. The "necessity" category was built by merging three reasons that are related to what the literature has defined as necessitydriven entrepreneurs (Reynolds et al., 2002). The "extrinsic" category was built by merging two reasons that are related to external factors affecting motivation drive. As for the "intrinsic" category, it was built by merging five reasons that are related to internal factors that resemble the Schumpeterian entrepreneurial profile described in Section 4.2.1. Table 4.1 below presents the reasons associated to each motivation category. The dependent variable is hence of a categorical type and captures the main drive that the owner or partner of the firm had to start the business.

Following Chapter 3, entrepreneurial motivations are explained by the following characteristics of the owner or partner of the firm: capital city; age; gender; education; prior professional experience; and prior business ownership experience (see definition of variables in Section 3.3.2.2 of Chapter 3).

\subsubsection{The innovation equation}

The dependent variable is of a binary type and captures firm innovation propensity. A broad indicator is built considering the implementation in 2009 of new or significantly improved (i) products (goods and services), (ii) processes, (iii) marketing methods and/or (iv) organizational methods. However, since the effects of firms' and entrepreneurs' characteristics might differ by type of innovation, the analysis also considers a narrower version of the indicator. This implies including only product and process innovations, which have been considered to be 
Table 4.1: Motivation categories

\begin{tabular}{llc}
\hline Main reason to start the business & $\begin{array}{l}\text { Main reason for wanting to or- } \\
\text { ganize your own business }\end{array}$ & $\begin{array}{l}\text { Motivation } \\
\text { category }\end{array}$ \\
\hline (1) Family tradition or inheritance & & Roles \\
\hline (2) Could not find a paid-job & & Necessity \\
\hline (3) I was dismissed from a waged job & Necessity \\
\hline (4) Complement family income & Necessity \\
\hline (5) Found a market opportunity & Extrinsic \\
\hline $\begin{array}{l}\text { (6) I wanted to organize my own busi- } \\
\text { ness }\end{array}$ & \\
\hline \multicolumn{2}{l}{ (6.1) Have more time flexibility } & Intrinsic \\
\hline & (6.2) Make my own decisions & Intrinsic \\
\hline & $(6.3)$ Achieve economic success & Extrinsic \\
\hline & (6.4) I like to take on new challenges & Intrinsic \\
\hline & (6.5) Social commitment & Intrinsic \\
\hline & (6.6) Obtain results of my own work & Intrinsic \\
\hline
\end{tabular}

more technology-intensive (OECD, 2005). Two dependent variables are therefore considered:

Overall innovation: Dummy variable that takes value $y_{i}=1$ if the $i_{\text {th }}$ firm introduced any type of innovation in 2009 (product, process, organizational or marketing innovation).

Technological innovation: Dummy variable that takes value $y_{i}=1$ if the $i_{t h}$ firm introduced a product or process innovation in 2009.

The explanatory variables included in the innovation equation include both entrepreneurial and firm traits. The literature based on innovation surveys has typically considered size, sector, market power and R\&D efforts as determinants of innovation propensity (Mairesse and Mohnen, 2010). A common finding regarding size is that larger firms, measured either as the level of total sales or employment, are more likely to innovate. Firm innovation dynamics are also considered to depend on the available technological opportunities faced by the firm in the sector in which it performs, known in the literature as the Schumpeterian "technology push" effect on innovation. This effect has been typically captured through sector dummies. Regarding the effect that market structure has over innovation, the literature has included different variables, like the Herfindahl index of industry concentration. And despite the fact that one may expect that dominant firms are more likely to be innovative because they have more to lose than newcomers by 
not innovating, the empirical evidence points towards mixed results. In contrast, $R \mathscr{G} D$ efforts, especially when performed on a continuous basis, are generally found to have a positive and significant effect over firm innovation propensity. Firm age has also been included as a proxy of the accumulated knowledge, or tacit knowledge, that a firm has accomplished along its life cycle, although results are also mixed and the direction of the effect is a priori ambiguous. Highly skilled labor within the firm, on the other hand, has been considered as a proxy of the technical capabilities a firm has to carry out innovations and a positive effect is expected. Export status has also been considered as a determinant of firm innovation given that exposure to international competition requires keeping high standards, which could act as an incentive for firms to invest in technology and innovate in order to meet the more rigorous requirements of external clients and remain internationally competitive. And despite the fact that there may be a double causality between exports and innovation, in the sense that because a firm innovates it is able to compete in international markets, the empirical literature available for a small economy like Chile has found that the effect goes from export to innovation status ${ }^{11}$.

The innovation equation includes both motivation and education as explanatory variables. I also control for the following firm characteristics (see also Table $4.2)$ :

Firm size: Continuous variable defined as the total number of employees in year 2009 (in logs). Size can also be captured through dummy variables according to the level of firm sales. However, a continuous variable was preferred for the analysis.

Exporter: Dummy variable that takes value 1 if the firm exported products or services in year 2009.

\footnotetext{
${ }^{11}$ Alvarez and Robertson (2004) study the effect of the exposure to foreign markets over plantlevel innovation in Chile and Mexico, distinguishing three mechanisms: exports, foreign investment and trade in intermediate inputs. Taking into consideration the potential problem of bicausality between foreign exposure and innovation by measuring all control variables at the beginning of the period, their results for Chile show a positive relationship between exports and technological innovation. However, they find that the effect of exports is not linear since the squared export term is negative and significant. This indicates that a higher ratio of exports to output increases the propensity to innovate, but at some level it decreases. This evidence may be consistent with the idea that plants more consolidated in the international markets require lower efforts in innovation to remaining competitive than plants that are in the first steps of the exporter process (Alvarez and Robertson, 2004). Furthermore, on a later paper, Alvarez and Garcia (2008) study whether innovation promotes exporting activities in Chilean manufacturing firms. They do not find evidence that product and process innovations affect the probability to export.
} 
Firm age: Continuous variable defined as the number of years since the firm formally initiated activities in the Tax Office (SII), meaning that the firm can be considered as "formal".

R\&D: Dummy variable that takes value 1 if the firm engaged in research and development activities (intra and/or extra mural) in 2009.

Skilled personnel: Continuous variable that captures the proportion of employees (in logs) with tertiary or more education over total employment.

Economic sector: The available information is at 1 digit level of the ISIC Rev. 3 so eleven sector dummies have been included; the base category is Manufacturing sector (Sector D).

Table 4.2: List of variables

\begin{tabular}{|c|c|c|}
\hline Var. name & Definition & Type \\
\hline \multicolumn{3}{|c|}{ A. Motivation equation: } \\
\hline \multicolumn{3}{|c|}{$\overline{\text { Dependent variable: }}$} \\
\hline motivation & Main reason to start the business: & $\begin{array}{l}\text { Categorical } \\
(4)\end{array}$ \\
\hline roles & Family tradition or inheritance of the business & \\
\hline necessity & $\begin{array}{l}\text { Did not find a job, dismissal or to complement family } \\
\text { income }\end{array}$ & \\
\hline extrinsic & Found a market opportunity or achieve economic success & \\
\hline intrinsic & $\begin{array}{l}\text { Time flexibility, make own decisions, take on new chal- } \\
\text { lenges, social commitment and obtain results of own work }\end{array}$ & \\
\hline \multicolumn{3}{|c|}{ Independent variables: } \\
\hline capital & 1 if from capital Santiago & Binary \\
\hline age_started & Age of individual when started activity & Continuous \\
\hline male & 1 if male & Binary \\
\hline education & Educational attainment: & $\begin{array}{l}\text { Categorical } \\
(6)\end{array}$ \\
\hline primary & 1 if primary or less education & \\
\hline secondary & 1 if secondary education & \\
\hline technical & 1 if technical education (CFT) & \\
\hline prof_institute & 1 if professional education (IP) & \\
\hline university & 1 if university (bachelor) education & \\
\hline graduate & 1 if graduate education & \\
\hline \multicolumn{2}{|c|}{ professional_exp1 if prior professional experience } & Binary \\
\hline business_exp & Number of business previously owned & Continuous \\
\hline
\end{tabular}

B. Innovation equation:

Dependent variable:

innovator $\quad 1$ if firm introduced any of the four types of innovation Binary

tech_inn $\quad 1$ if firm introduced product and/or process innovations Binary

Independent variables: 
... table 4.2 continued

\begin{tabular}{|c|c|c|}
\hline Var. name & Definition & Type \\
\hline motivation & Main reason to start the business (see above) & $\begin{array}{l}\text { Categorical } \\
\text { (4) }\end{array}$ \\
\hline education & Educational attainment (see above) & Categorical \\
\hline ln_size_emp & $\begin{array}{l}\text { Firm size, measured as the total number of employees (in } \\
\operatorname{logs})\end{array}$ & Continuous \\
\hline micro & 1 if firm is micro-sized, according to sales & Binary \\
\hline small & 1 if firm is small-sized, according to sales & Binary \\
\hline micro & 1 if firm is medium-sized, according to sales & Binary \\
\hline d_export & 1 if firm exported in 2009 & Binary \\
\hline age_firm & Number of years since firm initiated activities & Continuous \\
\hline d_RD & $\begin{array}{l}1 \text { if firm engaged in R\&D activities (intra- and/or extra- } \\
\text { mural) }\end{array}$ & Binary \\
\hline skilled & Proportion of employees with tertiary or more education & Continuous \\
\hline sector & Sector in which the firm performs its activities & $\begin{array}{l}\text { Categorical } \\
(12)\end{array}$ \\
\hline sector $A$ & 1 if sector A (Agriculture, hunting and forestry) & \\
\hline sector $B$ & 1 if sector B (Fishing) & \\
\hline sector $C$ & 1 if sector $\mathrm{C}$ (Mining and quarrying) & \\
\hline sector $D$ & 1 if sector D (Manufacturing) & \\
\hline sector $E$ & 1 if sector E (Electricity, gas and water supply) & \\
\hline sector $F$ & 1 if sector $\mathrm{F}$ (Construction) & \\
\hline sector $G$ & 1 if sector $\mathrm{G}$ (Wholesale and retail trade) & \\
\hline sector $H$ & 1 if sector $\mathrm{H}$ (Hotels and restaurants) & \\
\hline sector $I$ & 1 if sector I (Transport, storage and communications) & \\
\hline sector $J$ & 1 if sector $\mathrm{J}$ (Financial intermediation) & \\
\hline sector $K$ & 1 if sector $K$ (Real estate, renting and business activities) & \\
\hline sector $O$ & $\begin{array}{l}1 \text { if sector } \mathrm{O} \text { (Other community, social and pers. serv. } \\
\text { activ.) }\end{array}$ & \\
\hline
\end{tabular}

\subsubsection{Descriptive Statistics}

The descriptive statistics were calculated considering expansion factors and are presented in Table 4.3. Regarding the characteristics of the owner ${ }^{12}$, it can be observed that $33 \%$ of the business owners in the sample under analysis reported that they started their business motivated by "intrinsic" drivers, while $30 \%$ of them engaged in a business motivated by "extrinsic" ones. The rest were driven by "roles" (21\%) and "necessity" (16\%). This implies that the launch of the businesses under analysis was the result of a decision making process determined by different underlying motivations.

In terms of gender, the data shows that firms under study are more prone to be owned and managed by men: only $25 \%$ of firms are led by a woman. While

\footnotetext{
${ }^{12}$ It is important to remark that a firm may share its ownership between several partners. Therefore, when talking about owners I refer to both sole owners and partners. I also refer to them indistinctly as entrepreneurs.
} 
in terms of age, on average, business owners started their business in their early 40s, which coincides with the upper bound of the free-choice period (between 25 and 40 years old) where entrepreneurship is more likely to take place according to Martin (1984).

In terms of education, $44 \%$ of the population of business owners reached only secondary level while another $30 \%$ accomplished a bachelor degree. A quick look at the descriptive statistics suggests that two types of owners can be distinguished: those that have pursued more than the mandatory level of secondary education, which includes those with tertiary or more education attainment (i.e. technical, professional institute, bachelor and graduate levels) which totals 45\%; and those who have attained secondary or less education levels.

Regarding prior experience, half of the owners have worked as employees before. This is consistent with the life cycle of an individual who starts labor life at middle-twenties as an employee and starts gaining progressive experience until he is faced to a triggering event conducive to entrepreneurship. In terms of prior business ownership experience, $52 \%$ of owners have had a prior experience in entrepreneurship, with an average number of 2 prior businesses (or 1 if we consider also novice entrepreneurs, that is, those that did not have prior business ownership experience). One may expect that this subset of the population may have acquired some tacit knowledge on how a businesses is managed and on how markets work. They may also have developed a social network that proves useful to the business ${ }^{13}$.

When considering the subsample for which complete information on both firm and entrepreneurial characteristics is available (1,714 observations), it can be observed that half of the businesses introduced an innovation in 2009, while $38 \%$ introduced a technological innovation. The average age of the firm is 12 years old, meaning the average firm in the sample does not fall under the category of young startups. A small proportion of them export (4\%) while $10 \%$ has been engaged in $R \& D$ activities. The average share of high skilled labor on total employment is $20 \%$. The sample is composed of $42 \%$ micro-sized firms, $49 \%$ small-sized firms and $9 \%$ medium-sized ${ }^{14}$. These proportions suggests a slight bias toward smaller firms since the distribution of the national firm population by size in 2009, when leaving aside large firms, was: $7 \%$ medium-sized firms, $24 \%$ small-sized firms and $70 \%$ micro-sized firms.

\footnotetext{
${ }^{13}$ See Chapter 5 for a discussion on the role of prior experience and the development of social networks key to the performance of the venture.

${ }^{14}$ Large firms are not included in the analysis, as explained in section 4.3 .1
} 
Table 4.3: Descriptive statistics

\begin{tabular}{|c|c|c|c|c|c|}
\hline Variable & Mean & Std. Dev. & Min. & Max. & $\mathbf{N}$ \\
\hline roles & 0.21 & 0.41 & 0 & 1 & 3366 \\
\hline necessity & 0.16 & 0.37 & 0 & 1 & 3366 \\
\hline extrinsic & 0.30 & 0.46 & 0 & 1 & 3366 \\
\hline intrinsic & 0.33 & 0.47 & 0 & 1 & 3366 \\
\hline RM & 0.43 & 0.49 & 0 & 1 & 3366 \\
\hline age_started & 40.56 & 10.77 & 17 & 83 & 3366 \\
\hline gender & 0.75 & 0.43 & 0 & 1 & 3366 \\
\hline primary_less & 0.11 & 0.32 & 0 & 1 & 3366 \\
\hline secondary & 0.44 & 0.50 & 0 & 1 & 3366 \\
\hline CFT & 0.04 & 0.19 & 0 & 1 & 3366 \\
\hline IP & 0.09 & 0.28 & 0 & 1 & 3366 \\
\hline university & 0.30 & 0.46 & 0 & 1 & 3366 \\
\hline graduate & 0.02 & 0.15 & 0 & 1 & 3366 \\
\hline prior_employee & 0.51 & 0.50 & 0 & 1 & 3366 \\
\hline business_exp & 1.1 & 1.87 & 0 & 85 & 3366 \\
\hline innovator & 0.53 & 0.50 & 0 & 1 & 1714 \\
\hline tech_inn & 0.38 & 0.49 & 0 & 1 & 1714 \\
\hline ln_size_emp & 1.71 & 1.27 & 0 & 8.22 & 1714 \\
\hline micro & 0.42 & 0.49 & 0 & 1 & 1714 \\
\hline small & 0.49 & 0.50 & 0 & 1 & 1714 \\
\hline medium & 0.09 & 0.29 & 0 & 1 & 1714 \\
\hline d_export & 0.04 & 0.20 & 0 & 1 & 1714 \\
\hline age_firm & 11.76 & 7.61 & 1 & 60 & 1714 \\
\hline d_RD & 0.10 & 0.30 & 0 & 1 & 1714 \\
\hline skilled & 0.20 & 0.31 & 0 & 1 & 1714 \\
\hline sector_A & 0.12 & 0.32 & 0 & 1 & 1714 \\
\hline sector_B & 0.01 & 0.07 & 0 & 1 & 1714 \\
\hline sector_C & 0.01 & 0.08 & 0 & 1 & 1714 \\
\hline sector_D & 0.15 & 0.36 & 0 & 1 & 1714 \\
\hline sector_E & 0.00 & 0.01 & 0 & 1 & 1714 \\
\hline sector_F & 0.10 & 0.30 & 0 & 1 & 1714 \\
\hline sector_G & 0.29 & 0.46 & 0 & 1 & 1714 \\
\hline sector_H & 0.05 & 0.21 & 0 & 1 & 1714 \\
\hline sector_I & 0.09 & 0.29 & 0 & 1 & 1714 \\
\hline sector_J & 0.00 & 0.03 & 0 & 1 & 1714 \\
\hline sector_K & 0.15 & 0.36 & 0 & 1 & 1714 \\
\hline sector_O & 0.04 & 0.20 & 0 & 1 & 1714 \\
\hline
\end{tabular}

\subsection{Methodology}

This paper focuses on how firm innovation propensity is related to entrepreneurial motivation and education, controlling for the usual explanatory variables that determine firm innovation propensity. Since motivation is expected to be correlated with the error term through unobservable variables that may be determining 
both the propensity of a firm to innovate and the motivation to start the business (i.e. personality traits), I estimate simultaneously two equations: one for entrepreneurial motivation and one for innovation propensity. The former equation involves estimating a multinomial probit while the latter one involves estimating a probit model.

\subsubsection{The motivation equation}

As discussed in Chapter 3, the underlying motivations of entrepreneurs to launch a new venture differ between them, which stems from the fact that the population under study is of a heterogeneous nature. Motivation can then be modeled as a function of a set of observable characteristics of the entrepreneur. Therefore, a vector $\mathbf{x}$ of individual characteristics is assumed to determine the motivation category chosen by individuals. The dependent variable $y$ captures the main reason for motivated individuals to start a business activity, thus it can take any value $j$ where $j=1, \ldots, 4$. The probability that motivation $j$ is chosen by an individual $i$ is given by $p_{i j}=\operatorname{Pr}\left[y_{i}=j \mid \mathbf{x}_{i}\right]$, where $j=1, \ldots, 4$. The categorical nature of the dependent variable can be modeled through a Multinomial Probit (MNP).

As opposed to Multinomial Logit (MNL) models, MNP models allow for correlation across choices through the unobserved component which requires to work with normally distributed error terms. This means that in a $m$-choice multinomial model, utility of choice $j^{\text {th }}$ is given by $U_{j}=V_{j}+\varepsilon_{j}$ with $j=1,2, \ldots, m$, where the errors are assumed to be joint normally distributed, with $\varepsilon \sim \mathcal{N}[\mathbf{0}, \boldsymbol{\Sigma}]$ and the $m \times 1$ vector $\varepsilon=\left[\varepsilon_{1} \ldots \varepsilon_{2}\right]^{\prime}$. Allowing correlation across errors implies allowing some of the off-diagonal entries in the covariance matrix $\Sigma$ to be nonzero. Restrictions on $\Sigma$ are required to ensure identification, which implies considering the difference $U_{j}-U_{1}$ between utility of alternative $j$ and that of alternative 1 as a benchmark alternative.

Estimation of MNP models is done preferably by Maximum Likelihood and requires to calculate $(m-1)$-fold integrals making it more challenging than the estimation of a MNL model. Cameron and Trivedi (2005b) assert that a trivariate normal integral is the limit for numerical methods, limiting standard numerical integration methods to a four-choice MNP model (Cameron and Trivedi, 2005b, p. 518 ), hence the four motivation categories considered in the motivation equation. 


\subsubsection{The innovation equation}

Innovation propensity is modeled through a binary variable $y_{i}$ that captures if the firm $i$ introduced an innovation in 2009 or not. The observed binary outcome $y_{i}$ can be interpreted as the result of a latent process through which the firm evaluates its decision to innovate. Let $y_{i}^{*}$ be a continuous unobservable variable that depends on a vector of covariates $\mathbf{x}_{\mathbf{i}}$ and a normally distributed error term $u_{i}$. The vector of covariates $\mathbf{x}_{\mathbf{i}}$ include firm characteristics $w_{i}$, entrepreneurial motivations $m_{i}$, as previously modeled in 4.4.1, and the education level $s_{i}$ of the owner or partner of the firm.

$$
\begin{aligned}
& y_{i}^{*}=\mathbf{x}_{\mathbf{i}}^{\prime} \boldsymbol{\beta}+u_{i} \\
& y_{i}^{*}=m_{i}^{\prime} \beta^{m}+s_{i}^{\prime} \beta^{s}+w_{i}^{\prime} \beta^{w}+u_{i}
\end{aligned}
$$

And although $y_{i}^{*}$ is not observable, we do observe if the firm innovated or not:

$$
y_{i}= \begin{cases}1 & \text { if } y_{i}^{*}>0 \rightarrow \text { the firm introduced an innovation in } 2009 \\ 0 & \text { if } y_{i}^{*} \leq 0 \rightarrow \text { otherwise }\end{cases}
$$

The probability that a firm $i$ innovates is then given by

$$
\begin{aligned}
p_{i}=\operatorname{Pr}\left[y_{i}=1 \mid \mathbf{x}\right] & =\operatorname{Pr}\left[\mathbf{x}_{\mathbf{i}}^{\prime} \boldsymbol{\beta}+u_{i}>0 \mid \mathbf{x}\right] \\
& =\operatorname{Pr}\left[-u_{i}<\mathbf{x}_{\mathbf{i}}{ }^{\prime} \boldsymbol{\beta} \mid \mathbf{x}\right] \\
& \left.=\Phi\left(\mathbf{x}^{\prime} \beta\right)\right)
\end{aligned}
$$

where $\Phi\left(\mathbf{x}^{\prime} \beta\right)$ is the standard normal cumulative distribution function that defines a Probit model.

An important remark is that in Equation (4.1) the error term $u_{i}$ embodies all unobservable factors that determine the propensity that a firm introduces an innovation. Since in this paper firm innovation propensity is modeled as a function of the characteristics of the owner or partner that manages the business, then it is expected that $u_{i}$ may include unobservable factors that affect both $m_{i}$ and $y_{i}^{*}$. The consequence of this expected correlation between $m_{i}$ and $u_{i}$ is that the estimator for $\beta^{m}$ will be biased and inconsistent. To address this the motivation and innovation equation are estimated simultaneously through maximum likelihood taking into account the full covariance structure to obtain more efficient estimators (Roodman, 2011). This is done using the Stata [cmp] command developed by Roodman (2011). 


\subsection{Results}

The results of the simultaneous estimation of the innovation and motivation equations show that the correlation between the error terms of both equations is not statistically significant at the usual levels (see p-values of the atanhrhos in Table 4.4). This means that an unbiased and a consistent estimator can be obtained directly from estimating the innovation equation. Therefore, the following discussion of results will rely on the probit estimation of this equation.

For information purposes the results of the motivation equation have been reported in Appendix B and a comparison with the results in Chapter 3 is presented (although different datasets are used in each Chapter, so comparisons should be made with caution).

Table 4.4: Error correlation between the motivation and innovation equation

\begin{tabular}{lcccccc} 
Variable & Coef. & Std. Err. & $\mathrm{z}$ & $P>|z|$ & \multicolumn{2}{c}{$[95 \%$ Conf.Interval $]$} \\
\hline \hline atanhrho_13 & 0.3165763 & 0.2182951 & 1.45 & 0.147 & -0.1112743 & 0.7444269 \\
atanhrho_14 & -0.0349566 & 0.399346 & -0.09 & 0.930 & -0.8176604 & 0.7477472 \\
atanhrho_15 & -0.3977657 & 0.2175138 & -1.83 & 0.067 & -0.8240849 & 0.0285535 \\
\hline rho_13 & 0.3064079 & 0.1978003 & & & -0.1108173 & 0.6318123 \\
rho_14 & -0.0349424 & 0.3988584 & & & -0.6737944 & 0.633803 \\
rho_15 & -0.3780356 & 0.1864287 & & & -0.6772871 & 0.0285457 \\
\hline
\end{tabular}

Note: Equation 1 is the innovation equation. Equations 2 to 5 represent the four equations of the multinomial probit related to the motivation equation, one per motivation category. The first motivation category (Roles) is represented by equation 2 and is used as the base category. Therefore, correlation is tested between equation 1 and the third, fourth and fifth equations, representing Necessity, Extrinsic and Intrinsic motivation categories. So, for example, the atanhrho_13 representes the correlation between the error terms of the innovation equation and the equation of the second motivation category, Necessity.

Table 4.5 reports the average marginal effects after the probit estimation of the innovation equation, which give the magnitude of the average effect of each variable on the propensity that a firm introduces an innovation (see list of variables in part B. of table 4.2). It is important to remark that the relationship between the regressors and the probability of innovating is non linear. The marginal effect for a continuous variable $x_{j}$ is given by $\partial p / \partial x_{j}=\phi\left(x^{\prime} \beta\right) \beta_{j}$ and for a dummy variable is $\partial p / \partial x_{j}=\Phi\left(x^{\prime} \beta\right)_{\left(x_{j}=1\right)}-\Phi\left(x^{\prime} \beta\right)_{\left(x_{j}=0\right)}$, interpreted as the change in the probability due to variable $x_{j}$ going from value 0 to 1 .

The results in column 1 of Table 4.5 show that, when compared to the base category of firms managed by 'extrinsically' motivated entrepreneurs, firms that 
are managed by 'intrinsically' motivated ones have, on average, a higher propensity to innovate of about 6 percentage points. The same holds for technological innovations (see column 2). No difference is observed between the base and the rest of the categories, 'roles' and 'necessity'.

Table 4.5: Innovation Equation: Average Marginal Effects

\begin{tabular}{|c|c|c|c|c|}
\hline Variables & $\begin{array}{c}(1) \\
\text { Innovator }\end{array}$ & $\begin{array}{l}(2) \\
(\mathrm{se})\end{array}$ & $\begin{array}{c}(3) \\
\text { Tech. Innovator }\end{array}$ & $\begin{array}{l}(4) \\
\text { (se) }\end{array}$ \\
\hline roles & -0.049 & $(0.033)$ & -0.046 & $(0.032)$ \\
\hline necessity & 0.036 & $(0.044)$ & 0.011 & $(0.044)$ \\
\hline intrinsic & $0.058 * *$ & $(0.029)$ & $0.055^{*}$ & $(0.029)$ \\
\hline primary & -0.080 & $(0.054)$ & -0.051 & $(0.052)$ \\
\hline technical & -0.042 & $(0.065)$ & 0.043 & $(0.064)$ \\
\hline prof_institute & -0.044 & $(0.043)$ & -0.008 & $(0.042)$ \\
\hline university & $0.083^{* * *}$ & $(0.031)$ & $0.059^{* *}$ & $(0.030)$ \\
\hline graduate & $0.157^{* *}$ & $(0.063)$ & $0.108^{*}$ & $(0.065)$ \\
\hline ln_size_emp & $0.017^{*}$ & $(0.010)$ & $0.023^{* *}$ & $(0.009)$ \\
\hline d_export & 0.024 & $(0.050)$ & $0.090^{*}$ & $(0.047)$ \\
\hline age_firm & $-0.003^{* *}$ & $(0.002)$ & -0.001 & $(0.002)$ \\
\hline d_RD & $0.081^{* *}$ & $(0.035)$ & $0.131^{* * *}$ & $(0.034)$ \\
\hline skilled & 0.018 & $(0.050)$ & 0.015 & $(0.050)$ \\
\hline sector A & -0.047 & $(0.053)$ & -0.075 & $(0.054)$ \\
\hline sector B & $-0.178 * * *$ & $(0.065)$ & $-0.150 * *$ & $(0.063)$ \\
\hline sector $\mathrm{C}$ & $-0.110^{*}$ & $(0.059)$ & $-0.105^{*}$ & $(0.058)$ \\
\hline sector E & -0.294 & $(0.279)$ & -0.229 & $(0.260)$ \\
\hline sector F & $-0.155^{* * *}$ & $(0.047)$ & $-0.155^{* * *}$ & $(0.046)$ \\
\hline sector $\mathrm{G}$ & -0.017 & $(0.043)$ & -0.040 & $(0.044)$ \\
\hline sector $\mathrm{H}$ & -0.019 & $(0.046)$ & -0.029 & $(0.047)$ \\
\hline sector I & $-0.107^{* *}$ & $(0.048)$ & $-0.105^{* *}$ & $(0.048)$ \\
\hline sector J & -0.030 & $(0.137)$ & $-0.217^{*}$ & $(0.121)$ \\
\hline sector K & $-0.113^{* *}$ & $(0.049)$ & $-0.114^{* *}$ & $(0.048)$ \\
\hline sector O & -0.079 & $(0.058)$ & -0.043 & $(0.058)$ \\
\hline Observations & 1,714 & & 1,714 & \\
\hline
\end{tabular}

The effect of 'intrinsically' motivated entrepreneurs on firm innovation holds once the educational background of the entrepreneur has been controlled for. From the results discussed in Chapter 3 and the results from the motivation equation discussed in Appendix B, we know that higher educational attainment is related to the propensity to be an 'intrinsically-driven' entrepreneur. So one may expect that due to the positive correlation between the two variables, one of 
them would not be significant in the innovation equation. This may happen if the effect of education over firm innovation propensity was only indirect through the effect it has on motivation. However, the fact that both education and 'intrinsic' motivation have a positive and statistically significant effect over firm innovation means that education plays two roles in determining firm innovation: one is its effect over the type of motivation that drives an entrepreneur to pursue the launch of its business, and the other one is the direct effect it has over the performance of the firm, in terms of the propensity to be innovative.

As discussed in Chapter 3, not all entrepreneurs are the same as they have different entrepreneurial motivations that, according to the results in this Chapter, ultimately affect the performance of the firms they manage. In fact, the results show that entrepreneurs who wanted to launch their businesses pulled by their need of autonomy and by the enjoyment of facing challenge and obtaining the outcome of their own effort were more likely to run innovative businesses. This is consistent with the literature on personality traits, who argues that entrepreneurs are characterized by their need for achievement, self efficacy and internal locus of control ${ }^{15}$. This also coincides with the Schumpeterian profile of entrepreneurs, who have the will to conquer, the impulse to prove themselves superior to others, to succeed for the sake of it and not for wealth. The Schumpeterian entrepreneur is characterized by the joy of creating and getting things done (see section 4.2.1). All these characteristics are related to the motivations included in the 'Intrinsic' category studied in this Chapter.

Regarding the effect of education, the results show that higher levels of education have a positive effect on firm innovation propensity for both overall and technological innovations, although the effect is slightly larger for the former category. An interesting result is that having attained a graduate level (master or $\mathrm{PhD}$ degree) doubles the effect of having a bachelor degree, in both models. For example, a business managed by an owner that has attained a bachelor degree increases the propensity that the firm introduces any innovation by 8 percentage points; while attaining a graduate level (master or $\mathrm{PhD}$ ) increases the probability of introducing an innovation by 16 percentage points.

Both entrepreneurial variables, education and motivation, have a statistically significant effect on firm innovation after controlling for firm characteristics, and their effect go in the expected direction. The positive effect of size is consistent with the literature, which suggests that larger firms are more prone to engage in

\footnotetext{
${ }^{15}$ See a review of personality traits of entrepreneurs in Rauch and Frese (2007) and Zhao et al. (2010).
} 
innovation activities. R\&D efforts also have the expected direction: engagement in R\&D activities increases the propensity of firm innovation, especially for technological innovation (as expected) where the effect is almost doubled, reaching an increase in the probability of 13 percentage points. Firm age seems to have a negative effect on overall innovation propensity, although the magnitude of the effect is negligible. This goes in line with the empirical literature where mixed effects are found.

A relevant question that emerges after the prior findings is how much the probability that a firm innovates varies after fixing the characteristics of the entrepreneur. To examine this an exercise was done using the estimated coefficients. Education and motivation were fixed to specific profiles and then the predicted probability was calculated by letting firm characteristics vary. Afterwards, its density distribution ${ }^{16}$ was plotted. The following set of graphs in Figure 4.1 show the variation in the probability of innovating due to firm characteristics for different entrepreneurial profiles.

The first graph in the upper left side of Figure 4.1 shows that the probability distribution slightly shifts to the right for firms that are managed by 'intrinsicallydriven' entrepreneurs. The same pattern is observed when analyzing how the probability distributions change for different educational levels. The graph in the upper right side shows that for graduate entrepreneurs the probability of innovating is always higher than $50 \%$. When combining both education and motivation characteristics, we can see that no matter what size the firm is, what R\&D profile it has or the sector it performs in, if the owner has graduate education and is 'intrinsically' motivated, the probability that the firm introduces an innovation (overall) is between $60 \%$ and $80 \%$. The next "virtuous" profile is an owner being 'intrinsically' motivated and having a bachelor degree. The less "virtuous" one is having low levels of education and pursuing a business due to family role models.

\subsection{Concluding remarks}

Understanding why firms go innovative needs to take into consideration both the heterogeneous nature of the firm and of the entrepreneur behind the business. This is important when it comes to the design of effective policy instruments as there is no such 'one-size-fits-all' in a heterogeneous context like this.

To better understand what makes firms go innovative we also need to understand who is behind the decision making process: the entrepreneur. Entrepreneurs

\footnotetext{
${ }^{16}$ The density function of the predicted probability was estimated using a epanechnikov density function and the default bandwidth.
} 
Figure 4.1: Probability of innovating according to different entrepreneurial profiles
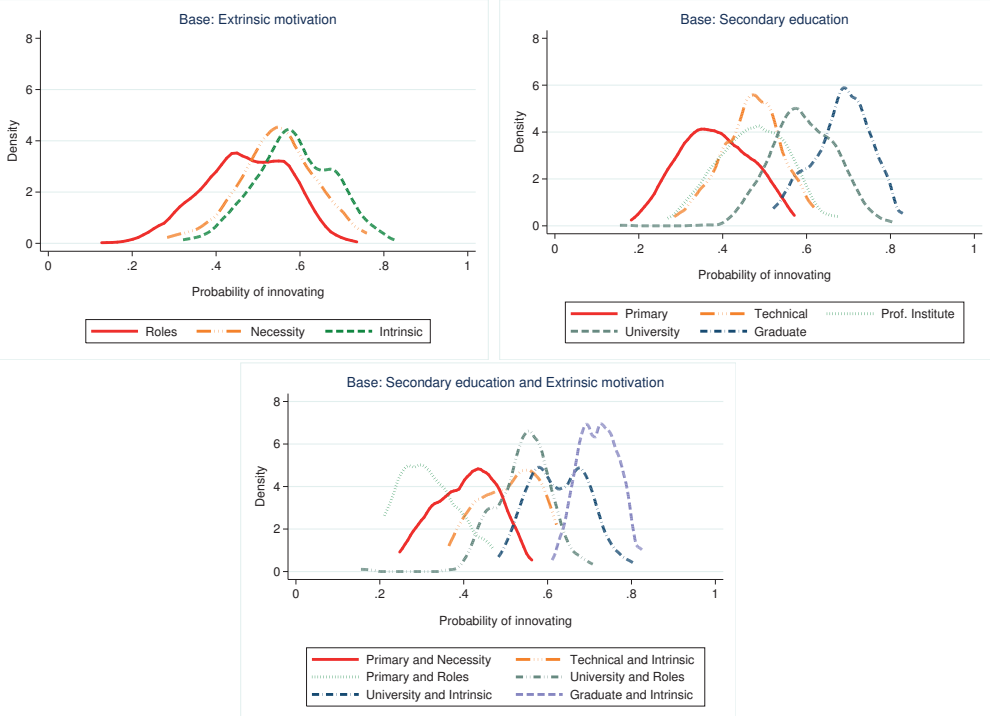

have different motivations to pursue the launch of a business, which implies different individual behaviors and subsequent firm performances (in interaction with the context in which the firm is embedded).

As discussed in Chapter 3, entrepreneurs have different backgrounds and are driven by different motivations which, according to the results in this Chapter, ultimately affect the performance of the firms they run, at least in terms of innovation engagement. The results of this research show that both entrepreneurial motivations and education attainment are important for explaining firm innovation propensity (even after controlling for firm characteristics) and consequently any attempt to understand what makes a firm go innovative needs to take into consideration who is behind the decision making process: the entrepreneur. In particular, different entrepreneurial motivations and educational backgrounds affect differently the propensity of a firm to introduce an innovation. That is, different entrepreneurial profiles, as determined by their motivations and education backgrounds, are related to different innovation propensities. This paper found that intrinsically motivated and highly educated entrepreneurs are more prone to have businesses that innovate. This intrinsically motivated individuals resemble the Schumpeterian entrepreneur discussed in section 4.2.1. Furthermore, in 
Chile, the Schumpeterian entrepreneur behind innovative firms seems to be highly educated.

An interesting result is that having a graduate degree doubles the probability of innovating (16 percentage points) compared to having a bachelor degree (8 percentage points). These results somehow go against Lazear's theory that entrepreneurs must be jacks-of-all-trades who need not excel in any one skill but to be competent in many. Notwithstanding, in a country like Chile that exhibits high levels of inequality that determine the access to quality education, having a graduate degree may be a proxy for other unobservable factors that may be relevant for, or act as enablers of, firm innovation, like a better socio-economic background and/or a larger, more diversified and high quality social networks. This relationship between education and the 'quality' of social networks, in terms of their influence on firm behavior and performance, will be addressed in Chapter 5 .

This study has aimed to make a contribution by enlarging the empirical evidence on the relationship between firm innovation propensity and entrepreneurial traits. However, this work still suffers from limitations coming from the crosssectional nature of our data. First, endogeneity problems are always present in this setting given that some variables are simultaneously determined. If suitable instruments are not available, solving endogeneity problems becomes very difficult, and we are left exposed to inconsistent estimators. This is the main reason why other controls were not included, like export status, certification and other firm characteristics (although the information is available). Furthermore, simultaneity issues makes it difficult to make statements about directions of causality, so we are just able to identify relationships. Finally, with a cross sectional dataset we are not able to study the dynamics of the firm, which is key to understand firm behavior. 



\section{Chapter 5}

\section{Understanding the emergence of innovative entrepreneurship}

\subsection{Introduction}

The main objective of this Chapter is to understand why and how the complex process of innovative entrepreneurship emerges in Chile. It starts from the fact that the process is triggered by a particular type of entrepreneur that has somehow devised a new business idea that has the potential of having a high economic impact and decides to take action to put it in the market despite the uncertainty involved. The decision to take action can be driven by different motivations and the means through which the innovative idea is introduced in the market is by pursuing the founding of a startup.

The process of launching a startup is shaped by internal and external factors to the entrepreneur. The former ones are related to the characteristics of the entrepreneur or the founding team, in terms of personality traits, motivations and skills. The interaction of these unobservable factors determines the behavior and strategic decisions made by the entrepreneur, which ultimately determine the type of business outcome achieved (Wasserman, 2012, Ch. 1). On the other hand, external factors are related to the ecosystem in which the process of innovative entrepreneurship occurs.

But studying why and how innovative entrepreneurship arises is extremely challenging because it is shaped by many unobservable factors that interact permanently to determine the emergence and evolution of a business venture. And it all starts with the intriguing figure of the entrepreneur: who they are in terms of their life background, personality traits and skills; what motivated them to decide to engage in an activity that in most cases is doomed to fail; what tools 
and resources they had, or lacked, to pursue the launch of their venture; and who they relied on to help them in the process. These inquiries, among others, need to be addressed in order to have a better understanding of why and how innovative entrepreneurship emerges.

In Chapters 3 and 4 I partly addressed these questions following a quantitative approach. I analyzed how observable individual traits relate to entrepreneurial motivations (Chapter 3) and how these relate to innovative ventures (Chapter 4). The results showed that although entrepreneurs are driven by different motivations, those that started their ventures driven by intrinsic motives are somewhat more prone to manage innovative businesses, resembling the Schumpeterian entrepreneurial profile. Also, firms founded by highly educated entrepreneurs are more prone to introduce innovations. At the same time, entrepreneurs driven by intrinsic motives tend to be highly skilled, defined as a combination of high educational attainment (formal human capital) and prior experience (informal human capital).

Still, there are many questions that remain unanswered and are difficult to address from a quantitative approach. For example, how do we interpret the result that education is important for innovative entrepreneurship in Chile? Is it just formal knowledge that matters, or is it representing something else? What background characteristics determine entrepreneurial activity? How personality traits, skills and motivations interact to shape entrepreneurial behavior? All of these inquiries that deal with rather unobservable factors are better addressed through a qualitative approach. Therefore, in this Chapter I aim to complement the results I obtained in the previous two Chapters, in order to have a better picture of why and how innovative entrepreneurship emerges in Chile.

\subsection{Conceptual framework and research questions}

The process of innovative entrepreneurship can be understood as a highly complex and nonlinear phenomenon (Aldrich and Ruef, 2006), in which the interaction between different factors explains the emergence and evolution of a new company. Its complex nature means that the outcome we observe cannot be inferred directly from the characteristics of these factors separately. Alternatively, the outcome, which adapts and evolves through time, is the result of the interaction between different factors that produce emergent properties at a higher level ${ }^{1}$.

\footnotetext{
${ }^{1}$ See Aldrich and Ruef (2006) and Aldrich (2011) for an evolutionary approach to the study of entrepreneurship.
} 
At the center of this process we find an individual who has devised an innovative idea and interacts with the environment in the quest of transforming this idea into a business that is valued by the market. The individual, or entrepreneur, is therefore regarded as a necessary condition for innovative entrepreneurship to emerge, because the innovative idea is embedded in the entrepreneur.

Following the conceptual framework described in Chapter 3, based on the model of Herron and Robinson (1993), this study starts from the individual behind the startup and attempts to understand why and how the process of innovative entrepreneurship emerges. It starts from the fact that the outcome we observe is partly a consequence of individual capabilities, personality traits, motivations, circumstances at birth and also the little twists and turns of fate at the individual level. All these unobservable factors combined explain the particular path followed by an individual towards entrepreneurship. And these factors, in interaction with the environment under which the entrepreneurial process occurs, determine the decisions that entrepreneurs make and the actions they take, which ultimately determine the evolution of the business they pursue. Therefore, despite the fact that innovative entrepreneurship is uncertain by nature, this does not mean that the outcome of the entrepreneurial process is subject to randomness. The outcome we observe is the consequence of specific dynamics within a given ecosystem, which explain the path followed. The key of these dynamics is that small differences at one point can lead to major differences down the road (path dependency). For example, access to a key social connection may open a door unavailable to other entrepreneurs and may put one in a better off position. Hence, outcomes between both entrepreneurs may end up diverging.

From this standpoint, the research question this Chapter aims at answering is Why and how innovative startups emerge? Addressing this question entails facing the challenge of dealing with unobservable factors, which precludes the use of quantitative tools. For example, the entrepreneur itself is a key factor that closely influences the emergence of innovative startups, but the personality traits, motivations and life experiences that drive the entrepreneur to pursue the launch of a venture are unobservable factors that are not easily quantifiable, let alone the social capital involved along the process of orchestrating resources to set up a new venture. Also, key external factors or events that significantly shaped the path followed by the business cannot be clearly identified from a quantitative approach. The way these factors impact the business depend on how the entrepreneur deals with them, emphasizing the importance of interactions. 
Therefore, understanding the 'black box' of emerging innovative startups is probably better addressed from a qualitative approach. This way, the richness of this latent process can be better grasped. A set of topics that allow addressing the research question presented above were initially defined and then used as guidelines to conduct a collection of in-depth interviews to entrepreneurs and other relevant interviewees. The methodology used to collect information is described in the next section. The topics covered and the related research questions to be answered are described below.

- Background of the entrepreneur. Background traits of the entrepreneur like educational attainment, prior experience and interaction with role models, exert influence on the process of founding a startup. How these traits influence the emergence process of an innovative startup? How do they influence entrepreneurial behavior (type of decisions made and actions taken)?

- Personality of the entrepreneur. What are the main personality traits associated to innovative entrepreneurs? How do these personality traits influence entrepreneurial motivations? What type of behaviors are associated to particular personality traits in the particular context of founding an innovative startup?

- Entrepreneurial motivations. What triggered an individual to take action and turn an innovative business idea into a startup? How own life experiences, personality, social connections and external factors relate to the main motivation that led an entrepreneur to found an innovative business venture?

- Social capital. Which type of actors within the social network of the core founders were especially important to the emergence of startups? How did they influence the emergence process of the startup? In what dimension they became useful? (i.e. financial capital, emotional support, tacit knowledge, access to key social networks). What type of relationship did these actors have with the entrepreneurs?

\subsection{Methodology}

The research questions presented in the previous section are better answered using the approach of qualitative interviewing because it is mostly of the 'why' 
and 'how' type (Rubin and Rubin, 2005; Yin, 2009): This means that understanding the phenomenon under scrutiny requires that involved actors explain their answers, give examples and/or describe their experiences, especially if we are dealing with unobservable factors that explain the phenomenon under study. Through in-depth interviews it is possible to understand experiences and reconstruct events, which is not possible to accomplish through a quantitative approach. As Rubin and Rubin (2005, p. vii) suggest, "qualitative interviews have operated for us like night-version goggles, permitting us to see that which is not ordinarily on view and examine that which is often looked at but seldom seen".

Depth qualitative interviewing can be implemented through different approaches depending for example on how narrow or broad the questions are. If the goal is to get a general flavor of a specific phenomenon, then unstructured open-ended interviews should be carried out (broad approach). A narrower approach would advocate for more structured or semi-structured interviews.

The approach used in this study is the responsive interviewing model (RIM) proposed by Rubin and Rubin (2005), which rely heavily on the interpretive constructionist philosophy mixed with a bit of critical theory. This model of interview starts from the fact that in-depth interviewing research requires openness to new ideas not anticipated at the beginning, which is quite realistic when studying a complex phenomenon like innovative entrepreneurship. Consequently, the RIM is a flexible and adaptive approach, which does not mean that it is random or happen-stance; it just adapts to changing circumstances ${ }^{2}$. Therefore, the aim was to apply in-depth interviews to a set of key actors (entrepreneurs, general managers, directors of innovation project departments, among other key interviewees) from an innovative venture such that different perceptions could be contrasted and complemented.

It is important to clearly define what the study seeks to accomplish and how far it aims to be generalized. This study aims at understanding, from the perspective of the entrepreneur, why and how the complex process of innovative entrepreneurship emerges in Chile. This involves determining which combination of factors brought about the founding of startups that have the potential to have a market impact through their innovative business idea. A better understanding of the

\footnotetext{
${ }^{2}$ About the responsive interviewing model, Rubin and Rubin (2005) argue that 'The term responsive interviewing is intended to communicate that qualitative interviewing is a dynamic and iterative process, not a set of tools to be applied mechanically. (...) Responsive interviewers begin a project with a topic in mind but recognize that they will modify their questions to match the knowledge and interests of the interviewees. (...) Qualitative research is not simply learning about a topic, but also learning what is important to those being interviewed.' (Rubin and Rubin, 2005, p. 15).
} 
mechanisms that link cause and effect in the process of innovative entrepreneurship can contribute to identify key actions that can be taken to build a critical mass of innovative startups that can push towards the structural transformation of the Chilean economy. The aim is not to generalize to a specific population, but to contribute to the theory of entrepreneurship in a developing context. In the words of Bryman (2008, p. 391) "People interviewed in qualitative research are not meant to be representative of a population (...) Instead, the findings of qualitative research are to generalize a theory rather than to populations".

The unit of analysis are ventures that fall under the category of innovative entrepreneurship. The ventures were selected from the portfolio of companies supported by one or more of the following organizations: Austral Capital, Endeavor Chile and Fundación Chile.

Austral Capital is a venture capital firm founded in 2007 with contributions from the public and private sector. Public support came from the main public agency responsible for promoting entrepreneurship and innovation in the country, CORFO. The ratio of public to private contribution to the fund was $3: 1$. The US $\$ 45$ million fund managed by Austral Capital invested in 12 emerging companies that were in the stage of creation or expansion, had the potential to multiply their value significantly in a period of four to six years (the fund expires in 2017) and were expected to internationalize. The companies supported perform mainly in the sector of information technologies and have received investments that range from US $\$ 400$ thousand to US $\$ 5$ million, with an average investment of US $\$ 3.2$ million. ${ }^{3}$

Endeavor is a global non-profit organization that promotes high impact entrepreneurship in emerging markets. It was created in 1997 in the United States with the mission of promoting economic and social development through high impact entrepreneurship. To accomplish this, they cherry-pick entrepreneurs that have the potential to generate high impact through the ventures they pursue, and provide them with access to a network of mentors and specialized services, at the local and world level, to help them to scale up and internationalize. Endeavor was launched in Chile in 1998 and currently has three offices in the country, strategically located in different regions: one in the north, Endeavor Atacama; one in the capital, Endeavor Santiago; and one in the south, Endeavor Patagonia. Since 1998, Endeavor Chile has supported 139 high impact entrepreneurs from 83 selected companies; 46 of them have started another venture after being supported

\footnotetext{
${ }^{3}$ See more information in their website: www.australcap.com
} 
by Endeavor Chile. In 2014 firms supported by Endeavor Chile had a turnover of US\$802 million. ${ }^{4}$

Fundación Chile (FCh) is a non-for profit private organization created in 1976 with the mission of enhancing competitiveness in the Chilean economy through the introduction of high impact innovation in the productive sector. Through the model of technology transfer, FCh has created more than 65 companies in different productive sectors and has been a key actor in the emergence of dynamic sectors that have had an important impact in the economy, like the acquaculture sector. FCh is organized in five strategic areas, one of them being the entrepreneurship platform 'Emprende', which currently operates through a business accelerator, a business angels investors network (Chile Global Angels) and a corporate open innovation area. The business accelerator is currently supporting 25 high potential ventures in early stage phase, which altogether represent an investment of US $\$ 2.5$ million approximately. Ventures supported receive seed capital from CORFO for up to US\$85 thousand approximately (CLP \$60 million), supporting services, and access to networks and knowledge that is key for the development and success of the venture. ${ }^{5}$

The selection of ventures included in the analysis was made by the representative of each organization with which I established contact $^{6}$. Each representative was asked to pick between four to eight cases from the organization's portfolio according to the following criteria: (i) the business idea should be innovative; (ii) they should have varying performances; (iii) they should be in different stages of their life cycle; (iv) they should be established in different regions of Chile; and (iv) they should perform in different sectors. A total number of 28 ventures were initially selected by the representatives following these guidleines: 6 from Austral Capital; 6 from Endeavor Santiago; 8 from Fundación Chile; 4 from Endeavor Patagonia; and 4 from Endeavor Atacama.

The guidelines to select the cases aimed at having a sample as heterogeneous as possible to avoid problems of sample selection. Because, to understand which actions and decisions lead to successful startups in varying environments, researchers should cast as wide a net of startups as possible, beginning with even very modest and unlikely startup efforts (Aldrich and Ruef, 2006, p. 64).

\footnotetext{
${ }^{4}$ See more information in their website: www.endeavor.cl

${ }^{5}$ See more information in their website: www.fch.cl/emprende/

${ }^{6}$ I thank Gonzalo Miranda and Felipe Camposano from Austral Capital; Andrés Pesce from Fundación Chile; María de los Ángeles Romo and Francisca Moreno from Endeavor Santiago; Anette Krohn from Endeavor Patagonia; and José Manuel Correa from Endeavor Atacama for helping in the selection of ventures and for putting me in contact with the entrepreneurs.
} 
In spite of setting criteria that ensured diversity among the cases under study, the sample is still composed of companies that already exist, which implies that there is a sample selection towards those entrepreneurs that effectively founded a startup. This means that the analysis only considers entrepreneurs after they have founded their startups, meaning that the pre-founding stage is missing. With this in mind I tried to collect as much information as possible about the pre-founding process, such that at least I can identify some patterns that led to the act of founding.

For each venture I aimed to interview at least two people, prioritizing founders. I also tried to include general managers, angel investors or venture capitalists involved in the venture. A venture was included in the analysis if: (i) at least one entrepreneur from the founding team was successfully interviewed; and (ii) at least two interviews per venture were successfully made. The minimum of two interviews per venture aimed at contrasting answers to the same question. For example, when asked about the personality traits of the entrepreneur behind the business idea, it was possible to contrast the self-assessment of the entrepreneur with the opinion of another person.

Interviews were conducted in person ${ }^{7}$ during the months of June and July of 2013 in four cities of Chile: Antofagasta, Santiago, Puerto Varas and Puerto Montt $^{8}$. The interviews were recorded in agreement with the interviewee and it was established at the beginning of the conversation that the information provided by the person was going to be used with the sole purpose of research. The average length of the interview was 1.5 hours and generally took place in the office of the company.

\subsection{Data}

A total number of 16 companies fulfilled the inclusion criteria described above. A total number of 47 interviews were analyzed, which include 22 interviews to founders. The rest of the interviewees were co-founders, employees, angel investors or venture capital investors. The complete list of interviewees can be found in Table C.1 in the Appendix.

The main characteristics of the sixteen innovative ventures under analysis are presented below in Table 5.1. They are mainly focused on the supply of

\footnotetext{
${ }^{7}$ Couple of interviews were carried out by Skype given that the founder was located outside Chile.

${ }^{8} \mathrm{I}$ am grateful to Austral Capital for financing fieldwork expenses in Chile and by providing me with office space during this period.
} 
technological products and services to different sectors of the economy, mainly mining, retail and aquaculture.

Area: More than half of the cases provide IT services, serving mainly the retail and mining sectors. The sample also includes two biotechnology startups, one focused on human health and the other one on animal health. The others provide products and services based on the application of robotics, metallurgy, naval engineering and solar energy.

Founding year: All ventures were in different development stages when they were interviewed in 2013: four of them were 5 years old or less; seven were between 6 and 8 years old; and the remaining ones were 13 years old or more.

Location: More than half of the cases are located in the capital Santiago while the rest are distributed between the north (3 cases) and the south of the country (2 cases).

Access to smart money: Most ventures located in Santiago had access to smart money (either an angel investor or a venture capitalist). This does not hold for the regional ventures.

Buyout: By the time the interviews were conducted three of the ventures in the IT sector had gone through the process of buyout: one was sold at year 2.5 for 10 times the initial value; another one at year 4 for 36 times; and the last one at year 9 in 4 to 5 times the initial value.

All these companies can be considered as good examples of companies that have a high potential to positively impact the sector in which they perform. For example, Andes Biotechnologies, founded in 2008, is a bio-entrepreneurship that is researching and developing an innovative and effective treatment against cancer. This is a fascinating case since it has the potential to revolutionize health world markets through the cure of cancer. A second bio-entrepreneurship launched in 2011 is ActivaQ, which is the second venture launched by two women scientists, who can now be considered as serial bio-entrepreneurs. Their R\&D-based company applies last generation biotherapeutics for the veterinary industry, particularly in aquaculture. 
Table 5.1: List of companies under analysis

\begin{tabular}{|c|c|c|c|c|c|}
\hline Venture & Area & $\begin{array}{l}\text { Founding } \\
\text { year }\end{array}$ & Region & $\begin{array}{c}\text { Access to } \\
\text { smart } \\
\text { money? }\end{array}$ & Buyout? \\
\hline $\begin{array}{c}\text { Andes } \\
\text { Biotechnologies }\end{array}$ & Biotechnology & 2008 & Santiago & $\mathrm{VC}$ & No \\
\hline Producto Protegido & IT Services & 2007 & Santiago & $\mathrm{AC}-\mathrm{VC}$ & No \\
\hline Multicaja & IT Services & 2007 & Santiago & $\mathrm{VC}$ & No \\
\hline Paperless & IT Services & 2000 & Santiago & $\mathrm{VC}$ & No \\
\hline Scopix & IT Services & 2006 & Santiago & $\mathrm{VC}$ & No \\
\hline Kibernum & IT Services & 1991 & Santiago & No & No \\
\hline ActivaQ & Biotechnology & 2011 & Santiago & No & No \\
\hline Astilleros Ascon & $\begin{array}{c}\text { Naval } \\
\text { engineering }\end{array}$ & 2000 & $\begin{array}{l}\text { Puerto } \\
\text { Montt }\end{array}$ & No & No \\
\hline Innovex & Technology & 2007 & $\begin{array}{l}\text { Puerto } \\
\text { Montt }\end{array}$ & No & No \\
\hline Scrum & IT Services & 2007 & Antofagasta & No & No \\
\hline GProcess & Metallurgy & 2007 & Antofagasta & No & No \\
\hline Opendat & IT Services & 1994 & Antofagasta & No & No \\
\hline Certifica & IT Services & 2000 & Santiago & $\mathrm{PE}$ & Yes \\
\hline Maquintel & Robotic services & 2011 & Santiago & $\mathrm{AC}$ & No \\
\hline Solar Chile & Solar energy & 2010 & Santiago & $\mathrm{AC}$ & Yes \\
\hline Axxon Axis & IT Services & 2006 & Santiago & $\mathrm{AC}$ & Yes \\
\hline
\end{tabular}

Note: PE: Private Equity; VC: Venture Capital; AC: Angel Investor.

There are also several companies developing new solutions for the mining industry, a key sector for Chile, the main producer of copper and lithium in the world, as it represents $13.5 \%$ of its national GDP. This is as a very important trend since the emergence of new knowledge-intensive business services around natural resource-based sector opens up new opportunities to foster structural change 
through sectors that are commonly regarded as not very innovative (Marin et al., 2015). For example, Maquintel, was founded by a young electric engineer after arriving from his post doctoral studies in robotics in the United States, to develop cutting edge technology to improve the efficiency of the mining process, particularly in the pipe system. The company uses 3D printing, laser cutting technology and rapid prototyping tools to manufacture robots that can be introduced inside the mining pipes to monitor their condition. Also, GProcess, launched in 2007 in the Antofagasta region, the copper capital of Chile, is a company focused in the development of innovative metallurgic processes. It has developed a revolutionary purifying additive (DXG-F7) used to optimize the process of copper extraction.

Also, prompted by the advent of information technologies, new companies offering innovative services have been emerging. For example Paperless, a growing company founded by two friends in the year 2000, took advantage of new regulations on electronic signature and invoicing to develop the technology to generate, process and manage electronic documents. Their good results have allowed them to open offices in Brasil, Peru and Colombia.

\subsection{Analysis}

This section presents the main results of the interviews that allow answering the research questions presented in Section 5.2. It is divided into four subsections related to different traits of the entrepreneur, which are assumed to influence the emergence of innovative entrepreneurship: (1) background; (2) personality; (3) motivations; and (4) social capital.

\subsubsection{The background of entrepreneurs}

In all cases under analysis there was a team behind the process of founding the business. However, within the founding team there is in general one 'core founder' or two, defined as the person that had the idea to launch the startup and drove the initial stages of building it (Wasserman, 2012, p. 69). This is what we typically associate with the idea of the entrepreneur. Within the sixteen companies under analysis, half of them had one core founder and the other half had two. From these 24 core founders I was able to interview 22 of them. A summary of some characteristics of the core founders of each company under study is presented in Table 5.2.

The first interesting pattern is that all core founders of the sixteen companies are highly educated: all of them completed at least a bachelor degree and most of 
them graduated from one of the top ten universities in Chile ${ }^{9}$. This pattern is consistent with the positive relationship between the level of educational attainment and firm innovation propensity found in Chapter 4.

However, when considering the attainment of graduate education a different pattern emerges between the core founders from the capital Santiago and the ones from regions: from the eleven companies located in the capital Santiago, in four of them at least one of the core founders had completed a master degree (generally a master in business administration) and in other five companies at least one of the core founders completed a doctorate degree, in most cases abroad. This pattern does not hold for entrepreneurs of companies located in regions: only in one of the five companies located outside de capital the core founders completed a master degree. Overall this implies that innovative entrepreneurs tend to be highly educated. But those located in the capital Santiago are even more educated than their counterparts in regions.

Regarding the attitude towards becoming an entrepreneur ${ }^{10}$, a third of the entrepreneurs interviewed said that they always pictured themselves founding a business. And even though the sample is not balanced in terms of geographical location, it seems that entrepreneurs from the capital Santiago were less prone to have envisioned themselves founding a venture as compared to their counterparts from the regions. Also, those that did not envision themselves as entrepreneurs tend to have a higher educational attainment (at the graduate level). Therefore, entrepreneurs from the capital Santiago resemble a type of individual profile that is more career oriented, or that is more focused on climbing the professional ladder. However, as we will discuss later in Section 5.5.3, some events can trigger that an individual like this ends up making a swerve in their professional career to found a company and become an entrepreneur.

In terms of prior entrepreneurial experience, approximately half of the core founders were previously involved in the founding of a business. Some of them managed to found a company and make it grow; these can be regarded as serial entrepreneurs. Some others did not succeed ${ }^{11}$. Whether the prior business was a

\footnotetext{
${ }^{9}$ Three universities lead the list: University of Chile, Catholic University of Chile and Austral University of Chile. These three universities are in the top ten ranking of Chilean universities according to the Quacquarelli Symonds (QS) World University Rankings. See website http://www.topuniversities.com/ (website last time checked: December 2015).

${ }^{10}$ The question asked was "Did you always see yourself founding a company?".

${ }^{11}$ One of the most frequent reasons given by entrepreneurs to explain prior business failure was not devoting enough time to the development of the business. This typically happened when the entrepreneurs were employed for somebody else and were involved in the business on the side, more like a hobby. Other reason was related to a mismatch between the business idea and the effective market need. Limited knowledge about the sector was also mentioned as another
} 
success or a failure, or something in between, the experience acquired constitutes a powerful source of tacit knowledge regarding the entrepreneurial process.

Learning from prior experiences, and even from ongoing experiences, is very important to increase the odds of success in any entrepreneurial endeavor. It involves learning about how the process of entrepreneurship works in practice, which most surely differs from the expectations based on entrepreneurship theory or what a master program in business administration may teach. But it also implies that entrepreneurs learn about their own limitations, in technical skills or even in personality. Some of these limitations can be acquired by training, others not. In the latter case, finding good advisors and partners that complement the core entrepreneur becomes crucial. Learning is important because it modifies the behavior of the entrepreneur and leads him to make new decisions that can change substantially the path followed by the business. In other words, as the entrepreneur learns, the business evolves.

Table 5.2: Background characteristics of core founders

\begin{tabular}{|c|c|c|c|c|}
\hline Venture & $\begin{array}{c}\text { Prior } \\
\text { entrepr. } \\
\text { exp. }\end{array}$ & $\begin{array}{c}\text { Always } \\
\text { wanted to } \\
\text { start a } \\
\text { business? }\end{array}$ & Educ. Attainment* & Area of education \\
\hline $\begin{array}{r}\text { Andes } \\
\text { Biotech. }\end{array}$ & Yes & No & PhD abroad & Biochemistry \\
\hline $\begin{array}{l}\text { Producto } \\
\text { Protegido }\end{array}$ & Yes & Yes & Bachelor & $\begin{array}{c}\text { Business and } \\
\text { economics }\end{array}$ \\
\hline Multicaja & No & No & PhD abroad & $\begin{array}{l}\text { Engineering } \\
\text { (industrial) }\end{array}$ \\
\hline Paperless & No & No & MBA abroad & $\begin{array}{l}\text { Engineering } \\
\text { (industrial) }\end{array}$ \\
\hline Scopix & Yes & Yes & PhD abroad & $\begin{array}{l}\text { Engineering } \\
\text { (industrial) }\end{array}$ \\
\hline Kibernum & Yes & Yes & Bachelor & $\begin{array}{l}\text { Engineering } \\
\text { (informatics) }\end{array}$ \\
\hline ActivaQ & Yes & No & $\mathrm{PhD}$ in Chile & Biology \\
\hline
\end{tabular}

explanation for prior founding failure. It is important to mention that in none of the cases the entrepreneur mentioned financial constraints. 
... Table 5.2 continued

\begin{tabular}{|c|c|c|c|c|}
\hline Venture & $\begin{array}{c}\text { Prior } \\
\text { entrepr. } \\
\text { exp. }\end{array}$ & $\begin{array}{c}\text { Always } \\
\text { wanted to } \\
\text { start a } \\
\text { business? }\end{array}$ & Educ. Attainment* & Area of education \\
\hline $\begin{array}{c}\text { Astilleros } \\
\text { Ascon }\end{array}$ & No & No & Bachelor & Engineering (naval) \\
\hline Innovex & Yes & Yes & Master abroad & Marine Biology \\
\hline Scrum & Yes & No & Bachelor & $\begin{array}{c}\text { Engineering } \\
\text { (informatics) - } \\
\text { Business and } \\
\text { economics }\end{array}$ \\
\hline GProcess & Yes & Yes & Bachelor & Industrial design \\
\hline Opendat & Yes & Yes & Bachelor & $\begin{array}{c}\text { Engineering } \\
\text { (chemical) }\end{array}$ \\
\hline Certifica & No & Yes & MBA abroad & $\begin{array}{l}\text { Engineering } \\
\text { (industrial) }\end{array}$ \\
\hline Maquintel & No & No & Post Doc abroad & $\begin{array}{c}\text { Engineering } \\
\text { (electric) }\end{array}$ \\
\hline Solar Chile & Yes & No & MBA abroad & $\begin{array}{l}\text { Engineering } \\
\text { (industrial) - } \\
\text { Economics }\end{array}$ \\
\hline Axxon Axis & No & No & MBA in Chile & $\begin{array}{c}\text { Engineer } \\
\text { (informatics) }\end{array}$ \\
\hline
\end{tabular}

Note: * Whenever the company had two core founders, the highest level of educational attainment was reported.

\subsubsection{The personality of entrepreneurs}

A lot has been written about the personality of entrepreneurs and for a long time scholars could no reach a consensus about differentiating features between entrepreneurs and non-entrepreneurs. As discussed previously in Section 3.2.1 of Chapter 3, in the late 80s the 'trait approach' to entrepreneurship was considered to have failed to provide a consensus on a generic definition of the entrepreneur from a personality point of view. However, the interest in the role of personality in entrepreneurship reemerged in the 2000s arguing that prior contradictory findings were due to a lack of theoretically derived hypotheses and various research artifacts (Rauch and Frese, 2007; Shane et al., 2003). The meta-analyses 
approach was therefore considered an appropriate technique to analyze the relationship between personality and the entrepreneurial process since it can correct for sampling error and poor reliability (Zhao et al., 2010). As a consequence, several meta-analysis were conducted in this decade ${ }^{12}$ showing that contrary to prior conclusions, entrepreneurs do differ from other groups of individuals in terms of personality ${ }^{13}$.

This section does not aim at arguing in favor of a particular set of personality traits that differentiate (Chilean) entrepreneurs from the rest of the population. The purpose of this section is to discuss about a set personality traits that interviewees considered important ${ }^{14}$ in an entrepreneur to be able to deal with the diverse situations founders are faced with throughout the entrepreneurial process. In fact, the hypothesis is that personality traits influence the behavior of entrepreneurs shaping the type of decisions they make and the actions they take, which, in interaction with the environment, ultimately influences the performance of the business.

A list with the most important personality traits that emerged from the interviews is presented below, discussing how they influence the behavior of the entrepreneur and how it may affect the path followed by the business.

- Tolerance for uncertainty: An entrepreneur is able to cope with the many ambiguous situations that emerge every day and is able to make decisions in moments of doubt and fear. The uncertain nature of creating an innovative business implies being faced with a set of pitch black roads that may or may not lead to the goal the entrepreneur has envisioned. Since resources are scarce, taking wrong roads may end up consuming too many resources, jeopardizing the accomplishment of the goal. It is important to remark that being able to make decisions under uncertainty does not imply that entrepreneurs fall in the category of risk lovers because they do fear ${ }^{15}$.

\footnotetext{
${ }^{12}$ See Rauch and Frese (2007) for a meta-analysis on personality traits of entrepreneurs and how they relate to business creation and success; and Zhao et al. (2010) for a meta-analysis on the role of personality in entrepreneurial intentions and firm performance.

${ }^{13}$ And also in motivations, as suggested by Wasserman (2012, Ch. 2)

${ }^{14}$ Interviewees were asked questions like 'How do you define entrepreneurs in terms of their personality?' or 'What personality traits do you consider an entrepreneur should have and why?' Therefore, answers are based on perceptions of interviewees. Personality tests were not applied to the founders interviewed to objectively measure their personality.

${ }^{15} \mathrm{In}$ line with this $\mathrm{Xu}$ and Ruef (2004) find that nascent entrepreneurs from the US are even more risk-averse than non-entrepreneurs, which goes against the assumption that entrepreneurs are more risk-tolerant than the general population.
} 
- Resilience or perseverance: An entrepreneur steadily persists in the course of an action in spite of problems and failures and is able to quickly recover from adversity. Throughout the rather lonely process of entrepreneurship, especially when founding the business, uncertainty prevails and therefore numerous things will not work as expected. Many doors will be closed, many phone calls will not be answered, the prototype will not yield the expected results, potential clients will not trust the new product or service, money will run short, among many other obstacles. One interviewee mentioned that 'the question is not whether you will fail or not, as failure is a certainty; the question is how long it is going to take you to stand up again'. The trait of being able to repeatedly stand up was associated to the trait of being passionate about what the entrepreneur is trying to accomplish. And there is passion because of the belief that the effort is worth the discomfort of failures and adversity, because there is a meaning and a value to what the entrepreneur is pursuing, that typically goes beyond economic reward as will be discussed later in the section of entrepreneurial motivations. Therefore, the idea that entrepreneurs feel a strong enthusiasm about the goal that is being pursued may help them to be resilient and keep moving forward despite the many obstacles faced.

- Self-confidence or self-efficacy: An entrepreneur trusts his or her personal judgement and abilities, which gives him or her the capacity to make decisions under pressure and in uncertain situations. However, self-confidence should be present in a balanced way such that there is space for listening and taking advise when needed. That is, the entrepreneur should be careful not to step across the threshold and go all the way to overconfidence, which increases the propensity to make (avoidable) mistakes.

- Internal locus of control: The fact that entrepreneurs keep trying to find the best way to deal with the uncountable obstacles that emerge on a daily basis means that they believe they can effectively change the situation they are faced with. In other words, they think that they can somehow control the events affecting them. Entrepreneurs, therefore, believe that change is possible and will act accordingly to control the destiny of their business within the uncertain environment in which they are embedded. And not only do they think they can change their environment, but also that they have what it takes to do it, meaning that internal locus of control comes together with self-confidence. 
- Need for Achievement: Entrepreneurs decide to found a company with the goal that the innovative business they have in mind eventually succeeds. But given the uncertain nature of innovation itself and the high odds of failing, the goal seems quite challenging. However, entrepreneurs think that this goal is achievable and can be successfully accomplished with their effort and ability. Need for achievement, or N-Ach, is one of the most well known personality trait associated with entrepreneurs ${ }^{16}$ and could be clearly perceived from the interviews by how they talk and refer to some situations. Like how sometimes they feel all odds are against them but still think they can defeat these odds and find the strength and drive to keep going towards the difficult and challenging goal they are pursuing. The desire to accomplish something difficult keeps them motivated, as it will be discussed later in the discussion about motivations.

- Learning: The entrepreneur is able to capitalize on prior mistakes and failures and learn. As discussed in the previous section, failures and mistakes are in fact a powerful source of learning for the entrepreneur and can be actually considered a valuable source of experience by angel and venture capitalists. The tolerance for failure, however, is embedded in the local culture within a country or region. Little tolerance to failure gives little space for learning and provokes inefficiencies in the sense that entrepreneurs may lose perspective obsessed with the fear of failing, which may lead to inflexibility and bad decisions.

- Humbleness: An entrepreneur who is modest in behavior and attitude can influence the performance of the business in different ways. For example, launching a venture implies, in general, starting from scratch with limited resources, which most probably will require the entrepreneur to be involved in all sorts of activities, from answering the phone, selling, doing accounting, cleaning the office and so on. Many entrepreneurs had good jobs before becoming an entrepreneur and had accomplished some degree of professional status, but becoming a novice entrepreneur is like going to your first day

\footnotetext{
${ }^{16}$ One of the most influential researchers in this strand of literature is the psychologist David McClelland, who in his book The Achieving Society published in 1961 demonstrated the link between the need for achievement in societies and economic development. A person's motivation for achievement is related to the need for success and goal achievement, which typically comes together with internal locus of control and self-efficacy. McClelland argued that entrepreneurs driven by the need for achievement could contribute significantly to economic growth through the ventures they pursued. See also Landström et al. (2012, Ch. 2) for a discussion on the contribution of David McClelland to the field of entrepreneurship studies.
} 
of university: you know nobody and nobody knows you. Earning a space in the new network and gaining the trust and respect from peers requires a lot of effort, perseverance and humbleness. Being humble also increases the ability to listen and to receive criticism and advice, which allows reshaping decisions that can substantially change the path followed by the business.

- Self-criticism: An entrepreneur should be able to acknowledge his or her own flaws and weaknesses. A healthy dose of self-criticism encourages learning and brings flexibility into the business as there is space to change direction quickly when needed.

- Leadership: An entrepreneur is a good leader in the sense that he is able to communicate to the employees the objectives of the company and which is the contribution of each person to the accomplishment of it. He is able to keep employees motivated, engaged and committed despite the uncertain environment.

- Creativity: This trait is related to the phenomenon whereby something novel, original and worthwhile is formed. Entrepreneurs, through curiosity and perceptiveness, are able to identify needs and visualize opportunities. Their creativity allows them to develop an innovative way to fulfill a need or attack an opportunity. In general, core entrepreneurs are regarded as 'machines of ideas' which somehow relates to the 'thinking out of the box' approach. This means a fertile mind necessary to make the business attractive but also to devise creative strategies to deal with the many obstacles daily faced.

The above set of personality traits were considered as desirable characteristics of an entrepreneur, some of which are very related, like need for achievement, internal locus of control, resilience and self-confidence ${ }^{17}$. This is consistent with the typical personality traits that the literature has assigned to entrepreneurs: need for achievement, self-efficacy and internal locus of control (McClelland, 1961; Bandura, 1997; Rotter, 1966). However, when the intensity of a trait goes beyond a threshold it may turn counterproductive, especially if it is not counterbalanced by some key abilities. For example, too much creativity may turn against the entrepreneur if he is not able to focus and prioritize. Many ideas and projects may emerge along the way but prioritization is key to prevent efforts and resources

\footnotetext{
${ }^{17}$ However, this does not mean that this combination of personality traits is only present in entrepreneurs as they can surely be present in individuals pursuing different challenging life goals.
} 
from diluting, especially at the beginning when the startup is struggling to survive. Some of the entrepreneurs that were regarded as 'machines of ideas' were also characterized as very disperse, meaning that they shift their attention from one idea to the other without devoting enough time to think about the feasibility of executing each of them. Therefore, creativity should be complemented with some focus because, after all, there is a time and a place for everything. Also, creativity should be accompanied by the capacity to execute ideas, which at the end is what distinguishes a creative person from an entrepreneur.

In general, the founding team included 'a dreamer' that is permanently thinking about new ideas, and a 'feet to earth' co-founder or partner who brings focus and structure to the chaos that dreamers sometimes are prone to generate. In some cases, structure was 'imported' by incorporating key actors, like a general manager or an angel investor, which helped the core founder(s) to focus and redirect scarce resources and efforts towards the accomplishment of one or two clear goals. The importance of focusing is considered especially important at the beginning, when the business is just starting to grow but has not reached the break-even point yet. Focusing on consolidating one product or service in the market constitutes a key signal that the business has survived the death valley, meaning that uncertainties about the feasibility of the business idea start dissipating, giving space to the next stage of scaling up.

Management skills become crucial in the stage of scaling up and technical limitations of the entrepreneur may become real bottlenecks to the steady growth of the business. Some of the core founders may be able to realize this by themselves or may be able to listen to advise from investors, which is consistent with a humble and self-critical personality. This explains why some of the core founders ended up hiring a general manager when the business started to grow. Because they could understand that at some point a division of labor was needed for the business to grow. For some other core founders it may take longer to realize this because the attachment they have developed towards their business is too strong to allow somebody else to lead it. Fears that the 'intruder' may not share the values or the vision of the company, or may disrupt the balance the business may have reached, prevent core founders from stepping aside and letting somebody else manage the daily life of a business. However, this situation may end up in an inefficient distribution of efforts and resources within a company because as the business grows the daily management becomes extremely burdensome leaving little time to the entrepreneur, if any, to be creative or to re-think the direction where the 
business is heading. Being focused on the daily business routine may prevent creative founders to identify new opportunities they could be exploiting.

The set of personality traits described above were regarded as desirable traits an entrepreneur should have to be able to deal with the process of entrepreneurship $^{18}$. However, because it is unrealistic to expect that all desired personality traits and abilities are going to be present in one single person when launching a new venture, complementarity between members of the founding team and partners becomes extremely relevant. In fact, the sooner the founding team realizes this, the sooner they can take action. However, as mentioned earlier, identifying and accepting lack of skills requires humbleness and the ability to conduct self-criticism.

Complementarity between members of the founding team and partners is not only important to complete each other's traits, but also to reinforce them. Theoretically, the definition of complementarity is as follows (Milgrom and Roberts, 1990): for a given function $f(x, y)$ that depends on two variables $x$ and $y$, there will be a complementary relationship between both variables if $f(1,1)-f(1,0) \geq$ $f(0,1)-f(0,0)$. In both sides of the equation the $y$ variables goes from being absent $(y=0)$ to being present $(y=1)$. But the increase in the outcome of the function is higher whenever $x$ is present $(x=1)$ meaning that $x$ and $y$ positively reinforce each other. This implies that it is desirable to have both variables present simultaneously rather than separately. Applying this to the founding team means that complementarity between members can help fostering good results through the synergic interaction between their traits and abilities.

\subsubsection{Entrepreneurial motivations}

As previously discussed in the conceptual framework of Chapter 3, motivation can be considered as the closest stage during a person's unobservable decision making process before a venture changes its status from an intention to an action. If the motivation determines the vision an entrepreneur has from the venture, then it may be considered as an important factor determining the trajectory followed by a venture since the aspiration the person has from its venture will determine the type of decisions made and the actions taken to fulfill that vision (Wasserman, 2012, Ch. 1). This idea is related to the concept of path dependency whereby initial conditions determine future trajectories and ultimate outcomes. In practical terms, when facing two entrepreneurs $\mathrm{A}$ and $\mathrm{B}$ in time $t=0$, one

\footnotetext{
${ }^{18}$ There were no differences between the sets of characteristics associated to core founders from the capital Santiago and the ones from the regions.
} 
aiming at creating a thriving local business and the other one aiming at conquering global markets with an innovative business idea, one may expect different strategic decisions that lead to different trajectories, shaped, of course, by the interaction with the environment in which the businesses is embedded.

In line with this, Wasserman (2012) distinguishes two types of entrepreneurs in terms of their motivations: (1) building wealth and (2) driving and controlling the growth of their startups. This two types of motivations, 'wealth' versus 'control', determine at the same time the type of decisions made by the founder, which influences the type of business outcome. For example, founders who consistently make decisions that build wealth are more likely to achieve what he calls a 'Rich' outcome (greater financial gain and lesser control). While founders who consistently make decisions that enable them to maintain control of the startup are more likely to achieve what he calls a 'King' outcome (greater control, lesser financial gain) (Wasserman, 2012, p. 13). And even though other motivations like intellectual challenge, altruism, and prestige can also prove to be important, the author argues that wealth and control are the two most common ones found in American technology startups, which seem to repeatedly come into conflict.

The conflict is related to the fact that the decisions related to co-founders, hires, investors, successors, among other factors, tend to differ depending on the desired outcome, Rich or King. For example, the decisions made regarding cofounders differ substantially between these two desired outcomes. Founders motivated by 'control' tend to: remain solo founders (or attract weak co-founders); look first into their immediate circle for "comfortable" co-founders; try to keep strong control of decision making; maintain most of all equity ownership. By contrast, founders motivated by 'wealth' tend to: build founding teams attracting the best co-founders they can find; tap strong and weak ties to find the best (an complementary) cofounders; give decision-making control to co-founders with expertise in specific areas; share equity to attract and/or motivate co-founders. In terms of investors-related decisions, founders motivated by 'control' tend to: selffund; rely on friends and family or money-only angels, trying to tap alternative sources (like customer prepayments or debt) if possible; resist investor-friendly terms avoiding supermajority rights; avoid building official boards. Founders motivated by 'wealth' tend to: take outside capital; target experienced angels or venture capitalists; are open to terms necessary to attract best investors; and are open to losing control of board if necessary to get best investors and directors (Wasserman, 2012, p. 16-17). 
Before presenting the type of motivations that drove the entrepreneurs interviewed, I analyze some of the factors that influenced their entrepreneurial motivations. The interviews showed that entrepreneurial motivations were influenced by personality traits and by different aspects of the founder's life, like having been exposed to role models, prior work events and experiences, key encounters with pivotal individuals and the little twists and turns in life.

One of the main factors explaining the type of motivation that drove individuals to pursue the launch of a venture was their 'attitude towards entrepreneurship', which is determined by the family and culture in which they grew up and the extent to which they were influenced by role models. In relation to this it is possible to identify two types of entrepreneurs: those that always had the idea to found a company and those that somehow ended up doing it. The influence of role models during adolescence are more important in the first type as they may have significantly influenced early decisions made by entrepreneurs regarding their professional future. This 'early clarity' about the idea to become an entrepreneur may explain why this type of entrepreneurs were less prone to pursue further educational degrees after attaining their bachelor degree, except for a few that had a Master's degree.

In their early years, this 'role model influenced' type of entrepreneurs were embedded in an environment where developing a business was seen as a normal activity because they had the example of parents or close friends that owned and managed a business. Some of them mentioned that they remember being involved in businesses since they were young, looking for opportunities to sell something at school or at the university. ${ }^{19}$ They grew up with the idea of founding a company and therefore made decisions at different stages of their life that would lead them to found a company. Some of them mentioned that they always saw themselves as entrepreneurs, so being a company founder, not an employee, was the "normal" occupation for them. These type of entrepreneurs were more prone to mention autonomy when asked about what motivated them to be involved in the launch of a startup. ${ }^{20}$ Nevertheless, some of them combined the need for autonomy with other intrinsic motivations like the need to create and accomplish something that is valued by people. In these cases the influence of personality traits -like need for achievement, internal locus of control and self-efficacy- on entrepreneurial motivations was clear.

\footnotetext{
${ }^{19}$ This is consistent with the discussion in Chapter 3 regarding the influence of cognitive heuristics when making occupational choices. See Katz (1992).

${ }^{20}$ This is consistent with findings in Chapter 3 where individuals are more likely to be motivated by independence at a younger age.
} 
The second category of entrepreneurs includes those individuals that did not always envision themselves as entrepreneurs but somehow ended up in this situation. So their life decisions were not made with the aim of becoming a business founder, at least not consciously. Interestingly, most of this type of entrepreneurs attained high educational degrees, as high as a master or doctorate degree. This differs from the pattern observed from individuals that consciously led their life decisions towards entrepreneurship, as discussed in the previous paragraphs. This type of decisions probably resembles a type of individual profile that is more career oriented, or that is more focused on climbing the professional ladder. However, even though life decisions of this second category of entrepreneur were not made with the aim of becoming founders of an innovative company, some events ended up triggering this swerve in their life and professional trajectory.

Different events can trigger a turn in an individual's life such that they decide to get involved in the complex process of entrepreneurship. Some of these events can occur unexpectedly, although timely because somehow it ended up being the right moment: the individual had an attractive and innovative business idea, the market seemed to be ready, the resources (financial, human and social) were available and, most importantly, the motivation to do it was there (see the Box below for an example on this). In other cases the trigger was related to the life stage through which the person was going, which called for a change in direction and made individuals voluntarily leave their usual comfort zone. For some individuals becoming an entrepreneur emerged as a possibility soon after finishing their graduate studies, especially for those that studied abroad. Some others were influenced by role models later on in their life; for example, having friends that became entrepreneurs or meeting people at work that inspired them.

Box: Andes Biotechnologies, serendipity and the cure of cancer

The bio-entrepreneurship Andes Biotechnologies emerged as a consequence of serendipity. In the 80 s Luis Burzio, a Chilean biochemist with a PhD in molecular biology at Delaware University and a postdoc at the Rockefeller University, was conducting basic research on the genetics of the sperm cell. The scientist and his team knew that when an egg is fertilized by an spermatozoon it starts quickly dividing into multiple cells, but they found that this process was triggered by an RNA molecule that is transferred to the egg by the spermatozoon. Luis and his team did not have prior experience with cells but made an analogy with tumors, which are known to grow and proliferate. So they started studying the behavior of tumors to see if they could find the same expression of this RNA molecule that they found in the spermatozoon. Luis mentioned that making this analogy was the first serendipity. The second one was related to the access they had, through an aquaintance, to samples of tumors. After they had different samples of tumors analyzed, they realized that they had 
the same expression of this RNA molecule: Bingo! by researching sperm cells' genetics they discovered how tumor cells reproduce. Luis talks about this as serendipity because if he had been working in the United States they may not have come up with the idea of testing the presence of the molecule in carcinogenic cells. Since they were not experts in cells they were forced to think out of the box. Back in the US, working at the University of Rockefeller, access to an expert in cells would have been much easier.

The serendipity happened in the year 1991 and since then Luis and his team have been slowly working on this research. And slowly not only because it takes time to conduct basic research, but also because they mostly relied on small amounts of money coming from public subsidies. Luis and his team have been working in the science and technology park Fundación Ciencia \& Vida led by Pablo Valenzuela, a Chilean scientist well known for his genetic studies on hepatitis viruses. Pablo participated in the discovery of the hepatitis $\mathrm{C}$ virus and in the invention of the world's first recombinant vaccine against hepatitis B. He has also been involved in the founding of successful biotechnology companies, like the multinational Chiron Corporation where Pablo was a co-founder (in 2006 it was bought by Novartis). Pablo, an exceptional scientist and businessman, has become highly experienced in the process of founding biotechnology companies, including the management of intellectual property rights naturally involved in ventures of this sort.

When the ecosystem of entrepreneurship in Chile was finally ready to finance, through venture capital, the initial development of a biotechnology entrepreneurship like this one, the three scientists Pablo Valenzuela, Luis Burzio and Arturo Yudelevich, co-founded in 2008 Andes Biotechnologies with the aim to research and develop innovative and effective treatments against cancer. They were able to initially raise US $\$ 5$ million in venture capital (from Austral Capital and Aurus) and US\$2 million in grants. With this initial budget they were able to speed up the development of a new proprietary technology based on the discovery of a novel family of RNA targets of mitochondrial origin that when disrupted by a complementary DNA oligo (Antisense Technology) they selectively destroy cancer cells. So far, the drugs developed by Andes Biotechnologies have shown to selectively destroy cancer cells in vitro and in vivo cancer models. The company also has completed studies that show efficacy of the drug in animal cancer and is currently in Phase I of clinical trials in humans. Looking ahead, the company expects to successfully commercialize the drugs developed through successful licensing and/or joint development arrangements with international pharmaceutical companies interested in oncology.

According to the website of Andes Biotechnologies, the World Health Organization has stated that cancer is a leading cause of death worldwide, with 12.4 million new incidents of cancer per year and causing around 7,9 million deaths per annum. There are 28 million cancer patients alive within 5 years of the initial diagnosis. Only in the United States it was estimated that about half a million Americans died of cancer in 2008, while over 1,4 million new cases were diagnosed during the same year. Moreover, the estimated cancer incidence rate is expected to rise by $50 \%$ in 2030. Andes Biotechnology, therefore, is a fascinating case that has the potential to revolutionize health markets worldwide through a non invasive way to cure cancer that emerged as a result of serendipity conducting basic research. However, it took almost twenty years before the ecosystem was ready to finance a venture of this sort, very intensive in capital and highly uncertain.

The motivation behind the core entrepreneurs, Luis Burzio and Pablo Valenzuela, to found this startup was to create something big that can change the life of human kind. The business idea from Luis and his team; the prior bio-entrepreneurial experience from Pablo; the availability of the required highly skilled human capital; and the motivation to pursue an uncertain endeavor like this one were ready when the window of opportunity opened with the emergence of venture capital funds like Austral Capital and Aurus around the year 2008 .

Within the category of individuals that did not always envision themselves as 
entrepreneurs, we also find those that ended up founding a company after coming back from their graduate studies in the United States. They mentioned that founding a company and becoming an entrepreneur is very much embedded in the US culture, not just when studying an MBA in Berkeley but also when doing a $\mathrm{PhD}$ in MIT or in Cornell. It is everywhere. This type of entrepreneurs, that did not initially envision themselves founding a company and pursued their graduate studies for academic or professional reasons, ended up making a swerve in their life paths by founding an innovative startup. It is difficult to understand what exactly triggered this swerve, but certainly studying abroad is a mind opening experience that helps individuals not only to think differently, but also to think that founding a company is a real possibility for them as well. It is important to mention that this type of entrepreneurs founded their companies together with other co-founders that were not part of their close social networks. The interviewees mentioned that meeting their partners was somehow a turn of fate, so finding the right partner in the right moment was probably also influential to make the decision to found a startup. However, more than fate, devising an innovative idea and finding the right partner in the right time is associated to this ability of entrepreneurs to make things happen and to be alert, which relates to an attitude of receptiveness to available, but overlooked, opportunities. Without knowing what to look for and without deploying any deliberate search technique, the entrepreneur is at all times scanning the horizon, as it were, ready to make discoveries (Kirzner, 1997, p. 72). This rather unconscious ability of awareness and alertness probably explains many of the events that entrepreneurs somehow attribute to the little twists and turns in life.

Another clear type of entrepreneur within the same category includes those individuals that were going through a life stage where a change was needed (jobwise). Some of them were quite successful in their professional careers but still felt that they needed to achieve something different, to face new challenges. This type of entrepreneurs were more prone to be driven by the non-pecuniary benefits of entrepreneurship as in some cases it is evident that they could be engaged in a different activity that could bring them higher returns but instead they chose to launch a new business venture. Relying on their prior experience they were able to devise an innovative business idea. Also, they had accumulated enough financial capital and, more importantly, social capital, that enabled them to leave their comfort zone and jump into the complex process of founding an innovative startup. This type of individuals tend to have the need for achievement personality trait, which partly explains the need to look for a new challenge to excel at when 
they felt that their former jobs were not fulfilling this need. So their motivation, other than make a change to their life routine, was to create something new that is valued by the market and ends up having an impact on the population.

Four main motivation categories were identified from the interviews with the entrepreneurs, which are listed and discussed below.

Need for autonomy This category, frequently cited in the literature, includes entrepreneurs that have a strong inclination towards the independence and control that brings being one's own boss. It is closely related to the value assigned to being the owner of one's time, to be the protagonist of the path chosen, to exert control over the decisions made and be responsible for their outcomes. This motivation was more likely to be mentioned by entrepreneurs that had always envisioned themselves as entrepreneurs as a consequence of early influences from family or friends that were involved in business ownership.

This category resembles somehow the 'control' driven entrepreneurs described by Wasserman (2012), in terms of the tendency to rely on "comfortable" cofounders (mostly friends) and the reluctance to take in outside capital from investors. In general, entrepreneurs driven by the need of autonomy want to keep control of the decisions made in the business and prefer to grow at the pace allowed by the revenues of the business, that is, at a gradual or moderate rate. This is a clear example of how entrepreneurial motivations influence the type of decisions made by the founder, which ultimately determines the rate at which the startup will grow.

Impact generation These entrepreneurs are highly driven by the desire to generate an impact in the environment that surrounds them, although the meaning of impact may vary widely. The desire to generate an impact seem to go beyond economic goals as some entrepreneurs explicitly mentioned that the focus should not be the money that can be earned. This category of motivation is related to the aspiration to create something valuable, to provoke a change and/or to leave a footprint that is recognized by society. Therefore, some of them expect to be noticed for what they have created.

However, as previously mentioned, the meaning of impact can differ between entrepreneurs. For example, the motivation to generate an impact may answer to more altruistic inner forces. For example, the drive to stop a status quo that has led to a situation of inertia that is considered undesirable for the population. Ventures that originate from this type of motivations are 
expected to relatively face more barriers along the way, so the personality, abilities and social networks are extremely important in these cases. Altruistic entrepreneurs also resemble some of the traits of the 'control' driven entrepreneurs described by Wasserman (2012), in terms of their need to keep strong control of the decision making. And although they are willing to take in external capital, particularly targeted experienced angel or venture capitalists, they avoid losing control of the company through this.

Need for achievement This type of motivation is related with the pleasure that provoke in a person the permanent challenge of solving complicated problems and of accomplishing specific objectives that require effort and putting the abilities of the entrepreneur to both test and practice. This person enjoys more the process that leads to success than reaching the goal itself. For example, even though economic success may be the outcome resulting from the entrepreneur's effort, this is not considered as a goal, but it is considered more as an indicator of success. Entrepreneurs in this category typically have the trait of internal locus of control, meaning that the origin of events is related to the person and not to external factors.

Life stage This category could also be called 'need for a change' since it includes those entrepreneurs that felt at some point the need to make a change to their work life. Therefore, it includes all those individuals that did not always envision themselves as entrepreneurs. Some of them were successful professionals but felt that they had already accomplished their professional aspirations. Others felt that their professional situation did not give them the satisfaction and fulfillment it used to. Some others just needed a change or were willing to try something new, like those that had finished their graduate studies abroad and felt the need to do something different.

It is important to clarify that even though this category includes individuals that wanted to make a swerve in their professional lives through entrepreneurship, they can still be motivated by the need for achievement or generating an impact.

It is important to remark that the four categories of motivation described above are non-exclusive and may be combined. They are also non-exhaustive. Furthermore, they may evolve through time. And although it is clear that the motivation (or set of motivations) that led an entrepreneur to start the startup cannot change in time, the reason to persevere in the business can change through 
time. For example, a person that was forced to start a business due to external shocks like a dismissal, may develop a taste for entrepreneurship and may discover hidden or unknown abilities that end up being conducive to a successful venture. In this case, the motivation to start the business is not the same as the one to continue with it.

\subsubsection{The role of social capital}

Social capital can be broadly defined as 'the resources available to people through their social connections' (Kim and Aldrich, 2005, p. 3). Social connections include strong and weak ties, which are defined in terms of the 'strength' of an interpersonal connection. Following Granovetter (1973, p. 1361), the strength of a tie is defined as 'a (probably linear) combination of the amount of time, the emotional intensity, the intimacy (mutual confiding), and the reciprocal services which characterize the tie'. Strong ties can be defined as long-term, two-way relationships that are not governed by short-term calculations or self-interest, hence are typically more reliable than other ties and involve a strong degree of trust and emotional closeness (Aldrich and Ruef, 2006, p. 70). On the other hand, weak ties are more casual relationships that involve little emotional connection. They are also of shorter duration and involve lower contact frequency, hence they are expected to be less reliable than strong ties (Aldrich and Ruef, 2006, p. 71).

The social network literature argues that the stronger the tie connecting two individuals, the more similar they are, which means that people with similar characteristics are more likely to be attracted to one another (also known as the principle of homophily in the social network literature). And given that individuals who share similar characteristics are more likely to know each other, these individuals tend to form dense clusters in which everybody knows each other. This means that the friends of an individual also know each other and are friends. This configuration of social networks affect entrepreneurs in both positive and negative ways according to Kim and Aldrich (2005). It has a positive effect in the sense that high-density networks provide social support, facilitate the transmission of complicated information and can foster economic relations through the creation of trust. However, at the same time, the lack of diversity that typically characterizes high-density networks can be detrimental to the extent that they induce conformity and constrain individuals' autonomy, creativity and innovation (Kim and Aldrich, 2005, p. 13).

The main contribution of Granovetter's work was to highlight the value and usefulness of weak ties for the spread of information in social networks. Weak 
ties improve the diffusion of information across a network because they are more likely to be bridges to outside networks, than strong ties. This access to diverse information is an important source of new information and new ideas which can provide the entrepreneur access to resources beyond those available in his or her close circle of acquaintances. When an individual is connected to different ties that do not know each other, there is less likelihood of information overlapping. This is known in the network literature as 'structural holes'. Hence, the more structural holes in a social network, the more diverse it is and the less redundant the connections are in terms of the information they can bring to the entrepreneur.

Understanding the composition of an entrepreneur's social network is important since it can determine the access to key resources and information that the entrepreneur lacks. This implies that, in theory, an entrepreneur can seek for required resources in a wider social network that go beyond the immediate strong ties. However, this holds true if the entrepreneur is able to recognize and use key social ties skillfully ${ }^{21}$. Also, different types of ties may be more important for different stages of the venture development. For example, according to Aldrich and Ruef (2006), strong and weak ties may be more important than contact with strangers for the mobilization of resources in early stages of business development. But later on, when the start up has achieved some stability, arm's length transactions and contacts with strangers may become more important.

The social network of an entrepreneur is influenced by the connections made through life, like family members, acquaintances from school and university, work colleagues, friends from club memberships, friends from the neighborhood, friends of friends, and so on. The interviews revealed that social networks determined the emergence of innovative startups in at least two dimensions. First, it determined the composition of the founding team. As previously mentioned in Section 5.5.1, in all cases under analysis there was a team behind the process of founding the business. Founding teams require the strength that characterize strong ties in a network as their members have to work side by side in the launch and development of the startup. Given that trust is a necessary condition to build a business partnership with somebody, entrepreneurs tend to choose partners with whom asymmetries of information are minimized, meaning that they are more likely to pick partners with whom they have strong ties. The interviews showed that, in

\footnotetext{
${ }^{21}$ Kim and Aldrich (2005) argue that the idea of leveraging all direct ties of the entrepreneur to form a wider social network of potential resource providers does not hold in reality since the entrepreneur faces several constraints. One of them is the lack of clairvoyance, which means that due to bounded rationality the entrepreneur cannot know the full potential of pursuing indirect network ties.
} 
fact, the type of connection between members of the founding team was either friends from school and university, or work colleagues.

The second dimension in which social networks determined the emergence of innovative startups was the access to key resources that the entrepreneur lacked. Everybody's network is composed of family members, friends from school and university, colleagues from work and other acquaintances, but the interviews showed that the quality of the social network differed between entrepreneurs. The quality of an entrepreneur's social network can be understood here as the extent to which different types of resources can be timely and effectively accessed through strong and weak ties. After reviewing and assessing the actors (strong and weak ties) that played a key role in the emergence and initial development stages of the ventures under analysis, it became clear that the ties that some entrepreneurs had access to were of high quality and played a pivotal role in the founding and/or development of the venture. These key ties were for example wealthy individuals willing to invest in the entrepreneur's business, or were influential characters that knew important people and therefore were able to open doors to the entrepreneur that otherwise would be closed, or were successful professionals that brought expertise and valuable contacts to the business. The question is why some entrepreneurs had access to this high quality ties. The answer is related to the background of the entrepreneur, in terms of education and socioeconomic status.

As claimed by Núñez and Gutierrez (2004), in Chile the type of secondary school an individual attended is a proxy of the socioeconomic background of origin, or "social class". Unfortunately, the school system in Chile is highly segregated in which the majority of public schools enroll mostly lower income students. While private schools are attended mostly by well-off students. Hence, school characteristics reveal information about the family background of an individual, as well as the socioeconomic background of the individual's classmates (Núñez and Gutierrez, 2004, p. 6). Furthermore, within private schools there is a subset of nine 'elite' schools that the Chilean business class has typically attended ${ }^{22}$. These private elite schools are located in Santiago, charge very high tuition fees and their admissions are exclusive. They are also very good schools in terms of the academic performance of their students, as measured by the average score in the $\mathrm{PSU}^{23}$ test $^{24}$, a standardized admission exam that students take after finishing

\footnotetext{
${ }^{22}$ According to Zimmerman (2015) the list of elite private schools are: Saint George's School, Colegio del Verbo Divino, the Grange School, Colegio Sagrados Corazones de Manquehue, Colegio Tabancura, Colegio San Ignacio, Alianza Francesa, Craighouse School and Scuola Italiana.

${ }^{23}$ Formerly known as the PAA, the PSU is the acronym for 'University Selection Test'.

${ }^{24}$ In 2015 these schools, except for the Colegio Sagrados Corazones de Manquehue, were among the best 50 average scores in the PSU test.
} 
high school to apply to a degree program in one of the 25 'traditional' universities. These are known as $\mathrm{CRUCH}^{25}$ universities and include a combination of private and public institutions. The two most selective ones are the University of Chile and the Catholic University of Chile, which are world class institutions (see Footnote 9). As described earlier in 5.5.1, most of the entrepreneurs under analysis graduated from these top universities.

If the type of secondary school that an individual attended determines some of the strong and weak ties of his or her social network, we can expect that the social network of entrepreneurs that went to a private school will be partly composed of acquaintances that (also) belong to a high social class. In fact, the majority of the entrepreneurs from the capital Santiago went to private secondary schools, and some of them to the subcategory of private elite schools. Furthermore, from Section 5.5.1 we know that most of the entrepreneurs interviewed went to top universities, which means that we can expect that their social network is at least partly composed of friends from private secondary schools and top universities.

Recent research has shown that attending elite private schools in Chile can be helpful to reach top management positions. Zimmerman (2015) studies the effect of top university admission on student's chances of reaching top management positions in Chile, exploring the importance of peer ties as an underlying mechanism. His results show that elite university admission play a causal role in the production of top managers, but only for students who attended elite private high schools. That is, elite high school students admitted to top universities become much more likely to work in management roles with their college peers than with non-peers from the same degree program in other cohorts or other degree programs in the same cohort. This result resembles the principle of homophily discussed above, in which people with similar characteristics are more likely to be attracted to one another and tend to form dense clusters in which everybody knows each other. Applied to this study, it would imply that individuals that share a similar socioeconomic background, attended the same private elite schools and graduated from the same top universities, are more prone to know each other and become friends, especially if their social networks tend to overlap. At the same time, this could imply that they are more likely to develop trust between each other, which can partly explain the finding that they are more likely to end up working together in top management positions.

The interviews showed that entrepreneurs that had high quality ties were mostly those that were connected to this elite group: those that lived in Santi-

\footnotetext{
${ }^{25} \mathrm{CRUCH}$ is the acronym for 'Council of Rectors of Universities of Chile'.
} 
ago, that went to private elite schools and graduated from top universities. By default the acquaintances of these entrepreneurs belong to a wealthier socioeconomic background and have a higher probability to hold a top managerial position or know someone that does. This type of acquaintances helped entrepreneurs to access capital, contacts, investors, customers and expertise. However, having a quality social network is a necessary but not sufficient condition to effectively access resources or to succeed in the process of founding or growing an innovative venture.

Even though the results of the interviews do not allow to derive a causal relationship between quality networks and emergence of innovative startups, my hypothesis is that entrepreneurs that have quality social networks are in a better position than their counterparts that do not, which includes entrepreneurs from the regions. According to the theory of small worlds everybody is six nodes away from any other person. This means that strictly speaking an outsider to high quality networks could be able to find his way to high quality ties, like wealthy investors. However, as the number of degrees increases, trust starts decreasing and so does the probability to effectively access the required resources.

On the other hand, high potential innovative entrepreneurship falls under the category of uncertain businesses and therefore an innovative idea is no warranty of success. This leaves investors in a difficult situation to be forced to apply rules of thumb to be able to make decisions on whether to invest or not in a business. When an investor and an entrepreneur meet the asymmetries of information are huge. Even though the idea may be extremely appealing, it is nonetheless surrounded by uncertainty. On top of this, the investor does not know whether the entrepreneur has the capabilities to execute the idea he has in mind. This is why investors need to run a cross-check of the person they are going to invest their money in. They are looking for an entrepreneur they can trust and that has some key traits like being able to execute the idea he has in mind. This is why investors tend to emphasize the fact that they put the money in the person or the team first, and then in the idea or project. This is due to the fact that the probability that the business plan presented by the entrepreneur does not occur is close to one due to the uncertain nature of the business. The main source of information to carry out the cross-check is contact networks, from school, university and work. If the entrepreneur's social network overlaps with the investor's, the screening process of the investor becomes easier as there are higher chances to have acquaintances in common that can reduce the asymmetries of information ${ }^{26}$.

\footnotetext{
${ }^{26}$ In fact, this also partly explains why investors, entrepreneurs and partners tend to continue
} 


\subsection{Concluding remarks}

This Chapter analyzed why and how innovative entrepreneurship arises in Chile, focusing on the entrepreneur, that elusive character that constitutes a necessary condition for new innovative ventures to emerge. The analysis focused on a set of unobservable traits that are expected to influence the emergence process of innovative ventures and their subsequent outcome: background characteristics, personality traits, motivations and social capital.

One clear finding is that entrepreneurs behind the innovative ventures under analysis are highly educated: all of them had a bachelor's degree, most of them from top Chilean universities. This result is consistent with the positive relationship between the level of educational attainment and firm innovation propensity found in Chapter 4. Nonetheless, entrepreneurs from the capital Santiago tended to be even more educated than their counterparts in regions as the majority had attained a master or a doctorate degree, most of them from universities abroad. Identifying the reasons that could explain this difference go beyond this study, but it is alarming and deserves further research from a public policy point of view.

In line with previous related literature, the most important personality traits that an entrepreneur should have were: tolerance for uncertainty, resilience, internal locus of control, creativity and self-efficacy. The combination of these traits, in a balanced way, is part of the 'toolkit' that enables entrepreneurs to deal with the numerous challenges involved in the founding and growing of an innovative business venture. However, other personality traits also seem to matter, like humbleness and self-criticism, which encourages learning and brings flexibility into the business, as it gives the space to change directions when needed. These traits were highly valued by angel and venture capital investors as entrepreneurs tend to lack managerial skills, so they need to be able to acknowledge weaknesses and listen to advice. Given that the majority of entrepreneurs hold a degree in engineering and just a few pursued a master in business administration, it is not surprising that investors remarked the lack of managerial skills in entrepreneurs. Humbleness and self-criticism can help entrepreneurs realize their limitations quickly so they can act faster by bringing the key skills that they lack, in the form of cofounders, partners or hires. In other words, this type of personality traits can save entrepreneurs time and money because they can shape a more flexible behavior and influence the type of decisions they make, which at the aggregate level can ultimately influence the performance of the business.

working together in subsequent startups: information asymmetries have been lowered substantially after working together and therefore they tend to trust each other 
Regarding entrepreneurial motivations, the interviews showed that they were influenced by personality traits and by different aspects of the founder's life, like having been exposed to role models, prior work events and experiences, key encounters with pivotal individuals and the little twists and turns in life. A key factor explaining the type of motivation that drove an individual to pursue the launch of a venture was their attitude towards entrepreneurship, which is determined by the family and culture in which they grew up and the extent to which they were influenced by role models in their adolescence. Relatedly, two types of entrepreneurs could be clearly distinguished: those that always had the idea to found a company and those that somehow ended up doing it.

The first category of entrepreneurs was influenced by role models in their adolescence and made rather conscious decisions throughout their life, regarding their professional future, that led them to become entrepreneurs. This 'early clarity' about the idea to become an entrepreneur may explain why this type of entrepreneurs were less prone to pursue further educational degrees after attaining their bachelor's degree. As expected, their motivations were very much related to the need for autonomy, which is closely related to the inclination towards independence and to the value assigned to being the owner of one's time. However, they were also driven by the need to generate an impact in the environment that surrounds them and by the desire to generate an impact that goes beyond economic gains or wealth.

The second category of entrepreneurs included those who somehow ended up in this situation. Interestingly, this subset of entrepreneurs were highly educated as the majority had attained a master or doctorate degree abroad. Clearly, their life goals were different at some point and were probably more focused on climbing the professional ladder. However, some events triggered a swerve in their paths and ended up becoming founders of an innovative business venture. For example, in some cases the trigger was related to the life stage through which the person was going, where substantial changes of direction can suddenly emerge, making individuals voluntarily leave their usual comfort zone. For some individuals becoming an entrepreneur emerged as a possibility soon after finishing their graduate studies, especially for those that studied abroad. Some others were influenced by role models later on in their life.

A general finding is that the four categories of motivation that drove interviewed entrepreneurs ('need for autonomy', 'impact generation', 'need for achievement' and 'life stage') to launch their startups, fall in the broader category of intrinsic motivations, which is consistent with the findings of Chapter 4 where firms 
owned and managed by intrinsically motivated entrepreneurs are more prone to innovate. The type of motivation that drives an entrepreneur clearly influences the vision he has from the venture, and therefore decisions will be made accordingly shaping the type of business outcome. For example, entrepreneurs strongly driven by autonomy are more prone to maintain control of their companies and therefore are less open to take in outside capital, determining the pace at which the company grows (most likely at a gradual or moderate rate). The outcome of this business venture, at least in terms of job creation, may substantially differ from the outcome of a business venture led by an entrepreneur strongly led by impact generation, who is more likely to make decisions focused on achieving high growth rates.

The social network of an entrepreneur is influenced by the connections made through life, like family members, acquaintances from school and university, work colleagues, friends from friends, and so on. The interviews revealed that social networks determined the emergence of innovative startups in at least two dimensions. First, it determined the composition of the founding team (co-founders were mostly friends from school or university and, to a lesser extent, work colleagues). And second, it determined the access to key resources that the entrepreneur lacked. However, it was clear that the quality of the social network differed between entrepreneurs, in the sense that social connections that some entrepreneurs had played a pivotal role in their access to capital, contacts, investors, customers and expertise.

The reason why some entrepreneurs had access to quality ties is related to the background of the entrepreneur, in terms of education and socioeconomic status. The interviews showed that entrepreneurs with quality social connections were mostly those that went to private elite schools and top universities. These entrepreneurs were therefore connected to an elite social network composed of individuals that lived in Santiago, that went to private elite schools and graduated from top universities. By default the acquaintances of these entrepreneurs belong to a wealthier socioeconomic background and have a higher probability to hold a top managerial position or know someone that does.

Even though it is not possible to derive a causal relationship between quality networks and emergence of innovative startups, and also having access to quality social connections is a necessary but not sufficient condition for entrepreneurial success, my hypothesis is that entrepreneurs that have quality social networks are in a better-off position than their counterparts that do not (including those in regions). Furthermore, the relationship between education and high quality 
social networks provides another explanation to the positive relationship between high educational attainment and firm innovation propensity found in Chapter 4. The variable education in Chile not only captures formal human capital, it also captures socioeconomic background and quality social connections. 


\section{Chapter 6}

\section{Conclusions}

This Thesis aimed at broadening the understanding of the intriguing and elusive figure of the innovating entrepreneur, one particular character among the continuum of individuals that compose the highly heterogeneous population of entrepreneurs. Focusing on them is important because innovating entrepreneurs are the ones that have the potential to generate larger economic impacts. However, they are a select few among the entrepreneurial population. New insights that uncover who they are and what makes them different from the rest is crucial to identify effective ways to promote their emergence and development.

The Chilean economy, with its highly concentrated business structure, could benefit from promoting and fostering the emergence of a critical mass of innovating entrepreneurs in order to democratize the business sector and promote social mobility. Furthermore, it has the potential to drive structural change as the economy needs urgently to develop new areas of specialization, especially in knowledge-intensive sectors, in order to increase its productivity. The Schumpeterian entrepreneur can be regarded as a potential source of creative destruction, social mobility and economic development.

The research relied on both quantitative and qualitative methods to answer a set of research questions that explore the sources of entrepreneurial heterogeneity and how it relates to innovative businesses. The reason to apply this combined methodological strategy is related to the fact that some of the factors that are expected to influence the emergence of innovative ventures are unobservable and therefore are difficult to be captured in standard surveys. Therefore, qualitative interviewing was applied in order to complement the results obtained from the Chapters that used quantitative methods. This strategy was important in exploring the nature of the relationship between entrepreneurial traits and firm 
innovation. This methodological approach also uncovered important unobservable factors that complete the puzzle of innovative entrepreneurship in Chile.

This thesis provided new empirical evidence on the sources of entrepreneurial heterogeneity. Since entrepreneur's behavior is viewed as a causal determinant of firm performance, factors that affect behavior will also affect firm performance. This implies that the variety of ventures we observe is partly explained by the heterogeneous traits of the entrepreneurs. Therefore, any attempt to understand the emergence of innovative startups begins by understanding the person behind the business. Findings from the quantitative and qualitative Chapters show that both observable and unobservable characteristics are important in understanding the emergence of innovative ventures. First, educational attainment was associated with specific motivations that drove entrepreneurs to launch a startup. The results show that an increase in the educational attainment also increased the probability of being motivated by the need of being independent. Second, the interplay of motivations and the entrepreneur's educational attainment explain the extent to which their business innovates. Particularly, intrinsically-motivated entrepreneurs (which includes those motivated by independence) that are highly educated are more prone to run innovative businesses. These results confirm the idea that not all entrepreneurs are the same and that innovating entrepreneurs have particular traits that determine the innovation propensity of their businesses.

An interesting contribution of this Thesis is the new insights it brings regarding the role of unobservable factors as sources of heterogeneity among innovative entrepreneurs. Qualitative interviewing allowed the study of unobservable factors that are key in explaining the emergence of innovative ventures, such as personality traits, life background events, motivations and social capital. These interactive factors shape the entrepreneur's behavior, thus determining the type of venture that emerges as well as its development. For example, a key factor explaining the type of motivation that drove an individual to pursue the launch of a venture was the extent to which they were influenced by role models in their adolescence. Relatedly, two types of entrepreneurs could be clearly distinguished: those that always had the idea to found a company and those that somehow ended up doing it. The first category of entrepreneurs was influenced by role models in their adolescence and made rather conscious decisions throughout their life, regarding their professional future, that led them to become entrepreneurs. The second category of entrepreneurs included those that somehow ended up in this situation. Interestingly, this subset of entrepreneurs were more educated than the previous category. Clearly, their professional goals were different before becoming 
entrepreneurs as they seem to be more focused on climbing the professional ladder. This constitutes a clear example of how different initial conditions can determine different life paths followed by individuals. Another finding is that the innovative entrepreneurs interviewed were driven by intrinsic motivations, consistent with the findings of the quantitative analysis where firms owned by intrinsically motivated entrepreneurs were more prone to innovate. Furthermore, entrepreneur's motivations set the vision for their venture and therefore shape the actions they take and decisions they make.

The interviews also revealed that social capital determined the emergence of innovative startups by providing access to resources that the entrepreneur lacked. However, it was clear that the quality of the social network differed between entrepreneurs. High quality social connections played a pivotal role in having access to capital, contacts, investors, customers and technical expertise. The reason why some entrepreneurs had access to quality ties is related to the background of the entrepreneur, namely education and socioeconomic status. The interviews showed that entrepreneurs with high quality social connections were mostly those that went to private elite schools and top universities. These findings suggest that entrepreneurs with high quality social networks and higher socioeconomic status are in a better position to successfully launch and grow an innovative startup when compared to others, especially those located outside of the capital region, Santiago.

This Thesis has shown that entrepreneurial traits, observable and unobservable, partly influence the emergence and development of innovative ventures in Chile. This has important implications for policymakers. First, when designing policies to promote innovative entrepreneurship, policymakers must take into account a set of unobservable factors that explain entrepreneurial activity. These factors are often neglected by index measures, such as those reviewed in Chapter 2. Second, given that access to quality education and social capital is unevenly distributed in Chilean society, with a few in a better position to launch innovative ventures, policymakers must ensure equitable access to resources. If the playing field is not leveled, the expectations that innovative entrepreneurship can democratize the business sector and promote social mobility could be jeopardized.

The behavioral characteristics of entrepreneurs, their traits and motivations, the policymakers setting the entrepreneurship agenda, and the particularities of the Chilean society, are all crucial pieces of the innovative entrepreneurship puzzle. The interplay between these factors must be further examined in order to design 
policies, enact programs and create conditions for a functioning ecosystem that enables innovative entrepreneurship. 


\section{References}

Acs, Z. (2008). Foundations of high impact entrepreneurship. Jena Economic Research Papers 60.

Acs, Z. and D. Audretsch (1988). Innovation in large and small firms: An empirical analysis. The American Economic Review, 678-690.

Acs, Z. and P. Correa (2014). Identifying the obstacles to high-impact entrepreneurship in Latin America and the Caribbean. Technical report, The World Bank.

Acs, Z., L. Szerb, and E. Autio (2016). Global Entrepreneurship Index. Technical report, The Global Entrepreneurship and Development Institute, Washington D.C., USA.

Acs, Z. and N. Virgill (2009). Entrepreneurship in developing countries. Jena Economic Research Papers 23.

Aghion, P., U. Akcigit, A. Bergeaud, R. Blundell, and D. Hémous (2015). Innovation and top income inequality. NBER Working Paper 21247.

Aldrich, H. (2011). An Evolutionary Approach to Entrepreneurship: Selected Essays by Howard E. Aldrich. Edward Elgar.

Aldrich, H. and M. Ruef (2006). Organizations Evolving (Second ed.). SAGE Publications.

Aldrich, H. and C. Zimmer (1986). Entrepreneurship through social networks. In D. Sexton and R. Smilor (Eds.), The Art and Science of Entrepreneurship, Chapter 2, pp. 3-23. Ballinger Publishing Company.

Alvarez, R. and A. Garcia (2008). Innovación y exportaciones en la industria manufacturera. Central Bank of Chile Working Papers 476.

Alvarez, R. and R. Robertson (2004). Exposure to foreign markets and plant-level innovation: Evidence from Chile and Mexico. Journal of International Trade and Economic Development 13(1).

Aninat, C., J. Benavente, I. Briones, N. Eyzaguirre, P. Navia, and J. Olivari (2010). The political economy of productivity. The case of Chile. IADB Working Paper Series 105.

Antonelli, C. (2009). The economics of innovation: From the classical legacies to the economics of complexity. Economics of Innovation and New Technology 18(7), 611-646.

Arrighetti, A. and M. Vivarelli (1999). The role of innovation in the postentry performance of new small firms: Evidence from Italy. Southern Economic Journal 65(4), 927-939.

Arthur, W. B. (2013). Complexity economics: A different framework for economic thought. Complexity Economics, Oxford University Press (forthcoming). 
Audretsch, D. and M. Keilbach (2007). The theory of knowledge spillover entrepreneurship. Journal of Management Studies 44(7).

Audretsch, D. and R. Thurik (2001). Linking entrepreneurship to growth. OECD Science, Technology and Industry Working Papers, OECD Publishing 2001/02.

Bandura, A. (1997). Self-efficacy: The Exercise of Control. Macmillan.

Baumol, W. J. (1990). Entrepreneurship: Productive, unproductive, and destructive. Journal of Political Economy 98(5)(1), 893-921.

Baumol, W. J. (2010). The Microtheory of Innovative Entrepreneurship. Princeton University Press.

Beinhocker, E. (2006). The Origin of Wealth: Evolution, Complexity, and the Radical Remaking of Economics. Harvard Business Press.

Benavente, J. M. (2005). Innovación tecnológica en Chile: Dónde estamos y qué se puede hacer. Economía Chilena 8(1), 53-77.

Benavente, J. M. (2006). Antecedentes para el diseño de una política tecnológica nacional. Working Paper 229, Department of Economics, University of Chile.

Bergmann, H. and R. Sternberg (2007). The changing face of entrepreneurship in Germany. Small Business Economics 28(2-3), 205-221.

Bhidé, A. V. (2000). The Origin and Evolution of New Businesses. Oxford University Press.

Birch, D. (1981). Who creates jobs? The public interest (65), 3.

Birley, S. and P. Westhead (1994, January). A taxonomy of business start-up reasons and their impact on firm growth and size. Journal of Business Venturing 9(1), 7-31.

Blanchflower, D. and A. Oswald (1998). What makes an entrepreneur? Journal of Labor Economics 16(1), 26-60.

Block, J. and M. Wagner (2010). Necessity and opportunity entrepreneurs in Germany: Characteristics and earnings differentials. Schmalenbach Business Review 62(April), 154-174.

Boeninger, E. (2007). Políticas Públicas en Democracia. Institucionalidad y experiencia Chilena 1990-2006. Santiago: Uqbar Editores.

Braunerhjelm, P., Z. Acs, D. Audretsch, and B. Carlsson (2010). The missing link: Knowledge diffusion and entrepreneurship in endogenous growth. Small Business Economics 34(2), 105125 .

Brockhaus, R. (1980). The effect of job dissatisfaction on the decision to start a business. Journal of Small Business Management 18, 37-43.

Brockhaus, R. and P. Horwitz (1986). The psychology of the entrepreneur. In D. Sexton and R. Smilor (Eds.), The Art and Science of Entrepreneurship, Chapter 2, pp. 25-48. Ballinger Publishing Company.

Bryman, A. (2008). Social Research Methods (Third ed.). Oxford University Press.

Cameron, A. and P. Trivedi (2005a). Microeconometrics. Methods and Applications. Chapter 24, Stratified and Clustered Samples, pp. 813-859. Cambridge University Press. 
Cameron, A. and P. Trivedi (2005b). Microeconometrics. Methods and Applications. Cambridge University Press.

Cameron, A. and P. Trivedi (2010). Microeconometrics using Stata. Cambridge University Press.

Carland, J. W., F. Hoy, and J. A. Carland (1988). Who is an entrepreneur? is a question worth asking. American Journal of Small Business 12(4), 33-39.

Carlsson, B., S. Jacobsson, M. Holmén, and A. Rickne (2002). Innovation systems: Analytical and methodological issues. Research Policy 31(2), 233-245.

Carsrud, A. and M. Brännback (2011). Entrepreneurial motivations: What do we still need to know? Journal of Small Business Management 49(1), 9-26.

Carter, N., W. Gartner, K. Shaver, and E. Gatewood (2003). The career reasons of nascent entrepreneurs. Journal of Business Venturing 18, 13-39.

Cea, S., M. I. Contreras, C. Martínez, and E. Puentes (2009). Trabajadores por cuenta propia : Quienes son? De donde vienen? Para donde van? Working Paper 308, Department of Economics, University of Chile.

Coad, A. and P. Nightingale (2013). Muppets and gazelles: Political and methodological biases in entrepreneurship research. SPRU Working Paper Series 2013-03.

Cooper, A., F. Gimeno-Gascon, and C. Woo (1994). Initial human and financial capital as predictors of new venture performance. Journal of Business Venturing 9, 371-395.

de Jong, J. (2013). The decision to exploit opportunities for innovation: A study of high-tech small business owners. Entrepreneurship Theory and Practice 37(2), 281-301.

de Mel, S., D. Mckenzie, and C. Woodruff (2009). Innovative firms or innovative owners? Determinants of innovation in micro, small, and medium enterprises. IZA Discussion Papers 3962.

Edquist, C. (1997). Systems of Innovation: Technologies, Institutions, and Organizations. Routledge.

Edquist, C. (2005). Systems of Innovation: Perspectives and Challenges. In J. Fagerberg, D. C. Mowery, and R. R. Nelson (Eds.), The Oxford Handbook of Innovation, Chapter 7, pp. 181208. Oxford University Press.

Edquist, C. and C. Chaminade (2006). Industrial policy from a systems-of-innovation perspective. EIB papers $11(1), 108-132$.

Edquist, C. and L. Hommen (2008). Small Country Innovation Systems: Globalization, Change and Policy in Asia and Europe. Edward Elgar Publishing.

Edquist, C. and B. Johnson (1997). Institutions and Organizations in Systems of Innovation. In C. Edquist (Ed.), Systems of Innovation: Perspectives and Challenges, Chapter 2, pp. 41-63. Routledge.

Evans, D. and L. Leighton (1989). Some empirical aspects of entrepreneurship. American Economic Review 79(3), 519-535.

Eyzaguirre, N., M. Marcel, J. Rodríguez, and M. Tokman (2005). Hacia la economía del conocimiento: El camino para crecer con equidad en el largo plazo. Estúdios Públicos 97.

Farmer, J. D. (2012). Economics needs to treat the economy as a complex system. Complexity Research Initiative for Systemic instabilities (CRISIS). 
Freeman, C. (1987). Technology and Economic Progress: Lessons from Japan. London: Pinter.

Galasso, A. and T. S. Simcoe (2011). CEO overconfidence and innovation. Management Science $57(8), 1469-1484$.

Gartner, W. B. (1985). A conceptual framework for describing the phenomenon of new venture creation. The Academy of Management Review 10(4), 696-706.

Gartner, W. B. (1988). Who is the entrepreneur? Is the wrong question. American Journal of Small Business 12, 11-32.

Gartner, W. B. (1989). Some suggestions for research on entrepreneurial traits and characteristics. Entrepreneurship Theory and Practice (Fall), 27-38.

Gebreeyesus, M. (2011). Innovation and Microenterprise Growth in Ethiopia. In W. Naudé, A. Szirmai, and M. Goedhuys (Eds.), Entrepreneurship, Innovation and Economic Development, Chapter 6, pp. 122-146. Oxford University Press.

Gilad, B. and P. Levine (1986). A behavioral model of entrepreneurial supply. Journal of Small Business Management 4(October), 45-53.

Granovetter, M. S. (1973). The strength of weak ties. American Journal of Sociology, 1360-1380.

Grilo, I. and R. Thurik (2008). Determinants of entrepreneurial engagement levels in Europe and the US. Industrial and Corporate Change 17(6), 1113-1145.

Hamilton, B. H. (2000). Does entrepreneurship pay? An empirical analysis of the returns to self-employment. Journal of Political Economy 108(3), 604-631.

Hausman, A. (2005). Innovativeness among small businesses: Theory and propositions for future research. Industrial Marketing Management 34(8), 773-782.

Hellmann, T. (2007). When do employees become entrepreneurs? Management Science 53(6), 919-933.

Herron, L. and R. B. Robinson (1993). A structural model of the effects of entrepreneurial characteristics on venture performance. Journal of Business Venturing 8(3), 281-294.

Hessels, J., M. Gelderen, and R. Thurik (2008). Entrepreneurial aspirations, motivations, and their drivers. Small Business Economics 31(3), 323-339.

Hessels, J., M. van Gelderen, and R. Thurik (2007). Drivers of entrepreneurial aspirations at the country level: The role of start-up motivations and social security. SCALESInitiative H200710(October), 1-22.

Hollenbeck, J. and E. Whitener (1988). Reclaiming personality traits for personnel selection: Self-esteem as an illustrativa case. Journal of Management 14(1), 81-91.

ILO (1993, January). Resolution concerning the International Classification of Status in Employment (ICSE), Adopted by the Fifteenth International Conference of Labour Statisticians. International Labour Organization.

INE (2011). Metodología Muestral Encuesta Longitudinal de Empresas. Technical report, Instituto Nacional de Estadísticas.

INE (2013). Encuesta de Microemprendimiento 2013, Diseño Muestral. Technical report, Instituto Nacional de Estadísticas. 
Kahneman, D. (2011). Thinking, Fast and Slow. Penguin Books.

Kantis, H., J. Federico, and S. Ibarra (2015a). Index of Systemic Conditions for Dynamic Entrepreneurship. A tool for action in Latin America. Technical report.

Kantis, H., J. Federico, and S. Ibarra (2015b). Systemic Conditions for Dynamic Entrepreneurship. Latin America in the new global scenario. Technical report.

Kantis, H., J. Federico, S. Ibarra, and C. Menéndez (2015). Condiciones sistémicas e institucionalidad para el emprendimiento y la innovación. Informe Chile. Technical report, Mimeo.

Katz, J. A. (1992). A psychosocial cognitive model of employment status choice. Entrepreneurship Theory and Practice Fall, 29-37.

Kim, P. and H. Aldrich (2005). Social Capital and Entrepreneurship. Now Publishers Inc.

Kirzner, I. M. (1973). Competition and Entrepreneurship. Universisty of Chicago Press.

Kirzner, I. M. (1997). Entrepreneurial discovery and the competitive market process: An Austrian approach. Journal of Economic Literature 35(1), 60-85.

Landström, H. (2005). Pioneers in Entrepreneurship and Small Business Research. Springer Science \& Business Media.

Landström, H., G. Harirchi, and F. Åström (2012). Entrepreneurship: Exploring the knowledge base. Research Policy 41(7), 1154-1181.

Lazear, E. P. (2005). Entrepreneurship. Journal of Labor Economics 23(4), pp. 649-680.

Lee, E. and R. Forthofer (2006). Analyzing Complex Survey Data. Sage Publications, Inc.

Long, J. S. and J. Freese (2014a). Estimation, testing and fit. In Regression Models for Categorical Dependent Variables Using Stata (Third ed.)., Chapter 3, pp. 385-479. Stata Press.

Long, J. S. and J. Freese (2014b). Models for nominal outcomes. In Regression Models for Categorical Dependent Variables Using Stata (Third ed.)., Chapter 8, pp. 385-479. Stata Press.

Lundvall, B.-Å. (1992). National Systems of Innovation: Towards a Theory of Innovation and Interactive Learning. London: Pinter.

Lundvall, B.-Å. (2007). National Innovation Systems - Analytical concept and development tool. Industry and Innovation 14(1), 95-119.

Lundvall, B.-Å., K. Joseph, C. Chaminade, and J. Vang (2009). Handbook of Innovation Systems and Developing Countries: Building Domestic Capabilities in a Global Setting. Edward Elgar Publishing.

Mairesse, J. and P. Mohnen (2010). Using innovations surveys for econometric analysis. National Bureau of Economic Research $1585 \%$.

Marcati, A., G. Guido, and A. Peluso (2008). The role of SME entrepreneurs' innovativeness and personality in the adoption of innovations. Research Policy 37(9), 1579-1590.

Marin, A., L. Navas-Alemán, and C. Perez (2015). Natural resource industries as a platform for the development of knowledge intensive industries. Tijdschrift voor economische en sociale geografie 106(2), 154-168. 
Martin, M. J. (1984). Small is beautiful: Spin-offs, innovation and entrepreneurship in small businesses. In M. J. Martin (Ed.), Managing technological Innovation and Entrepreneurship, Chapter 14, pp. 252-272. Reston Publishing Company, Inc.

McClelland, D. C. (1961). The Achieving Society. Simon and Schuster.

Milgrom, P. and J. Roberts (1990). The economics of modern manufacturing: Technology, strategy, and organization. The American Economic Review, 511-528.

MINECON (2005). Innovar en Chile. Programa de Desarrollo e Innovación Tecnológica 20012006. Technical report, Undersecretary of Economics, Government of Chile.

MINECON (2014). Informe de Resultados Tercera Encuesta de Microemprendimiento 2013. Technical report, Ministry of Economics, Government of Chile.

Nelson, R. R. (1993). National Innovation Systems: A Comparative Analysis. Oxford University Press.

Nightingale, P. and A. Coad (2013). Muppets and gazelles: Political and methodological biases in entrepreneurship research. SPRU Working Paper Series 2013-03.

Niosi, J. (2010). Building National and Regional Innovation Systems: Institutions for Economic Development. Edward Elgar Publishing.

North, D. C. (1990). Institutions, Institutional Change and Economic Performance. Cambridge University Press.

Núñez, J. and R. Gutierrez (2004). Classism, discrimination and meritocracy in the labor market: The case of Chile. Working Paper 208, Department of Economics, University of Chile.

OECD (2005). Oslo Manual. Guidelines for Collecting and Interpreting Innovation Data. (Third ed.).

OECD (2012). Public and Private Schools. How management and funding relate to their socioeconomic profile. OECD Publishing.

Pérez-Luño, A., J. Wiklund, and R. Cabrera (2010). The dual nature of innovative activity: How entrepreneurial orientation influences innovation generation and adoption. Journal of Business Venturing 26, 555-571.

Quatraro, F. and M. Vivarelli (2014). Drivers of entrepreneurship and post-entry performance of newborn firms in developing countries. The World Bank Research Observer lku012.

Radosevic, S. (2007). National Systems of Innovation and Entrepreneurship: In search of a missing link. Economics Working Paper, UCL-SSEES 73.

Rauch, A. and M. Frese (2007). Let's put the person back into entrepreneurship research: A metaanalysis on the relationship between business owners' personality traits, business creation, and success. European Journal of Work and Organizational Psychology 16(4), 353-385.

Reynolds, P. D., W. D. Bygrave, E. Autio, L. W. Cox, and M. Hay (2002). Global Entrepreneurship Monitor, Executive Report. Technical report, Babson College, Ewing Marion Kauffman Foundation and London Business School.

Robson, P., C. Akuetteh, P. Westhead, and M. Wright (2011). Innovative opportunity pursuit, human capital and business ownership experience in an emerging region: Evidence from Ghana. Small Business Economics, 1-23. 
Romero, I. and J. Martínez-Román (2011). Self-employment and innovation. exploring the determinants of innovative behavior in small businesses. Research Policy 41, 178-189.

Roodman, D. (2011). Estimating fully observed recursive mixed-process models with CMP. The Stata Journal 11(2), 159-206.

Rotter, J. B. (1966). Generalized expectancies for internal versus external control of reinforcement. Psychological monographs: General and applied 80(1), 1.

Rubin, H. and I. Rubin (2005). Qualitative Interviewing. The Art of Hearing Data. (Second ed.). SAGE Publications.

Sautet, F. (2013). Local and systemic entrepreneurship: Solving the puzzle of entrepreneurship and economic development. Entrepreneu 37(2), 387-402.

Scheinberg, S. and I. MacMillan (1988). An 11 country study of motivations to start a business. Frontiers of Entrepreneurship Research.

Schjoedt, L. and K. G. Shaver (2007). Deciding on an entrepreneurial career: A test of the pull and push hypotheses using the panel study of entrepreneurial dynamics data. Entrepreneurship Theory and Practice (September), 733-753.

Schumpeter, J. A. (1934). The Theory of Economic Development (Third ed.). Harvard University Press. Translation from the German by Redvers Opie.

Shane, S. (2009). Why encouraging more people to become entrepreneurs is bad public policy. Small Business Economics 33(2), 141-149.

Shane, S., E. Locke, and C. Collins (2003). Entrepreneurial motivation. Human Resource Management Review 13(2), 257-279.

Smith, K. (2000). Innovation as a systemic phenomenon: Rethinking the role of policy. Enterprise and innovation management studies 1(1), 73-102.

Solimano, A. (2012). Capitalismo a la Chilena y la prosperidad de las Élites. Catalonia.

Stinchcombe, A. (1965). Social structure and organizations. In J. G. March (Ed.), Handbook of Organizations, pp. 142-193. Chicago, MA: Rand MvNally.

Szirmai, A., W. Naudé, and M. Goedhuys (2011). Entrepreneurship, innovation and economic development: An overview. In A. Szirmai, W. Naudé, and M. Goedhuys (Eds.), Entrepreneurship, Innovation and Economic Development, Chapter 1, pp. 3-32. Oxford University Press.

Tversky, A. and D. Kahneman (1974). Judgment under uncertainty: Heuristics and biases. Science 185(4157), 1124-1131.

Ucbasaran, D., P. Westhead, and M. Wright (2009). The extent and nature of opportunity identification by experienced entrepreneurs. Journal of Business Venturing 24 (2), 99-115.

Valenzuela, J., C. Bellet, and D. de los Rios (2013). Socioeconomic school segregation and a market-oriented educational system. The case of Chile. Journal of Education Policy 29(2), $217-241$.

Verheul, I., R. Thurik, J. Hessels, and P. V. D. Zwan (2010). Factors influencing the entrepreneurial engagement of opportunity and necessity entrepreneurs. EIM Research Reports (March), 1-26. 
Vesper, K. (1982). Introduction and summary of entrepreneurship research. In C. Kent, D. Sexton, and K. H. Vesper (Eds.), Encyclopedia of Entrepreneurship, pp. xxi-xxxviii. Englewood Cliffs NJ: Prentice Hall.

Vivarelli, M. (2013). Is entrepreneurship necessarily good? Microeconomic evidence from developed and developing countries. Industrial and Corporate Change 22(6), 1453-1495.

Wagner, J. (2005). Nascent necessity and opportunity entrepreneurs in Germany: Evidence from the Regional Entrepreneurship Monitor (REM). IZA Discussion Paper Series May(1608).

Wasserman, N. (2012). The Founder's Dilemma. Princeton University Press.

Williams, R. (2012). Using the margins command to estimate and interpret adjusted predictions and marginal effects. The Stata Journal 12(2), 308-331.

Woolthuis, R. K., M. Lankhuizen, and V. Gilsing (2005). A system failure framework for innovation policy design. Technovation 25(6), 609-619.

World Bank (2008). Chile. Toward a Cohesive and Well Governed National Innovation System. Technical report, World Bank.

$\mathrm{Xu}$, H. and M. Ruef (2004). The myth of the risk-tolerant entrepreneur. Strategic Organization 2(4), 331-355.

Yin, R. (2009). Case Study Research. Design and Methods (Fourth ed.). SAGE Publications.

Zhao, H., S. E. Seibert, and G. T. Lumpkin (2010). The relationship of personality to entrepreneurial intentions and performance: A meta-analytic review. Journal of Management 36(2), 381-404.

Zimmerman, S. D. (2015). Making Top Managers: The Role of Elite Universities and Elite Peers. Working Paper. 
Appendix A

Apendix to Chapter 3 


\section{A.1 Multinomial Logit Model (whole sample)}

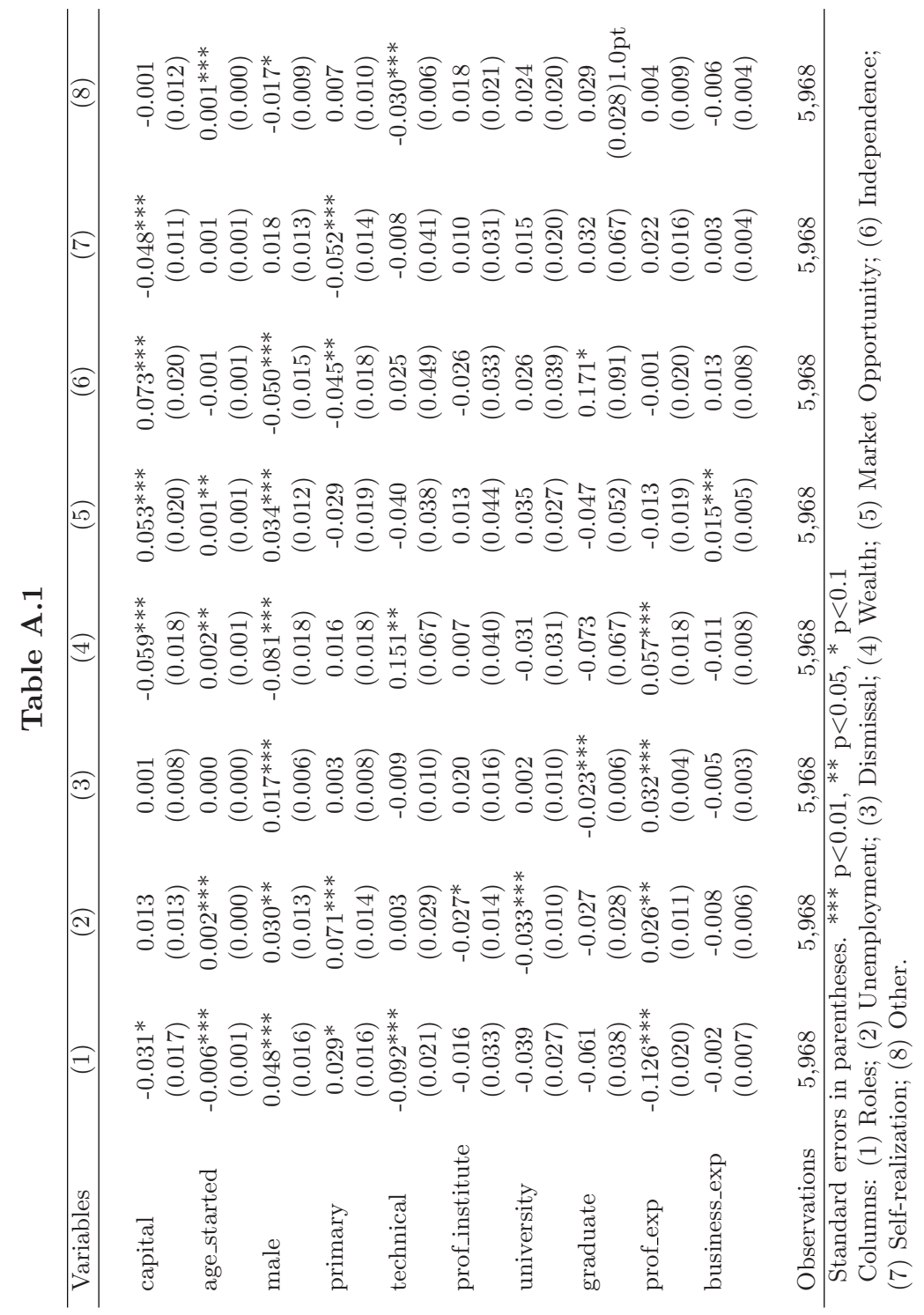




\section{A.2 Multinomial Probit Model (whole sample)}

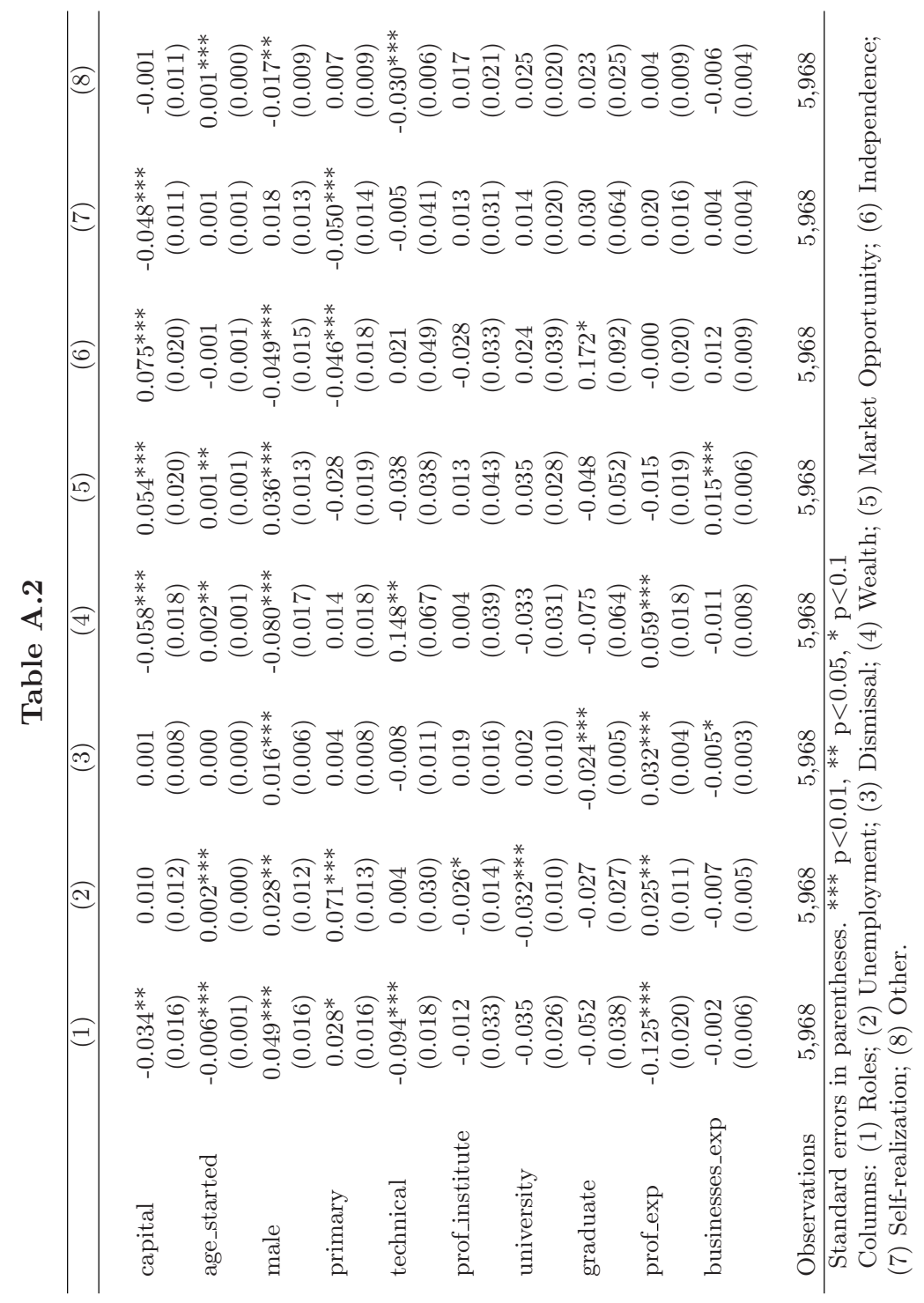




\section{A.3 Multinomial Logit Model: Estimated coefficients for employers}

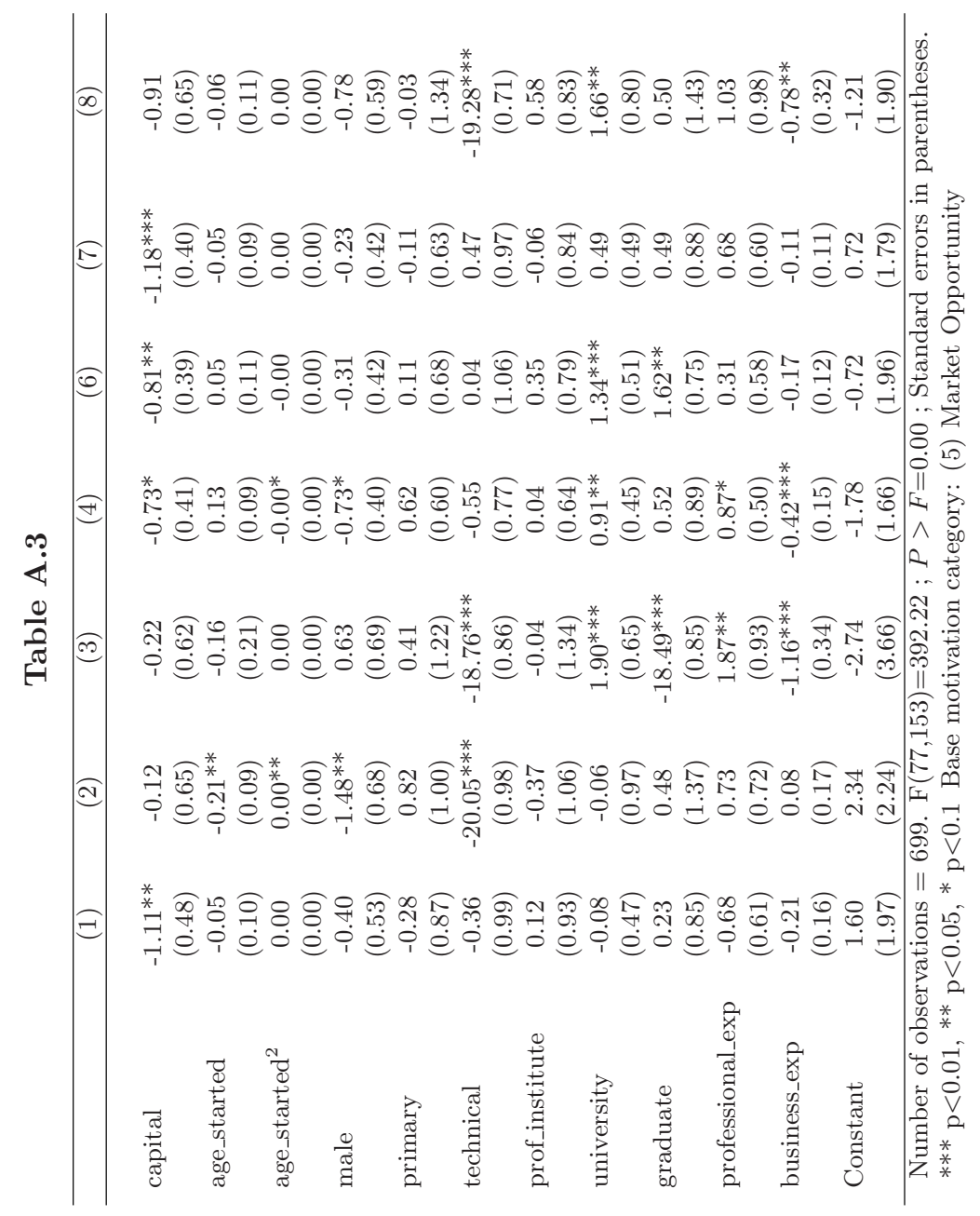




\section{A.4 Multinomial Logit Model: Estimated coefficients for own account workers}

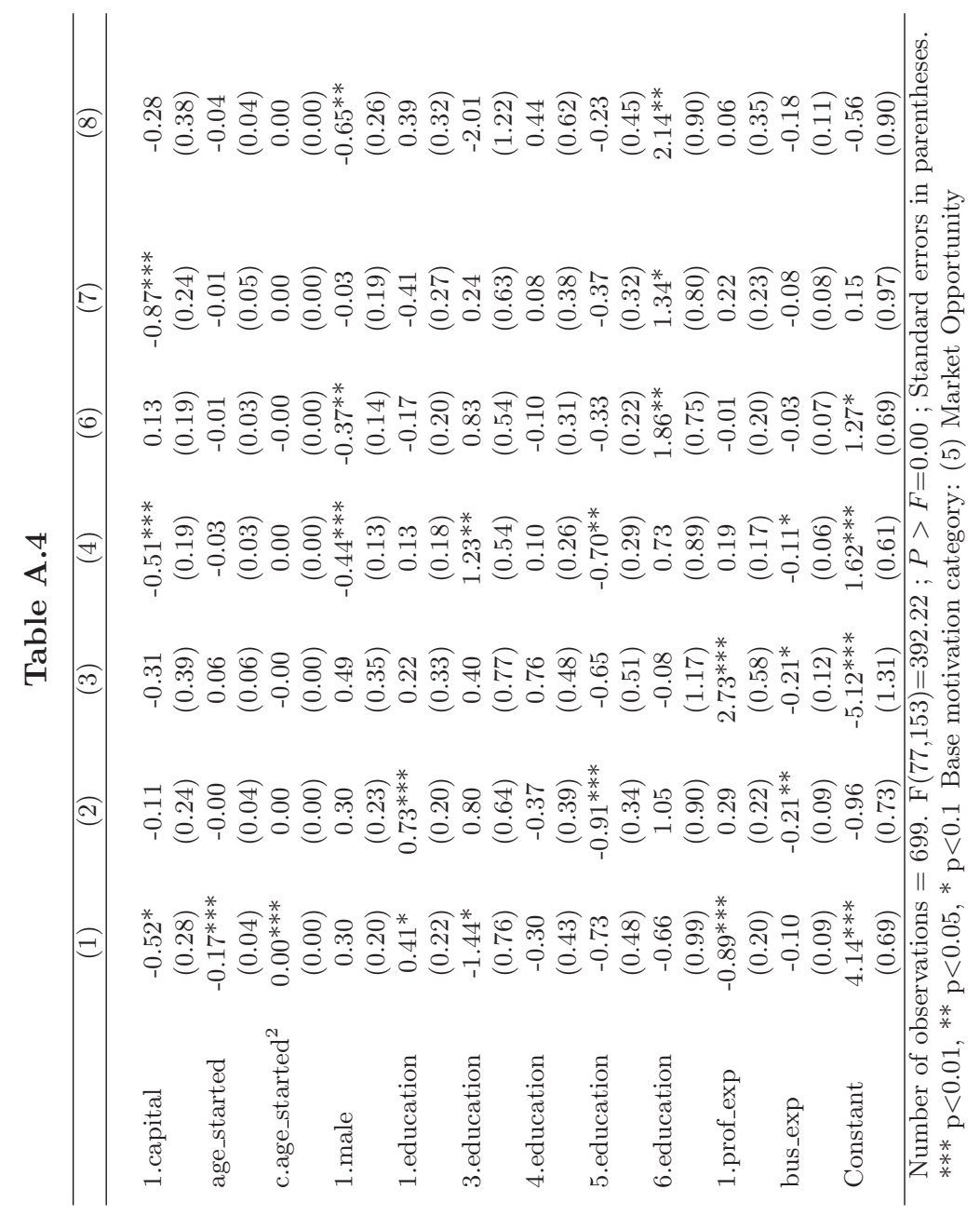





\section{Appendix B}

\section{Appendix to Chapter 4}

\section{B.1 The motivation equation: A comparison between the ELE and EME Surveys}

Table B.1 shows the results for the motivation equation, which can be compared to the results for employers obtained in the previous chapter where the relationship between entrepreneurial motivations and individual background traits was studied. However, different databases with different units of analysis (individuals versus formal firms) were used in each paper so comparisons should be made with caution. Furthermore, the motivation categories are not directly comparable. Therefore, it is better to disaggregate the four motivation categories studied in this paper to build categories comparable to the ones analyzed in the previous chapter. The new results of the multinomial probit estimations are presented in Table B.2.

Table B.2 shows that male entrepreneurs are more prone to be motivated by 'Independence' and "Self-realization", which is consistent with the positive and significant coefficient of "Intrinsic" motivation in Table B.1. It can also be observed that male entrepreneurs are less motivated by 'Unemployment' and "Necessity" than women. This raises a warning regarding the entrepreneurial culture, or spirit, in Chile, which seems to be more prevalent among men. This result does not hold for the sample of employers in the previous chapter where there seems to be no difference between men and women regarding entrepreneurial motivations.

Professional experience slightly increases the probability of being motivated by 'Self-realization', while the effect is doubled for the 'Independence' category, reaching 7 percentage points. In the previous chapter, however, professional experience was relevant for employers motivated by 'Wealth'. In both papers, as 
expected, professional experience is negatively related to entrepreneurs motivated by 'Roles'. Overall, all the motivations that are positively and significantly related to prior professional experience are pull-motivations, which is consistent with the literature that argues that individuals are more prone to voluntarily decide to start a business after they have accumulated some experience, resources and social capital.

Prior business ownership experience does not seem to have a substantial effect in this paper; although some effects were found in the previous chapter. Age in which the business was started does not seem to have a relation with motivation categories (in either of the chapters).

Regarding the relationship between education and motivation categories, results in Table B.2 show that achieving education levels beyond the mandatory secondary level increases the probability of being motivated by 'Self-realization'. This holds for those individuals that attain a professional, university or graduate degree, the latter degree being the one that has a larger effect ( 9 percentage points). In the same direction, less educated individuals, that have attained only primary level education, are less prone to start a business due to having found a 'Market opportunity' or due to 'Self-realization'. These results seem to go in a similar direction to the ones in the previous chapter, where I found that employers attaining higher educational levels (university and graduate) have a higher propensity to start a business motivated by "Independence". The latter findings regarding education imply that 'Intrinsically' motivated entrepreneurs are, therefore, more prone to have a higher educational background. 
Table B.1: Motivation Equation: Average Marginal Effects

\begin{tabular}{|c|c|c|c|c|}
\hline Variables & $\begin{array}{c}(1) \\
\text { Roles }\end{array}$ & $\begin{array}{c}(2) \\
\text { Necessity }\end{array}$ & $\begin{array}{c}(3) \\
\text { Extrinsic }\end{array}$ & $\begin{array}{c}(4) \\
\text { Intrinsic }\end{array}$ \\
\hline capital & $\begin{array}{c}0.000 \\
(0.014)\end{array}$ & $\begin{array}{l}-0.003 \\
(0.011)\end{array}$ & $\begin{array}{c}-0.009 \\
(0.016)\end{array}$ & $\begin{array}{c}0.012 \\
(0.017)\end{array}$ \\
\hline age_started & $\begin{array}{c}-0.004^{* * *} \\
(0.001)\end{array}$ & $\begin{array}{c}0.002^{* * *} \\
(0.001)\end{array}$ & $\begin{array}{c}0.001 \\
(0.001)\end{array}$ & $\begin{array}{c}0.001 \\
(0.001)\end{array}$ \\
\hline male & $\begin{array}{l}-0.021 \\
(0.018)\end{array}$ & $\begin{array}{c}-0.057^{* * *} \\
(0.015)\end{array}$ & $\begin{array}{l}-0.005 \\
(0.021)\end{array}$ & $\begin{array}{c}0.083^{* * *} * \\
(0.020)\end{array}$ \\
\hline primary & $\begin{array}{c}0.050^{*} \\
(0.027)\end{array}$ & $\begin{array}{c}0.031 \\
(0.022)\end{array}$ & $\begin{array}{l}-0.031 \\
(0.029)\end{array}$ & $\begin{array}{c}-0.050^{*} \\
(0.028)\end{array}$ \\
\hline technical & $\begin{array}{c}-0.081^{* *} \\
(0.034)\end{array}$ & $\begin{array}{c}-0.003 \\
(0.030)\end{array}$ & $\begin{array}{c}0.036 \\
(0.045)\end{array}$ & $\begin{array}{c}0.048 \\
(0.044)\end{array}$ \\
\hline prof_institute & $\begin{array}{l}-0.013 \\
(0.027)\end{array}$ & $\begin{array}{c}-0.033^{*} \\
(0.019)\end{array}$ & $\begin{array}{l}-0.024 \\
(0.030)\end{array}$ & $\begin{array}{c}0.070^{* *} \\
(0.031)\end{array}$ \\
\hline university & $\begin{array}{l}-0.013 \\
(0.017)\end{array}$ & $\begin{array}{c}-0.033^{* * *} \\
(0.013)\end{array}$ & $\begin{array}{l}-0.020 \\
(0.019)\end{array}$ & $\begin{array}{c}0.066^{* * *} \\
(0.019)\end{array}$ \\
\hline graduate & $\begin{array}{c}-0.073^{*} \\
(0.039)\end{array}$ & $\begin{array}{l}-0.027 \\
(0.031)\end{array}$ & $\begin{array}{c}0.026 \\
(0.049)\end{array}$ & $\begin{array}{c}0.074 \\
(0.049)\end{array}$ \\
\hline professional_exp & $\begin{array}{c}-0.172^{* * *} \\
(0.015)\end{array}$ & $\begin{array}{c}0.055^{* * *} \\
(0.011)\end{array}$ & $\begin{array}{c}0.008 \\
(0.016)\end{array}$ & $\begin{array}{c}0.109^{* * *} \\
(0.017)\end{array}$ \\
\hline business_exp & $\begin{array}{c}0.007^{* *} \\
(0.003)\end{array}$ & $\begin{array}{c}-0.013^{* * *} \\
(0.003)\end{array}$ & $\begin{array}{c}0.007^{*} \\
(0.003)\end{array}$ & $\begin{array}{c}0.000 \\
(0.004)\end{array}$ \\
\hline Observations & 3,366 & 3,366 & 3,366 & 3,366 \\
\hline
\end{tabular}


Table B.2: Motivation Equation: Average Marginal Effects

\begin{tabular}{lccccccc}
\hline \hline Variables & $(1)$ & $(2)$ & $(3)$ & $(4)$ & $(5)$ & $(6)$ & $(7)$ \\
\hline \multirow{2}{*}{ capital } & 0.001 & -0.007 & 0.003 & 0.001 & 0.002 & -0.009 & 0.008 \\
& $(0.014)$ & $(0.009)$ & $(0.006)$ & $(0.015)$ & $(0.015)$ & $(0.010)$ & $(0.010)$ \\
age_started & $-0.004^{* * *}$ & 0.000 & $0.001^{* * *}$ & $0.002^{* *}$ & -0.000 & -0.001 & $0.001^{* * *}$ \\
& $(0.001)$ & $(0.000)$ & $(0.000)$ & $(0.001)$ & $(0.001)$ & $(0.000)$ & $(0.000)$ \\
male & -0.022 & $-0.060^{* * *}$ & 0.005 & -0.024 & $0.054^{* * *}$ & 0.017 & $0.030^{* * *}$ \\
& $(0.018)$ & $(0.014)$ & $(0.008)$ & $(0.019)$ & $(0.018)$ & $(0.012)$ & $(0.012)$ \\
primary & $0.050^{*}$ & 0.017 & 0.012 & $-0.064^{* * *}$ & -0.019 & 0.033 & $-0.030^{* * *}$ \\
& $(0.028)$ & $(0.019)$ & $(0.012)$ & $(0.024)$ & $(0.027)$ & $(0.021)$ & $(0.011)$ \\
technical & $-0.079^{* *}$ & -0.035 & 0.031 & 0.029 & -0.009 & 0.010 & $0.053^{*}$ \\
& $(0.034)$ & $(0.022)$ & $(0.021)$ & $(0.041)$ & $(0.040)$ & $(0.029)$ & $(0.029)$ \\
prof_inst. & -0.014 & $-0.049^{* * *}$ & 0.016 & -0.007 & 0.016 & -0.019 & $0.057^{* * *}$ \\
& $(0.026)$ & $(0.014)$ & $(0.013)$ & $(0.027)$ & $(0.029)$ & $(0.018)$ & $(0.020)$ \\
university & -0.014 & $-0.030^{* * *}$ & -0.003 & -0.011 & -0.006 & -0.010 & $0.073^{* * *}$ \\
& $(0.017)$ & $(0.011)$ & $(0.007)$ & $(0.017)$ & $(0.018)$ & $(0.012)$ & $(0.012)$ \\
graduate & $-0.075^{*}$ & -0.009 & -0.016 & 0.060 & -0.017 & -0.034 & $0.090^{* * *}$ \\
& $(0.039)$ & $(0.029)$ & $(0.012)$ & $(0.046)$ & $(0.043)$ & $(0.026)$ & $(0.034)$ \\
prof_exp & $-0.172^{* * *}$ & 0.005 & $0.051^{* * *}$ & -0.004 & $0.071^{* * *}$ & 0.012 & $0.037^{* * *}$ \\
& $(0.015)$ & $(0.009)$ & $(0.006)$ & $(0.015)$ & $(0.015)$ & $(0.010)$ & $(0.010)$ \\
bus._exp & $0.008^{* * *}$ & $-0.006^{* *}$ & $-0.008^{* * *}$ & $0.007^{* *}$ & -0.005 & 0.000 & $0.004^{* *}$ \\
& $(0.003)$ & $(0.003)$ & $(0.002)$ & $(0.003)$ & $(0.004)$ & $(0.003)$ & $(0.002)$ \\
& & & & & & & \\
Obs. & 3,363 & 3,363 & 3,363 & 3,363 & 3,363 & 3,363 & 3,363 \\
\hline Stanc & & & & &
\end{tabular}

Standard errors in parentheses. ${ }^{* * *} \mathrm{p}<0.01,{ }^{* *} \mathrm{p}<0.05,{ }^{*} \mathrm{p}<0.1$

Columns: (1) Roles; (2) Unemployment; (3) Dismissal; (4) Market Opportunity;

(5) Independence; (6) Wealth; (7) Self Realization. 


\section{Appendix $\mathrm{C}$}

\section{Appendix to Chapter 5}

\section{C.1 List of interviewees}

Table C.1: List of interviewees

\begin{tabular}{|c|c|c|c|}
\hline Name & Role & Venture & Affiliation \\
\hline 1. Gonzalo Miranda & Venture Capitalist & & $\mathrm{AC}$ \\
\hline 2. Luis Burzio & Core Founder & Andes Biotechnologies & $\mathrm{AC}$ \\
\hline 3. Pablo Valenzuela & Core Founder & Andes Biotechnologies & $\mathrm{AC}$ \\
\hline 4. Christian Hernandez & General Manager & Andes Biotechnologies & $\mathrm{AC}$ \\
\hline 5. Daniel Dacarett & Core Founder & Producto Protegido & $\mathrm{AC}$ \\
\hline 6. Fernando Rubio & General Manager & Producto Protegido & $\mathrm{AC}$ \\
\hline 7. Juan Enrique Suárez & Ex General Manager & Producto Protegido & $\mathrm{AC}$ \\
\hline 8. Eduardo Novoa & Angel Investor & Producto Protegido & $\mathrm{AC}$ \\
\hline 8. Javier Etcheberry & Core Founder & Multicaja & $\mathrm{AC}$ \\
\hline 10. Patricio Seguel & Employee & Multicaja & $\mathrm{AC}$ \\
\hline 11. Marcelo Salazar & Employee & Multicaja & $\mathrm{AC}$ \\
\hline 12. Pedro Cabezón & Core Founder & Paperless & $\mathrm{AC}$ \\
\hline 13. Aliosha Bertini & Technology Manager & Paperless & $\mathrm{AC}$ \\
\hline 14. Alfredo Guardiola & General Manager & Paperless & $\mathrm{AC}$ \\
\hline 15. Luis Vera & Core Founder & Scopix & $\mathrm{AC}$ \\
\hline 16. Ariel Schilkrut & Core Founder & Scopix & $\mathrm{AC}$ \\
\hline 17. Mario Araya & Core Founder & Kibernum & ES \\
\hline 18. Marcelo Solari & Employee & Kibernum & $\mathrm{ES}$ \\
\hline 19. Karen Valladares & Employee & Kibernum & $\mathrm{ES}$ \\
\hline 20. Geraldine Mlynarz & Core Founder & ActivaQ & $\mathrm{ES}$ \\
\hline 21. Ana Maria Sandino & Core Founder & ActivaQ & $\mathrm{ES}$ \\
\hline 22. Manuel Aravena & Core Founder & Astilleros Ascon & $\mathrm{EP}$ \\
\hline 23. Patricio Aros & Employee & Astilleros Ascon & $\mathrm{EP}$ \\
\hline $\begin{array}{l}\text { 24. Gonzalo Santama- } \\
\text { rina }\end{array}$ & Core Founder & Innovex & $\mathrm{EP}$ \\
\hline 25. Patricio Catalán & Core Founder & Innovex & $\mathrm{EP}$ \\
\hline 26. Alvaro Pinochet & Employee & Innovex & $\mathrm{EP}$ \\
\hline 27. Karen Muoz & Employee & Innovex & $\mathrm{EP}$ \\
\hline 28. Patricio Rojas & Core Founder & Scrum & EA \\
\hline 29. Alfredo Gómez & Core Founder & Scrum & EA \\
\hline
\end{tabular}


... table C.1 continued

\begin{tabular}{llll}
\hline \hline Name & Position & Firm & Affiliation \\
\hline 20. Rolando Jofré & Employee & Scrum & EA \\
31. Roberto Cifuentes & Core Founder & Gprocess & EA \\
32. Hugo Torres & Co-Founder & Gprocess & EA \\
33. Ejnar Trollund & Empleado & Gprocess & EA \\
34. Víctor Devia & Core Founder & Opendat & EA \\
35. Luis Emilio Guerra & Co-Founder & Opendat & EA \\
36. Pedro Rosetti & Co-Founder & Opendat & EA \\
37. Alejandro Fosk & Core Founder & Certifica & FC \\
38. Alvaro Fischer & Co-Founder & Certifica & FC \\
39. Juan Cristóbal Zagal & Core Founder & Maquintel & FCh \\
40. Rodrigo Arriagada & Employee & Maquintel & FCh \\
41. José Mardonez & Employee & Maquintel & FCh \\
42. Cristián Sjogren & Core Founder & Solar Chile & FCh \\
43. Koichi Arimitsu & Core Founder & Solar Chile & FCh \\
44. Daniel Villablanca & Co-Founder - Angel Inv. & Solar Chile & FCh \\
45. Marcos Almendras & Core Founder & AxxonAxis & FCh \\
46. Hernán Orellana & Co-Founder - Angel Inv. & AxxonAxis & FCh \\
47. Roberto Musso & Angel Investor & Solar Chile - AxxonAxis & FCh \\
\hline \multicolumn{2}{c}{ Note: AC: Austral Capital ES: Endeavor Santiago; EP Endeavor Patagonia; }
\end{tabular}

Note: AC: Austral Capital; ES: Endeavor Santiago; EP: Endeavor Patagonia;

EA: Endeavor Atacama; FCh: Fundación Chile. 


\section{Valorization}

In accordance to Article 23 of the Regulation Governing de Attainment for Doctoral Degree in the Maastricht University, the following section discusses the valorization opportunities offered by this Dissertation. Following the corresponding guidelines, these opportunities are analyzed in terms of the social and economic relevance of the thesis, the potential target groups to whom the results can be interesting and the degree of innovativeness of the research methods used.

My research interests are related to the innovation shortfalls that Chile is facing, which prevents the economy from jumping into the next stage of development. From a policy perspective, innovation can be increased by fostering existing firms to be more innovative and by fostering the emergence of new innovative ventures. In this dissertation I focused on the latter strategy by analyzing a set of factors that shape the emergence of innovative entrepreneurship, a small subset of the heterogeneous population of ventures that has the potential to generate larger economic impacts, putting emphasis on the role of the person behind the phenomenon under study, the innovative entrepreneur. The literature has been increasingly discouraging public support towards generic entrepreneurship as there seems to be a flawed belief that more startups will boost economic growth, generate innovation and create growth. Empirical evidence shows that the typical startup is not innovative, creates few jobs and generates little wealth. Investigating the traits of the person that triggers the process of venture creation and how these traits influence the emergence of innovative businesses is a valuable piece of research that can feedback the design of policies aimed at fostering innovation.

Following a market failure approach, entrepreneurship and innovation policies in Chile have mostly relied on supply side financial instruments (for example, promoting the availability of seed and venture capital). But the truth is that the emergence process of innovative ventures starts before a new business organization has been created by an entrepreneur: it starts with the motivation to turn an intention into an action. Therefore, when investigating the determinants of the emergence of innovative ventures in general, and in Chile in particular, we need to 
put the entrepreneur back into the analysis in order to broaden our understanding about the role that its (mostly unobservable) traits play in the phenomenon under analysis. This has been the main goal of my thesis.

This thesis showed that observable and unobservable entrepreneurial traits, like motivation, education and social capital, influence the emergence and development of innovative startups in Chile. This finding has important policy implications for the Chilean economy. First, policymakers should take into consideration both observable and unobservable factors when designing policies to promote innovative entrepreneurship. Second, given that access to quality education and social capital is unevenly distributed in the Chilean society, with a few in a better position to launch innovative ventures, policymakers must ensure equitable access to resources. If the playing field is not leveled, the expectations, as Schumpeter suggested, that innovative entrepreneurship can democratize the business sector and promote social mobility could be jeopardized. These findings also advocate for a broader approach to entrepreneurship and innovation policies, which obviously go beyond financial instruments.

Therefore, the results of the thesis have a social and economic relevance that go beyond pure scientific relevance. The findings derived from this research can be of interest not only to the academic community, but also to policy makers and executives of public development agencies in both developing and developed economies. In particular, it can provide interesting insights to decision makers in the field of entrepreneurship and innovation policy.

Regarding the research approach, the complex phenomenon under analysis and the unobservable nature of the entrepreneurial traits studied required a combination of both quantitative and qualitative research methods. This strategy allowed interpreting some of the relationships that were found in the quantitative analysis, like the relationship between a higher educational attainment of the entrepreneur and the innovativeness of the venture. The application of in depth interviews to a number of entrepreneurs allowed bringing new insights regarding the role that education plays in the emergence of innovative entrepreneurship and how it relates to other key factors like social capital. The scope of the messages derived from the research was possible only by combining the findings of both quantitative and qualitative methods.

In terms of the diffusion of the research, some results have been presented in international conferences and workshops. This has constituted an opportunity not only to disseminate the results of this research, but also to receive important comments and suggestions on how to further improve the research. Results were 
presented in Lalics, 2013 in Rio de Janeiro, Brazil; in the 7th MEIDE Conference in Santiago, Chile; in the PhD Workshop of the Economics of Innovation, Entrepreneurship and Competition in 2012 in Maastricht, The Netherlands; and in two internal seminars, one in the Economics Department of University of Chile, and in the Public Policies Institute of the Diego Portales University. Some Chapters are currently being reshaped in order to be submitted to journals in the field of entrepreneurship and innovation. 



\section{Biography}

Jocelyn Olivari Narea was born in Santiago, Chile in 1980. She obtained her Bachelor's and Master's degree in Economics at the University of Chile. After graduating in 2005, she worked in the Innovation Division of the Ministry of Economy and in the Executive Secretary of the National Innovation Council for Competitiveness. Later, in 2006, she joined the Department of Economics at the University of Chile as an associate researcher and as the Head of Innovation Research of the INTELIS Center for Innovation and Entrepreneurship Studies. During 2008 and the beginning of 2009 she also performed as an external consultant for the Undersecretary of Economy in innovation policy topics.

Jocelyn joined the UNU-MERIT PhD Program in Economics and Policy Studies of Technical Change in September 2009. Her main research interests include firm innovation, innovation systems, entrepreneurship and public policies related to these topics. During her PhD fellowship she participated in several workshops and conferences to present her research in progress, including MEIDE Conference 2013 in Santiago and LALICS 2013 in Río de Janeiro. Jocelyn has also been involved in consultancies for the OECD and the Inter-American Development Bank and has taught the course of Systems of Innovation at the Master's level.

Jocelyn currently works as a Consultant in the Competitiveness and Innovation Division at the Inter-American Development Bank, Washington DC. 



\section{UNITED NATIONS UNIVERSITY}

UNU-MERIT

\section{6}

102. Jocelyn Olivari

Entrepreneurial Traits and Innovation:

Evidence from Chile

\section{Muhammad Shafique}

Essays on the role of knowledge, R\&D, and technology-based firms in the evolution of sociotechno-economic system

\section{Serdar Türkeli}

Governance of Innovation Policy: Empirical Studeis on Applied Political Economy by Multi-Methos Analysis

\section{5}

\section{Hibret Belete Maemir}

Dissecting Aggregate Productivity:

International Integration and Growth with Heterogeneous Firms

\section{Giorgio Triulzi}

Looking for the Right Path: Technology Dynamics, Inventive Strategies and Catching-up in the Semiconductor Industry

\section{Abdul Baseer Qazi}

Knowledge flows and networks in the ICT sector: The case of Pakistan

\section{Ajay Thutupalli}

Technology Paradigm Shifts in Agriculture: Drivers of Sustainability and Catch up

\section{Eduardo Urias}

Improving access to HIV/AIDS treatment in Brazil: When are compulsory licenses effective in price negotiations?

\section{Daniel Opolot}

The evolution of beliefs and strategic behavior

\section{Alejandro Lavopa}

Structural Transformation and Economic

Development: Can Development Traps be Avoided?

\section{Jinjin Zhao}

Urban water management reform: The case of China

\section{4}

\section{Dirk Crass}

The Impact of Brands on Innovation and Firm Performance: Empirical Evidence from Germany

\section{Samyukta Bhupatiraju}

The Geographic Dimensions of Growth and Development

\section{François Lafond}

The evolution of knowledge systems

\section{Annalisa Primi}

Promoting Innovation in Latin America: What Countries Have Learned (and What They Have Not) in Designing and Implementing Innovation and Intellectual Property Policies

\section{Fatoumata Lamarana Diallo}

Evaluation of Meal and Deworming Programs for Primary Schools in Rural Senegal

\section{3}

\section{Anant Kamath}

Information Sharing through Informal Interaction in Low-Tech Clusters

\section{Flavia Pereira de Carvalho} What we talk about when we talk about Brazilian Mulitantionals: an investigation on Brazilian FDI, economic structure, innovation and the relationship between them

\section{Jun Hou}

Complementarity in Innovation and Development: A Cross-country Comparison

\section{Francesca Guadagno}

Why have so few countries industrialised? 


\section{Rufin Baghana}

Impacts of Government Incentives to R\&D,

Innovation and Productivity:

A Microeconometric Analysis of the Québec Case

\section{Lilia I. Stubrin}

High-Tech Activities in Emerging Countries: A Network perspective on the Argentinean biotech activity

\section{2}

\section{Abdul Waheed}

Innovation Determinants

and Innovation as a Determinant:

Evidence from Developing Countries

\section{Bilal Mirza}

Energy Poverty and Rural Energy Markets in Pakistan

\section{Benjamin Engelstätter}

Enterprise Software and Video Games: An Empirical Analysis

\section{Fulvia Farinelli}

Natural Resources, Innovation and Export Growth: The Wine Industry in Chili and Argentina

\section{Rodolfo Lauterbach}

Innovation in Manufacturing: From Product Variety and Labor Productivity Growth to Economic Development in Chile

\section{Kirsten Wiebe}

Quantitative Assessment of Sustainable Development and Growth in Sub-Saharan Africa.

\section{Julio Miguel Rosa}

Organizational Strategies, Firms' Performance and Spatial Spillovers. The Canadian Case in Research and Development.

\section{Johannes Wilhelmus Marie Boels}

Joseph Schumpeter, honderd jaar economische ontwikkeling. Een historisch-theoretische beschouwing.

\section{1}

\section{Daniel Vertesy}

Interrupted Innovation: Emerging economies in the structure of the global aerospace industry.

\section{Tina Saebi}

Successfully managing alliance portfolios: an alliance capability view.

\section{Nora Engel}

Tuberculosis in India - A case of innovation and control.

\section{Evans Mupela}

Connectivity and growth in Sub-Saharan Africa: The role of communication satellites

\section{Nantawan Kwanjai}

Cross cultural intelligence amid intricate cultural webs: A tale of the UnDutchables in the land of 1002 smiles

\section{Lina Sonne}

Innovation in Finance to Finance Innovation: Supporting pro-poor entrepreneur-based innovation

\section{0}

\section{Fernando Santiago}

Human Resources Management Practices and Learning for Innovation in Developing Countries: Pharmaceutical Firms in Mexico

\section{Zakaria Babutsidze}

Essays on Economies with Heterogenous Interacting Consumers

\section{Bertha Vallejo} Learning and Innovation Under Changing Market Conditions: The Auto Parts Industry in Mexico

\section{Donatus Ayitey}

Technical Change, Competitiveness and Poverty Reduction: A Study of the Ghanaian Apparel Industry

\section{Sergey Fillipov}

Multinational Subsidiary Evolution: Corporate Change in New EU Member States 


\section{Asel Doranova}

Technology Transfer and Learning under the Kyoto regime; Exploring the Technological Impact of CDM projects in developing countries

\section{9}

\section{Alexis Habiyaremye}

From Primary Commodity Dependence to Diversification and Growth". "Absorptive Capacity and Technological Catch Up in Botswana and Mauritius".

\section{Yoseph Getachew}

The Role of Public Capital in Economic Development

\section{Sandra Leitner}

Embodied Technological Change and Patterns of Investment in Austrian Manufacturing

\section{Semih Akçomak}

The Impact of Social Capital on Economic and Social Outcomes

\section{Abraham Garcia}

The Role of Demand in Technical Change

\section{Saurabh Arora}

Coherence in socio-technical systems: a network perspective on the innovation process

\section{8}

\section{Rutger Daems}

Medicines for the developing world

\section{Johannes Hanel}

Assessing Induced Technology: Sombart's

Understanding of Technical Change in the History of Economics

\section{Rifka Weehuizen}

Mental Capital: the economic significance of mental health

\section{Danielle Cloodt}

The relationship between R\&D partnership formation, social embeddedness and innovative performance

\section{Sabine Fuss}

Sustainable Energy Development under Uncertainty

\section{7}

\section{Tobias Kronenberg}

Reconciling Environmental Conservation with Economic Prosperity: The Feasibility of Double Dividends in the Short and Long Run

\section{Viktoria Kravtsova}

Assessing the Impact of Foreign Direct Investment in Transition Economies

\section{Suhail Sultan}

The Competitive Advantage of Small and Medium Sized Enterprises: The Case of Jordan's Natural Stone Industry

\section{6}

46. Bulat Sanditov

Essays on Social Learning and Imitation

\section{Mamata Parhi}

Dynamics of New Technology Diffusion: A Study of the Indian Automotive Industry

\section{Andreas Reinstaller}

Social structures and the innovation process: Their role in the demand of firms and consumers

\section{Rose Kiggundu}

Innovation systems and development: the journey of a Beleaguered Nile Perch Fishery in Uganda

\section{Thomas Pogue}

The Evolution of Research Collaboration in South African Gold Mining: 1886-1933

\section{Geoffrey Gachino}

Foreign Direct Investment, Spillovers and Innovation: The Case of Kenyan Manufacturing Industry

\section{0. Önder Nomaler}

Technological Change, International Trade and Growth: An Evolutionary, Multi-Agents-Based Modeling Approach

\section{5}

\section{Samia Satti Osman Mohamed-Nour} Change and Skill Development in the Arab Gulf Countries 
38. Elad Harison

Intellectual Property Rights: Economics and Policy Analysis

\section{Daniel Dalohoun}

The relationship between R\&D partnership formation, social embeddedness and innovative performance: a multi-level approach of social embeddedness

\section{Müge Ozman}

Networks, Organizations and Knowledge

\section{Bas Straathof}

Product variety and economic growth: The counteracting effects of scale and idiosyncrasy

\section{Wilfred Schoenmakers}

Knowledge Flows between Multinational Companies: A Patent Data Analysis

\section{Myriam Cloodt}

Mergers and Acquisitions (M\&As) in High-Tech Industries: Measuring the Post-M\&A Innovative Performance of Companies

\section{4}

\section{Paola Criscuolo}

R\&D Internationalisation and Knowledge Transfer. Impact on MNEs and their Home Countries

\section{Maarten Verkerk}

Trust and Power on the Shop Floor

\section{Gottfried Leibbrandt}

Adoption, harmonization and succession of network technologies across countries

\section{Mark Sanders}

Skill Biased Technical change - Its Origins, the Interaction with the Labour Market and Policy Implications

\section{3}

\section{Nadine Roijakkers}

Inter-firm cooperation in high-tech industries: a study of R\&D partnerships in pharmaceutical biotechnology
27. Viki Sonntag

Speed, Scale and Sustainability

\section{Masaru Yarime}

From End-of-Pipe Technology to Clean Technology

\section{Stéphane Malo}

The combinatorial Chemistry Revolution -

Sustaining a Superior Performance Position through Technological Learning

\section{2}

\section{Annelies Hogenbirk}

Determinants of Inward Foreign Direct Investment: the Case of the Netherlands

\section{Bastiaan Johan ter Weel}

The Computerization of the Labour Market

\section{1}

\section{John Adeoti}

Technology Investment in Pollution Control in SubSaharan Africa: The Case of the Nigerian Manufacturing Industry

\section{Edward Huizenga}

Innovation Management: How Frontrunners Stay Ahead. An Empirical Study on Key Success Factors in the ICT sector

\section{0}

21. Machiel van Dijk

Technological Change and the Dynamics of Industries. Theoretical Issues and Empirical evidence from Dutch Manufacturing

\section{9}

\section{Jan Cobbenhagen}

Managing Innovation at the Company Level: A Study on Non-Sector-Specific Success Factors

\section{Marjolein Caniëls}

Regional Growth Differentials: The Impact of Locally Bounded Knowledge Spillovers 
1998

\section{Aldo Geuna}

Resource allocation and knowledge production: Studies in the economics of university research

\section{6}

\section{Reinoud Joosten}

Dynamics, Equilibria, and Values

\section{Hugo Kruiniger}

Investment, R\&D, and the Financing Decisions of the Firm

\section{5}

\section{Hans van Meijl}

Endogenous Technological Change: The Case of Information Technology. Theoretical Considerations and Empirical Results

\section{René Kemp}

Environmental Policy and Technical Change. A Comparison of the Technological Impact of Policy Instruments

\section{Rohini Acharya}

The Impact of New Technologies on Economic Growth and Trade. A Case Study of Biotechnology

\section{Geert Duysters}

The Evolution of Complex Industrial Systems. The Dynamics of Major IT Sectors

\section{Marjan Groen}

Technology, Work and Organisation, A Study of the Nursing Process in Intensive Care Units

\section{4}

\section{Huub Meijers}

On the Diffusion of Technologies in a Vintage Framework; Theoretical Considerations and Empirical Results

\section{Theon van Dijk}

The Limits of Patent Protection. Essays on the Economics of Intellectual Property Rights

\section{Hans Voordijk}

Naar Integrale Logistiek in Bedrijfsketens, Ontwikkelingen in de Bouw

\section{3}

\section{Paul Diederen}

Technological Progress in Enterprises and Diffusion of Innovations. Theoretical Reflections and Empirical Evidence.

\section{Ben Dankbaar}

Economic Crisis and Institutional Change. The crisis of Fordism from the perspective of the automobile industry

\section{Hanno Roberts}

Accountability and Responsibility: The Influence of Organisation Design on Management Accounting

\section{2}

\section{Bart Verspagen}

Uneven Growth Between Interdependent Economies. An Evolutionary View on Technology Gaps, Trade and Growth

\section{Sjoerd Romme}

A Self-organization Perspective on Strategy Formation

\section{9}

\section{John Spangenberg}

Economies of Scale, and Atmosphere in Research Organisations

\section{8}

\section{John Hagedoorn}

Evolutionary and heterodox innovation analysis: a study of industrial and technological development in process control and information technology 
